\title{
Experimental and Seismological Constraints on the Rheology, Evolution, and Alteration of the Lithosphere at Oceanic Spreading Centers \\ by
}

\section{Brian J. deMartin}

B. S., Georgia Institute of Technology, 1998

M. S., Georgia Institute of Technology, 2001

Submitted in partial fulfillment of the requirements for the degree of

Doctor of Philosophy

at the

MASSACHUSETTS INSTITUTE OF TECHNOLOGY

and the

WOODS HOLE OCEANOGRAPHIC INSTITUTION

February, 2007

(c) MMVII Brian J. deMartin

All rights reserved

The author hereby grants MIT and WHOI permission to reproduce paper and electronic copies of this thesis in whole or in part and to distribute them publicly.

Signature of Author

Joint Program in Oceanography Massachusetts Institute of Technology and Woods Hole Oceanographic Institution
$\cap$
, $1 \lambda$
January 12, 2007

Certified by

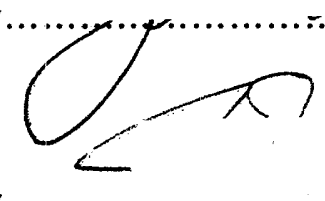

Dr. J. Gregory Hirth Thesis Supervisor

Certified by
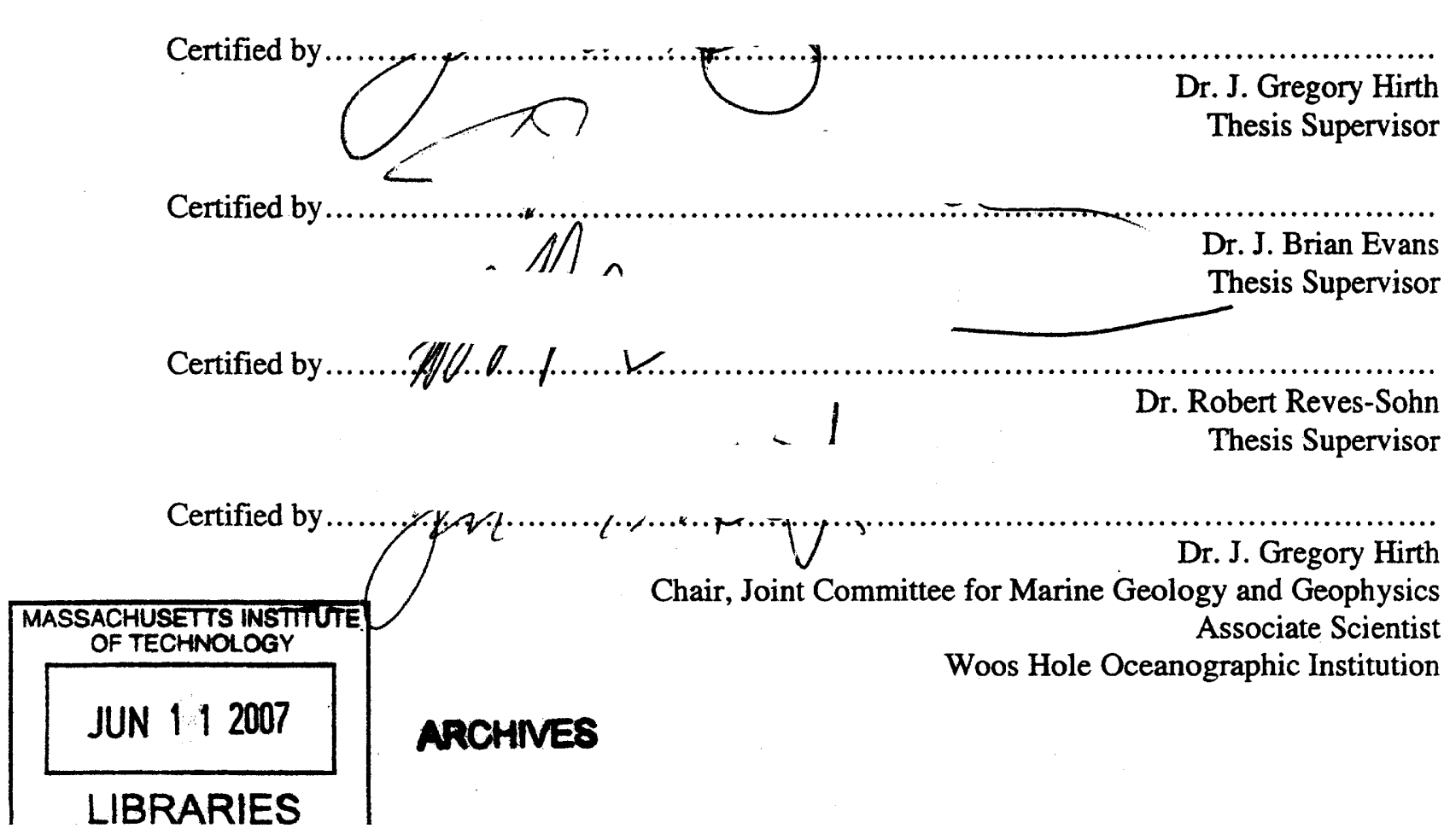

Experimental and Seismological Constraints on the Rheology, Evolution, and Alteration of the Lithosphere at Oceanic Spreading Centers

by

Brian J. deMartin

Submitted to the Department of Marine Geology and Geophysics, Massachusetts Institute of Technology-Woods Hole Oceanographic Institution, Joint Program in Oceanography on January 12, 2007, in partial fulfillment of the requirements for the degree of

Doctor of Philosophy

\begin{abstract}
Oceanic spreading centers are sites of magmatic, tectonic, and hydrothermal processes. In this thesis I present experimental and seismological constraints on the evolution of these complex regions of focused crustal accretion and extension. Experimental results from drained, triaxial deformation experiments on partially molten olivine reveal that melt extraction rates are linearly dependent on effective mean stress when the effective mean stress is low and non-linearly dependent on effective mean stress when it is high. Microearthquakes recorded above an inferred magma reservoir along the TAG segment of the Mid-Atlantic Ridge delineate for the first time the arcuate, subsurface structure of a long-lived, active detachment fault. This fault penetrates the entire oceanic crust and forms the high-permeability pathway necessary to sustain long-lived, high-temperature hydrothermal venting in this region. Long-lived detachment faulting exhumes lower crustal and mantle rocks. Residual stresses generated by thermal expansion anisotropy and mismatch in the uplifting, cooling rock trigger grain boundary microfractures if stress intensities at the tips of naturally occurring flaws exceed a critical stress intensity factor. Experimental results coupled with geomechanical models indicate that pervasive grain boundary cracking occurs in mantle peridotite when it is uplifted to within $4 \mathrm{~km}$ of the seafloor. Whereas faults provide the high-permeability pathways necessary to sustain high-temperature fluid circulation, grain boundary cracks form the interconnected network required for pervasive alteration of the oceanic lithosphere. This thesis provides fundamental constraints on the rheology, evolution, and alteration of the lithosphere at oceanic spreading centers.
\end{abstract}




\section{Acknowledgments}

Six years is fleeting. It's a little mind-boggling to believe that my time in the MIT/WHOI Joint Program is coming to a close. It seems like only a month ago I loaded my first sample into the Paterson rig, and only a few weeks ago I helped lower ocean bottom seismometers onto the flanks of the TAG hydrothermal mound. Although this thesis is the culmination of my graduate student studies, it would not have been possible without the guidance, assistance, and support of numerous individuals.

I have been mentored by three inimitable advisors: Greg Hirth, Rob Reves-Sohn, and Brian Evans. Each advisor has a unique perspective and distinctive attitude that helped shape my scientific development. Greg possesses an unparalleled breadth of knowledge, and his dictum, "jack of all trades, master of one", guided my approach to graduate school. Rob's enthusiasm is infectious. He enjoys a love of science and life that draws you in and makes you want to excel. Brian pragmatic questioning of the data taught me to look at my own results with a critical eye. Their doors were always open.

I am very grateful to the other members of my committee: Jeff McGuire and Susan Humphris. They're comments, insights and suggestions helped to improve the thesis. I would also like to thank Wenlu Zhu for chairing the defense.

My experimental endeavors and seismological studies were greatly helped the assistance of generous colleagues. Xiaohui Xiao, Uli Mok and Jock Hirst provided laboratory support and instruction when I learning the tricks of the trade in the rock mechanics laboratory at MIT. My seismology projects were made possible by the tireless efforts of the ship's crews of the R/Vs Atlantis, Ewing, and Knorr. In addition, I would like to thank everyone in the OBS lab at WHOI, their charitable donation of computational power made the timely completion of Chapter 4 possible. I would especially like to thank Pablo Canales.

It has truly been an honor to be a student of the MIT/WHOI Joint Program. This program has provided me with unsurpassed travel, educational, and research opportunities. I would like to thank everyone who improved my educational experience at both institutions: the faculty in EAPS at MIT, the scientists in G\&G at WHOI, and the warm, helpful folks in the education offices both up at MIT and down at WHOI.

I don't think it would be possible to maintain a balanced life if it were not for my all my wonderful friends. Thank you Mark, Amy, Jen, Scott, Erik, Alannah, Leyre, Sarah G., Joe, Liza, Nick A., Lili, Luc, Roxane, Emily V., Einat, Kyle, Maureen, Karen, Jenny, Blair, Joel, Lisa, Jake, Cindy, Jess, Clare, Trish, Anna, Matt, Chris, Rachel, Carlos, Nick D., Erin, Christian, Paul, Emily R., Andea, Margaret, Jeff, Cara, Rhea, Mea, Mike, Mark B., and Adam. Finally, I especially want to thank Sarah for her enduring friendship and Lynne for "being there" throughout the final push.

Finally, this amazing journey would not have been possible without the encouragement, support, and love of my family. My father instilled in me a love of nature, a respect for work, and a desire to figure out how things work. My mother nurtured my love of learning, respect for others, and the desire to be a good student, friend, and man. My little sister has always been an inspiration to me with her unbridled energy and optimism. I have been lucky to have them alongside me on this long road.

My research was funded by a MIT Presidential Fellowship and NSF grants OCE0095936, OCE-9907224, OCE-0137329, OCE-6892222, and OCE-6897400. 


\section{Table of Contents}

$\begin{array}{ll}\text { Abstract } & 3\end{array}$

$\begin{array}{ll}\text { Acknowledgements } & 5\end{array}$

$\begin{array}{ll}\text { Table of Contents } & 7\end{array}$

$\begin{array}{ll}\text { Chapter 1: Introduction } & 10\end{array}$

Chapter 2: Insights from high-temperature, drained deformation experiments on partially molten olivine: implications on the rheology, compaction, and evolution of deforming $\begin{array}{ll}\text { magma reservoirs } & 17\end{array}$

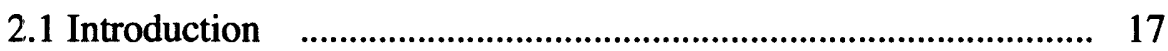

2.2 Experimental Details _............................................................... 21

2.2.1 Sample preparation and synthesis ....................................... 22

2.2.2 Melt extraction experimental procedure ………………....... 24

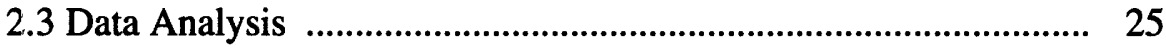

2.3.1 Microstructural analysis .................................................... 25

2.3.2 Volumetric strain analysis ............................................... 26

2.4 Results of Drained Deformation Experiments ............................. 27

2.4.1 Macroscopic observations ................................................... 27

2.4.2 Microstructural observations ............................................... 28

2.4.2.1 Grain size ......................................................... 28

2.4.2.2 Melt content before and after drained triaxial experiments ............................................... 29

2.4.2.3 Average volumetric strain rates ............................ 30

2.4.6 Connectivity of the olivine matrix ...................................... 31

2.5 Mechanical Data .............................................................................. 33

2.5.1 Hydrostatic experiments ………………………………....... 33

2.5.2 Nominally melt-free olivine experiments ............................. 34

2.5.3 Constant strain-rate melt extraction experiments ………...... 35

2.5.4 Mixed creep and hydrostatic experiments ............................ 38

2.6 Discussion of Mechanical Data ................................................... 40

2.6.1 Influence of experimental assembly on measurements ........ 41

2.6.2 Role of effective mean stress on compaction rate ................ 41

2.6.3 Melt pressure and sample strength ........................................ 43

2.6.4 Role of melt fraction on compaction rate .............................. 44

2.6.5 Role of differential stress on compaction rate ....................... 45

2.7 Discussion of Compaction Models and Melt Transport ................ 46

2.7.1 Triaxiality model of compaction .......................................... 46

2.7.2 Permeability of partially molten aggregates .......................... 48 
2.7.3 Constraints on shear and bulk viscosity ............................... 50

2.7.4 Compaction length ......................................................... 50

2.7.5 Drained versus transiently undrained melt extraction .......... 51

2.8 Conclusions ............................................................................ 54

Appendix A: Volumetric Strain Analysis ......................................... 55

Appendix B: Comparing Drained and Undrained Experiments ......... 58

B1. Influence of melt on strength ............................................... 60

B2. Drained deformation data compared to undrained flow-laws 63

Appendix C: Unique Experimental Observations ................................. 66

Appendix D: Tabulated Compaction Rates ……………………….... 67

Appendix E: Tabulated Uncorrected and Corrected Compaction Rates 71

References .................................................................................... 77

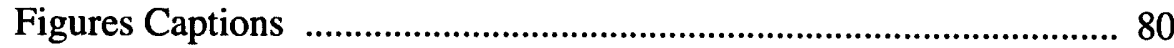

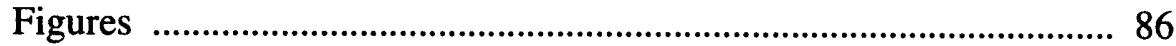

Chapter 3: Kinematics and geometry of active detachment faulting beneath the TAG hydrothermal field on the Mid-Atlantic Ridge 113

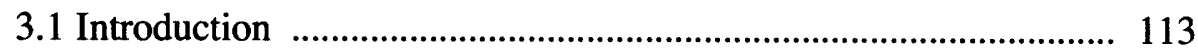

3.2 Seismic Observations ................................................................ 114

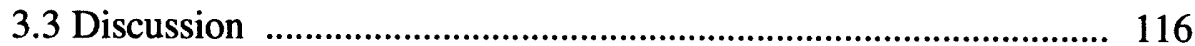

Appendix A: Earthquake waveforms, P- and S- phase arrivals ........... 123

Appendix B: Hypocenter Estimates ................................................ 124

Appendix B: Active Source Seismic Record .................................... 125

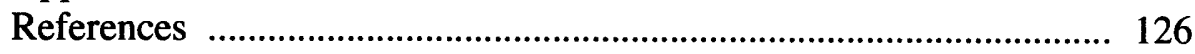

Chapter 4: Spatial and Temporal Characteristics of Seismicity at an Active Oceanic Detachment Fault: TAG Segment, Mid-Atlantic Ridge

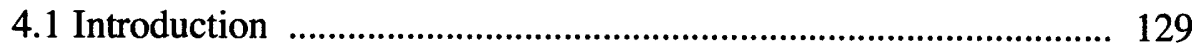

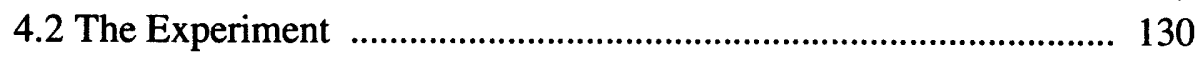

4.3 Seismograms and Seismicity Rates …………………………....... 131

4.4 Hypocenter Analysis ................................................................. 132

4.4.1 Seismicity Rates …………………………………................ 132

4.2.2 Cumulative earthquake moment release ................................. 133

4.4.3 Recurrence Interval .......................................................... 135

4.4.4 Depth Analysis ............................................................... 135

4.5 Clustering Analysis …………………………………………..... 135

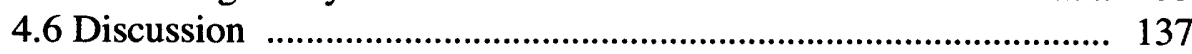

4.7 Comparison To Other Fault Systems ………………………...... 139

4.8 Geological Implications of Faulting at TAG ................................. 140

References .................................................................................. 141

Figure Captions .............................................................................. 144

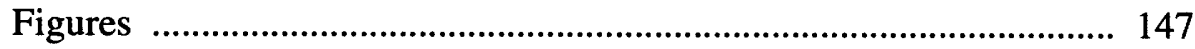




\section{Chapter 5: Experimental Constraints on Thermal Cracking of Peridotite}

at Oceanic Spreading Centers 163

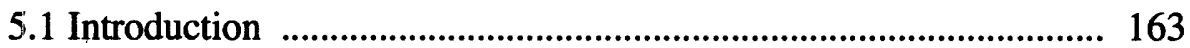

5.2 Micromechanical Models .......................................................... 165

5.3 Experimental Techniques ...................................................... 171

5.3.1 Sample Preparation and Experimental Procedure ................. 172

5.3.2 Permeability Measurement Techniques ............................. 173

5.4 Results of Thermal Cracking Experiments .................................. 175

5.4.1 Influence of Experimental Parameters on Permeability ....... 177

5.4.2 Microstructural Analysis .................................................... 178

5.5 Discussion of Experimental Results ...................................... 180

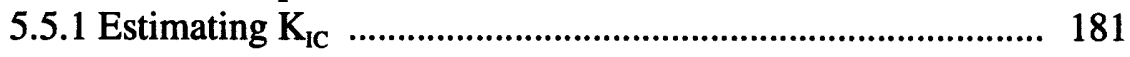

5.5.2 Modeling Thermal Cracking in Oceanic Lithosphere .......... 183

5.5.3 Serpentinization of Peridotite and Seismic Evidence .......... 186

5.6 Conclusions ......................................................................... 187

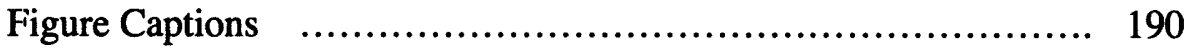

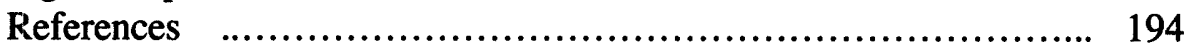

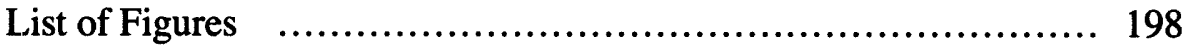




\section{Chapter 1: Introduction}

Oceanic spreading centers mark the constructive boundaries of tectonic plates. Stretching over 53,000 km around the earth's surface (Bird et al., 2002), they are characterized by elevated topography generated by hot, upwelling asthenosphere and tectonic extension (Figure 1a). Oceanic spreading centers rise over $3 \mathrm{~km}$ above the ocean basins with flanks that stretch tens to hundreds of kilometers in width. Despite their large topographic expression, crustal accretion is focused to within a few kilometers of the spreading axis. Within these few kilometers, complex magmatic, tectonic, and hydrological processes interact to shape the evolution of the oceanic lithosphere. In this thesis, I present experimental and seismological observations that provide fundamental constraints on the rheology, evolution, and alteration of the oceanic lithosphere in these regions.

Along the TAG segment of the Mid-Atlantic Ridge, both magmatic and tectonic processes control lithosphere extension. Morphological (Smith et al., 2006), geological (Zonenshain et al., 1989), and geophysical (Tivey et al., 2003) evidence indicates that the eastern valley wall of the northern region of the TAG segment is the surface expression of a long-lived detachment fault. The hanging wall of this long-lived detachment fault hosts one of the largest, most enduring zones of hydrothermal activity on the seafloor, the TAG hydrothermal field. Current hydrothermal circulation is focused at the active TAG mound, a massive sulfide deposit issuing high-temperature fluids at over $360^{\circ} \mathrm{C}$. Sustained, high-temperature hydrothermal circulation in this region requires a magmatic heat source (Humphris and Cann, 2000). Based on results presented in this thesis, the magma reservoir at the TAG segment of the Mid-Atlantic Ridge must lie at the base of the detachment fault over $6 \mathrm{~km}$ below the seafloor (Figure $1 \mathrm{~b}$ ).

The rheology of the magma reservoir at the TAG segment provides first order controls on the style of faulting and the pattern of hydrothermal circulation in the region. However, our understanding of the rheology of partially molten regions in the Earth is primarily limited to experiments on undrained, olivine plus MORB aggregates and twophase flow models. In Chapter 2, I present experimental measurements on bulk and 

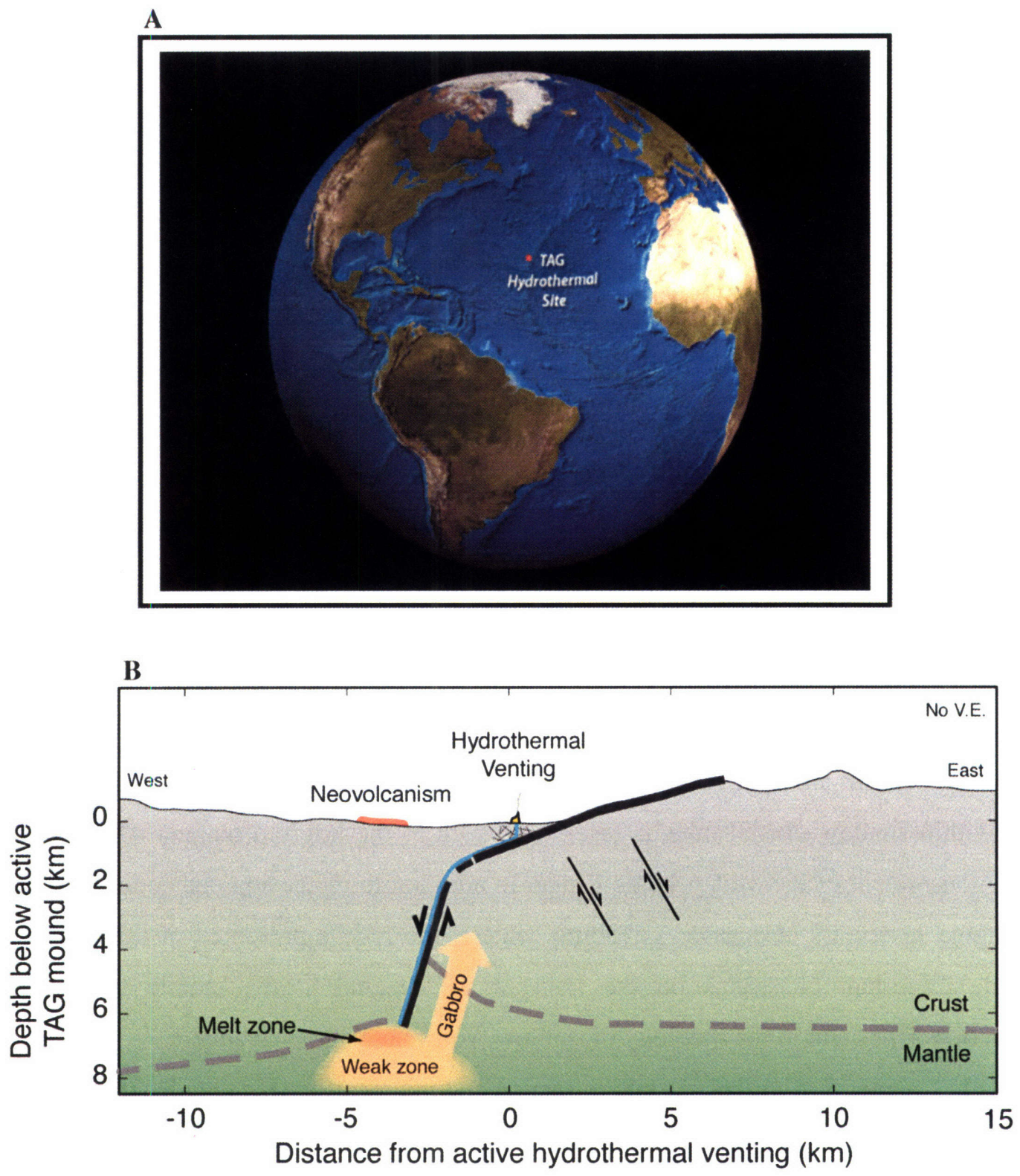

Figure 1. Overview of oceanic spreading centers. (a) View of the Atlantic Ocean basin from space with the ocean water removed. Wrapping its way down the center of the Atlantic Ocean is the Mid-Atlantic Ridge, a zone of focused magmatic accretion and extension. The TAG hydrothermal site, one of the largest, longest-lived zones of hightemperature hydrothermal venting on the seafloor, is the focus of two chapters in this thesis. (b) Schematic cross-section of the Mid-Atlantic Ridge at the TAG hydrothermal site. One of the most important contributions of this thesis was to provide first-order constraints on the subsurface structure of the Mid-Atlantic Ridge and for the first time identify where complex magmatic, tectonic, and hydrothermal processes interact. 
shear viscosity during high-temperature, drained deformation experiments on partially molten olivine aggregates as a function of melt fraction, grain size, melt pressure, confining pressure, and differential stress in order to understand the rheological and transport properties within magmatic regions of the Earth's mantle. The results from my experiments show that melt extraction rates are linearly proportional to effective mean stress when effective mean stress is low and non-linearly proportional to effective mean stress when it is high. Melt extraction rates increase as differential stress rises, owing to a concomitant rise in effective mean stress, and they are consistent with permeability proportional to melt content to the third power. Shear viscosity of the samples is lower than that predicted from flow-laws derived from undrained experiments, suggesting initial packing and subsequent reorganization of olivine grains during compaction influences the strength of partially molten aggregates. Over the range of experimental conditions tested, bulk viscosity is 1 to 50 times greater than shear viscosity. Our results suggest that the length scale of compaction is best modeled when shear viscosity is allowed to vary as a function of melt content. When models of permeability and compaction length are applied to the Earth, we estimate an effective mean stress of 0.24 MPa within shallow crustal magma reservoirs, such as the inferred magma reservoir at the TAG segment of the Mid-Atlantic Ridge. In addition to increasing our understanding of magma reservoirs at oceanic spreading centers, the results presented in this chapter provide important constrains on the transport of magma in the mantle wedge of subduction zones and in the rheology of shallow, volcanic magma chambers.

In Chapter 3, I present seismic refraction and microearthquake data from the TAG segment of the Mid-Atlantic Ridge. These data reveal for the first time the subsurface geometry of an active oceanic detachment fault (deMartin et al., submitted). Hypocenters from 19,232 microearthquakes form am approximately $15 \mathrm{~km}$ long, dome-shaped, fault surface that penetrates to depths greater than $7 \mathrm{~km}$ below the seafloor on a steeply dipping $\left(\sim 70^{\circ}\right)$ interface. A tomographic model of compressional-wave velocities demonstrates the detachment fault is uplifting lower-crustal rocks. The detachment fault becomes aseismic within $3 \mathrm{~km}$ of the seafloor, and must rollover to a shallow dip of approximately $20^{\circ}$ near the seafloor to be consistent with the tomography model and geological observations. Within the footwall of the detachment, ridge-parallel, 
antithetical, normal faulting deforms the lithosphere (Figure 1b). Our results suggest that hydrothermal fluids at the TAG field exploit the detachment fault to extract heat from a region near the crust/mantle interface over long periods of time.

It has been proposed that the vigor of hydrothermal convection and the distribution of vent fields along mid-ocean ridges are correlated with spreading rate through the magma budget, which predicts that vent fields should be rare on slow- and ultra-slow spreading ridges (Baker and German, 2004; Francheteau and Ballard, 1983). Recent field evidence from the ultra-slow spreading Gakkel (Edmonds et al., 2003) and Southwest Indian Ridges (Bach et al., 2002), however, challenge this hypothesis. The black-smoker fluids and faulting present at the TAG segment suggest that hightemperature hydrothermal circulation may be a natural consequence of the detachment faulting process. If venting and mineral deposition are common processes on hanging walls of active oceanic detachments, then significant numbers of hydrothermal fields may yet await discovery along the slowly diverging plate boundaries in the Atlantic, Indian, and Arctic Oceans.

Chapter 4 investigates the spatial and temporal aspects of detachment faulting at the TAG segment. I observe high-levels of microearthquake throughout the region during the entire observation period. Seismicity can be grouped into two spatially distinct areas: events along the detachment fault and events within the eastern valley wall. There are roughly twice as many events along the detachment fault than within the eastern valley wall. If extension is equally partitioned between the two regions, then the greater number of earthquakes along the detachment fault can be accounted for by the geometry of faulting. Spatial and temporal analysis of seismicity along the TAG segment reveals that, like the creeping section of the San Andreas fault, extension is accommodated by stable sliding lacking the typical mainshock-aftershock sequence. The relatively constant rates of seismicity could be related to elevated pore fluids along the fault or the presence of velocity strengthening minerals in the fault zones (e.g. serpentine).

Detachment faulting at TAG is currently uplifting lower crustal and mantle rocks. Although this detachment fault has not been active long enough to exhume mantle lithologies, we know from numerous other regions along slow and ultra-slow spreading centers that this process is capable of exposing deep crustal and shallow mantle rocks on 
the seafloor. In Chapter 5, I couple two-dimensional micromechanical models for thermal cracking with fracture mechanics data to constrain the conditions where diffuse fluid flow could occur in the oceanic lithosphere (deMartin et al., 2004). I ran controlled cooling rate experiments on hot-pressed olivine aggregates to test the micromechanical models of thermal cracking in peridotite and study the evolution of permeability during crack formation. In these experiments, impermeable olivine aggregates, formed at elevated temperatures and pressures, were cooled at constant rates. In situ permeability measurements, made as the aggregate cooled, allowed me to determine when an interconnected microcrack network develops. By varying grain size and confining pressure during the experiments, I was able to either enhance or suppress thermal cracking within the olivine samples. When the results of the experiments are coupled with micromechanical models, I estimate a polycrystalline olivine fracture toughness of approximately $0.6 \mathrm{MPa} \mathrm{m}{ }^{1 / 2}$. I scaled the results of our experiments to the Earth using models that account for the influence of grain size, cooling rate, and confining pressure. Thermal cracking of peridotite is likely at depths less than $4 \mathrm{~km}$ beneath the seafloor. These predictions agree well with the depth of a transition from serpentinized to unaltered peridotite in the oceanic lithosphere determined from seismic observations (Canales et al., 2000).

The models developed in Chapter 5 have also been applied to delineate where cooling-induced microfracture formation may form in "ocean planets" - planets, icy satellites, and other objects that may host subsurface liquid water (Vance et al., submitted). In that paper, we show that the cracking depth in smaller planets with shallower pressure-depth profiles and smaller magnitudes of internal heating is at least an order of magnitude greater that in the terrestrial, oceanic lithosphere, assuming extraterrestrial seafloors share similar material properties and cooling rates with the Earth's near-surface mantle. On Europa, for example, we estimated that pervasive cracking of the lithosphere could penetrate to depths to $15 \mathrm{~km}$. The enhanced depth of fluid circulation in small, ocean planets will have important implications for geochemical and possible biological processes arising from water-rock interactions. The Vance et al., (submitted) study highlights the importance of the research presented in this thesis far beyond just the TAG segment of the Mid-Atlantic Ridge. 


\section{References:}

Bach, W., Banerjee, N.R., Dick, H.J.B., and Baker, E.T., 2002, Discovery of ancient and active hydrothermal systems along the ultra-slow spreading Southwest Indian Ridge, $10^{\circ}-16^{\circ} \mathrm{E}$ : Geochem. Geophys. Geosyst., v. 3, p. $2001 \mathrm{GC} 000279$.

Baker, E.T., and German, C.R., 2004, On the global distribution of hydrothermal vent fields, in German, C.R., Lin, J., and Parson, L.M., eds., Mid-Ocean Ridges: Hydrothermal Interactions Between the Lithosphere and Oceans, Volume 148: Geophysical Monograph: Washington, DC, American Geophysical Union, p. 245266.

Bird, P., Kagan, Y.Y., and Jackson, D.D., 2002, Plate tectonics and earthquake potential of spreading ridges and oceanic transform faults, in Stein, S., and Freymueller, J.T., eds., Plate Boundary Zone, Volume 30, American Geophysical Union, p. 203-218.

Canales, J.P., Collins, J.A., Escartín, J., and Detrick, R.S., 2000, Seismic structure across the rift valley of the Mid-Atlantic Ridge at $23^{\circ} 20^{\prime}$ (MARK area): Implications for crustal accretion processes at slow spreading ridges: J. Geophys. Res., v. 105, p. $28,411-28,425$.

deMartin, B., Hirth, G., and Evans, B., 2004, Experimental constraints on thermal cracking of peridotite at oceanic spreading centers, in German, C.R., Jin, L., and Parson, L.M., eds., Mid-Ocean Ridges: Hydrothermal interactions between the lithosphere and oceans, Volume 148: Geophysical Monograph Series: Washington D.C., American Geophysical Union, p. 167-185.

deMartin, B., Reves-Sohn, R., Canales, J.P., and Humphris, S., submitted, Kinematics and geometry of active detachment faulting beneath the TAG hydrothermal field on the Mid-Atlantic Ridge: Geology.

Edmonds, H.N., Michael, P.J., Baker, E.T., Connelly, D.P., Snow, J.E., Langmuir, C.H., Dick, H.J.B., Mühe, R., German, C.R., and Graham, D.W., 2003, Discovery of abundant hydrothermal venting on the ultra-slow spreading Gakkel Ridge, Arctic Ocean: Nature, v. 421 , p. 252-256.

Francheteau, J., and Ballard, R., 1983, The East Pacific Rise near $21^{\circ} \mathrm{N}, 13^{\circ} \mathrm{N}$, and $20^{\circ} \mathrm{S}$ : inferences for along-strike variability of axial processes of the Mid-Ocean Ridge: Earth Planet. Sci. Lett., v. 64, p. 93-116.

Humphris, S.E., and Cann, J.R., 2000, Constraints on the energy and chemical balances of the modern TAG and ancient Cyprus seafloor sulfide deposits: J. Geophys. Res., v. 105, p. 28,477-28,488.

Smith, D.K., Cann, J.R., and Escartín, J., 2006, Widespread active detachment faulting and core complex formation near $13^{\circ} \mathrm{N}$ on the Mid-Atlantic Ridge: Nature, v. 442, p. 440-443.

Tivey, M.A., Schouten, H., and Kleinrock, M.C., 2003, A near-bottom magnetic survey of the Mid-Atlantic Ridge axis at $26^{\circ} \mathrm{N}$ : Implications for the tectonic evolution of the TAG segment: J. Geophys. Res., v. 108, p. doi:10.1029/2002JB001967.

Vance, S., deMartin, B., and Michael Brown, J., submitted, Enhanced depth of hydrothermal circulation in small ocean planets: Geophys. Res. Let.

Zonenshain, L.P., Kuz'min, M.I., Lisitsin, A.P., Bogdanov, Y.A., and Baranov, B.V., 1989, Tectonics of the Mid-Atlantic rift valley between the TAG and MARK areas $\left(26-24^{\circ} \mathrm{N}\right)$; evidence for vertical tectonism: Tectonophys., v. 159, p. 1-23. 


\section{Chapter 2: Insights from high-temperature, drained deformation experiments on partially molten olivine: implications for the rheology, compaction, and evolution of deforming magma reservoirs}

We simultaneously measure bulk and shear viscosity during high-temperature, drained deformation experiments on partially molten olivine aggregates as a function of melt fraction $(\phi)$, melt pressure, confining pressure, and differential stress to understand rheological and transport properties within magmatic regions of the Earth's mantle. Experiments were conducted at approximately $1473 \mathrm{~K}$ and effective confining pressures ranging from 0 to $50 \mathrm{MPa}$. Bulk viscosity is determined by recording the melt extraction rates from a compacting, partially molten aggregate into a glassy-carbon-sphere reservoir positioned immediately above the sample. Melt extraction rates depend on the effective mean pressure $\left(\sigma_{m}^{\text {eff }}\right)$. We control melt pressure by adjusting the fluid pressure of argon gas in contact with the melt using a servo-controlled pore fluid actuator. Shear viscosity is constrained by measuring axial strain and differential stress as a function of time.

We observe two regimes of compaction in partially molten olivine aggregates with $\phi_{0}>5 \%$. At low effective mean stress melt extraction rates are linearly proportional to $\sigma_{m}^{\text {eff }}$, while at high effective mean stress melt extraction rates are nonlinearly proportional to $\sigma_{m}^{\text {eff }}$ with an effective mean stress exponent greater than one. The transition between the two regimes is between 30-50 MPa for an axial strain rate of $1 \times 10^{-5} \mathrm{~s}^{-1}$ and is consistent with a change from diffusion to dislocation accommodated matrix compaction. We also observe evidence for fluid transport limited compaction. For example, measured melt extraction rates are roughly proportional to $\phi^{3}$. Volumetric strain records suggest dilatation occurred in several partially molten samples with starting melt contents less than $5 \%$. The melt content at the onset of dilatation is consistent with the transition from drained to transiently undrained conditions. As melt content decreases in compacting aggregates, bulk viscosity increases more rapidly than shear viscosity resulting in a bulk to shear viscosity ratio of 1 to 50 at low melt contents. The experimental constraints on permeability, bulk viscosity, and shear viscosity suggest that the length scale of compaction is best modeled when shear viscosity is allowed to vary as a function of melt content.

\subsection{Introduction}

Melt transport in the Earth plays a fundamental role in the formation of the oceanic crust, the movement of melt to hot-spots and volcanic arcs, and the dynamics of flow beneath oceanic spreading centers and within the mantle wedge of subduction zones. In the Earth, melt pressures may be close to lithostatic. In regions where effective pressure is low, brittle processes may dominate deformation, even at elevated temperatures. Experiments on rocks in the brittle regime demonstrate that the strength of 
the aggregate is dependent on the effective mean stress, the difference between mean stress and pore fluid pressure. In addition, the application of a deviatoric stress during drained deformation experiments has been observed to increase compaction rates during both brittle and ductile deformation [e.g.Wong, 1990; Xiao and Evans, 2003]. Laboratory studies on olivine and melt aggregates have been used to constrain processes active in the Earth, but have been limited primarily to undrained deformation experiments. We ran drained, triaxial deformation tests on partially molten olivine aggregates to test how strength depends on effective mean stress and if melt extraction rates are enhanced during triaxial deformation.

The earliest experiments designed to investigate the rheology of partially molten aggregates of mantle composition were conducted by Cooper and Kohlstedt [1984; 1986]. These experiments were followed by systematic studies investigating the influence of melt on the deformation of dry olivine [Hirth and Kohlstedt, 1995a; b], olivine at hydrous condition [Mei, et al., 2002], and olivine aggregates in simple shear [Zimmerman, et al., 1999; Holtzman, et al., 2003a; Holtzman, et al., 2003b]. In all cases, the presence of melt decreased the strength of the aggregates.

Previous experiments studying the role of melt on deformation have been limited by their inability to control the melt pressure during high-temperature pressure creep tests. Samples have sometimes been enclosed by alumina discs [e.g., Hirth and Kohlstedt, 1995a; b] or within metal capsules [Mei, et al., 2002]. In these configurations, often referred to as undrained deformation experiments, melt pressures may be as large as the mean stress if the sample is weak, melt is in isolated pores, or the melt viscosity is high. Low permeability aggregates or high viscosity melt can result in elevated melt pressures and can possibly lead to brittle processes (e.g., hydraulic fracturing), even during hightemperature deformation experiments. Observations of brittle processes during hightemperature, partially molten deformation experiments have been described in a number of studies, including granite [Dell'Angelo and Tullis, 1988], diabase [Fredrich and Evans, 1990], and peridotite [Bussod and Christie, 1991].

In addition to preventing the direct control of melt pressure, encapsulated samples also prohibit studying the rheology of compacting, partially molten aggregates. Owing to the lack of experimental studies on the compaction of partially molten aggregates, much 
of our inferences about melt extraction processes in the Earth are drawn from theoretical studies [e.g., Frank, 1968; Sleep, 1974; McKenzie, 1984; Scott and Stevenson, 1986; 1989; Fowler, 1990a; Bercovici, et al., 2001; Ricard, et al., 2001]. These studies start with the assertion that the melt is connected in a three-dimensional network throughout the rock, and is thus able to flow out of the aggregate in response to pressure gradients. In essence, compaction is a problem in two-phase flow: interacting motions of the solid matrix and interstitial melt both contribute to deformation and compaction. Most theoretical models of melt migration combine the properties of the melt, matrix, and aggregate into a single parameter referred to as the compaction length [e.g., McKenzie, 1984; Scott and Stevenson, 1986; Fowler, 1990b; Ricard, et al., 2001]. The compaction length is the characteristic length scale where pressure gradients develop, fluid content fluctuates, or compaction rates vary. The mathematical form of compaction length is dependent on model assumptions, but generally includes terms describing the permeability of the aggregate as well as the bulk and shear viscosities of the sample [e.g., McKenzie, 1984].

The majority of previous experimental work has focused on separately studying the shear and bulk viscosity of partially molten aggregates. Shear viscosity of partially molten aggregates is constrained by undrained deformation experiments [e.g., Hirth and Kohlstedt, 1995a; b; Mei, et al., 2002; Scott and Kohlstedt, 2006]. Renner et al., [2003] measured bulk viscosity and inferred sample permeability in hydrostatically compacting olivine aggregates containing various melt phases using a high-pressure carbon bead reservoir as a sink for melt. Values of compaction length calculated using shear viscosity constrained from undrained experiments and bulk viscosity and permeability constrained from hydrostatic experiments provide reasonable estimates on the length scales over which melt content may vary. For example, they accurately predict the absence of localized melt channels in aggregates deformed in shear containing only olivine and basaltic melt because the compaction length is larger than the sample size. However, in olivine and basalt aggregates containing chromite, the permeability of the aggregate is reduced, yielding compaction lengths smaller than the sample size and the formation of melt melt-rich bands and melt-depleted lenses [Holtzman, et al., 2003b]. While independent measurements of shear and bulk viscosity provide some estimates on the 
rheology of partially molten aggregates, they prohibit us from studying any feedbacks between deformation and compaction.

To investigate the influence of melt pressure, compaction, and loading conditions on the rheology of partially molten aggregates, we conducted drained, triaxial compression tests on olivine plus MORB samples. We use a high-pressure carbon bead reservoir surrounding a small alumina piston to provide a sink for the basaltic melt and a means to transfer stress to the partially molten olivine aggregate. Compaction rates are monitored via a pore fluid pressure system throughout the experiment allowing for the synchronized measurement of bulk and shear viscosity. Measured compaction rates provide important constraints on the theoretical forms of permeability and compaction length of partially molten olivine aggregates.

Throughout this chapter, we refer to stress and strain in various forms. Terminology and definitions are summarized in Table 1. We adopted the standard geological convention of measuring compressive stress and strains as positive. Accordingly, compaction is positive and dilatation is negative.

Table 1. Symbols, nomenclature, and definitions of pressure, strain, stress, and viscosity.

\begin{tabular}{llll}
\hline Symbol & Name & Definition & Units \\
\hline$P_{c}, \sigma_{3}$ & Confining Pressure & $\mathrm{MPa}$ \\
$P_{c}^{\text {eff }}$ & Effective Confining Pressure & $P_{c}-P_{p}$ & $\mathrm{MPa}$ \\
$P_{m}$ & Melt Pressure & & $\mathrm{MPa}$ \\
$P_{p}$ & Pore Fluid Pressure & $\mathrm{MPa}$ \\
$\varepsilon_{a x}$ & Total/Measured Axial Strain & $\varepsilon_{d}+\frac{1}{3} \varepsilon_{v}$ & \\
$\dot{\varepsilon}_{a x}$ & Total/Measured Axial Strain & & \\
$\varepsilon_{d}$ & Rate & $\mathrm{s}^{-1}$ \\
$\dot{\varepsilon}_{d}$ & Distortional Strain & \\
$\varepsilon_{v}$ & Distortional Strain Rate & & \\
$\varepsilon_{v}^{a x}$ & Volumetric Strain & $\mathrm{s}^{-1}$ \\
$\varepsilon_{v_{r}}^{i m g}$ & Volumetric Strain calculated & \\
$\varepsilon_{v}^{v o l}$ & using axial actuator & & \\
$\dot{\varepsilon}_{v}$ & Volumetric Strain calculated & \\
$\dot{\varepsilon}_{v}^{a x}$ & using image analysis & \\
& Volumetric Strain calculated & \\
& Using volumometer & $\mathrm{s}^{-1}$ \\
& Volumetric strain rate & $\mathrm{s}^{-1}$
\end{tabular}




\begin{tabular}{llll}
\hline Symbol & Name & Definition & Units \\
\hline$\dot{\varepsilon}_{v_{T}}^{\dot{i m g}}$ & $\begin{array}{l}\text { calculated using axial actuator } \\
\text { Volumetric strain rate } \\
\text { calculated using image analysis } \\
\text { Volumetric strain rate }\end{array}$ & & $\mathrm{s}^{-1}$ \\
$\dot{\varepsilon}_{v}^{\text {vol }}$ & $\begin{array}{l}\text { calculated using volumometer } \\
\text { Melt fraction }\end{array}$ & $\mathrm{s}^{-1}$ \\
$\phi$ & Initial melt fraction & \\
$\phi_{0}$ & Melt extraction rate & & \\
$\dot{\phi}$ & Shear viscosity & $\mathrm{s}^{-1}$ \\
$\eta$ & Shear viscosity of melt & $\sigma_{d} / \dot{\varepsilon}_{a x}$ & $\mathrm{~Pa} \mathrm{~s}$ \\
$\mu$ & Differential stress & $\mathrm{Pa} \mathrm{s}$ \\
$\sigma_{d}$ & Mean stress & $\sigma_{1}-\sigma_{3}$ & $\mathrm{MPa}$ \\
$\sigma_{m}$ & $\frac{\sigma_{d}+3 \sigma_{3}}{3}$ & $\mathrm{MPa}$ \\
$\sigma_{m}^{e f f}$ & Effective mean stress & $\frac{\sigma_{d}+3 \sigma_{3}}{3}-P_{p}$ & $\mathrm{MPa}$ \\
$\zeta$ & Bulk viscosity & $\sigma_{m}^{e f f} / \dot{\varepsilon}_{v}$ & $\mathrm{~Pa} \mathrm{~s}$ \\
\hline
\end{tabular}

\subsection{Experimental Details}

All experiments were conducted in an internally heated, servo-controlled, gasmedium apparatus equipped with a pore pressure system [Paterson, 1970]. During the melt extraction experiments, we measure confining and pore fluid pressure, the axial displacement of the sample during deformation, the load on the sample, and the position of the servo-controlled volumometer piston. The uncertainty in the pressure difference between confining and pore fluid pressure is $\sim 0.1 \mathrm{MPa}$ and is constrained by calibrating the two electronic pressure gauges against a Heise gauge. Axial displacement during melt extraction is measured using an external actuator with a resolution of $\sim 0.3 \mu \mathrm{m}$, and we use an internal load cell with an accuracy of $\sim 0.5 \mathrm{MPa}$ to quantify the axial force on the sample. Constant pressure in the pore fluid system is maintained during deformation experiments using a servo-controlled volumometer. The uncertainty in the position of the servo-controlled volumometer piston is $\sim 2 \times 10^{-4} \mathrm{~mm}$. Temperature during deformation experiments is constrained by conducting furnace calibrations. During calibrations, temperature varies less than $2^{\circ} \mathrm{C}$ along the length of the sample with an absolute accuracy 
in temperature of $\pm 10^{\circ} \mathrm{C}$. Thermocouples were not present during all experiments. Absolute temperature accuracy was $\pm 10^{\circ} \mathrm{C}$ in samples during experiments with thermocouples present and $\pm 30^{\circ} \mathrm{C}$ in samples during experiments without thermocouples. The presence of small crystals in the melt phase during several experiments without thermocouples indicates sample temperatures during compaction were too cold and below the melt solidus. These experiments are noted in Table 2.

\subsubsection{Sample preparation and synthesis}

Experimental samples are synthesized from mixtures of San Carlos olivine and mid-ocean ridge basalt (MORB) powers. Powders are made by first pulverizing millimeter sized, essentially unaltered, grains of both materials in a shatter-box until grain sizes are approximately $100 \mu \mathrm{m}$. Two different techniques were used to further reduce grain sizes for our experiments. For experimental numbers 1-13, powders were sieved and settled to yield an initial grain size ranging from 30 to $38 \mu \mathrm{m}$ for the olivine powder and a grain size less than $15 \mu \mathrm{m}$ for the MORB. For experimental numbers 14 and greater, we decreased the initial grain size by injecting $100 \mu \mathrm{m}$ powders into a fluid ion mill. Using a laser diffraction particle size analyzer (Beckman Coulter Counter), we measured a mean grain size of $19.0 \mu \mathrm{m}$ for both the olivine and MORB powder. We smeared together known weight fractions of olivine and MORB powders prepared from both techniques with a small, metal spatula on wax paper to produce experimental samples with approximately $0,5,10,15$, and 30 weight percent MORB.

Experimental sample powders for the melt extraction experiments are hotisostatically pressed (HIP) to create well-characterized, low-porosity olivine plus MORB aggregates. Sample powders are first cold-pressed into a Ni capsule (11.7 mm O.D., 11.0 $\mathrm{mm}$ I.D., $26 \mathrm{~mm}$ high) with a uniaxial stress of approximately $100 \mathrm{MPa}$ and then stored in a $60^{\circ} \mathrm{C}$ oven for at least 12 hours prior to insertion into the gas medium apparatus. For experimental numbers greater than 14 we attempted to further dry out samples by placing them in a 1-atmosphere oven and heating them to $400^{\circ} \mathrm{C}$ for half an hour to remove excess water from the surface of grain boundaries. The sample assembly for the HIP is shown in Figure 1a and b. Ni capsules are capped by $\mathrm{Ni}$ foil to encapsulate the samples in $\mathrm{Ni}$ and buffer oxygen fugacity near $\mathrm{Ni} / \mathrm{NiO}$ [e.g. Hirth and Kohlstedt, 1995a; b]. We HIP 
all samples at $1200^{\circ} \mathrm{C}$ and $300 \mathrm{MPa}$. For experimental numbers less than 8, we HIP samples for 10 hours. For experimental numbers greater than and equal to 9 we attempted to further dry out the powders and decrease porosity during deformation by connecting the samples to a vacuum system. The vacuum system was activated a half an hour before applying any external pressure load to the sample. Calibration experiments indicate that the steel jacket surrounding the sample cuts off permeability around $250^{\circ} \mathrm{C}$ and $250 \mathrm{MPa}$. At this point, the sample is sealed off from the atmosphere. Vacuum-sealed samples were HIPed for approximately 8 hours. No systematic differences are observed between samples of the same starting powders with or without the vacuum. After the HIP samples are extracted from the gas-medium apparatus, the metal jackets are dissolved using a mixture of hydrochloric and nitric acid (aqua regia). A disc from the HIP sample is retained for microstructural analysis, while the remaining sample is machined to a square cylinder $9 \mathrm{~mm}$ diameter and approximately $13.5 \mathrm{~mm}$ tall for the melt migration experiments.

To control melt pressure, quantify the amount of melt leaving the sample, and deform the sample, we require a unique sample assembly for the melt extraction experiments (Figure 1a and c). The most novel element of the sample assembly is the configuration of the vitreous carbon sphere reservoir, which provides a sink for melt escaping from the sample and a means of transferring stress to the sample. Individual carbon beads are very stiff; however, the aggregate of carbon spheres comprising the reservoir cannot support significant shear stresses at low effective stress. Consequently, we use a small alumina piston ( $7.5 \mathrm{~mm}$ diameter and $7 \mathrm{~mm}$ tall) to transfer stress to our samples. The carbon bead reservoir measures $9 \mathrm{~mm}$ outer diameter, $7.5 \mathrm{~mm}$ inner diameter, and $7 \mathrm{~mm}$ tall, yielding a total volume of $136 \mathrm{~mm}^{3}$. Assuming a dense random packing value of $36 \%$ [Mavko, et al., 1998], the carbon bead reservoir can accommodate approximately $50 \mathrm{~mm}^{3}$ of melt. For a sample with a starting melt content of approximately $10 \%$, this volume corresponds to a melt content of approximately $5 \%$. A split alumina spacer lies above the carbon beads and small alumina piston. The split spacer allows communication with the argon pore fluid pressure system, and generally prohibits the extrusion of carbon spheres into the thermocouple bore. The bottom of the 
sample is separated from the alumina spacer with $\mathrm{Ni}$ foil, while the top of the sample is coated with graphite to separate it from the small alumina piston.

\subsubsection{Melt extraction experimental procedure}

Experimental samples are loaded into the gas-medium apparatus and initially heated to $\sim 700^{\circ} \mathrm{C}, \sim 270 \mathrm{MPa}$ confining pressure, and $0.1 \mathrm{MPa}$ pore fluid pressure. Temperature is increased at a rate of $15^{\circ} \mathrm{C} \mathrm{min}^{-1}$ for all portions of the experiments. Samples remain at $700^{\circ} \mathrm{C}$ for 15 minutes. The pore fluid pressure system is then connected to the confining pressure system, bringing the two into equilibrium. Temperature is increased to $900^{\circ} \mathrm{C}$ with a concomitant rise in both pore fluid and confining pressure. The pore fluid pressure system is then isolated from the confining pressure system and pore pressure lowered $100 \mathrm{MPa}$ (effective confining pressure $=P_{e}=$ $\left.P_{c}-P_{p}=100 \mathrm{MPa}\right)$ to compact the carbon reservoir while the melt phase is still solid. Calibration experiments by Renner et al., [2003] for hydrostatic experiments using similar carbon spheres as a reservoir material showed that this procedure minimizes additional compaction of the carbon reservoir at the high temperatures and smaller pressure differences used during compaction experiments. After the reservoir-compaction phase, we interconnect the confining and pore fluid pressure systems and raise the temperature of the sample to $1200^{\circ} \mathrm{C}$. This procedure results in some decompaction of the carbon reservoir [Renner et al., 2003], but it limits melt from leaving the sample before the beginning of the melt extraction experiment. Confining and pore fluid pressure remain interconnected for at least one hour after the sample has reached $1200^{\circ} \mathrm{C}$ to minimize pressure and temperature gradients within the sample.

Melt extraction experiments begin by isolating the pore fluid pressure from the confining pressure and then decreasing pore fluid pressure to increase the effective pressure on the sample. Effective pressures during melt extraction experiments range from 10 to $50 \mathrm{MPa}$. We use three different types of mechanical tests during the melt extraction experiments: hydrostatic compaction experiments (HYD), constant strain-rate tests (CSR), and creep tests (CRP). In several experiments we use both hydrostatic and creep tests (MXD). The mechanical tests differ in the way in which the axial load is applied to the sample. During hydrostatic experiments a small, relatively constant differential stress of $\sim 3 \mathrm{MPa}$ is imposed on the sample to obtain a continuous length 
record. The differential stress is significantly less than the effective confining pressure to minimize its influence on compaction. Constant strain-rate tests displace the axial piston at a constant speed. Creep tests are analogous to hydrostatic experiments, except a higher differential stress is applied to the sample. Differential stresses during creep tests are approximately equal to or greater than the mean stress. Confining pressure during all hydrostatic and constant-strain rate experiments is $300 \mathrm{MPa}$. During creep and mixed type experiments, effective mean stress was held constant at $\sim 50 \mathrm{MPa}$. For these experiments pore fluid pressure was maintained at $250 \mathrm{MPa}$, and confining pressure was varied between 266 to $288 \mathrm{MPa}$ to achieve a relatively constant effective mean stress. At the end of the mechanical testing we reconnect the confining and pore fluid pressures systems and quench the sample by shutting off power to the furnace. The average cooling rate above the melt solidus was $\sim 150 \mathrm{~K} \mathrm{~min}^{-1}$.

\subsection{Data Analysis}

\subsubsection{Microstructural analysis}

We used digital images acquired from an optical light microscope to quantify grain sizes and melt fractions before and after the melt extraction experiments. Prior to melt extraction experiments, we remove a small, cylindrical portion of the sample end perpendicular to the sample axis. The exposed sample surface is at least $2 \mathrm{~mm}$ away from either the top or the bottom of the sample to minimize the impact of the sample ends on the microstructure. After the melt extraction experiments, samples are separated from the large alumina pistons and impregnated with epoxy. Samples are cut along the cylindrical axis to expose the carbon bead reservoir and complete cross-section of the sample. For microstructural analysis, the small alumina piston and carbon bead reservoir are cut away from one of the sample halves to facilitate polishing. Surfaces of pre- and postdeformation samples are polished using 400-1200 grit silicon carbide paper, 1-0.1 $\mu \mathrm{m}$ alumina powder, and $0.02 \mu \mathrm{m}$ colloidal silica.

We estimated grain size using line intercept techniques (Underwood, 1970). A regularly spaced $7 \times 7$ grid was placed over the sample images, and the intercept lengths of the olivine grains are measured along two orthogonal sets of lines. Grid spacing is 56 $\mu \mathrm{m}$ on the sample images and appreciably greater than the average grain size. For the 
post-deformation samples, one set of lines are aligned with the sample axis. Grain sizes for the deformed samples are calculated near the middle of the samples, between 4 to 6 mm away from the melt reservoir. CSR-1 and CSR-15 show significant porosity in the middle of the sample and grain sizes are measured within a few millimeters of the sample reservoir, where porosity is relatively low.

We constrain volume fractions of olivine and melt by point counting. Points are arranged on a $7 \times 7$ test grid spaced $84 \mu \mathrm{m}$ from each other. The test grid is placed on a single image, and the number of points that coordinated with olivine, melt or pores is divided by the total number of points (49) to determine the volume fraction of a particular phase. This processes is repeated eleven times for each image. We calculate the mean volume fraction, standard deviation, and the $95 \%$ confidence intervals of both parameters for olivine, melt, and pores. We used at least three images (33 grids) oriented perpendicular to the cylindrical axis of the sample to constrain pre-deformation volume fractions. Volume fractions of olivine, melt, and pores for the post-deformation samples were measured every $1 \mathrm{~mm}$ along the center axis of the sample to create melt content profiles. We constrain average post-deformation melt fractions by calculating the mean volume fraction and standard deviation from all along-axis grids (approximately 110 grids).

\subsubsection{Volumetric strain analysis}

We quantify volumetric strain and strain rate during triaxial melt extraction experiments by using changes in the reservoir volume recorded by the position of the volumometer actuator. In addition, we use microstructural observations to verify and correct, where necessary, the volumetric strain measurements calculated from the volumometer record. Corrections are necessary due to small pressure leaks. During hydrostatic experiments, changes in sample length measured by the position of the axial actuator were also used to constrain volumetric strain and strain rate. We describe volumetric strain calculations in Appendix A. 


\subsection{Results of Drained Deformation Experiments}

\subsubsection{Macroscopic observations}

Macroscopic sample cross-sections are shown in Figure 2. Images are of scanned samples impregnated with epoxy and cut in half using a low speed saw. They have not been polished. Figure $2 a$ and $b$ are characteristic images of hydrostatic and deformed samples, respectively.

Hydrostatic experiments deform relatively homogenously, e.g. barreling of the sample is minimal. Figure 2a shows a sample that started with approximately $10 \%$ melt and was hydrostatically deformed at an effective pressure of $50 \mathrm{MPa}$ for approximately 5.4 hours (HYD-11). In this experiment, melt expulsion led to a decrease in both the longitudinal and radial dimensions of the sample. Measurements from the sample image indicate the sample length decreased from $13.48 \mathrm{~mm}$ to $13.18 \mathrm{~mm}$, and the sample diameter decreased from $8.91 \mathrm{~mm}$ to $8.89 \mathrm{~mm}$. These length changes correspond to a volumetric strain of $3.9 \%$, which agrees, within error, to the final melt fraction calculated from image analysis (Table 2). The small amount of melt removed from the sample during the compaction experiment was insufficient to fill the carbon bead reservoir. Consequently, carbon beads escaped from the sample assembly during the impregnation process and became suspended in the epoxy mould.

Triaxially deformed samples exhibit inhomogeneous deformation, indicated by barreling and intrusion of the sample into the carbon bead reservoir. Barreling developed from the no-slip boundary condition at the interface between the sample and alumina pieces. The intrusion of the sample into the carbon bead reservoir is due to the strength contrast between the small alumina piston and the carbon bead reservoir. Both barreling and intrusion of the samples into the carbon bead reservoir are more pronounced in samples deformed to higher axial strains. Figure $2 \mathrm{~b}$ shows a triaxially deformed sample that started with $\sim 10 \%$ melt (CSR-7). During the melt extraction experiment, we deformed the sample to $22.1 \%$ axial strain. There was an accompanying $5.1 \%$ reduction in melt content. Unlike the hydrostatic experiment discussed above, the triaxially deformed sample's width increased. In this case, the mean sample diameter expanded from $8.94 \mathrm{~mm}$ to $9.44 \mathrm{~mm}$. In all triaxially deformed samples, radial expansion resulting from axial deformation outpaced radial contraction owing to melt extraction. We see no 
evidence for carbon beads in the epoxy mould of sample CSR-7 (Figure 2b). This observation suggests melt completely filled the carbon bead reservoir during this experiment, thus preventing the removal of carbon beads during the impregnation process.

\subsubsection{Microstructural observations}

Microstructural observations are used to constrain sample grain size and melt content before and after the melt extraction experiments. In addition, microstructural observations allow us to inspect the sample and carbon bead reservoir. Example microstructures of several samples are shown in Figure 3. Dihedral angles for the samples are clearly less than $60^{\circ}$, in agreement with other experiments on olivine plus MORB [e.g. Waff and Bulau, 1979; Riley and Kohlstedt, 1991; Renner, et al., 2003]. Microstructural examination of the melt reservoirs following the experiments reveal there is no sintering, fracturing or other noticeable permanent deformation of the carbon spheres.

Numerous small crystals are present in the melt phase of sample MXD-16 prior the melt extraction experiments (Figure $3 \mathrm{~g}$ ). Several other experiments, denoted by the $\S$ symbol in Table 2, show similar features. To the unaided eye these samples are gray, in contrast to the light green hue of the samples containing less than $\sim 15 \%$ MORB and no small crystals. Crystals form in melt when the sample temperature falls below the MORB's liquidus. If temperature is raised above the liquidus after crystals have formed, as was the case for MXD-16 during the melt extraction experiment, these crystals melt (Figure $3 \mathrm{~h}$ ). Although these crystals represent only a small portion of sample volume, they influence the permeability of the sample, the viscosity of the melt, and the rheology of the aggregate. Three samples (CSR-4, CRP-15 and MXD-17) retained these small crystals following melt extraction experiments.

\subsubsection{Grain size}

Grain size changes less than a few microns for most samples during melt extraction experiments (Table 2). Figure 4 shows histograms of grain size for three samples, CSR-7, HYD-14, and MXD-16, before and after melt extraction. The grain size distributions are log-normal. Probability distribution functions are comparable before and 
after the melt extraction experiments. Grain size in samples formed from powers separated by stokes settling (CSR-7: Figure 4a) are similar to grain sizes in samples with powders produced in a fluid ion mill (e.g. CSR-14: Figure 4c or MXD-16: Figure 4e). The mean grain size and standard deviation of grain size is larger in samples where crystallization of the MORB resulted in the formation of small crystals (e.g., Figure 3g). Following HIP's, samples MXD-16, MXD-17, and HYD-18 all have relatively large mean grain sizes and a large variation in grain size: grain size ranges from 1-2 $\mu \mathrm{m}$ to as large as $\sim 100 \mu \mathrm{m}$ in these samples. We used the average of the initial and final grain sizes for our rheological analyses.

\subsubsection{Melt content before and after drained triaxial experiments}

Microstructural observations reveal lower melt fractions in all samples following melt extraction experiments. Average post-deformation melt factions are shown in Table 2 , and melt fraction as a function of distance from the carbon bead reservoir for two hydrostatic and two triaxially deformed samples is shown in Figure 5. Hydrostatic experiments show a relatively uniform melt fraction along the length of the sample, suggesting the compaction process is relatively isotropic and homogeneous (Figure 5a and b). Sample HYD-14 hydrostatically compacted for a longer time than HYD-11, and subsequently, more melt was extracted. Spatially homogenous melt fractions in hydrostatically compacted olivine + MORB samples were also observed by Renner et al., [2003].

Melt content is inhomogeneously distributed in triaxially deformed samples and is smaller near the sample ends than at the sample centers (Figure $5 \mathrm{c}$ and $\mathrm{d}$ ). We suspect lower melt fractions near the sample ends are caused by the no-slip boundary near the alumina pieces, which is also responsible for barreling the samples. The no-slip boundary condition prevents the radial expansion of the sample and increases the mean stress near the sample ends. In addition, the smaller cross-sectional area of the sample near the alumina pieces elevates the differential stress in these regions, further enhancing mean stress. As a result, melt content is lower near sample ends. Because melt content is symmetrical about the sample mid-point and melt on the sample end away from the 
reservoir is drained as effectively as the region near the sample reservoir, we attribute changes in melt fraction to higher mean stresses near the boundaries.

Table 2: Grain size and melt fractions before and after melt extraction experiments.

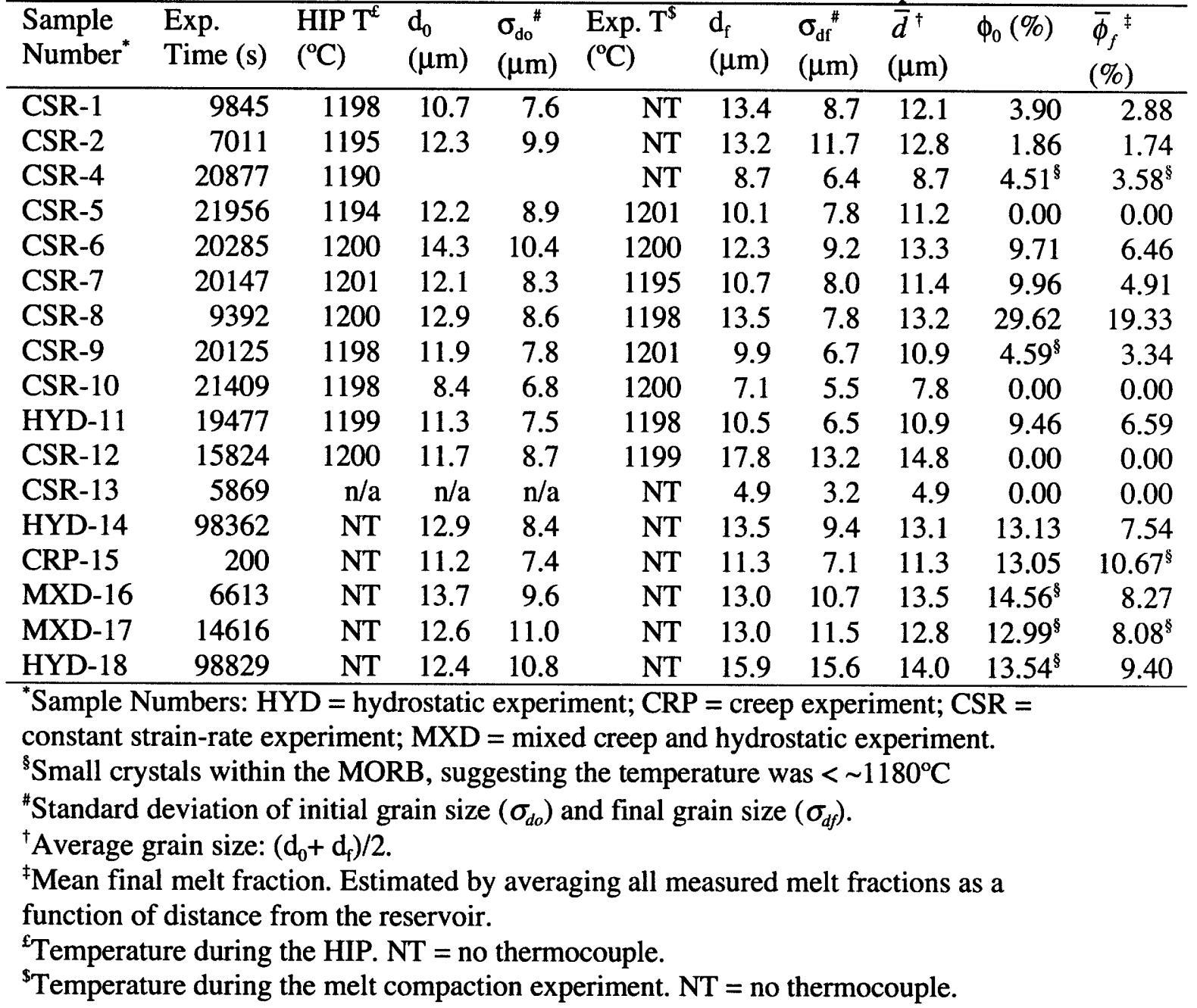

\subsubsection{Average volumetric strain rates}

We calculate average volumetric strain rates for each sample using the initial and final average melt fractions measured from sample micrographs. We convert the change in melt fraction to volumetric strain (see appendix A) and then divide by the experimental duration to obtain the average volumetric strain rate. Table 3 shows the average compaction rate for each melt extraction experiment. 
Table 3: Volumetric strain rates calculated from image analysis.

\begin{tabular}{crrrrrr}
\hline $\begin{array}{c}\text { Sample } \\
\text { Number }\end{array}$ & $\begin{array}{c}\text { Experimental } \\
\text { Duration }(\mathrm{s})\end{array}$ & \multicolumn{1}{c}{$\phi_{0}(\%)$} & $\phi_{\mathrm{f}}(\%)$ & $\Delta \phi(\%)$ & $\varepsilon_{v}^{i m g}(\%)$ & \multicolumn{1}{c}{$\dot{\varepsilon}_{v}^{i m g}\left(\mathrm{~s}^{-1}\right)$} \\
\hline CSR-1 & 9845 & 3.9 & 2.9 & 1.0 & 1.1 & $1.07 \times 10^{-06}$ \\
CSR-2 & 7011 & 1.8 & 1.7 & 0.1 & 0.1 & $1.62 \times 10^{-07}$ \\
CSR-4 & 20877 & 4.5 & 3.7 & 0.8 & 0.9 & $4.49 \times 10^{-07}$ \\
CSR-5 & 21956 & 0.0 & 0.0 & 0.0 & 0.0 & $\mathrm{n} / \mathrm{a}$ \\
CSR-6 & 20285 & 9.7 & 6.5 & 3.2 & 3.5 & $1.72 \times 10^{-06}$ \\
CSR-7 & 20147 & 10.0 & 4.9 & 5.1 & 5.5 & $2.71 \times 10^{-06}$ \\
CSR-8 & 9392 & 29.6 & 19.3 & 10.3 & 13.6 & $1.34 \times 10^{-05}$ \\
CSR-9 & 20125 & 5.1 & 4.6 & 0.5 & 1.4 & $6.73 \times 10^{-07}$ \\
CSR-10 & 21409 & 0.0 & 0.0 & 0.0 & 0.0 & $\mathrm{n} / \mathrm{a}$ \\
HYD-11 & 19477 & 9.5 & 6.6 & 2.9 & 3.1 & $1.60 \times 10^{-06}$ \\
CSR-12 & 15824 & 0.0 & 0.0 & 0.0 & 0.0 & $\mathrm{n} / \mathrm{a}$ \\
CSR-13 & 5869 & 0.0 & 0.0 & 0.0 & 0.0 & $\mathrm{n} / \mathrm{a}$ \\
HYD-14 & 98362 & 13.1 & 7.5 & 5.6 & 6.23 & $6.34 \times 10^{-07}$ \\
CRP-15 & 200 & 13.0 & 10.7 & 2.3 & 2.70 & $9.01 \times 10^{-03}$ \\
MXD-16 & 6613 & 14.6 & 8.3 & 6.3 & 7.12 & $1.08 \times 10^{-05}$ \\
MXD-17 & 14616 & 13.0 & 8.1 & 4.9 & 5.49 & $3.75 \times 10^{-06}$ \\
HYD-18 & 98829 & 15.2 & 9.4 & 5.8 & 4.63 & $4.69 \times 10^{-07}$ \\
\hline
\end{tabular}

\subsubsection{Connectivity of the olivine matrix}

We rneasure olivine contiguity before and after the melt extraction experiments in samples CSR-7, CSR-9, and HYD-11. Contiguity is a measure of the connectivity of the olivine grains and is defined as the fraction of the total interface area of a phase that is shared by particles of the same phase [Underwood, 1970]. Theoretical values of contiguity range from 0 in samples where grains of the same phase are completely isolated from each other to 1 for single-phase aggregates with no porosity. We constrain olivine contiguity before the melt extraction experiments along two radial directions oriented perpendicular to the sample axis and each other. These measurements are made near the sample ends and close to the cylindrical axis of the sample. Olivine contiguity after the melt extraction experiments is measured both in the radial direction and along the sample axis. Measurements are made in the compacted sample approximately $5 \mathrm{~mm}$ away from the sample reservoir near the cylindrical axis. Total contiguity values are the average of both directions before and after melt extraction experiments. In this section, 
we denote undeformed sample with the initials HIP (hot-isostatic press) using the same number as their deformed counterparts. Sample CSR-9 had numerous small crystals before and after the melt extraction experiment that may bias the olivine contiguity measurements.

Following the hot-isostatic presses and prior to the melt extraction experiments, samples with lower melt fractions have higher olivine contiguity than samples with higher melt fractions (Table 4). We measure a contiguity value of 0.71 for HIP-9 ( $\phi_{0} \approx$ $5 \%$ ) compared to 0.58 for HIP-7 $\left(\phi_{0} \approx 10 \%\right)$. Samples that start with the same initial melt fractions have similar olivine contiguity values. The difference in the total olivine contiguity between samples HIP-7 and HIP-11, two samples that both started with $\phi_{0} \approx$ $10 \%$, is less than 0.02 . Olivine contiguity is radially isotropic in samples following the hot-isostatic presses, and varies by less than 0.02 in the two orthogonal directions.

Following compaction, olivine contiguity is anisotropic owing to changes in the orientation of melt pockets (Table 4). Olivine contiguity is greater in the axial direction than the radial direction for both CSR-9 and CSR-7, indicating that melt pockets align in the direction of maximum compressive stress. Olivine contiguity is also greater in the axial direction for the hydrostatic compaction experiment. However, the difference in axial and radial contiguity is significantly less for HYD-11 than CSR-7: 0.04 compared to 0.16. The small load used to measure axial displacement may cause a preferred melt pocket orientation to form during hydrostatic compaction experiments.

Olivine contiguity decreased following melt extraction experiments for all samples (Table 4). This observation is counterintuitive since as melt fraction decreases, presumably more olivine grains would come into contact with each other. It appears flow and extraction of the melt pools during compaction leads to the decrease in olivine contiguity following the melt extraction experiments. However, more measurements of melt pool area, aspect ratio, and orientation are needed to constrain the processes controlling the evolution of olivine contiguity in compacting partially molten olivine aggregates. 
Table 4: Olivine contiguity measurements before and after deformation.

\begin{tabular}{lccccc}
\hline $\begin{array}{l}\text { Sample } \\
\text { Number }\end{array}$ & $\phi_{\text {image }}(\%)$ & $\begin{array}{l}\text { Total } \\
\text { Contiguity }\end{array}$ & $\begin{array}{l}\text { Axial } \\
\text { Contiguity }\end{array}$ & $\begin{array}{l}\text { Radial } \\
\text { Contiguity }\end{array}$ & $\begin{array}{l}\text { Maximum } \\
\sigma_{\mathrm{d}}(\mathrm{MPa})\end{array}$ \\
\hline HIP $^{*}-9^{\S}$ & 4.6 & 0.71 & $\mathrm{n} / \mathrm{a}$ & $0.70 \& 0.72$ & $\mathrm{n} / \mathrm{a}$ \\
CSR-9 $^{\S}$ & 4.5 & 0.52 & 0.56 & 0.47 & 90.4 \\
HIP $^{*}-7$ & 10.0 & 0.58 & $\mathrm{n} / \mathrm{a}$ & $0.58 \& 0.58$ & $\mathrm{n} / \mathrm{a}$ \\
CSR-7 $_{\text {HIP }}^{*}-11$ & 5.8 & 0.49 & 0.56 & 0.40 & 54.4 \\
HYD-11 & 9.5 & 0.56 & $\mathrm{n} / \mathrm{a}$ & $0.56 \& 0.56$ & $\mathrm{n} / \mathrm{a}$ \\
\hline
\end{tabular}

${ }^{*}$ HIP denotes measurements made on undeformed portions of the samples used in experiments of the same number.

${ }^{\S}$ Small crystals within the MORB, suggesting the temperature was $<\sim 1180^{\circ} \mathrm{C}$.

\subsection{Mechanical Data}

We present the mechanical data from the melt extraction experiments in the following sections. We first describe the results from hydrostatic experiments using our experimental assembly. We then present the data from nominally melt-free olivine aggregates and aggregates with olivine plus MORB deformed using constant strain-rate experiments. Finally, we report mechanical data from mixed hydrostatic and creep tests.

\subsubsection{Hydrostatic experiments}

We measured melt extraction rates in three nominally hydrostatic experiments (Table 5): one with $\phi_{o} \approx 10 \%$ (HYD-11) and two samples with $\phi_{o} \approx 15 \%$ (HYD-14 and HYD-18). We maintained a constant effective confining pressure of $50 \mathrm{MPa}$ throughout all three experiments. Applied differential stresses remained relatively constant throughout the three experiments (Figure 6a). An increase in differential stress of $\sim 0.5$ MPa was observed in sample HYD-14 around $\varepsilon_{a x} \approx 1 \%$ when actuator control was "lost" in a friction band and subsequently requilibrated at a slightly higher stress.

Volumetric strain calculated from the volumometer data $\left(\varepsilon_{v}^{v o l}\right)$ initially increases at rate approximately three times that of axial strain for all three hydrostatic experiments (Figure 6b). This trend is consistent with isotropic compaction of hydrostatically deformed samples. Above approximately $0.8 \%$ axial strain, volumetric strain begins to diverge from the hydrostatic compaction line. At this point, axial strain induced by the small axial load outpaces axial strain produced by hydrostatic compaction of the sample. 
Volumetric strain records for each hydrostatic experiment show distinctive characteristics after deviating from the hydrostatic compaction line. HYD-11 appears to stop compacting after approximately $1 \%$ axial strain. Volumetric strain for HYD-14 increases continuously throughout the experiment, albeit at a decreasing rate as the experiment proceeds. HYD-18 initially continues to compact, and then develops a large leak out of the pore fluid pressure system after approximately $1.5 \%$ axial strain.

Volumetric strain rates decrease as melt is extracted from the samples. Volumetric strain rates calculated using the corrected volumometer actuator data $\left(\dot{\varepsilon}_{v}^{\text {vol }}\right)$ and the axial displacement data $\left(\dot{\varepsilon}_{v}^{a x}\right)$ show good agreement over a large range in melt fractions (Figure 7). Volumetric strain rates calculated using both methods show that compaction rates decrease steadily for HYD-11, which started out with approximately $10 \%$ melt. Compaction rates initially decrease relatively slowly when HYD-14 and HYD-18 are at high melt fractions before decreasing dramatically. We infer that sudden decrease in volumetric strain rate is associated with the carbon bead reservoir filling up with melt, and the relatively constant values of $\dot{\varepsilon}_{v}^{a x}$ are the steady state strain-rates for the applied loading conditions. The agreement between $\dot{\varepsilon}_{v}^{v o l}$ and $\dot{\varepsilon}_{v}^{a x}$ at low volumetric strains indicates that we can use the axial actuator data to constrain volumetric strain rates in hydrostatic experiments where there are large pore fluid leaks and when the reservoir is not filled.

\subsubsection{Nominally melt-free olivine experiments}

We ran four experiments on nominally melt-free olivine aggregates to compare the mechanical data using a carbon bead reservoir to previously published results. Meltfree olivine experiments were deformed at constant strain-rates of $\sim 10^{-5} \mathrm{~s}^{-1}$. Experiments CSR-5, CSR-10, and CSR-12 used the carbon bead reservoir, while experiment CSR-13 was deformed immediately following a two-hour HIP without a carbon bead reservoir present. Experimental sample CSR-12 was not connected to the pore fluid pressure system during the melt extraction experiment, and was not flushed with Ar gas. It had large grain size and low stresses during deformation. Experimental sample CSR-13 had no thermocouple present during the constant strain-rate tests and also exhibited several 
unusual characteristics (e.g., small grain size and large flow stress). The results from experiments on samples CSR-12 and CSR-13 consequently were not used in the interpretation of our data.

Experiments CSR-5 and CSR-10 were deformed with a pore fluid pressure of 270 $\mathrm{MPa}$ and $10 \mathrm{MPa}$, respectively. During each experiment, we recorded the volumometer position. We were unable to correct for small leaks in the volumometer data during these two experiments since there was no melt phase to constrain the initial and final porosities. Differential stress does not follow a typical path for CSR-5, which may be due to high pore fluid pressure. Sample CSR-5 began to dilate after $\sim 10 \%$ strain (Figure $8 \mathrm{~b}$ ). CSR-10 has a smaller pore fluid pressure, and shows results more typical for a constant displacement-rate stress-strain curve. Confining pressure began to leak into pore fluid pressure at approximately 5\% axial strain during CSR-10 and prohibited us from using volumometer data at high axial strain. However, the leak was small enough that we were able to maintain pore fluid pressure constant throughout the experiment.

\subsubsection{Constant strain-rate melt extraction experiments}

We conducted constant strain-rate experiments on samples containing a range of melt fractions at several different effective confining pressures (Table 5). Samples were deformed at a constant displacement rate, corresponding to an axial strain-rate of approximately $1 \times 10^{-5} \mathrm{~s}^{-1}$. Samples containing a smaller melt fraction achieved higher stresses than samples with a higher melt fraction, regardless of the effective confining pressure (Figure 9a). In addition, samples with a smaller melt fraction strain harden to higher strain and deform at higher differential stresses than samples with a high melt fraction (Figure 9a).

We calculated volumetric strain for the constant strain-rate experiments from the volumometer actuator data corrected using the initial and final melt fractions (Appendix A). Large confining pressure leaks prevented us from constraining volumetric strain data above 5\% axial strain for sample CSR-10 or for the entire melt extraction experiment on sample CSR-9. The highest amounts of volumetric strain are achieved in samples with the greatest initial melt fractions (Figure 9b). 
Volumetric strain data indicate samples responded to loading conditions in one of two different ways. Aggregates with starting melt fractions greater than $10 \%$ (CSR-8, CSR-6, and CSR-7) compacted continuously throughout the experiments. Samples with initial melt fractions less than 5\% (CSR-4 and CSR-2) initially compacted and then appeared to dilate (Figure 9b). Compacting aggregates have positive volumetric strain versus axial strain slopes; whereas, dilating aggregates have negative volumetric strain versus axial strain slopes. The delineation between compaction and dilatation appears to be between melt fractions of 3 to 5\% when samples are deformed at an axial strain rate of $10^{-5} \mathrm{~s}^{-1}$. Sample CSR-4 had small crystals present in the melt phase that may have influenced the onset of compaction. The transition from compaction to dilation in samples CSR-2 and CSR-4 is not correlated with a concomitant change in the strength of the deforming aggregate (Figure $9 b$ ).

We tested experimental reproducibility and studied the effect of changing melt pressure during experiments on samples CSR-9 ( $\left.\phi_{0} \approx 5 \%\right)$, CSR-7 $\left(\phi_{0} \approx 10 \%\right)$, and CSR-8 $\left(\phi_{0} \approx 30 \%\right)$. During these experiments, we increased effective confining pressure $20 \mathrm{MPa}$ at approximately $5 \%$ axial strain. Below 5\% axial strain, the experiments on sample CSR-7 and CSR-9 were designed to test the reproducibility of experiments on samples CSR-6 and CSR-4, respectively. CSR-7 and CSR-6 had starting melt fractions of approximately 10\%, while CSR-4 and CSR-9 had starting melt fractions of approximately 5\%. The measured differential strength of sample CSR-7 agreed within $5 \%$ of the measured differential strength of sample CSR-6 when they were subjected to the same effective confining pressures. Over the same pressure conditions, volumetric strains agreed within $1 \%$ for these two samples. Samples CSR-4 and CSR-9 show an approximate $10 \%$ difference in differential stress when the samples are subjected to the same effective confining pressure. The larger difference between CSR-4 and CSR-9 is most likely associated with slightly different starting melt fractions and the presence of small crystals in the melt phase of CSR-4. There was no volumetric strain data for during the experiment on CSR-9 to compare with CSR-4.

Increasing the effective confining pressure during experiments on samples CSR-9, CSR-7, and CSR-8 induced relatively small changes in the overall strength of the aggregates (Figure 9a). The strength of CSR-9 instantaneously decreased when the melt 
pressure was reduced from $270 \mathrm{MPa}$ to $250 \mathrm{MPa}$ before it rebounded and followed a strain-hardening curve similar to sample CSR-4, which was deformed at a lower effective confining pressure. The strength of CSR-7 increased when the melt pressure was decreased from $270 \mathrm{MPa}$ to $250 \mathrm{MPa}$, and the strength of CSR-8 remained unchanged when melt pressure was decreased from $290 \mathrm{MPa}$ to $270 \mathrm{MPa}$.

Volumetric strain increases more quickly when melt pressure is lowered. Both sample CSR-7 and CSR-8 show rapid increases in volumetric strain after the effective confining pressures were increased. There was no volumetric strain data for CSR-9.

As melt is removed from the sample, volumetric strain rates decrease (Figure 10). We calculate volumetric strain rates from the volumometer data shown in Figure $9 \mathrm{~b}$ for CSR-2, CSR-4, CSR-6, CSR-7, and CSR-8. Where data overlap, as in the case of CSR-6 and CSR-7, there is extremely good agreement in measured volumetric strain rates. Increasing effective confining pressure causes an immediate increase in the volumetric strain rates (e.g. CSR-7, Figure 10). Thus, volumetric strain rates are faster at higher effective confining pressures at the same melt fraction.

Volumetric strain rates as a function of melt content for the sample with the largest initial melt fraction (CSR-8) shows similar characteristics to the hydrostatic experiments HYD-14 and HYD-18 (Figure 11). Initially, volumetric strain rates decrease relatively slowly. After approximately $2 \%$ of the melt has drained out of the sample, however, melt extraction rates decrease precipitously. Like the hydrostatic experiments, CSR-8 begins with a relatively high melt fraction draining at a high volumetric strain rate. The carbon bead reservoir can only accommodate a limited amount of melt at these high volumetric strain rates before flow out of the split-spacer at the top of the reservoir become the rate-limiting step on compaction. Investigation of CSR-8 shows that melt penetrated into the gap between the split alumina spacers and likely into the thermocouple bore. This explains why we measured an approximately $10 \%$ melt loss in CSR-8, when the carbon bead reservoir can accommodate only an approximately $5 \%$ reduction of melt a sample. When we increased effective confining pressure during CSR8 , we see a complimentary rise in volumetric strain rate like CSR-7. However, volumetric strain rates appear to increase after effective confining pressure is decreased, possibly indicating a reaction between the MORB and alumina pieces. 


\subsubsection{Mixed creep and hydrostatic experiments}

We ran consecutive creep tests and hydrostatic experiments on the same samples to measure the change in volumetric strain rates owing to changes in loading conditions (MXD-16 and MXD-17). Unfortunately, the pore fluid pressure developed small leaks during these two experiments prohibiting us from constraining volumetric strain and calculating melt extraction rates during the creep portion of the experiments. The leaks were not significant enough to prohibit us from maintaining constant pore fluid pressure.

The two coupled creep and hydrostatic experiments were conducted using slightly different procedures. Sample MXD-16 was deformed in two parts (Figure 12a). First, we ran a creep test at $P_{c} \approx 284 \mathrm{MPa}, P_{p}=250.0 \mathrm{MPa}$, and $\sigma_{d}=40.7 \mathrm{MPa}$ to $\varepsilon_{a x} \approx 18 \%$. We then ran a short hydrostatic experiment immediately following the creep test. During the hydrostatic portion of the experiment, $\sigma_{m}^{e f f} \approx 35 \mathrm{MPa}$. Sample MXD-17 was deformed in three parts (Figure 12b). First, we ran a hydrostatic experiment at $\sigma_{m}^{e f f} \approx 22 \mathrm{MPa}$. Next, we performed a short creep test at $P_{c} \approx 271 \mathrm{MPa}, P_{p}=250.0 \mathrm{MPa}$, and $\sigma_{d}=40.7 \mathrm{MPa}$ for about $15 \%$ axial strain. Finally, we repeated the initial hydrostatic experiment to measure changes in hydrostatic volumetric strain rates at lower melt fractions. The reduction in axial strain following the creep sections of MXD-16 and MXD-17 exceeds the expected amount from elastic unloading of the samples.

Volumetric strain rates can be constrained during the hydrostatic portions of the experiments using the axial strain rates. There was more noise during the hydrostatic sections of MXD-16 and MXD-17 than during experiments on HYD-11, HYD-14 and HYD-18. We estimate axial strain rates for MXD-16, by fitting a straight line through the peaks of strain versus time curve after $5000 \mathrm{~s}$ (Figure 12a). This analysis yields a volumetric strain rate of $3.52 \times 10^{-6} \mathrm{~s}^{-1}$. The axial strain data are slightly more reliable for MXD-17. We observe average values of $1.14 \times 10^{-6} \mathrm{~s}^{-1}$ and $7.46 \times 10^{-7} \mathrm{~s}^{-1}$ for the first and second hydrostatic experiments during MXD-17, respectively. It should be noted, however that MXD-17 contained numerous small crystals before and after the drained deformation experiments, and volumetric strain rates may be lower owing to small crystals inhibiting melt transport out of the sample. The reservoir at the end of MXD-16 was likely filled with melt. However, the results of the hydrostatic experiments in MXD- 
16 are consistent with the other hydrostatic experiments. This correlation is consistent with observations if the compaction rate of the sample is much lower than the flow-rate through of the carbon bead reservoir.

Both creep tests were performed at $\sigma_{m}^{\text {eff }} \approx 50 \mathrm{MPa}$ to determine if increased differential stresses generated higher melt extraction rates. Axial strain rates during the creep test are a superposition of axial and volumetric strain. In a pure olivine aggregate, we expect to measure a relatively constant strain rate during a creep test if the sample microstructure was constant. During melt extraction, melt drains from the sample, and consequently, we observe axial strain rate decreasing as deformation proceeds (Figure 13).

Table 5: Loading parameters. Initial and final melt fractions included.

\begin{tabular}{|c|c|c|c|c|c|c|c|c|}
\hline $\begin{array}{l}\text { Sample } \\
\text { Number }\end{array}$ & $\phi_{0}(\%)$ & $\phi_{\mathrm{f}}(\%)$ & $\begin{array}{l}\varepsilon_{\mathrm{Ax} \max } \\
(\%)\end{array}$ & $\begin{array}{l}\sigma_{\mathrm{d}}^{\dagger} \\
(\mathrm{MPa})\end{array}$ & $\begin{array}{l}\mathrm{P}_{\mathrm{c}} \\
(\mathrm{MPa})\end{array}$ & $\begin{array}{l}\mathrm{P}_{\mathrm{p}} \\
(\mathrm{MPa})\end{array}$ & $\begin{array}{l}\mathrm{P}_{\mathrm{e}} \\
(\mathrm{MPa})\end{array}$ & $\sigma_{m}^{\text {eff }}(\mathrm{MPa})$ \\
\hline CSR-1 & 3.9 & 2.9 & 10.5 & 32.1 & 299.3 & 299.3 & 0.0 & 10.7 \\
\hline CSR-2 & 1.9 & 1.7 & 6.1 & 120.9 & 303.7 & 253.7 & 49.9 & 90.3 \\
\hline CSR-4 & 4.5 & 3.7 & 22.6 & 103.8 & 301.6 & 272.0 & 29.6 & 64.2 \\
\hline CSR-5 & 0.0 & 0.0 & 22.4 & 178.2 & 302.8 & 273.2 & 29.5 & 89.0 \\
\hline CSR-6 & 9.7 & 6.5 & 22.1 & 49.0 & 301.7 & 272.1 & 29.6 & 45.9 \\
\hline \multirow[t]{2}{*}{ CSR-7 } & 10.0 & 4.9 & 21.9 & 54.4 & 301.0 & 271.0 & 30.0 & 48.1 \\
\hline & & & & & & 251.0 & 50.0 & 68.1 \\
\hline \multirow[t]{2}{*}{ CSR-8 } & 29.6 & 19.3 & 10.7 & 3.5 & 301.8 & 291.9 & 9.9 & 11.1 \\
\hline & & & & & & 271.9 & 29.9 & 31.1 \\
\hline \multirow[t]{2}{*}{ CSR-9 } & 5.1 & 4.6 & 21.7 & 90.4 & 302.0 & 272.8 & 29.2 & 59.3 \\
\hline & & & & & & 252.8 & 49.2 & 79.3 \\
\hline CSR-10 & 0.0 & 0.0 & 22.1 & 140.9 & 300.7 & 10.2 & 290.5 & 337.5 \\
\hline HYD-11 & 9.5 & 6.6 & 1.6 & 2.8 & 299.5 & 250.0 & 49.5 & 50.4 \\
\hline CSR-12 & 0.0 & 0.0 & 16.2 & 102.3 & 302.7 & $\mathrm{n} / \mathrm{a}^{*}$ & $\mathrm{n} / \mathrm{a}^{*}$ & $\mathrm{n} / \mathrm{a}^{*}$ \\
\hline CSR-13 & 0.0 & 0.0 & 5.0 & 226.4 & 300.5 & $\mathrm{n} / \mathrm{a}^{*}$ & $\mathrm{n} / \mathrm{a}^{*}$ & $\mathrm{n} / \mathrm{a}^{*}$ \\
\hline HYD-14 & 13.1 & 7.5 & 7.5 & 1.8 & 301.2 & 254.2 & 47.0 & 47.6 \\
\hline CRP-15 & 13.0 & 10.7 & 6.8 & 76.6 & 255.1 & 249.5 & 5.6 & 31.1 \\
\hline MXD-16 & 14.6 & 8.3 & 5.7 & 40.7 & 284.2 & 250.0 & 34.2 & 47.8 \\
\hline MXD-17 & 13.0 & 8.1 & 3.5 & 84.3 & 271.2 & 250.0 & 21.2 & 49.3 \\
\hline HYD-18 & 15.2 & 9.4 & 3.5 & 2.3 & 299.4 & 250.0 & 49.4 & 50.2 \\
\hline \multicolumn{9}{|c|}{$\begin{array}{l}{ }^{\dagger} \sigma_{d} \text { is the maximum measured differential stress for CSR experiments and the mean } \\
\text { measured differential stress for HYD, CRP, and MXD (during the creep portion) } \\
\text { experiments. }\end{array}$} \\
\hline
\end{tabular}




\subsection{Discussion of Mechanical Data}

Permanent compaction of partially molten rocks requires that pore space be reduced and melt flow out of the aggregate [Sleep, 1974; McKenzie, 1984]. These two restrictions yield two end-member models for compaction. First, melt expulsion may be limited by matrix compaction. In this model, the sample is perfectly drained and there is no resistance to fluid transport out of the aggregate. A generalized law of the following form can describe the compaction of the matrix,

$$
\dot{\varepsilon}_{v, m c}=A f(\phi, \theta)\left(\sigma_{m}^{e f f}\right)^{n} d^{-m} \exp \left(\frac{-E_{c}}{R T}\right),
$$

where $A$ is a pre-exponential factor, $f(\phi, \theta)$ is a function that describes the local stress enhancement and change in rate-limiting diffusion length owing to the melt content and dihedral angle of the solid liquid interface, $E_{c}$ is the apparent activation energy for compaction, and $m$ and $n$ are the grain size and stress exponents [Coble, 1970; Helle, et $a l ., 1985]$. The effective mean stress $\left(\sigma_{m}^{\text {eff }}\right)$ is defined as,

$$
\sigma_{m}^{e f f}=\frac{\sigma_{d}+3 P_{c}}{3}-P_{m}
$$

where $\sigma_{d}$ is the differential stress, $P_{c}$ is the confining pressure and $P_{m}$ is the melt pressure. When the effective mean stress is relatively low, hot-isostatic compaction experiments [Coble, 1970; Helle, et al., 1985] and hydrostatic compaction experiments [Renner, et al., 2003] indicate that $n=1$, suggestive of a Newtonian rheology. If the matrix is deforming via a non-linear rheology, then the stress exponent may be higher.

The second end-member model describing compaction assumes that a constant melt pressure gradient is sustained over the length of the sample. If there is no effect of local dilatation, the maximum pressure gradient through the sample is $\Delta \sigma_{m} / l$. In the presence of a pressure gradient, flow of fluid through a porous matrix can be expressed in terms of Darcy's Law. We can then cast the equation in terms of volumetric strain rate and effective mean stress to obtain,

$$
\dot{\varepsilon}_{v, f t} \approx \frac{k}{\mu l^{2}} \sigma_{m}^{e f f},
$$

where $\mu$ is the shear viscosity of fluid, $l$ is the sample length, and $k$ is the permeability of the aggregate. In this model the compaction of the aggregate is limited by the flow of 
melt out of the sample and compaction rates are linearly proportional to mean effective stress.

In this section we first discuss how melt extraction experiments using our unique sample assembly compare with previously published results. We next discuss the influence of effective mean stress on volumetric strain rates. Third, we consider the possible influence of melt pressure on the strength of a deforming partially molten aggregate. Fourth, we show how melt content influences compaction rates. Finally, we examine the dependence of volumetric strain rates on the differential stress.

\subsubsection{Influence of experimental assembly on measurements}

The experimental assembly used during the drained deformation experiments has a small diameter, strong alumina piston surrounded by a weaker cylinder of carbon beads (Figure 1). To see if the small alumina piston influenced our measurements of differential stress, we preformed experiments on nominally melt-free aggregates to compare with previously published results. The most reliable experiment on a nominally melt-free olivine aggregate was run on sample CSR-10. The steady state flow stress measured for this sample agrees well with published flow laws for pure olivine [Hirth and Kohlstedt, 2003]. For a strain rate of $1 \times 10^{-5} \mathrm{~s}^{-1}$, grain size of $11.7 \mu \mathrm{m}$, and temperature of $1200^{\circ} \mathrm{C}$, the steady state flow for melt-free olivine predicts a value of $\sim 140 \mathrm{MPa}$, less than $1 \%$ different from our measured value. In addition, we compared volumetric strain rates from our experiments to previously published hydrostatic experiments on olivine plus MORB. Our results agree well with previously published hydrostatic strain rates conducted on samples without a small alumina piston [Renner et al., 2003]. These results are discussed in more detail below. We conclude that the sample assembly adopted for drained triaxial deformation experiments has little effect on measured differential stress and volumetric strain.

\subsubsection{Role of effective mean stress on compaction rates}

We quantify the role of effective means stress $\left(\sigma_{m}^{\text {eff }}\right)$ on compaction rates by comparing the volumetric strain rates of partially molten aggregates at different $\sigma_{m}^{\text {eff }}$ and constant melt fractions (Figure 14). We first compared the volumetric strain rates before and after changing the effective mean stresses in CSR-7 and CSR-8. Volumetric strain 
rate increased during these experiments when mean stress increased (Figure 14a, red triangles). Volumetric strain rates in different samples at similar melt fractions can be compared if we assume that the melt topology and sample microstructure are similar between experiments. Sample micrographs (Figure 3) and microstructural analysis (Table 2) reveal that samples lacking small crystals in the melt phase following the HIP show similar characteristics, suggesting factors controlling melt extraction may be comparable between experiments. We compare the change in volumetric strain rates observed for different samples at similar melt fractions in Figure 14a. We also plot the results of drained hydrostatic experiments on other olivine and MORB aggregates [Renner, et al., 2003].

The change in compaction rate induced by changes in effective mean stress can be fit using the following relationship,

$$
\ln \left(\frac{\dot{\varepsilon}_{v_{1}}}{\dot{\varepsilon}_{v_{2}}}\right)=n \ln \left(\frac{\sigma_{m_{1}}^{e f f}}{\sigma_{m_{2}}^{e f f}}\right),
$$

where $\dot{\varepsilon}_{v_{1}}$ is the volumetric strain rate at an effective mean stress of $\sigma_{m_{1}}^{\text {eff }}$. If compaction is limited by fluid transport or matrix compaction via a diffusion creep accommodated process we expect $n=1$. If compaction is controlled by matrix compaction via a dislocation creep accommodated process we expect $n \approx 3$. Observations of dislocation creep on olivine aggregates deformed in shear suggest $n \approx 3.5$. [Hirth and Kohlstedt, 2003]. We have thus adopted this value for subsequent analysis. Melt extraction experiments where $\sigma_{m_{2}}^{\text {eff }}$ is less than $30 \mathrm{MPa}$ agree well with equation (2.4) when $n=1$ (Figure 14b). Melt extraction experiment where $\sigma_{m_{2}}^{\text {eff }}$ is greater than $60 \mathrm{MPa}$ are more consistent with $n \approx 3.5$ (Figure $14 \mathrm{~b}$ ). There appears to be a transition between the two stress exponents when $\sigma_{m_{2}}^{\text {eff }}$ is between 50 to $60 \mathrm{MPa}$ and $\sigma_{m_{1}}^{\text {eff }}$ is approximately $30 \mathrm{MPa}$. Several hydrostatic experiments from Renner et al., [2003] were deformed at high effective mean and low differential stress (Figure 14b). These experiments are consistent with an $n>1$, and suggest the transition from an effective mean stress exponent of $n=1$ to $n \approx 3.5$ is not dependent on the absolute value of differential stress. Rather, the mean effective stress, which is a function of differential stress, confining pressure and melt 
pressure, appears to determine the transition to a higher stress exponent and enhanced compaction rates.

Renner et al., [2003] observed that hydrostatic compaction experiments on olivine plus MORB were more consistent with compaction limited by fluid transport out of the matrix (equation (2.3)). Based on their inferences and our experiments, we conclude that the transition from a stress exponent of $n=1$ to $n \approx 3.5$ indicates a change from compaction limited by fluid transport to compaction accommodated by a dislocation creep process.

\subsubsection{Melt pressure and sample strength}

As we discussed in the previous section, lowering the melt pressure increases the effective mean stress and compaction rates. Lower melt fractions yield stronger aggregates with higher bulk viscosities. This effect can be clearly seen in the comparison between samples CSR-6 and CSR-7 (Figure 9). These samples started out with the same starting melt contents and were deformed at the same mean effective stresses until approximately 5\% axial strain. At this point we reduced the pore fluid pressure in CSR-7 from $270 \mathrm{MPa}$ to $250 \mathrm{MPa}$, and a small increase in the strain-hardening rate can be seen in sample C.SR-7 compared to sample CSR-6. The difference in measured differential stress at the end of CSR-6 and CSR-7 is consistent with the difference in final melt fractions for these two experiments. Sample CSR-7 was approximately $8 \mathrm{MPa}$ stronger than sample CSR-6 at the end of the melt extraction experiments. Sample CSR-7 had a final melt fraction of $4.9 \%$, and sample CSR-6 had a final melt fraction of $6.5 \%$. When sample CSR-7 had a melt content of $6.5 \%$ it was approximately $10 \mathrm{MPa}$ weaker than when it had a melt content of $4.9 \%$, consistent with the observed difference in differential stress at the ends of CSR-7 and CSR-6. This suggests that differences in the measured differential strength may be accounted for by variations in melt content.

We also changed melt pressure during experiments on CSR-8 and CSR-9. Differential stress did not change during the experiment on CSR-8 when melt pressure was changed from $290 \mathrm{MPa}$ to $270 \mathrm{MPa}$. There is a small transient in differential stress versus axial strain in CSR-9 (Figure 9a), but the rate of strain hardening before and after the strength transient is very similar. The limited effect of melt pressure on strength of 
CSR-7, CSR-8, and CSR-9 suggests that these samples are deforming in a relatively pressure-insensitive regime.

Samples with low initial melt contents (CSR-2 and CSR-4) show evidence for dilatation during melt extraction experiments. The switch from compaction to dilation requires melt pressure changes within the samples. We do not observe a change in rate of strain hardening in these samples at the transition from compaction to dilation (Figure 9). These observations indicate that there is only a modest effect of effective pressure on the strength at these conditions.

In addition to cases where there is no melt and high pore fluid pressures, melt pressure may play a significant role on the sample strength at extremely low effective pressures. In Appendix $\mathrm{C}$ we describe two experiments where the difference between confining pressure and pore fluid pressure was less than $5 \mathrm{MPa}$. In both of these experiments we observe evidence for brittle deformation mechanisms and substantial dilatation.

Melt pressure does not appear to influence the strength of the aggregates within the resolution of our measurements at melt contents greater than $5 \%$ and effective pressures greater than $10 \mathrm{MPa}$.

\subsubsection{Role of melt fraction on compaction rates}

Volumetric strain rates are lower in samples with smaller melt fractions. We use equation (2.4) to normalize volumetric strain rates to a common mean effective stress. We plot unnormalized data (Figure 15a), data normalized to $\sigma_{m}^{\text {eff }}=50 \mathrm{MPa}$ using equation (2.4) with $n=1$ for all experiments (Figure 15b), and data normalized to $\sigma_{m}^{\text {eff }}=$ $50 \mathrm{MPa}$ using equation (2.4) with $n=1$ for experiments with $\sigma_{m}^{\text {eff }}<30 \mathrm{MPa}$ and $n=3.5$ for experiments with $\sigma_{m}^{\text {eff }}>30 \mathrm{MPa}$ (Figure 15c). We also show normalized volumetric strain rates from hydrostatic experiments on olivine + MORB aggregates [Renner et al., 2003] for comparison. Normalizing the data using $n=1$ at low $\sigma_{m}^{\text {eff }}$ and $n=3.5$ at high $\sigma_{m}^{e f f}$ yields the smallest amount of scatter in the data.

Volumetric strain rapidly decreases for small changes in melt fraction melt extraction experiments on CSR-2 and CSR-4 (Figure 9b). There may be one of several 
sources for the observed dilatency, including an increase in porosity in the carbon bead reservoir and sample assembly, creation of pore space in the sample, or reentry of melt back into the sample. Since we only have the final melt fraction of the sample, we are unable to ascertain between the three options. However, we did not have to apply a significant correction to the volumometer data in these experiments, the volumetric strain calculated from the volumometer data agreed to within $0.1 \%$ of the image analysis.

Samples with melt contents greater than 5\% compacted throughout the triaxial compaction experiments. These samples show remarkable agreement with previous hydrostatic experiments on olivine + MORB [Renner et al., 2003] when data are normalized using $\sigma_{m}^{\text {eff }}$. As shown in Figure 15, compaction rates initially fall off quickly and then decrease as a slower rate. This is most easily observed in experiments with $\phi_{0} \approx$ 10. The enhanced compaction rates observed at the start of the experiment are likely associated with the rapid expulsion of melt from easily drained, large pools. After the large melt pools are removed, compaction proceeds at a slower rate. Volumetric strainrates shown for CSR-8 only represent the rapid compaction of the large melt pools, and they do not represent slower, post-transient compaction rates.

\subsubsection{Role of differential stress on compaction rates}

As indicated in equation (2.2), $\sigma_{m}^{\text {eff }}$ is proportional to differential stress. Thus, as we increase differential stress, we expect an accompanying rise in volumetric strain rate. Triaxial compaction experiments in the brittle regime show that compaction rates can increase at a rate faster than expected owing to changes in $\sigma_{m}^{\text {eff }}$ via a process called shearenhanced compaction. Shear-enhanced compaction refers to porosity reduction assisted by differential stress. The applied differential stress acts to increase stress concentration around pores. These larger stress concentrations cause more extensive pore collapse and compaction than expected from hydrostatic loading alone. To ascertain if shear enhanced compaction is occurring during high-temperature triaxial compaction experiments, we normalized our data using equation (2.4) and then compared the volumetric strain rates at various similar melt fractions and various differential stresses.

Increasing differential stress appears to have little effect on volumetric strain rate. Volumetric strain rates for several samples with the same initial starting melt fraction $\left(\phi_{0}\right.$ 
$\approx 10 \%$ ) are compared in Figure 16. Data are normalized to $\sigma_{m}^{\text {eff }}=50 \mathrm{MPa}$ using a stress exponent of $n=1$ (Figure 16a) and $n=3.5$ (Figure 16b). The normalization process shifted the data only a small amount since most of the data points are from when $\sigma_{m}^{\text {eff }}=$ $50 \pm 10 \mathrm{MPa}$. A small positive correlation between volumetric strain rate and differential stress is seen for $\phi \approx 8.5 \%$. The data points at elevated differential stress are from when the sample is initially loading. Thus, the initial compaction processes may be affected by the sudden increase in differential stress. Below melt contents of $8 \%$ increasing differential stress has no or a negligible effect on volumetric strain rate using stress exponents of either $n=1$ or $n=3.5$. These results indicate that shear-enhanced compaction is very modest when initial melt contents are approximately $10 \%$ and samples are deformed at an effective mean stress of $50 \mathrm{MPa}$.

\subsection{Discussion of Compaction Models and Melt Transport}

Modeling compaction requires constrains on the viscosity of the melt, the permeability of the sample, and the bulk and shear viscosities. In this section we discuss a micromechanical model for compaction that relates compaction rates to the mean effective stress and the differential stress. This model attempts to account for the full stress state on the sample to constrain compaction rates. More complicated compaction models require knowledge of the permeability of the deforming aggregate and the bulk and shear viscosities of the samples. We therefore compare our results to two permeability models. We then discuss constraints on shear and bulk viscosity during deformation, and calculate the compaction length for our experiments using the McKenzie [1984] and the Ricard et al., [2001] formulations. Finally, we discuss drained versus transiently undrained conditions for our experiments.

\subsubsection{Triaxiality model of compaction}

The compaction of a solid matrix can be constrained using a model that couples the effects of effective mean stress and differential stress into one parameter called triaxiality. This formulation for compaction has been successfully applied to modeling void collapse during non-linear viscous creep of porous calcite quartz aggregates [Xiao and Evans, 2003]. Constitutive relations for the compaction of solids containing dilute concentration of isolated spherical voids were developed by Duva and Hutchinson 
[1984]. The theoretical model of void growth or collapse (dilatation or compaction) requires the velocity field surrounding the void be described in terms of the stress state and stress exponent $n$. Budiansky et al., [1982] formulated approximate Rayleigh-Ritz solutions for a spherical void based on the minimum principle velocities given in Hill [1956]. Approximate solutions for the evolution of void space are cast in terms of the stress triaxiality $\chi$, defined as:

$$
\chi=\frac{\Sigma_{m}}{\Sigma_{e}},
$$

where $\Sigma_{\mathrm{m}}$ is the remote mean stress and $\Sigma_{\mathrm{e}}$ is the remote effective stress. In triaxial compaction experiments $\left(\sigma_{1}>\sigma_{2}=\sigma_{3}\right)$, triaxiality is equivalent to:

$$
\chi=\frac{\sigma_{m}^{e f f}}{\sigma_{d}} .
$$

The evolution of the void space in a viscously deforming porous aggregate is thus dependent both the mean stress and differential stress acting on the aggregate. For a hardening exponent of $n=3$, normalized compaction rate is equal to:

$$
\frac{\dot{\varepsilon}_{v}}{\dot{\varepsilon}_{a} \phi}=2.71(\chi+0.045) \text {. }
$$

Normalized volumetric strain rates observed during drained triaxial compaction experiments are consistent with the non-linear, viscous compaction triaxiality model (Figure 17). We constrain uncertainty in normalized volumetric strain rates two ways. First, we estimate uncertainty in samples with initial melt contents less than $5 \%$ by comparing the maximum and minimum values of normalized volumetric strain rates obtained by accounting for the uncertainty in the measurement of initial and final melt contents. Second, we estimate uncertainty in samples with starting melt contents greater than $5 \%$ by comparing normalized compaction rates calculated from the corrected volumetric strain data to the normalized compaction rates calculated from the uncorrected volumetric strain data. The normalized compaction rates calculated from the uncorrected data are inconsistent with microstructural observations, but they provide an estimate of the worst-case scenario. Normalized compaction rates are likely much closer to the data points. At higher triaxiality factors, the data matches the model predictions for a range of stress exponents. As differential stresses increases and triaxiality factors decrease, 
however, the viscous compaction models over predict compaction rates by a factor of approximately 1.5. This indicates that the triaxial model may overestimate the contribution of differential stress to compaction. However, this uncertainty is within measurement error, and to first order, the data is reasonably well fit by the triaxiality model of compaction.

\subsubsection{Permeability of partially molten aggregates}

Models that consider melt transport as well as solid deformation require knowledge of permeability. Micrographs reveal melt fractions are symmetric about the mid-line of the sample, suggesting melt content evolves through a series of states characterized by relatively homogenous melt distributions. Assuming the effects of microstructural rearrangement on permeability are negligible during compaction, permeability may be expressed in terms of melt content $(\phi)$ and matrix grain size $(d)$ using the following relationship,

$$
k=\frac{\phi^{r} d^{s}}{C},
$$

where $C$ characterizes the tortuosity of the fluid pathways. The melt fraction and grain size exponents ( $r$ and $s$ ) are dependent on the sample microstructure and may vary as deformation proceeds [Guéguen and Palciauskas, 1994; Bernabé, et al., 2003].

The porosity term in equation (2.8) represents the interconnected melt content contributing to fluid flow. In an isotropic material with a dihedral angle less than $60^{\circ}$, an interconnected network of fluid is expected at all melt fractions. Thus, $\phi$ is equivalent to the melt content of the sample. However, anisotropic interfacial energies within the olivine may require that a finite melt fraction be achieved before an interconnected melt network forms. In this case, $\phi$ can be considered as the difference between absolute porosity and a percolation threshold that depends on the dihedral angle [von Bargen and Waff, 1986]. Daines and Richter [1988] experimentally determined that melt networks in olivine and basalt systems form a completely interconnected network with no isolated melt pools at melt contents of at least $2 \%$. For the samples where compaction occurred throughout the experiment $\left(\phi_{0}>5 \%\right)$, this experimental observation indicates that there is 
no difference between using the current melt content or the difference between the current melt content and a percolation threshold.

Numerical modeling of olivine aggregates where melt topology is controlled by interfacial energy suggests $r=s=2$ and $C=1250$ [von Bargen and Waff, 1986]. Experiments on texturally equilibrated quartz-water aggregates are best explained by $r=3, s=2$, and $C=300$ [Wark and Watson, 1998]. The tortuosity term of 300 is obtained from Wark and Watson [1998] for a grain size derived from intercept length multiplied by 1.5 [Renner et al., 2003].

We compare normalized compaction rates in samples with similar initial melt fractions $\left(\phi_{0} \approx 10 \%\right)$ to two permeability models (Figure 18 ). These samples compacted throughout the entire compaction experiment. Data are normalized to $50 \mathrm{MPa}$ effective mean stress using equation (2.4) and $n=3.5$. Renner et al., [2003] observed hydrostatic compaction rates for olivine and MORB aggregates are well described by fluid transport limited compaction described by equation (2.3). For comparison, we plot hydrostatic compaction data from Renner et al., [2003], normalized to $\sigma_{m}^{e f f}=50 \mathrm{MPa}$, a grain size of $20 \mu \mathrm{m}$, and a sample length of $13 \mathrm{~mm}$ using equation (2.3) and the permeability relationship given in (2.8) with a grain size exponent of $s=2$. Permeability models overestimate compaction rates of the Renner et al., [2003] data at all melt fractions. However, the amount of volumetric strain rate change for given changes in melt content is better predicted by the permeability model of Wark and Watson [1998] than von Bargen and Waff [1986]. Neither permeability model predicts the rapid decrease in volumetric strain rate at the onset of compaction. During this phase of compaction, significant microstructural rearrangement is occurring and the melt exponent given in equation (2.8) may be changing rapidly. After large-scale microstructural rearrangement (approximately $7.5 \%$ in these samples), it appears the permeability model of Wark and Watson [1998] is consistent with both the triaxial and hydrostatic data of Renner et al., [2003]. However, this model over estimates volumetric strain rates by a factor of approximately 2 , suggesting that matrix compaction also contributes to melt transport for olivine and MORB samples at these conditions. 
In subsequent modeling, we assume that permeability in our triaxially compacting experiments is, to first order, consistent with the permeability model of Wark and Watson [1998] using the relationship described in equation (2.8) with $r=3, s=2$, and $C=300$.

\subsubsection{Constraints on shear and bulk viscosity}

We simultaneously measured bulk and shear viscosity for the first time in partially molten olivine aggregates. When melt fraction decreases, bulk viscosity decreases and shear viscosity increases. Thus, as compaction proceeds, the ratio of bulk to shear modulus grows. Recent theoretical models [Katz, et al., 2006] developed to understand the formation of melt rich zones in partially molten olivine aggregates deformed in simple shear [Holtzman, et al., 2003a], indicate that the ratio of bulk to shear viscosity may play an important role in determining the orientation of melt-rich bands. This orientation of melt pools could have important implications for the orientation and magnitude of seismic anisotropy, electrical conductivity and permeability in the Earth's mantle.

The ratio of bulk to shear viscosity ranges from approximately 1 to 50 for our experiments (Figure 19). With the exception of experiment MXD-16, all results shown in Figure 19 were deformed at a constant strain rate of $1 \times 10^{-5} \mathrm{~s}^{-1}$. We plot ratio of bulk to shear viscosity calculated from the average value of compaction rate for samples that dilated during triaxial compaction experiments (CSR-2, CSR-4, and CSR-9). As compaction reduces the melt content of the samples, bulk viscosity increases more rapidly than shear viscosity, and the ratio of shear to bulk viscosity increases.

\subsubsection{Compaction length}

Theoretical models of melt migration simultaneously solve the coupled equations of mass, momentum, and energy conservation. In addition, the rheology of melt, matrix, and composite aggregate must also be considered. Many models combine the properties of the melt, matrix, and aggregate into a scaling parameter called the compaction length [McKenzie, 1984; Scott and Stevenson, 1986; Ricard, et al., 2001]. The compaction length is the characteristic length scale where gradients in fluid content and compaction rates can develop. Compaction is thus expected to remain localized on scales of the compaction length. Model assumptions will dictate the precise formulation of the 
compaction length. McKenzie [1984] cast compaction length $\left(\delta_{M}\right)$ in terms of the bulk and shear viscosity of the aggregate,

$$
\delta_{M}=\sqrt{\frac{k(\phi)}{\mu}\left(\zeta+\frac{4}{3} \eta\right)},
$$

where $\mu$ is the fluid viscosity and $k(\phi)$ is the permeability given as a function of the melt fraction in the sample. In contrast, Ricard et al., [2001] formulated compaction in terms of the viscosity of the melt free aggregate $\left(\eta_{0}\right)$,

$$
\delta_{B R S} \approx \sqrt{\frac{\eta_{0} k_{0} \phi}{3 \mu}},
$$

where the permeability of the aggregate is given by $k=k_{0} \phi^{3}$, and $\mu \ll<\eta_{0}$.

We estimate compaction lengths in our experimental samples by using the volumetric and axial strain data recorded during our experiments to constrain bulk and shear viscosity respectively. In samples that dilate, we estimate average volumetric strain rates from image analysis. We assume that permeability is described by the relationship given in equation (2.8) with $k$ proportional to melt fraction to the third power and a grain size exponent of 3 [e.g., Wark and Watson, 1998]. Melt viscosity is approximately $40 \mathrm{~Pa}$ $\mathrm{s}$ [Renner, et al., 2003]. Calculated sample compaction lengths range between 9 to $35 \mathrm{~mm}$ using equation (2.9). These compaction lengths are on the order of the sample length (Figure 20). The compaction lengths calculated using the Ricard et al., [2001] formulation, equation (2.10), are 1-2 orders of magnitude greater than the sample length and range from $\sim 200$ to $\sim 1000 \mathrm{~mm}$.

\subsubsection{Drained versus transiently undrained melt extraction}

Fully drained deformation requires that melt pressure remains constant throughout the sample during compaction and melt extraction. When melt content is sufficiently high and the sample is deformed slowly, melt has the necessary time to flow and equilibrate throughout the aggregate. When loading is too rapid or the melt fraction and permeability of the aggregate are too low, melt has insufficient time to flow and equilibrate. When melt has inadequate time to equilibrate, deformation is referred to as transiently undrained even if the aggregates are physically connected to a fluid reservoir. The observation of symmetric melt distributions and compaction throughout melt extraction 
experiments in samples with initial melt contents greater than $5 \%$ suggests these samples are well drained. Volumetric strain measurements suggest that samples with initial melt contents less than 5\% dilate during the melt extraction experiments. This observation could signify that pore space is opening up in the aggregate, perhaps drawing melt back into the sample. The observation of rapidly decreasing volumetric strain rates eventually becoming negative suggest that the partially molten aggregates are transitioning from a drained to transiently undrained state.

Renner et al., [2000] formulated a theoretical expression the critical melt fraction separating drained from transiently undrained conditions. In their paper, they discussed the critical melt fraction in terms of the rheologically critical melt fraction, the melt fraction at which deformation switches from one controlled by viscous processes to one controlled by brittle processes. For melt extraction experiments on partially molten peridotite, we make no assumptions about the deformation mechanism. Rather we use the analysis of Renner et al., [2000] to ascertain when conditions change from dominantly drained to transiently undrained. Renner et al., [2000] extend analysis originally developed by Brace, Martin and Walsh [1968; Brace, et al., 1968] and Fischer and Paterson [1989].

Spatial and temporal gradients in melt pressure $\left(P_{m}\right)$ can be described by [Walsh, 1965; Brace, et al., 1968],

$$
\frac{\partial P_{m}}{\partial t}=\frac{k}{\mu \beta_{s}} \nabla^{2} P_{m},
$$

where $\mu$ is the fluid viscosity, $k$ is the permeability, and $\beta_{s}$ is the storage capacity per unit volume of the system (also referred to as storatitivity). From (2.11) we can define a characteristic decay time $\left(t_{c}\right)$ of a pore pressure perturbation across a characteristic length scale $\left(l_{c}\right)$ [Fischer and Paterson, 1989; 1992]:

$$
t_{c}=\frac{\mu \beta_{s}}{k} l_{c}^{2}
$$

At a constant deformation rate, time is related to an increment of axial deformation $(\Delta \varepsilon)$ by $t_{c}=\Delta \varepsilon / \dot{\varepsilon}$ [Renner, et al., 2000]. If we assume that the scale of the pressure gradient is on the order the sample length $l_{c}$, a critical strain rate can be defined [Fischer and Paterson, 1989]: 


$$
\dot{\varepsilon}_{c r i t}=\frac{\Delta \varepsilon}{l^{2}} \frac{k}{\mu \beta_{s}} .
$$

Renner et al., [2000] used volumetric strain data [Brace, et al., 1966; Edmond and Paterson, 1972; Fischer and Paterson, 1989; Renner and Rummel, 1996] to determine $\Delta \varepsilon$ is approximately $0.1 \%$ for brittle failure and $1 \%$ for semi-brittle flow. When $\dot{\varepsilon}_{d}>\dot{\varepsilon}_{c r i t}$ the melt pressure will not be able to respond quickly to pressure heterogeneities. Melt pressures will thus not be coupled to pore fluid pressures within the reservoir even if the rock is physically drained to a reservoir.

If the storativity and permeability of the sample is known, we can then constrain the critical melt fraction in terms of the strain rate. The storativity is a measure of the relatively change in fluid volume stored in a porous medium per unit change in $P_{m}$, and it can be described in terms of the compressibilities of the empty porous matrix $\left(\beta_{p m}\right)$, the pore fluid $\left(\beta_{f}\right)$ and the constituent crystals $\left(\beta_{c}\right)$ [Brace, et al., 1968; Fischer and Paterson, 1989]:

$$
\beta_{s}=\beta_{p m}+\phi \beta_{f}-(1+\phi) \beta_{c} .
$$

The compressibility of the porous matrix is given by $\beta_{p m}=\beta_{c}(1+b \phi)$, where $b$ ranges from 3-10 [Coble and Kingery, 1956]. This allows us to constrain the storativity of the experimental samples using the compressibilities of the liquid and crystals. The bulk modulus of silicate liquids is roughly $10 \mathrm{GPa}$, corresponding to $\beta_{f}=0.1 \mathrm{GPa}^{-1}[$ Fujii and Kushiro, 1977], and the compressibility of the olivine minerals is roughly an order of magnitude lower than the silicate liquid [Stopler, et al., 1981]. Analysis of volumetric strain data from the drained deformation experiments shows that the permeability of the partially molten olivine aggregates is consistent with permeability described by equation (2.8). Making the necessary substitutions for $k$ and $\beta_{s}$ into (2.13) [Renner, et al., 2000] obtained the following expression for the critical strain rate:

$$
\dot{\varepsilon}_{c r i t}=\frac{\Delta \varepsilon}{l^{2}} \frac{\phi^{r} d^{s}}{\mu \phi\left(\beta_{c}(b-1)+\beta_{f}\right)} .
$$

Solving equation (2.15) for $\phi$ yields the corresponding critical melt fraction separating drained from transiently undrained conditions [Renner, et al., 2000], 


$$
\phi_{c r i t}=\left(\frac{l_{c}^{2}}{\Delta \varepsilon} \frac{\dot{\varepsilon} C \mu\left(\beta_{c}(b-1)+\beta_{f}\right)}{d^{s}}\right)^{1 / r-1}
$$

Solving equation (2.16) for the experimental parameters with $\Delta \varepsilon=1.0 \%$ and $b=6.5$ yields a critical melt fraction of approximately $3 \%$. Above this value, samples are drained and compact. Below this value, samples are transiently undrained and dilate.

Sample CSR-4, which had small crystals present in the melt phase that may have influenced the permeability of the aggregate, is the only sample with in situ volumetric strain measurements at approximately 3-5\%. The volumetric strain for this sample switched from compaction to dilatation at a melt content of approximately $3.5 \%$, a value consistent with the calculation

The analysis of a switch from fully drained to transiently undrained deformation at a melt fraction of approximately $3 \%$ is consistent with the with the McKenzie [1984] formulation of compaction length. Both analyses indicate that at melt fractions around 3$4 \%$, under the experimental conditions presented in this paper, melt pressure gradients will develop. These gradients in melt pressure induce dilatation, and lead to a decrease in the measured volumetric strains. The strength of the samples does not respond immediately once the critical melt fraction is reached suggesting the transition from drained to transiently undrained conditions during high-temperature melt extraction experiments does not trigger a change in deformation mechanism.

\subsection{Conclusions}

We investigated the rheology of compacting, partially molten olivine aggregates at $1200^{\circ} \mathrm{C}$ over a range of effective pressures. Observations of microstructures, changes in macroscopic sample geometry and records of external displacement transducers indicate that hydrostatic compaction is isotropic and homogeneous. Triaxially deformed samples with $\phi_{o}<5 \%$ dilated during the melt extraction experiments. The transition from compaction to dilatation suggests that these samples changed from drained to transiently undrained conditions. The experimentally observed transition from drained to undrained conditions for these samples is consistent with models for the critical melt fraction, which predict a transition from drained to transiently undrained at approximately $3 \%$ melt content at laboratory conditions. All triaxially deformed samples with $\phi_{0}>10 \%$, 
compacted throughout the melt extraction experiments. Compaction rates decreased with diminishing melt content. Melt extraction rates are linearly proportional to effective mean for samples deformed at low effective mean stress and are proportional to effective mean stress raised to approximately the 3.5 power for samples deformed at effective mean stresses greater than $50 \mathrm{MPa}$. Our results are consistent with the permeability model of Wark and Watson [1998] and the compaction length formulation of McKenzie [1984].

\section{Appendix A: Volumetric Strain Analysis}

We quantify volumetric strain and strain rate during triaxial melt extraction experiments by using changes in the reservoir volume recorded by the position of the volumometer actuator. In addition, we use the results from the microstructural observations to verify and correct, where necessary, the volumetric strain measurements calculated from the volumometer displacement data. Occasional corrections are necessary due to small leaks from the confining pressure system into the pore fluid pressure system. During hydrostatic experiments, changes in sample length measured by the position of the axial actuator were used to further constrain volumetric strain and strain rate.

The difference between the mean stress and the melt pressure drives melt into the carbon bead reservoir during melt extraction experiments. Melt entering the reservoir displaces argon gas increasing pressure in the pore fluid pressure system. In order to compensate for this increase in pressure, the volumometer actuator retracts to keep pressure constant. The displacement $(b)$ of the volumometer piston is related to the change of melt volume in the sample $\left(\Delta V_{\text {melt }}\right)$ by the relationship,

$$
\Delta V_{\text {melt }}=\frac{\rho_{P, 293 K}}{\rho_{P, 1473 K}} \cdot b \cdot A_{v o l},
$$

where $A_{v o l}$ is the cross sectional area of the volumometer piston. The ratio $\rho_{P, 293 K} / \rho_{P, 1473 K}$ accounts for the difference in argon density within the low-temperature chamber of the volumometer, where we measure changes in volume, and the high-temperature sample reservoir, where we calculate the volume of melt entering the reservoir. At experimental conditions, $\rho_{P, 293 K} / \rho_{P, 1473 K}$ is on the order of 2 . Volumetric strain calculated from the volumometer position $\left(\varepsilon_{v}^{v o l}\right)$ is then given by, 


$$
\varepsilon_{v}^{v o l}=-\ln \left(1-\frac{\Delta V_{\text {melt }}}{V_{0}}\right),
$$

where $V_{o}$ is the initial sample volume.

Volumetric strain for hydrostatic experiments is constrained using two methods, equation (2.18) and the position of the axial actuator. For hydrostatic experiments a small differential stress applied to the sample ensured constant contact between the axial actuator and the sample assembly. Assuming isotropic compaction, volumetric strain $\left(\varepsilon_{v}^{a x}\right)$ is three times the axial strain $\left(\varepsilon_{a x}\right)$. We use the difference $(\Delta l)$ between the initial $\left(l_{0}\right)$ and current sample length $(l)$ to calculate axial and volumetric strain:

$$
\varepsilon_{v}^{a x}=-3 \varepsilon_{a x}=-3 \ln \left(\frac{l}{l_{0}}\right)=-3 \ln \left(1-\frac{\Delta l}{l_{0}}\right) .
$$

Volumetric strain constrained from the axial actuator includes a component of axial strain generated by the applied load. If the differential stress is small compared to the effective confining pressure and the sample is fully drained, we expect this contribution to be small. We will discuss limitations further in the results section.

The melt fraction $(\phi)$ of a sample is the instantaneous volume of melt in the sample $\left(V_{\text {melt }}\right)$ divided by the current volume of the sample $(V(t))$. Thus, for large amounts of compaction, the volumetric strain $\left(\varepsilon_{v}\right)$, which is calculated with respect to the initial volume of the sample, is not equal to the change in melt content. Renner et al., [2003] derived the following relationships between melt fraction and volumetric strain,

$$
\phi=\frac{V_{\text {melt }(t)}}{V(t)}=\left(\phi_{0}-1\right) \exp \left(\varepsilon_{v}\right)+1
$$

and,

$$
\varepsilon_{v}=\ln \left(\frac{\phi-1}{\phi_{0}-1}\right)
$$

where $\phi_{0}$ is the initial melt fraction of the sample. Measuring the position of the volumometer and applying equations (2.17) and (2.18), we can use equation (2.20) to calculate melt fraction as a function of time during the melt extraction experiments. In addition, knowing the final melt fraction of the experiment $\left(\bar{\phi}_{f}\right)$ from microstructural observations, we can use (2.21) to estimate the final volumetric strain of the sample. 
The melt extraction rate $(\dot{\phi})$ is the time rate of change of melt fraction, and the volumetric strain rate $\left(\dot{\varepsilon}_{v}\right)$ is the time rate of change of the sample volume. We calculated volumetric strain rate by linear regression over finite melt content intervals. Melt extraction rate is then calculated knowing the volumetric strain rate [Renner et al., 2003],

$$
\dot{\phi}=\dot{\varepsilon}_{v}\left(\phi_{0}-1\right) \exp \left(\varepsilon_{v}\right) .
$$

Inserting equation (2.21) into (2.22), we can calculate volumetric strain rate in terms of melt content and melt extraction rate:

$$
\dot{\varepsilon}_{v}=\frac{\dot{\phi}}{(\phi-1)} .
$$

Equation (2.23) indicates that volumetric strain rate is always greater than the melt extraction rate.

We estimate average volumetric strain rates for each compaction experiment using image analysis techniques. Average melt extraction rates $\left(\dot{\phi}_{T}\right)$ are calculated by dividing the difference between starting and final melt fractions by the total experimental time. Starting and final melt fractions are determined using the methods discussed in the microstructural analysis section. We then substitute average melt extraction rates into equation (2.23) to estimate the average volumetric strain rates $\left(\dot{\varepsilon}_{v_{T}}^{\text {img }}\right)$ for each compaction experiment.

Small leaks in the pore fluid pressure system can lead to incorrect estimates of the instantaneous melt fraction in the sample. If we assume that leaks are constant and the pore space of the carbon bead reservoir is not evolving with time, the effect of these leaks can be removed by applying a linear correction to the volumometer data. To do this, we need estimate the average volumetric strain rate for each experiment $\left(\dot{\varepsilon}_{v_{T}}^{\text {img }}\right)$ and the total volumetric strain rate determined from the volumometer displacement measurements $\left(\dot{\varepsilon}_{v_{\tau}}^{v o l}\right)$. We calculate the total volumometer strain rate by dividing the total measured volumetric strain calculated using equation $(2.18)$ by the total experiment duration. The leak rate $\left(\dot{\Lambda}_{T}\right)$, cast in terms of volumetric strain rate, is then given by,

$$
\dot{\Lambda}_{T}=\dot{\varepsilon}_{v_{T}}^{v o l}-\dot{\varepsilon}_{v_{T}}^{i m g} \text {. }
$$


True volumetric strain is then equal to the difference between the measured volumetric strain calculated using (2.18) and the correction factor multiplied by time since the beginning of the experiment:

$$
\varepsilon_{v}=\varepsilon_{v}^{v o l}-\dot{\Lambda}_{T} \cdot t
$$

where $\varepsilon_{v}$ and $\varepsilon_{v}^{v o l}$ are both functions of time. Figure 21a compares the volumetric strain data calculated using (2.18) and the corrected volumetric strain data calculated using (2.25).

We changed pore fluid pressure during three experiments. In the first part of these experiments, when melt fractions were relatively high, we applied a low effective pressure. After $\sim 5 \%$ axial strain, we decreased the pore fluid pressure to study the effect of increased effective pressure on melt extraction rate and strength. If the leak rate is linearly proportional to effective pressure, we can calculate leak rates for each portion of the experiment knowing $\dot{\Lambda}_{T}$ and both effective pressures. In this formulation, the leak rate in the first $\left(\dot{\Lambda}_{1}\right)$ and second $\left(\dot{\Lambda}_{2}\right)$ parts of the experiment are related to each other via the following equation:

$$
P_{c_{1}}^{e f f} \dot{\Lambda}_{1}=P_{c_{2}}^{e f f} \dot{\Lambda}_{2}
$$

where $P_{c_{1}}^{\text {eff }}$ and $P_{c_{2}}^{\text {eff }}$ are the effective pressures in the respective portions of the experiment. The total leak rate of the experiment $\left(\dot{\Lambda}_{T}\right)$ is related to $\dot{\Lambda}_{1}$ and $\dot{\Lambda}_{2}$ via,

$$
\dot{\Lambda}_{T} t_{T}=\dot{\Lambda}_{1} t_{1}+\dot{\Lambda}_{2} t_{2},
$$

where $t_{1}$ and $t_{2}$ are the durations of each part of the experiment. We simultaneously solve (2.26) and (2.27) to attain $\dot{\Lambda}_{1}$ and $\dot{\Lambda}_{2}$. These results are substituted into (2.25) to calculate the corrected volumetric strain for each section of the experiment. Figure $21 \mathrm{~b}$ shows the results of applying this correction to CSR-7.

\section{Appendix B: Comparing Drained and Undrained Experiments}

Much of our understanding of how the mantle deforms is derived from inferences made from undrained experiments of partially molten aggregates. In these experiments samples have been enclosed in ceramic or metal capsules, thus prohibiting the melt from leaving the sample. Melt pressures are generally considered to be close to the confining 
pressure, but they may be as large as the mean stress. The results from our experiments show that melt pressure does not have an effect on the differential strength of a partially molten aggregate. However, initial melt fraction appears to influence the final strength of partially molten aggregates owing to the microstructural rearrangement of olivine grains during compaction. Undrained experiments may therefore provide misleading constraints on the rheology of compacting aggregates. In this section, we compare our experimental observations to flow laws developed using data from undrained experiments.

The results of triaxial deformation experiments are generally plotted as differential stress versus axial strain. In the case of drained experiments, the total, measured axial strain $\left(\varepsilon_{a x}\right)$ is a superposition of both the distortional strain $\left(\varepsilon_{d}\right)$ owing to the deformation of the solid matrix and the volumetric strain $\left(\varepsilon_{v}\right)$ owing to the decrease in melt. Quantitatively we can represent total axial strain with the following equation:

$$
\varepsilon_{a x}=\varepsilon_{d}+\frac{1}{3} \varepsilon_{v}
$$

For high-temperature experiments, the constitutive equation can be written as follows,

$$
\dot{\varepsilon}_{a x}=\dot{\varepsilon}_{d}+\frac{1}{3} \dot{\varepsilon}_{v},
$$

where the dot represents the derivative with respect to time. In order to compare our experiments to undrained deformation experiments we first have to remove the volumetric strain component from our axial strain measurements.

Experimental observations and theoretical analysis show that the rheological behavior of olivine aggregates is well described by a power law relationship of the strainrate $\left(\dot{\varepsilon}_{d}\right)$ on differential stress $\left(\sigma_{d}\right)$ and grain size $(d)$, while the dependence of $\dot{\varepsilon}_{d}$ on $T$ and $P$ is generally expressed as an Arrenhius relationship, common for thermally activated processes. The equation expressing the creep behavior of the olivine + melt systems deformed under anhydrous (dry) conditions thus has the form,

$$
\dot{\varepsilon}_{d}(\sigma, d, \phi, T, P)=A \frac{\sigma^{n}}{d^{m}} F(\phi) \exp \left(\frac{E_{d}+P_{e} V}{R T}\right),
$$

where $A$ is a material dependent parameter, $n$ and $m$ are the stress and grain size exponents, and $E_{d}$ and $V$ are the activation energy and volume for creep [e.g., Hirth and 
Kohlstedt, 2003]. The melt-enhancement function $F(\phi)$ accounts for the influence of melt on the rheology of the olivine aggregate.

\section{B1. Influence of melt on strength}

The physical processes controlling the influence of melt on the strength are twofold: first, the presence of melt increases local stresses at grain-to-grain contacts, and second, it enhances the rate of diffusion along grain boundaries by creating short-circuit diffusion paths [Cooper, et al., 1989; Hirth and Kohlstedt, 1995a]. Early models quantifying the magnitude strain-enhancement owing to the presence of melt assumed melt distribution was controlled by isotropic interfacial energy. This restriction required that all the melt was constrained at three and four-grain junctions and enabled the melt topology to be described by a single dihedral angle $(\theta)$ between $0^{\circ}$ and $60^{\circ}$. Cooper et al., [1989] developed the following model for deformation in the diffusion creep regime (CK model) to explain the relationship between strain-rate and melt fraction,

$$
\dot{\varepsilon}_{d}(\phi) \propto \dot{\varepsilon}_{d}(0)\left(\frac{1}{1-\Delta \delta / \delta}\right)_{s e}^{2}\left(\frac{1}{1-\Delta \delta / \delta}\right)_{s c}^{2},
$$

where $\delta$ is the characteristic grain boundary diffusion distance and $\Delta \delta$ is the portion of this distance removed due to the presence of melt at triple junctions. The subscripts $s e$ and $s c$ refer to the strain-rate enhancement resulting from local stress enhancement and short-circuit mass transport, respectively.

The geometric factor $\Delta \delta / \delta$ is a function of the melt content and dihedral angle,

$$
\frac{\Delta \delta}{\delta}=1.05 f(\theta) \phi^{1 / 2}
$$

where,

$$
f(\theta)=\sin \left(30^{\circ}-\frac{\theta}{2}\right)\left(\frac{1+\cos \theta}{\sqrt{3}}-\sin \theta-\frac{\pi}{90}\left(30^{\circ}-\frac{\theta}{2}\right)\right)^{-1 / 2} .
$$

In general, the CK model under predicts the weakening effect of melt. The deviation of the CK model from the observed data is partially explained by the presence of melt along two-grain boundaries, which provide additional short-circuit diffusion paths for mass transport [Hirth and Kohlstedt, 1995a]. As melt fraction increases, the number of two-grain boundaries wetted by melt increases linearly with respect to melt fraction 
[Hirth and Kohlstedt, 1995a]. To account for the increased number of wetted two-grain boundaries Hirth and Kohlstedt [1995a] modified the CK model, yielding the HKdiffusion model:

$$
\dot{\varepsilon}_{d}(\phi) \propto \dot{\varepsilon}_{d}(0)\left(\frac{1}{1-\Delta \delta / \delta}\right)_{s e}^{2}\left(\frac{\rho}{1-\Delta \delta / \delta}\right)_{s c}^{2}
$$

where,

$$
\rho \approx(1-4.5 \phi)^{-1} \text {. }
$$

The approximation for $\rho$ accounts for the increased number of wetted two-grain boundaries, and is valid for melt fractions up to approximately $10 \%$.

The CK model (2.31) and the HK-diffusion model (2.34) were developed to account for the weakening effect of melt in the diffusion creep regime, but they can be extended to the dislocation creep accommodated grain-boundary sliding regime and dislocation creep regime by removing the short-circuit diffusion component and incorporating the appropriate stress-exponent. In the dislocation creep regime, the enhancement of strain-rate due to the presence of melt primarily results from the stress enhancement term in equation (2.31). In other words, as the amount of melt increases at triple junctions, the area of contact between grains decreases. In the dislocation creep regime, strain-rate is proportional to stress to the $n$th power. Thus, strain-rate is enhanced [Hirth and Kohlstedt, 1995b],

$$
\dot{\varepsilon}_{d}(\phi) \propto \dot{\varepsilon}_{d}(0)\left(\frac{1}{1-\Delta \delta / \delta}\right)_{s e}^{2 n},
$$

where $n=3.5$ in the dislocation creep accommodated grain boundary sliding regime and dislocation creep regime. We refer to this model as the HK-dislocation model.

In addition to these theoretical models describing the melt-weakening effect, data can be empirically fit over a wide-range of melt fractions in all deformation regimes using the simple relationship,

$$
F(\phi)=\exp (\alpha \phi)
$$

where $\alpha$ is the melt enhancement factor. This empirical fit has been extensively used and generally provides the best-fit to laboratory data [e.g. Hirth and Kohlstedt, 1995a; b; 
Kohlstedt, 2002; Mei, et al., 2002; Scott and Kohlstedt, 2006]. At small melt fractions the CK, HK-diffusion and HK-dislocation models approach the exponential relationship given by equation (2.37). In undrained experiments on olivine and basalt melt aggregates $\alpha=21 \pm 1$ for diffusion creep and $32 \pm 1$ for dislocation-accommodated grain boundary sliding and dislocation creep [Scott and Kohlstedt, 2006].

We can recast the CK, HK-diffusion, HK-dislocation, and empirical fit models in terms of viscosity rather than strain-rate, and thus quantify the relative decrease in viscosity for a concomitant rise in melt content. This analysis yields,

$$
\begin{gathered}
\frac{\eta(\phi)}{\eta(0)_{C K}}=\left(\frac{1}{1-\Delta \delta / \delta}\right)_{s e}^{-2}\left(\frac{1}{1-\Delta \delta / \delta}\right)_{s c}^{-2}, \\
\frac{\eta(\phi)}{\eta(0)_{H K-\text { diffusion }}}=\left(\frac{1}{1-\Delta \delta / \delta}\right)_{s e}^{-2}\left(\frac{\rho}{1-\Delta \delta / \delta}\right)_{s c}^{-2}, \\
\frac{\eta(\phi)}{\eta(0)_{H K-\text { dislocation }}}=\left(\frac{1}{1-\Delta \delta / \delta}\right)_{s e}^{-2 n}, \\
\frac{\eta(\phi)}{\eta(0)_{f i t}}=\exp (-\alpha \phi),
\end{gathered}
$$

where $\eta(\phi)$ is the shear viscosity at melt fraction $\phi$.

We have no constraints on the stress-exponent $n$ during the undrained experiments since all the experiments with reliable melt fractions were conducted at the same strain-rate. As a result, we show the results of equations (2.38), (2.39), (2.40), and (2.41) in Figure 22. The data in all panels have been scaled to a stress of $50 \mathrm{MPa}$ and a grain size of $15 \mu \mathrm{m}$, using the stress exponent $n$ and the grain size exponent $m$ indicated in each panel. The melt enhancement factor was fit using a least-square linear regression technique. The left hand panels of Figure 22 plot the entire dataset, while the right hand panels of Figure 22 show the results from CSR-6 and CSR-7. In all experimental data, we calculated viscosity using the distortional strain-rate as determined by (2.29). Melt fractions below 5\% were constrained by taking the average value before and after the experiment from image analysis. Less than $1 \%$ melt was extracted from these samples providing a $\pm 0.5 \%$ maximum uncertainty in melt fraction. Melt content during 
deformation for CDR-6 and CSR-7 was measured using the volumometer during deformation. The panels on the right therefore indicate the rate at which viscosity changed during a single experiment.

The HK-diffusion model does a reasonable job reproducing the amount of weakening predicted as a function of melt content in the diffusion creep regime (Figure $22 \mathrm{a}$ and $\mathrm{b}$ ). As expected based on undrained deformation experiments, the CK-model under predicts the decrease in viscosity owing to an increase in melt. The empirical fit of $\alpha=28$ for the whole dataset and $\alpha=20$ for CSR-6 and CSR-7 agree well with the value $\alpha=21$ constrained from undrained deformation experiments [Scott and Kohlstedt, 2006]. The normalized data from CSR-6 and CSR-7 appear to diverge at high melt fraction, suggesting that normalizing the data using $n=1$ and $m=3$ may be inappropriate.

The HK-dislocation model dramatically underestimates weakening in the dislocation accommodated grain boundary-sliding regime (Figure $22 \mathrm{c}$ and $\mathrm{d}$ ). In this regime, the empirical fit reproduces the reduction in viscosity; however, the values of $\alpha$, 70 for the whole dataset and 53 for CSR-6 and CSR-7, are significantly higher than $\alpha=$ 32 reported for dislocation accommodated grain boundary sliding [Scott and Kohlstedt, 2006]. The scatter in the normalized data is much lower using $n=3.5$ and $m=2$ than using values corresponding to diffusion creep (Figure 22a and $b$ ).

The HK-dislocation model does a good job estimating the reduction in viscosity at low-melt fraction when data are normalized using dislocation creep parameters, but underestimates the weakening effect at melt fractions greater than approximately $4 \%$ (Figure 22e and f). The melt enhancement values for dislocation creep, like the values for dislocation accommodated grain boundary sliding, are also higher than reported values. However, the value of $\alpha=45$ from Figure 22f, is within the range of $\alpha$ values reported in Hirth and Kohlstedt [2003] for dislocation creep. The scatter in the data in Figure 22e and f may be slightly greater than that observed in Figure $22 \mathrm{c}$ and $\mathrm{d}$.

\section{B2. Drained deformation data compared to undrained flow-laws}

The viscosities calculated using the flow-law presented using equation (2.30) coupled with the values constrained by undrained deformation experiments in Table B1 overestimate viscosity for drained triaxial deformation experiments (Figure 23). We 
calculated viscosity in Figure 23 using the relationship $F(\phi)=\exp (\alpha \phi)$ in equation (2.30). We plot two different values of $\alpha$ for each deformation mechanism. First, the value of $\alpha$ constrained by undrained deformation experiments (Table B1), and second, the value of $\alpha$ determined from the best-fit lines shown in Figure 22a, c, and e. Drained triaxial deformation data are normalized to a differential stress of $50 \mathrm{MPa}$ and a grain size of 15 $\mu \mathrm{m}$ using the appropriate scaling parameters in Table B1 for dislocation creep, dislocation accommodated grain boundary sliding and diffusion creep.

Table B1: Olivine + MORB flow parameters ${ }^{\dagger}$ from Hirth and Kohlstedt [2003] and Scott and Kohlstedt [2006].

\begin{tabular}{llll}
\hline Parameter & Diffusion & GBS & Dislocation \\
\hline $\mathrm{A}$ & $1.5 \times 10^{9}$ & $6500^{*}$ & $1.1 \times 10^{5}$ \\
$\mathrm{n}$ & 1 & 3.5 & 3.5 \\
$\mathrm{~m}$ & 3 & 2 & 0 \\
$\alpha$ & 21 & 32 & 32 \\
$\mathrm{E}(\mathrm{kJ} / \mathrm{mol})$ & $375 \pm 50$ & $400^{*}$ & $530 \pm 40$ \\
\hline
\end{tabular}

${ }^{\dagger}$ For stress in $\mathrm{MPa}$ and grain size in $\mu \mathrm{m}$.

${ }^{*}$ Temperature $<1250^{\circ} \mathrm{C}$ from Bai et al., [1991].

Dislocation creep flow-laws over estimate viscosity at all melt fractions (Figure 23).

Dislocation accommodated grain boundary sliding appears to provide the best fit to the undrained data at melt fractions greater than approximately $5.5 \%$ when $\alpha=70$ (Figure 23). The value of $\alpha$ from Scott and Kohlstedt [2006] over predicts the measured viscosities over the entire range tested.

Viscosities calculated using a diffusion creep rheology slightly over estimate viscosity at all melt fractions (Figure 23). However, both $\alpha=21$ and $\alpha=28$ match the overall trend in the data, even if they are shifted to somewhat higher values. If the activation energy of diffusion creep is reduced only $10 \mathrm{~kJ} / \mathrm{mol}$, the viscosity calculated from the diffusion creep flow law will pass directly through the all the data normalized with $n=1$ and $m=3$. This offset is well within the experimental uncertainty of activation energy. 
The agreement of the melt enhancement factor $\alpha$ calculated for drained and undrained experiments in the diffusion creep regime, may be explained by the fact that samples deforming with less than approximately $3.5 \%$ melt were effectively undrained, leading to the good correlation between drained and undrained experiments observed in Figure 23.

The normalized drained deformation data (Figure 23) suggest that we should correct the parameters from flow laws derived from undrained experiments and use $\alpha=28$ and $E=365 \mathrm{~kJ} \mathrm{~mol}^{-1}$ in the diffusion creep regime and $\alpha=70$ in the dislocation accommodated grain boundary sliding regime and dislocation creep regime. All other parameters in Table B1 remain unmodified. Substituting these new parameters into the flow law would yield a transition from diffusion creep to grain boundary sliding at a melt fraction of $\sim 5.5 \%$ for $50 \mathrm{MPa}$ differential stress and $15 \mu \mathrm{m}$ grain size. The data normalized using the grain boundary sliding parameters in Figure 23 (blue diamonds) show a small kink in the data at $\sim 6 \%$, which may be indicative of a change in deformation mechanism.

Enhanced values of alpha are possible if the strength of the partially molten olivine aggregate is influenced by the initial melt fraction. Results from the constant strain rate tests (Figure 9a) reveal the final melt fractions of CSR-7 and CSR-9 are approximately $4.9 \%$ and $3.3 \%$, respectively. However, final measured differential stresses at identical strain rates and effective confining pressures are 54 and $90 \mathrm{MPa}$, respectively. This large difference in measured differential stress for a relatively small difference in melt fraction (1.6\%) Conversely, during the course of experiment CSR-7, we observe nearly a 5\% reduction in the average amount of melt in the sample and only a more modest increase in strength from approximately 30 to $54 \mathrm{MPa}$. These results can only be explained if the initial melt fraction influences the ultimate strength of the rock.

We see some evidence of this by looking at our measurements of olivine contiguity (Table 4). These measurements show that following deformation olivine contiguity is slightly larger in the sample that started off with a smaller initial melt fraction. More significantly radial contiguity is greater in sample CSR-9 compared to CSR-7 (0.47 compared to 0.40 ). Horizontal contiguity is a measure of the olivine cross- 
sectional area capable of supporting the load. Therefore even though the melt fractions are relatively close, the higher radial melt contiguity in sample CSR-9 may make it stronger than CSR-7, which started out with a higher melt fraction.

\section{Appendix C: Unique Experimental Observations}

We observed brittle modes of deformation in two experiments: cataclastic flow during a drained, unconfined experiment (CSR-1), and localized shear deformation during a high-stress creep test (CRP-15). During the drained, unconfined experiment, we kept the valve connecting pore fluid and confining pressure open to assure equilibrium between the two reservoirs. Consequently, no reliable volumometer data is available since the combined volume of the reservoirs is too large to accurately measure small changes in melt content. We deformed CSR-1 at $1200^{\circ} \mathrm{C}$, an axial strain rate of approximately $1 \times 10^{-5} \mathrm{~s}^{-1}$, and $P_{c}=P_{p} \approx 300 \mathrm{MPa}$. The drained, triaxial results for CSR1 are shown in Figure 24 . After attaining peak stress of approximately $32 \mathrm{MPa}$ at $1.8 \%$ axial stain, the sample weakened throughout the remainder of the experiment. Although there is no dependable volumometer data, sample micrographs reveal significant dilation following deformation. Porosity increased from approximately $3 \%$ before the start of the experiment (Figure 24) to over $30 \%$ following deformation (Figure 24). The high porosity measured after the experiment likely includes a large proportion of pluck-outs, porosity created by grains coming loose during sample preparation. Pluck-outs are more likely to form in highly fractured rock, where there is little cohesion between grains, thus suggesting an extensive microfracture network formed in CSR-1 during deformation. The morphology of the strength profile and the evidence of dilation during deformation compares well with drained triaxial experiments on other dense granular aggregates that have a component of brittle deformation [Holtz and Kovacs, 1981]. We thus infer that CSR-1 deformed via microbrittle granular flow (also referred to as cataclastic flow) [Paterson and Wong, 2005]. In this process, an originally intact rock is fragmented more or less uniformly without appreciable shear localization. Frictional sliding of the constitutive grains past each other accommodates strain, and strength is strongly affected by effective confining pressure. We hypothesize that low effective pressure and high 
Argon pore fluid pressure promoted the development of cataclastic flow at the hightemperature conditions of CSR-1.

Localized deformation developed during the creep test of a sample deformed at a relatively high differential stress $\left(\sigma_{d} \approx 76 \mathrm{MPa}\right)$ and low effective pressure $\left(P_{e} \approx 5 \mathrm{MPa}\right)$. We initially deformed sample CSR-15 at a differential stress of approximately $7 \mathrm{MPa}$ for $100 \mathrm{~s}$ (Figure 25a). After the initial creep test, we attempted to increase differential stress to $136 \mathrm{MPa}$ in order to achieve an effective mean stress of $50 \mathrm{MPa}$. However, we were unable to reach test conditions, and the maximum differential stress reached was approximately $79 \mathrm{MPa}$ (Figure $25 \mathrm{a}$ ). The sample rapidly deformed to $\varepsilon_{A x} \approx 18 \%$ in about 6 seconds. Investigation of the sample after extraction from the gas-medium apparatus indicated that a localized shear zone had formed (Figure 26a). Sample micrographs reveal extensive dilation around the localized shear zone (Figure 26b). The numerous pluck-out make it difficult to ascertain if there is a higher melt fraction inside or outside the shear zone. It does appear evident, however, that the sample remains more cohesive within the shear zone. Moreover, the micrographs suggest a smaller grain size may be present in the shear zone. Smaller grain size have been observed within the shear zone of olivine aggregates during frictional sliding experiments [Boettcher, et al., in press] and within naturally occurring peridotite shear zones [Drury, et al., 1991]. From the strength profile (Figure 25a), we assert that the shear zone formed after approximately 6 seconds of deformation at $\sim 76 \mathrm{MPa}$. The strain-rate before the onset of localized deformation is approximately $4.8 \times 10^{-3} \mathrm{~s}^{-1}$ (Figure $25 \mathrm{~b}$ ). Given the small effective mean stress prior to the formation of the shear zone, we deduce that the melt fraction before failure was close to the initial melt fraction of the sample, $\phi_{0}=13.0 \%$. We attribute the formation of the localized shear zone to high-differential stress, low-effective confining pressure, and the relatively high melt fraction of the sample.

\section{Appendix D: Tabulated Compaction Rates}

Compaction rates as a function of effective pressure, differential stress, mean stress and melt content for data shown in Figure 15.

\begin{tabular}{lllllll} 
Exp. \# & $\mathrm{P}_{\mathrm{e}}(\mathrm{MPa})$ & $\begin{array}{c}\sigma_{1}-\sigma_{3} \\
(\mathrm{MPa})\end{array}$ & $\sigma_{\mathrm{m}}(\mathrm{MPa})$ & $\phi(\%)$ & $\dot{\varepsilon}_{v}\left(\mathrm{~s}^{-1}\right)$ & $\begin{array}{c}\dot{\varepsilon}_{v} \\
\text { Analysis }\end{array}$ \\
\hline
\end{tabular}




\begin{tabular}{|c|c|c|c|c|c|c|}
\hline Exp. \# & $\mathrm{P}_{\mathrm{e}}(\mathrm{MPa})$ & $\begin{array}{l}\sigma_{1}-\sigma_{3} \\
(\mathrm{MPa}) \\
\end{array}$ & $\sigma_{\mathrm{m}}(\mathrm{MPa})$ & $\phi(\%)$ & $\dot{\varepsilon}_{v}\left(\mathrm{~s}^{-1}\right)$ & $\begin{array}{c}\dot{\varepsilon}_{v} \\
\text { Analysis }\end{array}$ \\
\hline \multirow[t]{3}{*}{ CSR-2 } & 50.0 & 104.8 & 60.62 & 1.7 & $9.77 \mathrm{E}-07$ & $\dot{\boldsymbol{\varepsilon}}_{v}^{v o l}$ \\
\hline & 50.0 & 109.6 & 75.12 & 1.6 & $9.28 \mathrm{E}-07$ & $\dot{\varepsilon}_{v}^{v o l}$ \\
\hline & 49.8 & 113.9 & 88.13 & 1.4 & $1.27 \mathrm{E}-07$ & $\dot{\varepsilon}_{v}^{v o l}$ \\
\hline \multirow[t]{6}{*}{ CSR-4 } & 30.35 & 103.5 & 38.61 & 4.2 & $2.01 \mathrm{E}-06$ & $\dot{\varepsilon}_{v}^{v o l}$ \\
\hline & 30.25 & 107.1 & 49.44 & 4.0 & $9.81 \mathrm{E}-07$ & $\dot{\varepsilon}_{v}^{v o l}$ \\
\hline & 30.01 & 109.4 & 56.09 & 3.8 & 7.32E-07 & $\dot{\varepsilon}_{v}^{v o l}$ \\
\hline & 30 & 109.9 & 57.65 & 3.7 & $3.30 \mathrm{E}-07$ & $\dot{\varepsilon}_{v}^{v o l}$ \\
\hline & 29.69 & 110.5 & 59.56 & 3.6 & $2.66 \mathrm{E}-07$ & $\dot{\varepsilon}_{v}^{v o l}$ \\
\hline & 29.12 & 111.5 & 62.43 & 3.4 & $1.08 \mathrm{E}-07$ & $\dot{\varepsilon}_{v}^{v o l}$ \\
\hline \multirow[t]{16}{*}{ CSR-6 } & 30.0 & 0.0 & 30.0 & 9.6 & $4.20 \mathrm{E}-05$ & $\dot{\varepsilon}_{v}^{v o l}$ \\
\hline & 30.1 & 0.0 & 30.1 & 9.4 & $1.99 \mathrm{E}-05$ & $\dot{\varepsilon}_{v}^{v o l}$ \\
\hline & 30.0 & 0.0 & 30.0 & 9.2 & 8.93E-06 & $\dot{\varepsilon}_{v}^{v o l}$ \\
\hline & 30.0 & 0.2 & 30.1 & 9.0 & $9.64 \mathrm{E}-06$ & $\dot{\varepsilon}_{v}^{v o l}$ \\
\hline & 30.0 & 3.2 & 30.9 & 8.8 & $8.13 \mathrm{E}-06$ & $\dot{\varepsilon}_{v}^{v o l}$ \\
\hline & 30.0 & 12.1 & 33.9 & 8.6 & $6.21 \mathrm{E}-06$ & $\dot{\boldsymbol{\varepsilon}}_{v}^{v o l}$ \\
\hline & 30.0 & 21.5 & 37.0 & 8.4 & $5.76 \mathrm{E}-06$ & $\dot{\varepsilon}_{v}^{v o l}$ \\
\hline & 30.0 & 28.1 & 39.4 & 8.2 & $2.54 \mathrm{E}-06$ & $\dot{\varepsilon}_{v}^{v o l}$ \\
\hline & 30.0 & 32.0 & 40.6 & 8.0 & $2.52 \mathrm{E}-06$ & $\dot{\boldsymbol{\varepsilon}}_{v}^{v o l}$ \\
\hline & 29.9 & 34.5 & 41.4 & 7.8 & $1.39 \mathrm{E}-06$ & $\dot{\varepsilon}_{v}^{v o l}$ \\
\hline & 29.8 & 36.5 & 42.0 & 7.6 & $1.21 \mathrm{E}-06$ & $\dot{\varepsilon}_{v}^{v o l}$ \\
\hline & 29.7 & 38.7 & 42.6 & 7.4 & $1.20 \mathrm{E}-06$ & $\dot{\varepsilon}_{v}^{v o l}$ \\
\hline & 29.7 & 40.3 & 43.1 & 7.2 & $1.10 \mathrm{E}-06$ & $\dot{\varepsilon}_{v}^{v o l}$ \\
\hline & 29.5 & 42.9 & 43.8 & 7.0 & $7.70 \mathrm{E}-07$ & $\dot{\varepsilon}_{v}^{v o l}$ \\
\hline & 29.3 & 45.1 & 44.4 & 6.8 & 5.62E-07 & $\dot{\boldsymbol{\varepsilon}}_{v}^{v o l}$ \\
\hline & 29.3 & 47.0 & 44.9 & 6.6 & $7.06 \mathrm{E}-07$ & $\dot{\varepsilon}_{v}^{v o l}$ \\
\hline \multirow[t]{6}{*}{ CSR-7 } & 30.4 & 0.0 & 0.0 & 9.8 & $5.45 \mathrm{E}-05$ & $\dot{\varepsilon}_{v}^{v o l}$ \\
\hline & 30.3 & 0.0 & 0.0 & 9.6 & $2.73 \mathrm{E}-05$ & $\dot{\varepsilon}_{v}^{v o l}$ \\
\hline & 30.3 & 0.0 & 0.0 & 9.4 & $1.64 \mathrm{E}-05$ & $\dot{\varepsilon}_{v}^{v o l}$ \\
\hline & 30.4 & 0.0 & 0.0 & 9.2 & $1.41 \mathrm{E}-05$ & $\dot{\varepsilon}_{v}^{v o l}$ \\
\hline & 30.4 & 0.0 & 0.0 & 9.0 & $9.10 \mathrm{E}-06$ & $\dot{\varepsilon}_{v}^{v o l}$ \\
\hline & 30.4 & 1.9 & 18.0 & 8.8 & $5.82 \mathrm{E}-06$ & $\dot{\varepsilon}_{v}^{v o l}$ \\
\hline
\end{tabular}




\begin{tabular}{|c|c|c|c|c|c|c|}
\hline Exp. \# & $\mathrm{P}_{\mathrm{e}}(\mathrm{MPa})$ & $\begin{array}{l}\sigma_{1}-\sigma_{3} \\
(\mathrm{MPa}) \\
\end{array}$ & $\sigma_{\mathrm{m}}(\mathrm{MPa})$ & $\phi(\%)$ & $\dot{\varepsilon}_{v}\left(\mathrm{~s}^{-1}\right)$ & $\begin{array}{c}\dot{\boldsymbol{\varepsilon}}_{v} \\
\text { Analysis }\end{array}$ \\
\hline & 30.4 & 12.6 & 34.6 & 8.6 & $6.01 \mathrm{E}-06$ & $\dot{\varepsilon}_{v}^{v o l}$ \\
\hline & 30.3 & 22.7 & 37.9 & 8.4 & 4.78E-06 & $\dot{\varepsilon}_{v}^{v o l}$ \\
\hline & 30.3 & 28.2 & 39.7 & 8.2 & $4.42 \mathrm{E}-06$ & $\dot{\varepsilon}_{v}^{v o l}$ \\
\hline & 30.3 & 31.6 & 40.8 & 8.0 & 3.33E-06 & $\dot{\varepsilon}_{v}^{v o l}$ \\
\hline & 30.2 & 33.9 & 41.5 & 7.8 & $3.09 \mathrm{E}-06$ & $\dot{\varepsilon}_{v}^{v o l}$ \\
\hline & 30.2 & 35.4 & 42.0 & 7.6 & $2.98 \mathrm{E}-06$ & $\dot{\boldsymbol{\varepsilon}}_{v}^{v o l}$ \\
\hline & 30.2 & 36.5 & 42.4 & 7.4 & $2.04 \mathrm{E}-06$ & $\dot{\varepsilon}_{v}^{v o l}$ \\
\hline & 50.1 & 38.0 & 62.8 & 7.0 & $5.32 \mathrm{E}-06$ & $\dot{\varepsilon}_{v}^{v o l}$ \\
\hline & 50.1 & 39.5 & 63.3 & 6.8 & $2.60 \mathrm{E}-06$ & $\dot{\varepsilon}_{v}^{v o l}$ \\
\hline & 50.1 & 41.0 & 63.8 & 6.6 & $2.25 \mathrm{E}-06$ & $\dot{\varepsilon}_{v}^{v o l}$ \\
\hline & 50.1 & 42.7 & 64.3 & 6.4 & $2.01 \mathrm{E}-06$ & $\dot{\varepsilon}_{v}^{v o l}$ \\
\hline & 50.0 & 44.1 & 64.7 & 6.2 & $1.89 \mathrm{E}-06$ & $\dot{\varepsilon}_{v}^{v o l}$ \\
\hline & 50.0 & 46.0 & 65.3 & 6.0 & $1.72 \mathrm{E}-06$ & $\dot{\varepsilon}_{v}^{v o l}$ \\
\hline & 49.9 & 47.7 & 65.8 & 5.8 & $1.36 \mathrm{E}-06$ & $\dot{\varepsilon}_{v}^{v o l}$ \\
\hline & 49.9 & 48.3 & 66.0 & 5.6 & $1.76 \mathrm{E}-06$ & $\dot{\varepsilon}_{v}^{v o l}$ \\
\hline & 49.8 & 49.4 & 66.3 & 5.4 & $1.06 \mathrm{E}-06$ & $\dot{\varepsilon}_{v}^{v o l}$ \\
\hline & 49.7 & 51.4 & 66.8 & 5.2 & $1.20 \mathrm{E}-06$ & $\dot{\varepsilon}_{v}^{v o l}$ \\
\hline & 49.6 & 52.7 & 67.2 & 5.0 & 6.63E-07 & $\dot{\varepsilon}_{v}^{v o l}$ \\
\hline \multirow[t]{10}{*}{ CSR-8 } & 9.9 & 0.2 & 10.0 & 29.4 & $3.68 \mathrm{E}-04$ & $\dot{\varepsilon}_{v}^{v o l}$ \\
\hline & 10.0 & 0.6 & 10.2 & 29.2 & $3.22 \mathrm{E}-04$ & $\dot{\varepsilon}_{v}^{v o l}$ \\
\hline & 10.0 & 0.4 & 10.1 & 29.0 & $3.65 \mathrm{E}-04$ & $\dot{\varepsilon}_{v}^{v o l}$ \\
\hline & 10.0 & 0.5 & 10.1 & 28.8 & $3.62 \mathrm{E}-04$ & $\dot{\varepsilon}_{v}^{v o l}$ \\
\hline & 9.9 & 0.6 & 10.1 & 28.6 & $3.44 \mathrm{E}-04$ & $\dot{\varepsilon}_{v}^{v o l}$ \\
\hline & 9.9 & 0.4 & 10.1 & 28.4 & $2.73 \mathrm{E}-04$ & $\dot{\varepsilon}_{v}^{v o l}$ \\
\hline & 9.9 & 0.4 & 10.1 & 28.2 & $2.55 \mathrm{E}-04$ & $\dot{\varepsilon}_{v}^{v o l}$ \\
\hline & 9.9 & 0.0 & 9.9 & 28.0 & $2.31 \mathrm{E}-04$ & $\dot{\varepsilon}_{v}^{v o l}$ \\
\hline & 10.0 & 2.6 & 10.8 & 24.2 & $5.49 \mathrm{E}-06$ & $\dot{\varepsilon}_{v}^{v o l}$ \\
\hline & 29.9 & 2.6 & 30.8 & 23.8 & $1.37 \mathrm{E}-05$ & $\dot{\boldsymbol{\varepsilon}}_{v}^{v o l}$ \\
\hline CSR-9 & 45.6 & 79.5 & 72.0 & 4.0 & $6.73 \mathrm{E}-07$ & $\dot{\varepsilon}_{v}^{i m g}$ \\
\hline \multirow[t]{2}{*}{ HYD-11 } & 49.9 & 2.58 & 50.7 & 9.2 & $1.99 \mathrm{E}-05$ & $\dot{\varepsilon}_{v}^{a x}$ \\
\hline & 49.8 & 2.61 & 50.7 & 8.9 & $9.78 \mathrm{E}-06$ & $\dot{\varepsilon}_{v}^{a x}$ \\
\hline
\end{tabular}




\begin{tabular}{|c|c|c|c|c|c|c|}
\hline Exp. \# & $\mathrm{P}_{\mathrm{e}}(\mathrm{MPa})$ & $\begin{array}{c}\sigma_{1}-\sigma_{3} \\
(\mathrm{MPa})\end{array}$ & $\sigma_{\mathrm{m}}(\mathrm{MPa})$ & $\phi(\%)$ & $\dot{\varepsilon}_{v}\left(\mathrm{~s}^{-1}\right)$ & $\begin{array}{c}\dot{\varepsilon}_{v} \\
\text { Analysis }\end{array}$ \\
\hline & 49.8 & 2.58 & 50.6 & 8.4 & $5.49 \mathrm{E}-06$ & $\dot{\varepsilon}_{v}^{a x}$ \\
\hline & 49.6 & 2.64 & 50.5 & 7.8 & $3.12 \mathrm{E}-06$ & $\dot{\varepsilon}_{v}^{a x}$ \\
\hline & 49.7 & 2.85 & 50.6 & 7.3 & $1.43 \mathrm{E}-06$ & $\dot{\varepsilon}_{v}^{a x}$ \\
\hline & 49.6 & 2.76 & 50.6 & 6.7 & $1.38 \mathrm{E}-06$ & $\dot{\varepsilon}_{v}^{a x}$ \\
\hline & 49.3 & 2.73 & 50.3 & 6.1 & $1.70 \mathrm{E}-06$ & $\dot{\varepsilon}_{v}^{a x}$ \\
\hline & 49.2 & 2.76 & 50.1 & 5.6 & $1.42 \mathrm{E}-06$ & $\dot{\varepsilon}_{v}^{a x}$ \\
\hline & 49.2 & 2.76 & 50.1 & 5.0 & $1.57 \mathrm{E}-06$ & $\dot{\varepsilon}_{v}^{a x}$ \\
\hline \multirow[t]{8}{*}{ HYD-14 } & 254.18 & 50.03 & 1.6 & 13.0 & $5.04 \mathrm{E}-05$ & $\dot{\varepsilon}_{v}^{a x}$ \\
\hline & 254.21 & 49.98 & 1.8 & 12.7 & $2.91 \mathrm{E}-05$ & $\dot{\varepsilon}_{v}^{a x}$ \\
\hline & 254.21 & 49.99 & 1.8 & 12.5 & $3.18 \mathrm{E}-05$ & $\dot{\varepsilon}_{v}^{a x}$ \\
\hline & 254.2 & 49.99 & 1.8 & 12.2 & 2.77E-05 & $\dot{\varepsilon}_{v}^{a x}$ \\
\hline & 254.2 & 50.09 & 1.8 & 12.0 & $1.88 \mathrm{E}-05$ & $\dot{\varepsilon}_{v}^{a x}$ \\
\hline & 254.2 & 50.18 & 1.8 & 11.8 & $2.22 \mathrm{E}-05$ & $\dot{\varepsilon}_{v}^{a x}$ \\
\hline & 254.21 & 50.22 & 1.9 & 11.5 & $2.09 \mathrm{E}-05$ & $\dot{\varepsilon}_{v}^{a x}$ \\
\hline & 254.21 & 50.11 & 1.8 & 11.2 & $2.30 \mathrm{E}-05$ & $\dot{\varepsilon}_{v}^{a x}$ \\
\hline \multirow[t]{2}{*}{ MXD-16 } & 34.63 & 40.66 & 48.18 & 11.8 & $1.24 \mathrm{E}-05$ & $\dot{\varepsilon}_{v}^{a x \dagger}$ \\
\hline & 33.3 & 4.10 & 34.6 & 8.6 & $3.52 \mathrm{E}-06$ & $\dot{\varepsilon}_{v}^{a x}$ \\
\hline \multirow[t]{5}{*}{ HYD-18 } & 250 & 50.55 & 2.1 & 12.9 & $3.75 \mathrm{E}-05$ & $\dot{\varepsilon}_{v}^{a x}$ \\
\hline & 250 & 50.54 & 2.16 & 12.6 & $3.14 \mathrm{E}-05$ & $\dot{\varepsilon}_{v}^{a x}$ \\
\hline & 250 & 50.51 & 2.22 & 12.4 & $2.49 \mathrm{E}-05$ & $\dot{\varepsilon}_{v}^{a x}$ \\
\hline & 250 & 50.50 & 2.25 & 12.1 & $2.18 \mathrm{E}-05$ & $\dot{\varepsilon}_{v}^{a x}$ \\
\hline & 250 & 50.49 & 2.28 & 11.8 & $1.97 \mathrm{E}-05$ & $\dot{\varepsilon}_{v}^{a x}$ \\
\hline
\end{tabular}

${ }^{\dagger}$ Volumetric strain rate constrained for creep portion of MXD-16 by subtracting the initial melt fraction at the onset of the hydrostatic portion of MXD-16 from the initial sample melt fraction and then dividing by time. 


\section{Appendix E: Tabulated Uncorrected and Corrected Compaction Rates}

Compaction rates as a function of effective pressure, differential stress, mean stress and melt content for all drained triaxial deformation experiments.

\begin{tabular}{|c|c|c|c|c|c|c|c|c|c|}
\hline $\begin{array}{l}\text { Sample } \\
\text { Number }\end{array}$ & $\begin{array}{c}P_{c} \\
(\mathrm{MPa})\end{array}$ & $\begin{array}{c}P_{p} \\
(\mathrm{MPa})\end{array}$ & $\begin{array}{c}\sigma_{m}^{e f f} \\
(\mathrm{MPa})\end{array}$ & $\begin{array}{c}\mathcal{E}_{a x} \\
(\%)\end{array}$ & $\dot{\varepsilon}_{a x}\left(\mathrm{~s}^{-1}\right)$ & $\begin{array}{l}\varepsilon_{v}^{u c_{-} v o l} \\
(\%)\end{array}$ & $\begin{array}{c}\dot{\varepsilon}_{v}^{u c_{-} v o l} \\
\left(\mathrm{~s}^{-1}\right)\end{array}$ & $\begin{array}{l}\varepsilon_{\nu}^{v o l} \\
(\%)\end{array}$ & $\begin{array}{l}\dot{\varepsilon}_{v}^{v o l} \\
\left(\mathrm{~s}^{-1}\right)\end{array}$ \\
\hline \multirow[t]{5}{*}{ CSR-2 } & 303.7 & 253.71 & 60.62 & 0.51 & $5.80 \mathrm{E}-06$ & 0.19 & $1.07 \mathrm{E}-06$ & 0.18 & $9.77 \mathrm{E}-07$ \\
\hline & 303.7 & 253.7 & 75.12 & 1.07 & $6.82 \mathrm{E}-06$ & 0.28 & $1.04 \mathrm{E}-06$ & 0.26 & $9.28 \mathrm{E}-07$ \\
\hline & 303.53 & 253.7 & 88.13 & 3.59 & $1.00 \mathrm{E}-05$ & 0.52 & 2.33E-07 & 0.47 & $1.27 \mathrm{E}-07$ \\
\hline & 303.36 & 253.7 & 89.08 & 5.58 & $1.02 \mathrm{E}-05$ & 0.35 & $-3.07 E-06$ & 0.27 & $-3.18 \mathrm{E}-06$ \\
\hline & 303.41 & 253.7 & 89.39 & 5.95 & $1.02 \mathrm{E}-05$ & 0.21 & $-4.89 \mathrm{E}-06$ & 0.13 & $-5.00 \mathrm{E}-06$ \\
\hline \multirow[t]{7}{*}{ CSR-4 } & 302.35 & 272 & 38.61 & 0.5 & 7.35E-06 & 0.32 & $2.00 \mathrm{E}-06$ & 0.33 & $2.01 \mathrm{E}-06$ \\
\hline & 302.25 & 272 & 49.44 & 1.69 & $8.96 \mathrm{E}-06$ & 0.53 & $9.67 \mathrm{E}-07$ & 0.53 & $9.81 \mathrm{E}-07$ \\
\hline & 302.01 & 272 & 56.09 & 3.99 & $1.00 \mathrm{E}-05$ & 0.74 & $7.18 \mathrm{E}-07$ & 0.75 & $7.32 \mathrm{E}-07$ \\
\hline & 302 & 272 & 57.65 & 5.39 & $1.04 \mathrm{E}-05$ & 0.82 & $3.23 \mathrm{E}-07$ & 0.83 & $3.30 \mathrm{E}-07$ \\
\hline & 301.69 & 272 & 59.56 & 8.97 & $1.07 \mathrm{E}-05$ & 0.93 & 2.53E-07 & 0.94 & $2.66 \mathrm{E}-07$ \\
\hline & 301.12 & 272 & 62.43 & 17 & $1.16 \mathrm{E}-05$ & 1.14 & $9.29 \mathrm{E}-08$ & 1.16 & $1.08 \mathrm{E}-07$ \\
\hline & 300.71 & 272 & 63.12 & 21.81 & $1.23 \mathrm{E}-05$ & 0.97 & $-1.62 \mathrm{E}-06$ & 1.00 & $-1.61 \mathrm{E}-06$ \\
\hline \multirow[t]{23}{*}{ CSR-5 } & 303.08 & 273.25 & 65.91 & 4.17 & $9.07 \mathrm{E}-06$ & 0.09 & $1.68 \mathrm{E}-07$ & $\mathrm{NaN}$ & $\mathrm{NaN}$ \\
\hline & 302.98 & 273.25 & 68.02 & 6.27 & $1.01 \mathrm{E}-05$ & 0.2 & $5.34 \mathrm{E}-07$ & $\mathrm{NaN}$ & $\mathrm{NaN}$ \\
\hline & 302.81 & 273.25 & 73.46 & 9.59 & $1.03 \mathrm{E}-05$ & 0.33 & $4.46 \mathrm{E}-08$ & $\mathrm{NaN}$ & $\mathrm{NaN}$ \\
\hline & 302.7 & 273.25 & 77.75 & 11.69 & $1.04 \mathrm{E}-05$ & 0.2 & $-1.72 E-06$ & $\mathrm{NaN}$ & $\mathrm{NaN}$ \\
\hline & 302.63 & 273.25 & 80.28 & 12.77 & $1.03 \mathrm{E}-05$ & 0 & $-2.31 \mathrm{E}-06$ & $\mathrm{NaN}$ & $\mathrm{NaN}$ \\
\hline & 302.6 & 273.25 & 82.17 & 13.62 & $1.06 \mathrm{E}-05$ & -0.2 & $-2.50 \mathrm{E}-06$ & $\mathrm{NaN}$ & $\mathrm{NaN}$ \\
\hline & 302.52 & 273.25 & 83.66 & 14.42 & $1.03 \mathrm{E}-05$ & -0.41 & $-2.47 E-06$ & $\mathrm{NaN}$ & $\mathrm{NaN}$ \\
\hline & 302.55 & 273.25 & 85.02 & 15.06 & $1.10 \mathrm{E}-05$ & -0.59 & $-4.00 \mathrm{E}-06$ & $\mathrm{NaN}$ & $\mathrm{NaN}$ \\
\hline & 302.49 & 273.25 & 85.7 & 15.56 & $1.10 \mathrm{E}-05$ & -0.81 & $-5.15 E-06$ & $\mathrm{NaN}$ & $\mathrm{NaN}$ \\
\hline & 302.44 & 273.25 & 86.35 & 16.02 & $1.09 \mathrm{E}-05$ & -1.01 & $-4.54 \mathrm{E}-06$ & $\mathrm{NaN}$ & $\mathrm{NaN}$ \\
\hline & 302.41 & 273.25 & 87.02 & 16.46 & $1.10 \mathrm{E}-05$ & -1.21 & $-5.22 \mathrm{E}-06$ & $\mathrm{NaN}$ & $\mathrm{NaN}$ \\
\hline & 302.37 & 273.25 & 87.39 & 16.89 & $1.16 \mathrm{E}-05$ & -1.39 & $-4.24 \mathrm{E}-06$ & $\mathrm{NaN}$ & $\mathrm{NaN}$ \\
\hline & 302.34 & 273.25 & 87.6 & 17.36 & $1.15 \mathrm{E}-05$ & -1.6 & $-4.26 \mathrm{E}-06$ & $\mathrm{NaN}$ & $\mathrm{NaN}$ \\
\hline & 302.33 & 273.25 & 88.11 & 17.89 & $1.15 E-05$ & -1.81 & $-4.61 \mathrm{E}-06$ & $\mathrm{NaN}$ & $\mathrm{NaN}$ \\
\hline & 302.3 & 273.25 & 88.2 & 18.41 & $1.13 \mathrm{E}-05$ & -2.02 & $-4.84 \mathrm{E}-06$ & $\mathrm{NaN}$ & $\mathrm{NaN}$ \\
\hline & 302.29 & 273.25 & 88.16 & 18.91 & $1.16 \mathrm{E}-05$ & -2.22 & $-4.00 \mathrm{E}-06$ & $\mathrm{NaN}$ & $\mathrm{NaN}$ \\
\hline & 302.24 & 273.25 & 88.02 & 19.43 & $1.19 \mathrm{E}-05$ & -2.42 & $-4.86 \mathrm{E}-06$ & $\mathrm{NaN}$ & $\mathrm{NaN}$ \\
\hline & 302.2 & 273.25 & 87.77 & 19.94 & $1.25 \mathrm{E}-05$ & -2.63 & $-5.39 E-06$ & $\mathrm{NaN}$ & $\mathrm{NaN}$ \\
\hline & 302.18 & 273.25 & 87.55 & 20.44 & $1.20 \mathrm{E}-05$ & -2.83 & $-4.88 \mathrm{E}-06$ & $\mathrm{NaN}$ & $\mathrm{NaN}$ \\
\hline & 302.15 & 273.25 & 87.2 & 20.95 & $1.25 \mathrm{E}-05$ & -3.05 & $-4.93 \mathrm{E}-06$ & $\mathrm{NaN}$ & $\mathrm{NaN}$ \\
\hline & 302.12 & 273.25 & 86.63 & 21.47 & $1.26 \mathrm{E}-05$ & -3.25 & $-4.67 \mathrm{E}-06$ & $\mathrm{NaN}$ & $\mathrm{NaN}$ \\
\hline & 302.07 & 273.25 & 86.24 & 21.96 & $1.26 \mathrm{E}-05$ & -3.45 & $-5.74 \mathrm{E}-06$ & $\mathrm{NaN}$ & $\mathrm{NaN}$ \\
\hline & 302.08 & 273.24 & 86.11 & 22.34 & $1.10 \mathrm{E}-05$ & -3.61 & $-5.16 \mathrm{E}-06$ & $\mathrm{NaN}$ & $\mathrm{NaN}$ \\
\hline \multirow[t]{14}{*}{ CSR-6 } & 302.12 & 272.11 & 30.01 & 0.04 & 8.61E-06 & 0.12 & 4.32E-05 & 0.12 & $4.20 \mathrm{E}-05$ \\
\hline & 302.17 & 272.11 & 30.06 & 0.12 & $9.92 \mathrm{E}-06$ & 0.37 & $2.12 \mathrm{E}-05$ & 0.35 & $1.99 \mathrm{E}-05$ \\
\hline & 302.13 & 272.1 & 30.03 & 0.19 & $9.90 \mathrm{E}-06$ & 0.6 & $1.02 \mathrm{E}-05$ & 0.57 & 8.93E-06 \\
\hline & 302.12 & 272.1 & 30.07 & 0.26 & $1.00 \mathrm{E}-05$ & 0.86 & $1.09 \mathrm{E}-05$ & 0.79 & $9.64 \mathrm{E}-06$ \\
\hline & 302.11 & 272.1 & 30.85 & 0.28 & $7.65 \mathrm{E}-06$ & 1.09 & $9.41 E-06$ & 0.99 & $8.13 E-06$ \\
\hline & 302.1 & 272.1 & 33.87 & 0.52 & $7.53 \mathrm{E}-06$ & 1.34 & $7.51 \mathrm{E}-06$ & 1.21 & $6.21 E-06$ \\
\hline & 302.08 & 272.1 & 37.01 & 0.84 & 8.57E-06 & 1.63 & $7.10 \mathrm{E}-06$ & 1.44 & $5.76 \mathrm{E}-06$ \\
\hline & 302.1 & 272.1 & 39.44 & 1.44 & $9.54 \mathrm{E}-06$ & 1.93 & $3.85 \mathrm{E}-06$ & 1.66 & $2.54 \mathrm{E}-06$ \\
\hline & 302.07 & 272.11 & 40.55 & 2.17 & $9.95 \mathrm{E}-06$ & 2.23 & $3.84 \mathrm{E}-06$ & 1.86 & $2.52 E-06$ \\
\hline & 301.99 & 272.1 & 41.39 & 3.48 & $1.02 \mathrm{E}-05$ & 2.62 & $2.71 E-06$ & 2.08 & $1.39 \mathrm{E}-06$ \\
\hline & 301.94 & 272.1 & 41.97 & 5.06 & $1.03 \mathrm{E}-05$ & 3.04 & $2.53 \mathrm{E}-06$ & 2.29 & $1.21 \mathrm{E}-06$ \\
\hline & 301.84 & 272.1 & 42.61 & 7.11 & $1.06 \mathrm{E}-05$ & 3.54 & $2.51 \mathrm{E}-06$ & 2.54 & $1.20 \mathrm{E}-06$ \\
\hline & 301.76 & 272.1 & 43.05 & 9.21 & $1.08 \mathrm{E}-05$ & 3.99 & 2.41E-06 & 2.73 & $1.10 \mathrm{E}-06$ \\
\hline & 301.61 & 272.1 & 43.78 & 11.92 & $1.11 \mathrm{E}-05$ & 4.53 & $2.08 \mathrm{E}-06$ & 2.94 & $7.70 \mathrm{E}-07$ \\
\hline
\end{tabular}




\begin{tabular}{|c|c|c|c|c|c|c|c|c|c|}
\hline $\begin{array}{l}\text { Sample } \\
\text { Number }\end{array}$ & $\begin{array}{c}P_{c} \\
(\mathrm{MPa}) \\
\end{array}$ & $\begin{array}{c}P_{p} \\
(\mathrm{MPa}) \\
\end{array}$ & $\begin{array}{c}\sigma_{m}^{e f f} \\
(\mathrm{MPa})\end{array}$ & $\begin{array}{c}\varepsilon_{a x} \\
(\%) \\
\end{array}$ & $\dot{\boldsymbol{\varepsilon}}_{a x}\left(\mathrm{~s}^{-1}\right)$ & $\begin{array}{l}\varepsilon_{v}^{u c_{-} v o l} \\
(\%)\end{array}$ & $\begin{array}{c}\dot{\varepsilon}_{v}^{u c_{-} v o l} \\
\left(\mathrm{~s}^{-1}\right)\end{array}$ & $\begin{array}{l}\varepsilon_{v}^{v o l} \\
(\%)\end{array}$ & $\begin{array}{l}\dot{\varepsilon}_{v}^{v o l} \\
\left(s^{-1}\right)\end{array}$ \\
\hline & 301.43 & 272.1 & 44.36 & 15.37 & $1.15 \mathrm{E}-05$ & 5.14 & $1.88 \mathrm{E}-06$ & 3.16 & $5.62 \mathrm{E}-07$ \\
\hline & 301.43 & 272.1 & 44.89 & 19.14 & $1.19 \mathrm{E}-05$ & 5.78 & $2.02 \mathrm{E}-06$ & 3.37 & $7.06 \mathrm{E}-07$ \\
\hline \multirow[t]{24}{*}{ CSR-7 } & 301.35 & 271.07 & 30.31 & 0.07 & $9.38 \mathrm{E}-06$ & 0.22 & $5.56 \mathrm{E}-05$ & 0.22 & $5.45 \mathrm{E}-05$ \\
\hline & 301.34 & 271.01 & 30.38 & 0.15 & $9.79 \mathrm{E}-06$ & 0.45 & $2.84 \mathrm{E}-05$ & 0.44 & $2.73 E-05$ \\
\hline & 301.33 & 271 & 30.39 & 0.22 & $9.91 \mathrm{E}-06$ & 0.68 & $1.74 \mathrm{E}-05$ & 0.67 & $1.64 \mathrm{E}-05$ \\
\hline & 301.36 & 271 & 30.42 & 0.29 & $9.90 \mathrm{E}-06$ & 0.91 & $1.52 \mathrm{E}-05$ & 0.88 & $1.41 \mathrm{E}-05$ \\
\hline & 301.39 & 271 & 30.48 & 0.37 & $1.00 \mathrm{E}-05$ & 1.18 & $1.00 \mathrm{E}-05$ & 1.12 & $9.10 \mathrm{E}-06$ \\
\hline & 301.38 & 271 & 31.06 & 0.38 & 8.62E-06 & 1.41 & $6.82 \mathrm{E}-06$ & 1.33 & $5.82 \mathrm{E}-06$ \\
\hline & 301.37 & 271 & 34.54 & 0.66 & $7.74 \mathrm{E}-06$ & 1.66 & $7.00 \mathrm{E}-06$ & 1.54 & $6.01 \mathrm{E}-06$ \\
\hline & 301.35 & 271 & 37.86 & 0.99 & $8.76 \mathrm{E}-06$ & 1.94 & $5.79 \mathrm{E}-06$ & 1.78 & 4.78E-06 \\
\hline & 301.27 & 271 & 39.63 & 1.40 & $9.26 \mathrm{E}-06$ & 2.2 & $5.46 \mathrm{E}-06$ & 1.99 & 4.42E-06 \\
\hline & 301.26 & 271 & 40.8 & 1.90 & $9.72 \mathrm{E}-06$ & 2.46 & $4.38 \mathrm{E}-06$ & 2.19 & $3.33 \mathrm{E}-06$ \\
\hline & 301.24 & 271 & 41.52 & 2.49 & $1.01 \mathrm{E}-05$ & 2.75 & $4.08 E-06$ & 2.43 & $3.09 \mathrm{E}-06$ \\
\hline & 301.23 & 271 & 42.04 & 3.23 & $1.01 \mathrm{E}-05$ & 3.05 & $4.00 \mathrm{E}-06$ & 2.64 & $2.98 \mathrm{E}-06$ \\
\hline & 301.2 & 271 & 42.36 & 4.13 & $1.03 \mathrm{E}-05$ & 3.37 & $3.07 \mathrm{E}-06$ & 2.88 & $2.04 \mathrm{E}-06$ \\
\hline & 301.13 & 251 & 62.81 & 5.93 & $1.05 \mathrm{E}-05$ & 3.99 & $7.03 \mathrm{E}-06$ & 3.29 & $5.32 \mathrm{E}-06$ \\
\hline & 301.11 & 251 & 63.26 & 6.42 & $1.03 \mathrm{E}-05$ & 4.27 & 4.32E-06 & 3.49 & $2.60 \mathrm{E}-06$ \\
\hline & 301.11 & 251 & 63.77 & 7.23 & $1.05 \mathrm{E}-05$ & 4.63 & $3.97 \mathrm{E}-06$ & 3.71 & $2.25 \mathrm{E}-06$ \\
\hline & 301.09 & 251 & 64.33 & 8.32 & $1.07 \mathrm{E}-05$ & 5.02 & $3.74 \mathrm{E}-06$ & 3.93 & $2.01 \mathrm{E}-06$ \\
\hline & 301.00 & 251 & 64.7 & 9.55 & $1.08 \mathrm{E}-05$ & 5.44 & $3.62 \mathrm{E}-06$ & 4.15 & $1.89 \mathrm{E}-06$ \\
\hline & 300.98 & 251 & 65.25 & 10.73 & $1.09 \mathrm{E}-05$ & 5.82 & $3.43 \mathrm{E}-06$ & 4.35 & $1.72 \mathrm{E}-06$ \\
\hline & 300.91 & 251 & 65.8 & 12.19 & $1.11 \mathrm{E}-05$ & 6.27 & $3.08 \mathrm{E}-06$ & 4.57 & $1.36 \mathrm{E}-06$ \\
\hline & 300.88 & 251 & 65.99 & 13.69 & $1.13 E-05$ & 6.71 & $3.48 \mathrm{E}-06$ & 4.78 & $1.76 \mathrm{E}-06$ \\
\hline & 300.83 & 251 & 66.23 & 15.47 & $1.15 \mathrm{E}-05$ & 7.21 & $2.77 \mathrm{E}-06$ & 5.02 & $1.06 \mathrm{E}-06$ \\
\hline & 300.65 & 251 & 66.78 & 17.88 & $1.17 \mathrm{E}-05$ & 7.76 & $2.92 \mathrm{E}-06$ & 5.2 & $1.20 \mathrm{E}-06$ \\
\hline & 300.62 & 251 & 67.14 & 20.46 & $1.21 \mathrm{E}-05$ & 8.34 & $2.38 \mathrm{E}-06$ & 5.42 & $6.63 \mathrm{E}-07$ \\
\hline \multirow[t]{31}{*}{ CSR-8 } & 301.88 & 291.94 & 10.01 & 0.14 & $7.57 \mathrm{E}-06$ & 0.41 & $3.74 \mathrm{E}-04$ & 0.41 & $3.68 \mathrm{E}-04$ \\
\hline & 301.89 & 291.92 & 10.16 & 0.24 & $1.15 \mathrm{E}-05$ & 0.73 & $3.29 \mathrm{E}-04$ & 0.72 & $3.22 \mathrm{E}-04$ \\
\hline & 301.89 & 291.93 & 10.09 & 0.33 & $9.90 \mathrm{E}-06$ & 0.99 & $3.73 \mathrm{E}-04$ & 0.98 & $3.65 \mathrm{E}-04$ \\
\hline & 301.89 & 291.93 & 10.11 & 0.41 & $9.90 \mathrm{E}-06$ & 1.26 & $3.77 \mathrm{E}-04$ & 1.23 & $3.62 \mathrm{E}-04$ \\
\hline & 301.87 & 291.93 & 10.13 & 0.51 & $9.45 \mathrm{E}-06$ & 1.56 & $3.44 \mathrm{E}-04$ & 1.53 & $3.44 \mathrm{E}-04$ \\
\hline & 301.84 & 291.93 & 10.06 & 0.60 & $1.04 \mathrm{E}-05$ & 1.85 & $2.88 \mathrm{E}-04$ & 1.81 & 2.73E-04 \\
\hline & 301.84 & 291.92 & 10.05 & 0.69 & $1.00 \mathrm{E}-05$ & 2.11 & $2.55 \mathrm{E}-04$ & 2.07 & $2.55 \mathrm{E}-04$ \\
\hline & 301.86 & 291.93 & 9.93 & 0.79 & $1.07 E-05$ & 2.41 & $2.43 \mathrm{E}-04$ & 2.36 & $2.31 \mathrm{E}-04$ \\
\hline & 301.87 & 291.91 & 9.92 & 0.88 & $1.04 \mathrm{E}-05$ & 2.69 & $1.05 \mathrm{E}-04$ & 2.63 & $9.71 \mathrm{E}-05$ \\
\hline & 301.89 & 291.91 & 9.97 & 0.97 & $9.99 \mathrm{E}-06$ & 3 & $3.66 \mathrm{E}-05$ & 2.9 & $3.01 \mathrm{E}-05$ \\
\hline & 301.91 & 291.9 & 10.10 & 1.06 & $9.98 \mathrm{E}-06$ & 3.36 & $3.12 \mathrm{E}-05$ & 3.19 & $2.48 \mathrm{E}-05$ \\
\hline & 301.93 & 291.9 & 10.14 & 1.15 & $1.01 \mathrm{E}-05$ & 3.71 & $2.53 \mathrm{E}-05$ & 3.45 & $1.90 \mathrm{E}-05$ \\
\hline & 301.91 & 291.91 & 10.31 & 1.17 & $8.75 \mathrm{E}-06$ & 4.11 & $2.11 \mathrm{E}-05$ & 3.73 & $1.48 \mathrm{E}-05$ \\
\hline & 301.88 & 291.91 & 10.83 & 1.36 & $9.73 E-06$ & 4.51 & $1.90 \mathrm{E}-05$ & 4 & $1.24 \mathrm{E}-05$ \\
\hline & 301.92 & 291.9 & 11.02 & 1.57 & $1.01 \mathrm{E}-05$ & 4.91 & $1.82 \mathrm{E}-05$ & 4.27 & $1.16 \mathrm{E}-05$ \\
\hline & 301.91 & 291.91 & 10.87 & 1.85 & $1.04 \mathrm{E}-05$ & 5.38 & $1.65 \mathrm{E}-05$ & 4.55 & $9.98 \mathrm{E}-06$ \\
\hline & 301.96 & 291.91 & 10.77 & 2.10 & $1.02 \mathrm{E}-05$ & 5.81 & $1.69 \mathrm{E}-05$ & 4.82 & $1.04 \mathrm{E}-05$ \\
\hline & 301.95 & 291.91 & 10.87 & 2.40 & $1.02 \mathrm{E}-05$ & 6.28 & $1.41 \mathrm{E}-05$ & 5.1 & $7.53 \mathrm{E}-06$ \\
\hline & 301.95 & 291.9 & 10.98 & 2.70 & $9.97 \mathrm{E}-06$ & 6.73 & $1.54 \mathrm{E}-05$ & 5.37 & $8.81 \mathrm{E}-06$ \\
\hline & 301.97 & 291.9 & 11.01 & 3.00 & $1.01 \mathrm{E}-05$ & 7.2 & $1.43 \mathrm{E}-05$ & 5.63 & $7.81 \mathrm{E}-06$ \\
\hline & 301.92 & 291.91 & 11.00 & 3.38 & $1.03 \mathrm{E}-05$ & 7.71 & $1.33 E-05$ & 5.9 & $6.81 \mathrm{E}-06$ \\
\hline & 301.89 & 291.9 & 10.94 & 3.75 & $1.02 \mathrm{E}-05$ & 8.2 & $1.41 \mathrm{E}-05$ & 6.16 & 7.67E-06 \\
\hline & 301.88 & 291.9 & 10.91 & 4.14 & $1.03 \mathrm{E}-05$ & 8.73 & $1.33 \mathrm{E}-05$ & 6.44 & $6.74 \mathrm{E}-06$ \\
\hline & 301.88 & 291.9 & 10.87 & 4.54 & $1.03 E-05$ & 9.24 & $1.23 \mathrm{E}-05$ & 6.7 & 5.72E-06 \\
\hline & 301.90 & 291.9 & 10.89 & 4.94 & $1.04 \mathrm{E}-05$ & 9.77 & $1.32 \mathrm{E}-05$ & 6.98 & $6.74 \mathrm{E}-06$ \\
\hline & 301.90 & 291.91 & 10.87 & 5.31 & $1.05 \mathrm{E}-05$ & 10.25 & $1.33 \mathrm{E}-05$ & 7.22 & $7.75 \mathrm{E}-06$ \\
\hline & 301.87 & 291.91 & 10.84 & 5.78 & $1.05 \mathrm{E}-05$ & 10.84 & $1.13 \mathrm{E}-05$ & 7.52 & $5.51 \mathrm{E}-06$ \\
\hline & 301.82 & 271.91 & 30.76 & 6.40 & $1.05 \mathrm{E}-05$ & 12.06 & 3.39E-05 & 8.03 & $1.39 \mathrm{E}-05$ \\
\hline & 301.84 & 271.9 & 30.78 & 6.63 & $1.03 E-05$ & 12.75 & $2.89 \mathrm{E}-05$ & 8.3 & 9.64E-06 \\
\hline & 301.82 & 271.91 & 30.85 & 6.87 & $1.05 \mathrm{E}-05$ & 13.43 & $2.81 \mathrm{E}-05$ & 8.53 & $9.86 \mathrm{E}-06$ \\
\hline & 301.79 & 271.91 & 30.85 & 7.18 & $1.07 \mathrm{E}-05$ & 14.29 & $2.83 \mathrm{E}-05$ & 8.81 & 8.89E-06 \\
\hline
\end{tabular}




\begin{tabular}{|c|c|c|c|c|c|c|c|c|c|}
\hline $\begin{array}{l}\text { Sample } \\
\text { Number }\end{array}$ & $\begin{array}{c}P_{c} \\
(\mathrm{MPa})\end{array}$ & $\begin{array}{c}P_{p} \\
(\mathrm{MPa})\end{array}$ & $\begin{array}{c}\sigma_{m}^{e f f} \\
(\mathrm{MPa})\end{array}$ & $\begin{array}{c}\varepsilon_{a x} \\
(\%)\end{array}$ & $\dot{\varepsilon}_{a x}\left(s^{-1}\right)$ & $\begin{array}{l}\varepsilon_{v}^{u c_{-} \text {vol }} \\
(\%)\end{array}$ & $\begin{array}{c}\dot{\varepsilon}_{v}^{u c_{-} v o l} \\
\left(\mathrm{~s}^{-1}\right)\end{array}$ & $\begin{array}{l}\varepsilon_{v}^{v o l} \\
(\%)\end{array}$ & $\begin{array}{l}\dot{\varepsilon}_{v}^{v o l} \\
\left(\mathrm{~s}^{-1}\right)\end{array}$ \\
\hline & 301.78 & 271.91 & 30.83 & 7.48 & $1.07 \mathrm{E}-05$ & 15.1 & $2.88 \mathrm{E}-05$ & 9.08 & $1.03 \mathrm{E}-05$ \\
\hline & 301.73 & 271.91 & 30.58 & 7.76 & $1.05 \mathrm{E}-05$ & 15.86 & $2.83 \mathrm{E}-05$ & 9.33 & $8.94 \mathrm{E}-06$ \\
\hline & 301.74 & 271.91 & 30.61 & 8.04 & $1.08 \mathrm{E}-05$ & 16.62 & $2.98 \mathrm{E}-05$ & 9.59 & $9.96 \mathrm{E}-06$ \\
\hline & 301.72 & 271.91 & 30.56 & 8.31 & $1.08 \mathrm{E}-05$ & 17.36 & 2.75E-05 & 9.84 & 9.07E-06 \\
\hline & 301.73 & 271.9 & 30.66 & 8.59 & $1.07 \mathrm{E}-05$ & 18.11 & $2.96 \mathrm{E}-05$ & 10.09 & $1.10 \mathrm{E}-05$ \\
\hline & 301.71 & 271.91 & 30.60 & 8.84 & $1.08 \mathrm{E}-05$ & 18.83 & $2.89 \mathrm{E}-05$ & 10.35 & $7.94 \mathrm{E}-06$ \\
\hline & 301.70 & 271.91 & 30.55 & 9.13 & $1.09 \mathrm{E}-05$ & 19.63 & $2.90 \mathrm{E}-05$ & 10.62 & $9.68 \mathrm{E}-06$ \\
\hline & 301.67 & 271.91 & 30.51 & 9.37 & $1.07 \mathrm{E}-05$ & 20.33 & $3.01 \mathrm{E}-05$ & 10.88 & $1.10 \mathrm{E}-05$ \\
\hline & 301.64 & 271.91 & 30.53 & 9.62 & $1.09 \mathrm{E}-05$ & 21.03 & $3.02 \mathrm{E}-05$ & 11.13 & $1.02 \mathrm{E}-05$ \\
\hline & 301.62 & 271.91 & 30.41 & 9.88 & $1.08 \mathrm{E}-05$ & 21.73 & $3.06 \mathrm{E}-05$ & 11.39 & $1.23 \mathrm{E}-05$ \\
\hline & 301.65 & 271.91 & 30.43 & 10.09 & 1.13E-05 & 22.33 & $3.15 \mathrm{E}-05$ & 11.62 & $1.06 \mathrm{E}-05$ \\
\hline & 301.61 & 271.91 & 30.39 & 10.33 & $1.09 \mathrm{E}-05$ & 23.03 & $3.02 E-05$ & 11.89 & $1.05 \mathrm{E}-05$ \\
\hline & 301.60 & 271.9 & 30.44 & 10.56 & $1.09 \mathrm{E}-05$ & 23.71 & $3.26 \mathrm{E}-05$ & 12.14 & $1.07 \mathrm{E}-05$ \\
\hline & 301.58 & 271.91 & 30.39 & 10.77 & $1.10 \mathrm{E}-05$ & 24.32 & 2.99E-05 & 12.38 & $1.15 \mathrm{E}-05$ \\
\hline & 301.56 & 271.9 & 30.42 & 10.98 & $1.12 \mathrm{E}-05$ & 24.93 & $3.02 \mathrm{E}-05$ & 12.63 & $9.54 \mathrm{E}-06$ \\
\hline & 301.53 & 271.91 & 30.39 & 11.21 & $1.04 \mathrm{E}-05$ & 25.59 & $2.98 \mathrm{E}-05$ & 12.88 & $1.40 \mathrm{E}-05$ \\
\hline & 301.50 & 271.91 & 30.44 & 11.41 & $1.15 \mathrm{E}-05$ & 26.23 & $3.07 \mathrm{E}-05$ & 13.14 & $1.15 \mathrm{E}-05$ \\
\hline \multirow[t]{41}{*}{ CSR-9 } & 302.73 & 272.81 & 29.88 & 0.12 & $9.74 \mathrm{E}-06$ & 0.36 & $3.20 \mathrm{E}-05$ & -0.89 & $-1.02 \mathrm{E}-05$ \\
\hline & 302.69 & 272.8 & 29.88 & 0.48 & $9.72 \mathrm{E}-06$ & 1.43 & $2.98 \mathrm{E}-05$ & -1.3 & $-1.24 \mathrm{E}-05$ \\
\hline & 302.72 & 272.81 & 29.9 & 0.79 & $1.04 \mathrm{E}-05$ & 2.36 & $2.71 E-05$ & -1.77 & $-1.52 \mathrm{E}-05$ \\
\hline & 302.72 & 272.8 & 30.49 & 1.07 & 8.78E-06 & 3.22 & $2.83 \mathrm{E}-05$ & -2.25 & $-1.40 \mathrm{E}-05$ \\
\hline & 302.66 & 272.8 & 34.01 & 1.27 & $7.66 \mathrm{E}-06$ & 4.15 & $2.88 \mathrm{E}-05$ & -2.69 & $-1.34 \mathrm{E}-05$ \\
\hline & 302.62 & 272.8 & 37.28 & 1.53 & $8.51 \mathrm{E}-06$ & 5.13 & 2.92E-05 & -3.13 & $-1.31 \mathrm{E}-05$ \\
\hline & 302.64 & 272.81 & 40.4 & 1.82 & $8.68 \mathrm{E}-06$ & 6.22 & $3.03 E-05$ & -3.58 & $-1.19 E-05$ \\
\hline & 302.63 & 272.8 & 43.14 & 2.11 & $8.58 \mathrm{E}-06$ & 7.25 & $2.95 \mathrm{E}-05$ & -4.03 & $-1.27 \mathrm{E}-05$ \\
\hline & 302.60 & 272.8 & 45.69 & 2.42 & $9.00 \mathrm{E}-06$ & 8.32 & $2.95 \mathrm{E}-05$ & -4.5 & $-1.28 \mathrm{E}-05$ \\
\hline & 302.58 & 272.8 & 47.78 & 2.74 & $9.27 \mathrm{E}-06$ & 9.39 & $2.96 \mathrm{E}-05$ & -4.98 & $-1.27 E-05$ \\
\hline & 302.58 & 272.8 & 49.35 & 3.08 & $9.46 \mathrm{E}-06$ & 10.51 & $2.94 \mathrm{E}-05$ & -5.45 & $-1.23 E-05$ \\
\hline & 302.57 & 272.81 & 50.48 & 3.43 & $9.58 \mathrm{E}-06$ & 11.58 & $2.90 \mathrm{E}-05$ & -5.94 & $-1.31 \mathrm{E}-05$ \\
\hline & 302.63 & 272.8 & 51.43 & 3.80 & $9.53 \mathrm{E}-06$ & 12.71 & $2.94 \mathrm{E}-05$ & -6.43 & $-1.29 E-05$ \\
\hline & 302.63 & 272.8 & 52.25 & 4.17 & $1.00 \mathrm{E}-05$ & 13.82 & $2.90 \mathrm{E}-05$ & -6.92 & $-1.27 \mathrm{E}-05$ \\
\hline & 302.60 & 272.8 & 52.98 & 4.55 & $1.01 \mathrm{E}-05$ & 14.97 & $2.92 \mathrm{E}-05$ & -7.41 & $-1.31 E-05$ \\
\hline & 302.55 & 272.81 & 53.34 & 4.94 & $1.03 E-05$ & 16.13 & $2.90 \mathrm{E}-05$ & -7.91 & $-1.31 E-05$ \\
\hline & 302.52 & 272.8 & 53.8 & 5.35 & $1.04 \mathrm{E}-05$ & 17.33 & $2.87 E-05$ & -8.42 & $-1.32 E-05$ \\
\hline & 302.51 & 272.81 & 54.16 & 5.76 & $1.06 \mathrm{E}-05$ & 18.5 & $2.96 \mathrm{E}-05$ & -8.95 & $-1.21 \mathrm{E}-05$ \\
\hline & 302.46 & 257 & 69.96 & 6.48 & $1.03 \mathrm{E}-05$ & 21.32 & $5.06 \mathrm{E}-05$ & -9.93 & $-1.70 \mathrm{E}-05$ \\
\hline & 302.33 & 252.81 & 75.36 & 7.72 & $1.04 \mathrm{E}-05$ & 27.5 & $5.16 \mathrm{E}-05$ & -12.18 & $-1.88 \mathrm{E}-05$ \\
\hline & 301.97 & 252.81 & 76.67 & 10.97 & $1.08 \mathrm{E}-05$ & 44.87 & $6.11 \mathrm{E}-05$ & -16.26 & $-9.35 E-06$ \\
\hline & 301.47 & 252.81 & 77 & 14.21 & $1.13 \mathrm{E}-05$ & 64.2 & $7.37 \mathrm{E}-05$ & -17.68 & $3.32 \mathrm{E}-06$ \\
\hline & 301.59 & 252.8 & 77.54 & 15.23 & $1.13 \mathrm{E}-05$ & 71.16 & $7.87 \mathrm{E}-05$ & -17.13 & $8.42 E-06$ \\
\hline & 301.50 & 252.81 & 77.55 & 16.01 & $1.15 \mathrm{E}-05$ & 76.66 & $8.08 \mathrm{E}-05$ & -16.42 & $1.02 \mathrm{E}-05$ \\
\hline & 301.49 & 252.81 & 77.71 & 16.66 & $1.14 \mathrm{E}-05$ & 81.35 & 8.57E-05 & -15.72 & $1.46 \mathrm{E}-05$ \\
\hline & 301.51 & 252.81 & 77.97 & 17.26 & $1.12 \mathrm{E}-05$ & 85.94 & $8.89 \mathrm{E}-05$ & -14.82 & $1.82 \mathrm{E}-05$ \\
\hline & 301.52 & 252.81 & 77.97 & 17.76 & $1.16 \mathrm{E}-05$ & 89.77 & $8.98 \mathrm{E}-05$ & -13.99 & $1.98 \mathrm{E}-05$ \\
\hline & 301.49 & 252.81 & 78.13 & 18.20 & $1.18 \mathrm{E}-05$ & 93.38 & $9.41 \mathrm{E}-05$ & -13.1 & 2.37E-05 \\
\hline & 301.43 & 252.81 & 78.2 & 18.64 & $1.13 E-05$ & 96.88 & $9.66 \mathrm{E}-05$ & -12.2 & $2.61 \mathrm{E}-05$ \\
\hline & 301.36 & 252.81 & 78.12 & 19.03 & $1.15 \mathrm{E}-05$ & 100.12 & $9.86 \mathrm{E}-05$ & -11.28 & $2.57 \mathrm{E}-05$ \\
\hline & 301.31 & 252.81 & 78.12 & 19.40 & $1.22 \mathrm{E}-05$ & 103.25 & $1.05 \mathrm{E}-04$ & -10.35 & $3.00 \mathrm{E}-05$ \\
\hline & 301.31 & 252.81 & 78.27 & 19.72 & $1.24 \mathrm{E}-05$ & 106.18 & $1.04 \mathrm{E}-04$ & -9.42 & $3.42 \mathrm{E}-05$ \\
\hline & 301.29 & 252.81 & 78.16 & 20.03 & $1.30 \mathrm{E}-05$ & 108.89 & $1.00 \mathrm{E}-04$ & -8.56 & 3.32E-05 \\
\hline & 301.30 & 252.81 & 78.11 & 20.33 & $1.43 \mathrm{E}-05$ & 111.61 & $1.13 \mathrm{E}-04$ & -7.53 & 4.19E-05 \\
\hline & 301.27 & 252.81 & 77.92 & 20.61 & $1.22 \mathrm{E}-05$ & 114.04 & $1.13 \mathrm{E}-04$ & -6.64 & $3.94 \mathrm{E}-05$ \\
\hline & 301.26 & 252.8 & 77.96 & 20.88 & $1.30 \mathrm{E}-05$ & 116.68 & $1.07 E-04$ & -5.68 & $4.66 \mathrm{E}-05$ \\
\hline & 301.28 & 252.8 & 78.1 & 21.09 & $1.22 \mathrm{E}-05$ & 118.72 & $1.16 \mathrm{E}-04$ & -4.81 & $5.03 E-05$ \\
\hline & 301.30 & 252.81 & 78.3 & 21.32 & $1.09 \mathrm{E}-05$ & 121.11 & $1.33 \mathrm{E}-04$ & -3.86 & $4.75 E-05$ \\
\hline & 301.33 & 252.81 & 78.29 & 21.55 & $1.24 \mathrm{E}-05$ & 123.26 & $1.24 \mathrm{E}-04$ & -2.91 & $4.91 \mathrm{E}-05$ \\
\hline & 301.28 & 252.81 & 78.01 & 21.76 & $1.31 \mathrm{E}-05$ & 125.49 & $9.04 \mathrm{E}-05$ & -1.96 & 5.13E-05 \\
\hline & 301.27 & 252.8 & 78.19 & 21.93 & $1.17 \mathrm{E}-05$ & 127.42 & $1.06 \mathrm{E}-04$ & -1.11 & $5.80 \mathrm{E}-05$ \\
\hline
\end{tabular}




\begin{tabular}{|c|c|c|c|c|c|c|c|c|c|}
\hline $\begin{array}{l}\text { Sample } \\
\text { Number }\end{array}$ & $\begin{array}{c}P_{c} \\
(\mathrm{MPa})\end{array}$ & $\begin{array}{c}P_{p} \\
(\mathrm{MPa})\end{array}$ & $\begin{array}{c}\sigma_{m}^{e f f} \\
(\mathrm{MPa})\end{array}$ & $\begin{array}{c}\varepsilon_{a x} \\
(\%)\end{array}$ & $\dot{\varepsilon}_{a x}\left(s^{-1}\right)$ & $\begin{array}{l}\varepsilon_{v}^{u c_{-} v o l} \\
(\%)\end{array}$ & $\begin{array}{c}\dot{\varepsilon}_{v}^{u c} \text {-vol } \\
\left(\mathrm{s}^{-1}\right)\end{array}$ & $\begin{array}{l}\varepsilon_{v}^{v o l} \\
(\%)\end{array}$ & $\begin{array}{l}\dot{\varepsilon}_{v}^{v o l} \\
\left(\mathrm{~s}^{-1}\right)\end{array}$ \\
\hline & 301.24 & 252.8 & 78.15 & 22.13 & $1.09 \mathrm{E}-05$ & 129.52 & $9.73 \mathrm{E}-05$ & -0.14 & $5.91 \mathrm{E}-05$ \\
\hline & 301.21 & 252.81 & 78.18 & 22.32 & $9.86 \mathrm{E}-06$ & 131.53 & $9.84 \mathrm{E}-05$ & 0.74 & $5.89 E-05$ \\
\hline & 301.21 & 252.8 & 78.31 & 22.45 & $1.61 \mathrm{E}-05$ & 133 & $1.04 \mathrm{E}-17$ & 1.37 & $2.26 \mathrm{E}-05$ \\
\hline \multirow[t]{16}{*}{ CSR-10 } & 300.80 & 10.18 & 333.88 & 6.81 & $1.02 \mathrm{E}-05$ & 1 & $1.71 \mathrm{E}-05$ & $\mathrm{NaN}$ & $\mathrm{NaN}$ \\
\hline & 300.73 & 10.18 & 334.71 & 7.51 & $1.04 \mathrm{E}-05$ & 1.97 & $1.30 \mathrm{E}-05$ & $\mathrm{NaN}$ & $\mathrm{NaN}$ \\
\hline & 300.67 & 10.18 & 335.23 & 8.34 & $1.05 \mathrm{E}-05$ & 2.93 & $1.06 \mathrm{E}-05$ & $\mathrm{NaN}$ & $\mathrm{NaN}$ \\
\hline & 300.62 & 10.18 & 335.17 & 9.1 & $1.03 \mathrm{E}-05$ & 4 & $1.46 \mathrm{E}-05$ & $\mathrm{NaN}$ & $\mathrm{NaN}$ \\
\hline & 300.56 & 10.18 & 335.95 & 9.84 & $1.07 \mathrm{E}-05$ & 4.91 & $1.05 \mathrm{E}-05$ & $\mathrm{NaN}$ & $\mathrm{NaN}$ \\
\hline & 300.53 & 10.18 & 336.08 & 10.7 & $1.09 \mathrm{E}-05$ & 5.85 & $1.30 \mathrm{E}-05$ & $\mathrm{NaN}$ & $\mathrm{NaN}$ \\
\hline & 300.46 & 10.18 & 336.17 & 11.68 & $1.11 \mathrm{E}-05$ & 6.74 & $9.74 \mathrm{E}-06$ & $\mathrm{NaN}$ & $\mathrm{NaN}$ \\
\hline & 300.39 & 10.18 & 336.2 & 12.64 & $1.11 \mathrm{E}-05$ & 7.74 & $1.23 \mathrm{E}-05$ & $\mathrm{NaN}$ & $\mathrm{NaN}$ \\
\hline & 300.34 & 10.18 & 336.42 & 13.56 & $1.12 \mathrm{E}-05$ & 8.61 & $1.03 \mathrm{E}-05$ & $\mathrm{NaN}$ & $\mathrm{NaN}$ \\
\hline & 300.27 & 10.18 & 336.13 & 14.53 & $1.16 \mathrm{E}-05$ & 9.51 & $1.00 \mathrm{E}-05$ & $\mathrm{NaN}$ & $\mathrm{NaN}$ \\
\hline & 300.28 & 10.18 & 336.38 & 15.47 & $1.15 \mathrm{E}-05$ & 10.37 & $9.87 \mathrm{E}-06$ & $\mathrm{NaN}$ & $\mathrm{NaN}$ \\
\hline & 300.28 & 10.18 & 336.31 & 16.51 & $1.18 \mathrm{E}-05$ & 11.34 & $1.02 \mathrm{E}-05$ & $\mathrm{NaN}$ & $\mathrm{NaN}$ \\
\hline & 300.19 & 10.18 & 335.88 & 17.67 & $1.18 \mathrm{E}-05$ & 12.15 & $8.42 \mathrm{E}-06$ & $\mathrm{NaN}$ & $\mathrm{NaN}$ \\
\hline & 300.13 & 10.18 & 335.75 & 18.92 & $1.17 \mathrm{E}-05$ & 13.04 & $9.09 \mathrm{E}-06$ & $\mathrm{NaN}$ & $\mathrm{NaN}$ \\
\hline & 300.09 & 10.18 & 335.8 & 20.12 & $1.20 \mathrm{E}-05$ & 13.89 & $9.21 \mathrm{E}-06$ & $\mathrm{NaN}$ & $\mathrm{NaN}$ \\
\hline & 300.01 & 10.18 & 335.39 & 21.54 & $1.25 \mathrm{E}-05$ & 14.79 & $6.79 \mathrm{E}-06$ & $\mathrm{NaN}$ & $\mathrm{NaN}$ \\
\hline \multirow[t]{9}{*}{ HYD-11 } & 299.86 & 250 & 50.72 & 0.1 & $6.63 \mathrm{E}-06$ & 0.6 & $2.95 \mathrm{E}-05$ & 0.52 & $2.48 \mathrm{E}-05$ \\
\hline & 299.82 & 250 & 50.69 & 0.2 & $3.26 \mathrm{E}-06$ & 1.12 & $1.81 \mathrm{E}-05$ & 0.92 & $1.34 \mathrm{E}-05$ \\
\hline & 299.76 & 250 & 50.62 & 0.4 & $1.83 \mathrm{E}-06$ & 2.21 & $1.04 \mathrm{E}-05$ & 1.63 & $5.62 \mathrm{E}-06$ \\
\hline & 299.6 & 250 & 50.48 & 0.6 & $1.04 \mathrm{E}-06$ & 3.37 & $7.23 \mathrm{E}-06$ & 2.11 & $2.47 \mathrm{E}-06$ \\
\hline & 299.69 & 250 & 50.64 & 0.8 & $4.76 \mathrm{E}-07$ & 5.12 & $6.41 \mathrm{E}-06$ & 2.61 & $1.65 \mathrm{E}-06$ \\
\hline & 299.64 & 250 & 50.56 & 1 & 4.59E-07 & 6.71 & $6.18 \mathrm{E}-06$ & 3.08 & $1.42 \mathrm{E}-06$ \\
\hline & 299.34 & 250 & 50.25 & 1.2 & $5.67 \mathrm{E}-07$ & 8.76 & 4.14E-06 & 3.25 & $-6.24 E-07$ \\
\hline & 299.22 & 250 & 50.14 & 1.4 & 4.73E-07 & 10.27 & $4.82 \mathrm{E}-06$ & 3.27 & $5.75 \mathrm{E}-08$ \\
\hline & 299.18 & 250 & 50.1 & 1.6 & $5.24 \mathrm{E}-07$ & 11.93 & $4.57 \mathrm{E}-06$ & 3.22 & $-1.96 \mathrm{E}-07$ \\
\hline \multirow[t]{18}{*}{ HYD-14 } & 304.21 & 254.18 & 50.57 & 0.06 & $1.68 \mathrm{E}-05$ & 0.29 & $3.97 \mathrm{E}-05$ & 0.29 & $3.89 \mathrm{E}-05$ \\
\hline & 304.19 & 254.21 & 50.57 & 0.16 & $9.69 \mathrm{E}-06$ & 0.6 & $4.00 \mathrm{E}-05$ & 0.59 & $3.88 \mathrm{E}-05$ \\
\hline & 304.2 & 254.21 & 50.6 & 0.25 & $1.06 \mathrm{E}-05$ & 0.97 & $3.73 \mathrm{E}-05$ & 0.94 & $3.62 \mathrm{E}-05$ \\
\hline & 304.19 & 254.2 & 50.59 & 0.35 & $9.25 \mathrm{E}-06$ & 1.3 & $2.88 \mathrm{E}-05$ & 1.26 & $2.76 \mathrm{E}-05$ \\
\hline & 304.29 & 254.2 & 50.7 & 0.43 & $6.28 \mathrm{E}-06$ & 1.62 & $2.61 \mathrm{E}-05$ & 1.57 & $2.50 \mathrm{E}-05$ \\
\hline & 304.38 & 254.2 & 50.78 & 0.52 & $7.42 \mathrm{E}-06$ & 2.01 & $2.40 \mathrm{E}-05$ & 1.95 & $2.28 \mathrm{E}-05$ \\
\hline & 304.43 & 254.21 & 50.84 & 0.61 & 6.97E-06 & 2.38 & $2.07 \mathrm{E}-05$ & 2.3 & $1.96 \mathrm{E}-05$ \\
\hline & 304.32 & 254.21 & 50.72 & 0.72 & $7.65 \mathrm{E}-06$ & 2.72 & $1.71 \mathrm{E}-05$ & 2.62 & $1.59 \mathrm{E}-05$ \\
\hline & 304.39 & 254.2 & 50.79 & 0.88 & $1.87 \mathrm{E}-06$ & 3.11 & $4.21 \mathrm{E}-06$ & 2.95 & $3.12 \mathrm{E}-06$ \\
\hline & 304.29 & 254.2 & 50.68 & 1.13 & $1.21 \mathrm{E}-06$ & 3.67 & $2.44 \mathrm{E}-06$ & 3.3 & $1.35 \mathrm{E}-06$ \\
\hline & 303.83 & 254.2 & 50.26 & 1.36 & $5.50 \mathrm{E}-07$ & 4.25 & $2.11 \mathrm{E}-06$ & 3.59 & $1.02 \mathrm{E}-06$ \\
\hline & 303.45 & 254.2 & 50.07 & 1.6 & $7.99 \mathrm{E}-07$ & 5.02 & $1.95 \mathrm{E}-06$ & 3.94 & 8.52E-07 \\
\hline & 302.71 & 254.21 & 49.3 & 2.02 & 8.05E-07 & 5.9 & $1.72 \mathrm{E}-06$ & 4.27 & $6.24 \mathrm{E}-07$ \\
\hline & 301.83 & 254.2 & 48.42 & 2.63 & $7.55 \mathrm{E}-07$ & 7.15 & $1.37 \mathrm{E}-06$ & 4.62 & $2.78 \mathrm{E}-07$ \\
\hline & 301.48 & 254.2 & 48.07 & 3.36 & 7.33E-07 & 8.53 & $1.49 \mathrm{E}-06$ & 4.93 & $3.97 \mathrm{E}-07$ \\
\hline & 301.56 & 254.2 & 48.14 & 4.26 & $6.94 \mathrm{E}-07$ & 10.51 & $1.49 \mathrm{E}-06$ & 5.59 & $3.94 \mathrm{E}-07$ \\
\hline & 301.02 & 254.2 & 47.57 & 4.98 & $6.52 \mathrm{E}-07$ & 12 & $1.34 \mathrm{E}-06$ & 5.92 & $2.44 \mathrm{E}-07$ \\
\hline & 299.56 & 254.21 & 46.08 & 6.88 & $5.36 \mathrm{E}-07$ & 16.09 & $1.22 \mathrm{E}-06$ & 6.21 & $1.26 \mathrm{E}-07$ \\
\hline \multirow[t]{9}{*}{ MXD-16 } & 285.6 & 250 & 50.34 & 3.07 & $1.25 \mathrm{E}-04$ & 0.49 & $6.92 \mathrm{E}-06$ & 0.55 & $1.93 \mathrm{E}-05$ \\
\hline & 285.53 & 250 & 50.11 & 4.34 & $7.36 \mathrm{E}-05$ & 0.58 & $7.00 \mathrm{E}-06$ & 0.77 & $1.30 \mathrm{E}-05$ \\
\hline & 285.44 & 250 & 49.86 & 5.55 & $5.78 \mathrm{E}-05$ & 0.63 & $6.49 \mathrm{E}-06$ & 0.98 & $1.52 \mathrm{E}-05$ \\
\hline & 285.33 & 250 & 49.6 & 6.71 & $4.70 \mathrm{E}-05$ & 0.70 & $3.47 \mathrm{E}-07$ & 1.22 & $9.78 \mathrm{E}-06$ \\
\hline & 285.22 & 250 & 49.34 & 7.79 & 4.19E-05 & 0.70 & $1.36 \mathrm{E}-20$ & 1.45 & $7.88 \mathrm{E}-06$ \\
\hline & 285.12 & 250 & 49.1 & 8.83 & $3.93 \mathrm{E}-05$ & 0.70 & $3.56 \mathrm{E}-20$ & 1.68 & $9.11 \mathrm{E}-06$ \\
\hline & 285 & 250 & 48.83 & 9.86 & $3.47 \mathrm{E}-05$ & 0.70 & $-1.10 \mathrm{E}-20$ & 1.91 & $8.51 E-06$ \\
\hline & 284.86 & 250 & 48.56 & 10.85 & $3.38 \mathrm{E}-05$ & 0.70 & $1.26 \mathrm{E}-20$ & 2.15 & $6.91 \mathrm{E}-06$ \\
\hline & 284.75 & 250 & 48.33 & 11.7 & $3.05 \mathrm{E}-05$ & 0.70 & $-2.59 \mathrm{E}-20$ & 2.37 & $8.11 \mathrm{E}-06$ \\
\hline
\end{tabular}




\begin{tabular}{|c|c|c|c|c|c|c|c|c|c|}
\hline $\begin{array}{l}\text { Sample } \\
\text { Number }\end{array}$ & $\begin{array}{c}P_{c} \\
(\mathrm{MPa})\end{array}$ & $\begin{array}{c}P_{p} \\
(\mathrm{MPa})\end{array}$ & $\begin{array}{c}\sigma_{m}^{e f f} \\
(\mathrm{MPa})\end{array}$ & $\begin{array}{l}\varepsilon_{a x} \\
(\%)\end{array}$ & $\dot{\varepsilon}_{a x}\left(s^{-1}\right)$ & $\begin{array}{l}\varepsilon_{v}^{u c_{-} v o l} \\
(\%)\end{array}$ & $\begin{array}{c}\dot{\varepsilon}_{v}^{u c_{-} v o l} \\
\left(\mathrm{~s}^{-1}\right)\end{array}$ & $\begin{array}{l}\varepsilon_{v}^{v o l} \\
(\%)\end{array}$ & $\begin{array}{l}\dot{\varepsilon}_{v}^{v o l} \\
\left(\mathrm{~s}^{-1}\right)\end{array}$ \\
\hline & 284.63 & 250 & 48.11 & 12.46 & $2.77 \mathrm{E}-05$ & 0.70 & 8.72E-08 & 2.6 & $1.16 \mathrm{E}-05$ \\
\hline & 284.55 & 250 & 47.95 & 13.09 & $2.71 \mathrm{E}-05$ & 0.72 & 8.91E-07 & 2.82 & $8.85 E-06$ \\
\hline & 284.48 & 250 & 47.8 & 13.66 & $2.65 \mathrm{E}-05$ & 0.80 & $3.56 \mathrm{E}-20$ & 3.06 & $8.90 \mathrm{E}-06$ \\
\hline & 284.36 & 250 & 47.6 & 14.23 & $2.38 \mathrm{E}-05$ & 0.83 & $5.41 \mathrm{E}-06$ & 3.28 & $1.13 \mathrm{E}-05$ \\
\hline & 284.28 & 250 & 47.47 & 14.72 & $2.42 \mathrm{E}-05$ & 0.90 & $-3.22 \mathrm{E}-20$ & 3.51 & $1.12 \mathrm{E}-05$ \\
\hline & 284.2 & 250 & 47.32 & 15.26 & $2.28 \mathrm{E}-05$ & 0.93 & $5.31 \mathrm{E}-06$ & 3.73 & $1.02 \mathrm{E}-05$ \\
\hline & 284.14 & 250 & 47.2 & 15.78 & $2.32 \mathrm{E}-05$ & 0.99 & $1.94 \mathrm{E}-06$ & 3.97 & $1.20 \mathrm{E}-05$ \\
\hline & 284.05 & 250 & 47.04 & 16.22 & $2.40 \mathrm{E}-05$ & 1.05 & $6.02 \mathrm{E}-06$ & 4.18 & $1.22 \mathrm{E}-05$ \\
\hline & 283.94 & 250 & 46.88 & 16.67 & $2.02 \mathrm{E}-05$ & 1.10 & $-1.61 \mathrm{E}-20$ & 4.41 & $1.05 \mathrm{E}-05$ \\
\hline & 283.85 & 250 & 46.73 & 17.1 & $2.12 \mathrm{E}-05$ & 1.19 & $2.69 \mathrm{E}-06$ & 4.64 & $1.15 \mathrm{E}-05$ \\
\hline & 283.76 & 250 & 46.6 & 17.53 & $1.43 E-05$ & 1.20 & $1.02 E-06$ & 4.86 & $8.46 \mathrm{E}-06$ \\
\hline & 283.67 & 250 & 44.58 & 17.2 & $-1.48 \mathrm{E}-04$ & 1.29 & $3.06 \mathrm{E}-06$ & 5.07 & $1.42 \mathrm{E}-05$ \\
\hline & 283.59 & 250 & 35 & 15.72 & $-2.84 \mathrm{E}-06$ & 1.30 & $1.58 \mathrm{E}-07$ & 5.3 & $1.04 \mathrm{E}-05$ \\
\hline & 283.52 & 250 & 34.93 & 15.8 & $1.45 \mathrm{E}-05$ & 1.35 & $3.42 \mathrm{E}-06$ & 5.52 & $9.78 \mathrm{E}-06$ \\
\hline & 283.49 & 250 & 34.89 & 15.94 & $3.18 \mathrm{E}-05$ & 1.40 & $7.01 \mathrm{E}-20$ & 5.75 & $9.27 \mathrm{E}-06$ \\
\hline & 283.43 & 250 & 34.85 & 15.87 & $-1.78 \mathrm{E}-05$ & 1.46 & $4.96 \mathrm{E}-06$ & 5.95 & $1.00 \mathrm{E}-05$ \\
\hline & 283.34 & 250 & 34.73 & 15.84 & $2.09 \mathrm{E}-05$ & 1.50 & $9.01 \mathrm{E}-21$ & 6.19 & $1.01 \mathrm{E}-05$ \\
\hline & 283.27 & 250 & 34.67 & 16.27 & $1.06 \mathrm{E}-05$ & 1.54 & $5.72 \mathrm{E}-06$ & 6.4 & $1.15 \mathrm{E}-05$ \\
\hline & 283.21 & 250 & 34.62 & 16.45 & $8.56 \mathrm{E}-06$ & 1.60 & $-1.37 \mathrm{E}-19$ & 6.63 & $1.03 \mathrm{E}-05$ \\
\hline & 283.13 & 250 & 34.55 & 16.23 & $-2.80 \mathrm{E}-05$ & 1.66 & $7.51 \mathrm{E}-06$ & 6.84 & $9.45 \mathrm{E}-06$ \\
\hline & 283.08 & 250 & 34.49 & 15.78 & $-6.21 \mathrm{E}-06$ & 1.70 & $-6.83 E-20$ & 7.05 & $9.39 \mathrm{E}-06$ \\
\hline \multirow[t]{26}{*}{ MXD-17 } & 272.03 & 250.01 & 22.77 & 0.1 & $2.98 \mathrm{E}-07$ & -0.24 & $-2.43 \mathrm{E}-06$ & -0.18 & $5.97 \mathrm{E}-07$ \\
\hline & 271.98 & 250 & 22.74 & 0.22 & $4.90 \mathrm{E}-06$ & -0.08 & $8.15 \mathrm{E}-06$ & 0.04 & $9.16 \mathrm{E}-06$ \\
\hline & 271.98 & 250 & 22.75 & 0.24 & $-6.78 \mathrm{E}-07$ & 0.1 & $8.06 \mathrm{E}-06$ & 0.28 & $1.01 \mathrm{E}-05$ \\
\hline & 271.96 & 250 & 22.72 & 0.33 & $3.88 \mathrm{E}-06$ & 0.26 & $5.70 \mathrm{E}-06$ & 0.51 & $9.08 \mathrm{E}-06$ \\
\hline & 271.92 & 250 & 22.7 & -0.38 & $-7.33 E-06$ & 0.44 & $4.45 \mathrm{E}-06$ & 0.74 & $5.00 \mathrm{E}-06$ \\
\hline & 271.93 & 250 & 22.71 & 0.09 & $-2.60 \mathrm{E}-07$ & 0.56 & $3.37 \mathrm{E}-06$ & 0.95 & $4.26 \mathrm{E}-06$ \\
\hline & 271.92 & 250 & 22.68 & 0.39 & $3.96 \mathrm{E}-06$ & 0.74 & $4.47 \mathrm{E}-06$ & 1.19 & 6.39E-06 \\
\hline & 271.9 & 250 & 22.71 & 0.19 & $-2.47 \mathrm{E}-05$ & 0.88 & $2.75 \mathrm{E}-06$ & 1.42 & $4.78 \mathrm{E}-06$ \\
\hline & 271.91 & 250 & 23.06 & -0.58 & $-2.91 E-05$ & 1 & 8.03E-07 & 1.64 & $3.81 \mathrm{E}-06$ \\
\hline & 271.89 & 250 & 23.69 & 0.25 & $6.07 \mathrm{E}-06$ & 1.12 & $1.75 \mathrm{E}-06$ & 1.88 & $3.55 \mathrm{E}-06$ \\
\hline & 271.82 & 250 & 23.63 & 0.57 & $6.17 \mathrm{E}-07$ & 1.2 & $2.19 \mathrm{E}-08$ & 2.1 & $3.51 \mathrm{E}-06$ \\
\hline & 271.75 & 250 & 23.56 & 0.52 & $1.15 \mathrm{E}-06$ & 1.28 & $1.08 \mathrm{E}-06$ & 2.31 & $3.50 \mathrm{E}-06$ \\
\hline & 271.56 & 250 & 23.36 & 0.75 & $7.16 \mathrm{E}-07$ & 1.33 & $1.29 \mathrm{E}-06$ & 2.55 & $2.35 \mathrm{E}-06$ \\
\hline & 271.38 & 250 & 23.19 & 0.76 & $1.77 \mathrm{E}-06$ & 1.4 & $2.49 \mathrm{E}-07$ & 2.77 & $2.36 \mathrm{E}-06$ \\
\hline & 271.3 & 250 & 23.1 & 0.72 & $-7.32 \mathrm{E}-07$ & 1.4 & $2.30 \mathrm{E}-08$ & 2.99 & $2.87 \mathrm{E}-06$ \\
\hline & 271.24 & 250 & 25.3 & 0.34 & $1.26 \mathrm{E}-05$ & 1.42 & $7.10 \mathrm{E}-07$ & 3.19 & $2.52 \mathrm{E}-06$ \\
\hline & 270.96 & 250 & 50.25 & 5.72 & $1.30 \mathrm{E}-04$ & 1.58 & $4.28 \mathrm{E}-06$ & 3.45 & $6.64 \mathrm{E}-06$ \\
\hline & 270.7 & 250 & 48.58 & 10.74 & $8.03 E-05$ & 1.7 & $1.43 \mathrm{E}-20$ & 3.66 & $2.28 \mathrm{E}-06$ \\
\hline & 270.64 & 250 & 22.23 & 13.64 & $-4.71 \mathrm{E}-06$ & 1.49 & $1.99 \mathrm{E}-06$ & 3.87 & $4.52 \mathrm{E}-06$ \\
\hline & 270.55 & 250 & 22.12 & 13.68 & $1.47 \mathrm{E}-05$ & 1.66 & $4.07 \mathrm{E}-06$ & 4.1 & $4.96 \mathrm{E}-06$ \\
\hline & 270.5 & 250 & 22.07 & 13.73 & $4.00 \mathrm{E}-06$ & 1.79 & $2.29 \mathrm{E}-06$ & 4.32 & $5.62 \mathrm{E}-06$ \\
\hline & 270.49 & 250 & 22.07 & 13.75 & $1.54 \mathrm{E}-06$ & 1.94 & $3.90 \mathrm{E}-06$ & 4.54 & $5.91 \mathrm{E}-06$ \\
\hline & 270.29 & 250 & 21.87 & 13.86 & $7.16 \mathrm{E}-07$ & 2.06 & $2.27 \mathrm{E}-06$ & 4.76 & $2.90 \mathrm{E}-06$ \\
\hline & 270.38 & 250 & 22.04 & 13.44 & $-1.87 \mathrm{E}-05$ & 2.14 & $2.86 \mathrm{E}-06$ & 4.96 & $3.74 \mathrm{E}-06$ \\
\hline & 270.55 & 250 & 22.3 & 13.59 & $5.98 \mathrm{E}-06$ & 2.29 & $1.13 \mathrm{E}-06$ & 5.2 & $2.71 \mathrm{E}-06$ \\
\hline & 270.52 & 250 & 22.34 & 13.82 & $-3.52 \mathrm{E}-07$ & 2.37 & $2.21 \mathrm{E}-06$ & 5.41 & $4.55 \mathrm{E}-06$ \\
\hline \multirow[t]{10}{*}{ HYD-18 } & 300.55 & 250 & 51.25 & 0.24 & $1.25 \mathrm{E}-05$ & 0.77 & $3.27 \mathrm{E}-05$ & 0.8 & $3.42 \mathrm{E}-05$ \\
\hline & 300.54 & 250 & 51.26 & 0.34 & $1.05 \mathrm{E}-05$ & 1.08 & $3.18 \mathrm{E}-05$ & 1.11 & $3.32 \mathrm{E}-05$ \\
\hline & 300.52 & 250.01 & 51.25 & 0.43 & $8.28 \mathrm{E}-06$ & 1.37 & $3.45 \mathrm{E}-05$ & 1.42 & $3.59 \mathrm{E}-05$ \\
\hline & 300.5 & 250 & 51.25 & 0.53 & $7.25 \mathrm{E}-06$ & 1.7 & $2.91 \mathrm{E}-05$ & 1.76 & $3.05 \mathrm{E}-05$ \\
\hline & 300.49 & 250 & 51.25 & 0.64 & $8.56 \mathrm{E}-06$ & 2.03 & $2.63 \mathrm{E}-05$ & 2.11 & $2.77 \mathrm{E}-05$ \\
\hline & 300.42 & 250 & 51.17 & 0.79 & $1.99 \mathrm{E}-06$ & 2.39 & $4.46 \mathrm{E}-06$ & 2.52 & $5.89 \mathrm{E}-06$ \\
\hline & 300.31 & 250 & 51.06 & 0.94 & $1.11 \mathrm{E}-06$ & 2.49 & $4.50 \mathrm{E}-07$ & 2.78 & $1.88 \mathrm{E}-06$ \\
\hline & 300.21 & 250 & 50.95 & 1.11 & $8.13 E-07$ & 2.56 & $3.23 \mathrm{E}-07$ & 3.13 & $1.75 \mathrm{E}-06$ \\
\hline & 300.16 & 250 & 50.91 & 1.24 & $5.44 \mathrm{E}-07$ & 2.63 & $3.21 \mathrm{E}-07$ & 3.45 & $1.74 \mathrm{E}-06$ \\
\hline & 300.04 & 250 & 50.79 & 1.34 & $5.15 \mathrm{E}-07$ & 2.7 & $4.28 \mathrm{E}-07$ & 3.82 & $1.84 \mathrm{E}-06$ \\
\hline
\end{tabular}




\begin{tabular}{|c|c|c|c|c|c|c|c|c|c|}
\hline $\begin{array}{c}\text { Sample } \\
\text { Number }\end{array}$ & $\begin{array}{c}P_{c} \\
(\mathrm{MPa})\end{array}$ & $\begin{array}{c}P_{p} \\
(\mathrm{MPa})\end{array}$ & $\begin{array}{c}\sigma_{m}^{\text {eff }} \\
(\mathrm{MPa})\end{array}$ & $\begin{array}{l}\varepsilon_{a x} \\
(\%)\end{array}$ & $\dot{\varepsilon}_{a x}\left(\mathrm{~s}^{-1}\right)$ & $\begin{array}{l}\varepsilon_{v}^{u c_{-} v o l} \\
(\%)\end{array}$ & $\begin{array}{c}\dot{\varepsilon}_{v}^{u c_{-} v o l} \\
\left(\mathrm{~s}^{-1}\right)\end{array}$ & $\begin{array}{l}\varepsilon_{v}^{v o l} \\
(\%)\end{array}$ & $\begin{array}{l}\dot{\varepsilon}_{v}^{v o l} \\
\left(s^{-1}\right)\end{array}$ \\
\hline & 299.89 & 250 & 50.65 & 1.42 & $4.12 \mathrm{E}-07$ & 2.78 & $4.22 \mathrm{E}-07$ & 4.13 & $1.83 \mathrm{E}-06$ \\
\hline & 299.89 & 250 & 50.67 & 1.51 & $5.01 \mathrm{E}-07$ & 2.85 & $4.00 \mathrm{E}-07$ & 4.47 & $1.80 \mathrm{E}-06$ \\
\hline & 299.77 & 250 & 50.55 & 1.61 & $5.55 \mathrm{E}-07$ & 2.92 & $2.66 \mathrm{E}-07$ & 4.8 & $1.66 \mathrm{E}-06$ \\
\hline & 299.56 & 250 & 50.32 & 1.71 & $5.40 \mathrm{E}-07$ & 2.97 & $2.01 \mathrm{E}-07$ & 5.11 & $1.59 \mathrm{E}-06$ \\
\hline & 299.34 & 250 & 50.11 & 1.82 & 4.04E-07 & 2.98 & $-1.17 \mathrm{E}-07$ & 5.47 & $1.28 \mathrm{E}-06$ \\
\hline & 299.15 & 250 & 49.94 & 1.92 & $3.44 \mathrm{E}-07$ & 2.76 & $-1.44 \mathrm{E}-06$ & 5.65 & $-6.30 \mathrm{E}-09$ \\
\hline & 298.53 & 250 & 49.3 & 2.15 & $3.69 \mathrm{E}-07$ & 1.62 & $-1.81 \mathrm{E}-06$ & 5.46 & $-3.47 \mathrm{E}-07$ \\
\hline & 299 & 250 & 49.76 & 2.41 & $1.53 \mathrm{E}-07$ & 0 & $-1.76 \mathrm{E}-06$ & 5.15 & $-2.75 \mathrm{E}-07$ \\
\hline & 301.08 & 250 & 51.88 & 2.58 & $1.69 \mathrm{E}-07$ & -2.09 & $-1.89 \mathrm{E}-06$ & 4.77 & $-3.59 \mathrm{E}-07$ \\
\hline & 299.36 & 250 & 50.09 & 2.95 & $1.59 \mathrm{E}-07$ & -5.41 & $-1.56 \mathrm{E}-06$ & 4.55 & $-2.28 \mathrm{E}-09$ \\
\hline
\end{tabular}




\section{References:}

Bai, Q., et al. (1991), High-temperature creep of olivine single crystals 1. Mechanical results for buffered samples, J. Geophys. Res., 96, 2441-2463.

Bercovici, D., et al. (2001), A two-phase model for compaction and damage 1. General theory, J. Geophys. Res., 106, 8887-8907.

Bernabé, Y., et al. (2003), Permeability-porosity relationships in rocks subujected to various evolution processes, Pure Appl. Geophys., 160, 937-960.

Boettcher, M. S., et al. (in press), Olivine Friction at the Base of Oceanic Seismogenic Zones, J. Geophys. Res.

Brace, W. F., and R. J. Martin (1968), A test of the effective stress for crystalline rocks of low porosity, Int. J. Rock Mech. Min. Sci. Geomech. Abstr., 5, 415-426.

Brace, W. F., et al. (1966), Dilatancy in the fracture of crystalline rocks, J. Geophys. Res., $71,3939-3954$.

Brace, W. F., et al. (1968), Permeability of granite under high pressure, J. Geophys. Res., $73,2225-2236$.

Budiansky, B., et al. (1982), Void Growth and Collapse in Viscous Solids, in Mechanics of Solids, edited by H. G. Hopkins and M. J. Sewell, pp. 13-45.

Bussod, G. Y., and J. M. Christie (1991), Textural development and melt topology in spinel lherzolite experimentally deformed at hypersolidus conditions, J. Petrol., Special Lherzolite Issue, 17-39.

Coble, R. L. (1970), Diffusion models for hot pressing with surface energy and pressure effects, J. Appl. Phys., 41, 4798-4807.

Coble, R. L., and W. D. Kingery (1956), The effect of porosity on phyiscal properties of sintered alumina, J. Am. Ceram. Soc., 39, 377-385.

Cooper, R. F., and D. L. Kohlstedt (1984), Solution-precipitation enhanced diffusional creep of partially molten olivine-basalt aggregates during hot-pressing, Techtonophysics, 107, 207-233.

Cooper, R. F., and D. L. Kohlstedt (1986), Rheology and structure of olivine-basalt partial melts, J. Geophys. Res., 91, 9315-9323.

Cooper, R. F., et al. (1989), Solution-precipitation enhanced creep in solid-liquid aggregates with display non-zero dihedral angle, Acta Metall., 37, 1759-1771.

Daines, M. J., and F. M. Richter (1988), An experimental method for directly determining the interconnectivity of melt in a partially molten system, Geophys. Res. Let., 15, 1459-1462.

Dell'Angelo, L. N., and J. Tullis (1988), Experimental deformation of partially melted granitic aggregates, J. Metamorphic Geol., 6, 495-515.

Drury, M. R., et al. (1991), Shear localisation in upper mantle peridotites, Pure Appl. Geophys., 137, 439-460.

Duva, J. M., and J. W. Hutchinson (1984), Constitutive potentials for dilutely voided nonlinear materials, Mechanics of Materials, 3, 41-54.

Edmond, J. M., and M. S. Paterson (1972), Volume changes during the deformation of rocks at high pressure, Int. J. Rock Mech. Min. Sci., 9, 161-182.

Fischer, G. J., and M. S. Paterson (1989), Dilatancy during rock deformation at thigh temperatures and pressures, J. Geophys. Res., 94, 17607-17617. 
Fischer, G. J., and M. S. Paterson (1992), Measurement of permeability and storage capacity in rocks during deformation at high temperature and pressure, in Fault mechanics and transport properties of rocks, edited by B. Evans and T.-f. Wong, pp. 213-252, Academic Press, London.

Fowler, A. C. (1990a), A compaction model for melt transport inthe Earth's asthenosphere. Part I: the basic model, in Magma Transport and Storage, edited by M. P. Ryan, pp. 3-14, John Wiley \& Sons.

Fowler, A. C. (1990b), A compaction model for melt transport inthe Earth's asthenosphere. Part II: applications, in Magma Transport and Storage, edited by M. P. Ryan, pp. 15-32, John Wiley \& Sons.

Frank, F. C. (1968), Two-component flow model for convection in the earth's upper mantle, Nature, 220, 350-352.

Fredrich, J. T., and B. Evans (1990), High temperature fracture and flow of Maryland Diabase, Eos Trans. Fall Meeting Supp., 71, 1750.

Fujii, T., and I. Kushiro (1977), Density, viscosity and compressibility of basaltic liquid at high pressures, Carnegie Institute of Washington Year Book, 76, 419-424.

Guéguen, Y., and V. Palciauskas (1994), Introduction to the Physics of Rocks, Princeton University Press, Princeton.

Helle, A. S., et al. (1985), Hot-isostatic pressing diagrams: New developments, Acta Metall. Mater., 33, 2163-2174.

Hill, R. (1956), New horizons in the mechanics of solids, J. Mech. Phys. Solids, 5, 66-74.

Hirth, G., and D. L. Kohlstedt (1995a), Experimental constrains on the dynamics of the partially molten upper mantle: Deformation in the diffusion creep regime, $J$. Geophys. Res., 100, 1981-2000.

Hirth, G., and D. L. Kohlstedt (1995b), Experimental constraints on the dynamics of the partially molten upper mantle 2 . Deformation in the dislocation creep regime, $J$. Geophys. Res., 100, 15,441-415,449.

Hirth, G., and D. L. Kohlstedt (2003), Rheology of the upper mantle and mantle wedge: A view from the experimentalists, in Inside the Suduction Factory, edited, pp. 83105, American Geophysical Union.

Holtz, R. D., and W. D. Kovacs (1981), in Introduction to Geotechnical Engineering, edited, pp. 496-503, Prentice Hall, Englewood Cliffs, NJ.

Holtzman, B. K., et al. (2003a), Stress-driven melt segregation in partially molten rocks, Geochemistry, Geophysics, Geosystems, 4, 8607, doi:8610.1029/2001GC000258.

Holtzman, B. K., et al. (2003b), Melt segregation and strain partitioning: implications for seismic anisotropy and mantle flow, Nature, 301, 1227-1230.

Katz, R. F., et al. (2006), The dynamics of melt and shear localization in partially molten aggregates, Nature, 442, 676-679.

Kohlstedt, D. L. (2002), Partial Melting and Deformation, in Plastic Deformation of Minerals and Rocks, edited by S.-i. Karato and H.-R. Wenk, pp. 121-135, Mineralogical Society of America, Washington D.C.

Mavko, G., et al. (1998), The Rock Physics Handbook 148 pp., Cambridge University Press.

McKenzie, D. (1984), The generation and compaction of partially molten rock, J. Petrol., $25,713-765$. 
Mei, S., et al. (2002), Influence of melt on the creep behavior of olivine-basalt aggregates under hydrous conditions, Earth Planet. Sci. Lett., 201, 491-507.

Paterson, M. S. (1970), A high temperature high pressure apparatus for rock deformation, Int. J. Rock Mech. Min. Sci., 7, 517-526.

Paterson, M. S., and T.-f. Wong (2005), in Experimental Rock Deformation -- The Brittle Field, edited, pp. 224-225, Springer.

Renner, J., et al. (2000), On the rheologically critical melt fraction, Earth Planet. Sci. Lett., 181, 585-594.

Renner, J., and F. Rummel (1996), The effect of experimental and microstructural parameters on the transition from brittle failure to cataclastic flow of carbonate rocks, Techtonophysics, 258, 151-169.

Renner, J., et al. (2003), Melt extraction from partially molten peridotites, Geochemistry, Geophysics, Geosystems, 4, 8606, doi: 8610.1029/2002GC000369.

Ricard, Y., et al. (2001), A two-phase model for compaction and damage 2. Applications to compaction deformation and the role of interfacial surface tension, J. Geophys. Res., 106, 8907-8924.

Riley, G. N., and D. L. Kohlstedt (1991), Kinetics of melt migration in upper mantle-type rocks, Earth Planet. Sci. Lett., 105, 500-521.

Scott, D. R., and D. J. Stevenson (1986), Magma ascent by porous flow, J. Geophys. Res., 91, 9283-9296.

Scott, D. R., and D. J. Stevenson (1989), A self-consistent model of melting, magma migration, and buoyancy-driven circulation beneath mid-ocean ridges, $J$. Geophys. Res., 94, 2973-2988.

Scott, T., and D. L. Kohlstedt (2006), The effect of large melt fraction on the deformation behavior of peridotite, Earth and Planet. Sci. Lett., 246, 177-187.

Sleep, N. H. (1974), Segregation of magma from a mostly crystalline mush, Bull. Geol. Soc. Am., 85, 1225-1232.

Stopler, E., et al. (1981), Melt segregation from partially molten source regions: the importance of melt density and source region size, J. Geophys. Res., 86, 62616271.

Underwood, E. E. (1970), Quantitative Stereology, 274 pp., Addison Wesley, Reading, MA.

von Bargen, N., and H. S. Waff (1986), Permeabilities, interfacial area and curvatures of partially molten systems: Results of numerical computation of equilibrium microstructures, J. Geophys. Res., 91, 9261-9276.

Waff, H. S., and J. R. Bulau (1979), Equilibrium fluid distribution in an ultramafic partial melt under hydrostatic stress conditions, J. Geophys. Res., 84, 6109-6114.

Walsh, J. B. (1965), The effect of cracks on the compressibility of rock, J. Geophys. Res., 70, 381-389.

Wark, D. A., and E. B. Watson (1998), Grain-scale permeabilites of texturally equilibrated, monomineralic rocks, Earth and Planet. Sci. Lett., 164, 591-605.

Wong, T.-f. (1990), Mechanical compaction and the brittle-ductile transition in porous sandstones, in Deformation Mechanisms, Rheology and Tectonics, edited by R. J. Knipe and E. H. Rutter, pp. 111-122, Geological Society Speical Publication.

Xiao, X., and B. Evans (2003), Shear-enhanced compaction during non-linear viscous creep of porous calcite-quartz aggregates, Earth Planet. Sci. Lett., 216, 725-740. 
Zimmerman, M. E., et al. (1999), Melt distribution in mantle rocks deformed in shear, Geophys. Res. Let., 26, 1505-1508.

\section{Figure Captions:}

Figure 1. Experimental sample assemblies. (a) Schematic of experimental assembly. (b) Detail of hot-isostatic pressing assembly. Olivine + MORB sample is undrained and completely encapsulated in $\mathrm{Ni}$ to prevent melt from draining during synthesis. (c) Detail of drained deformation configuration. Melt is drained into a reservoir of carbon beads that is in contact with Ar gas via the pore fluid pressure line. A small alumina piston transfers stress from the deformation pistons to the sample.

Figure 2. Macroscopic images of (a) HYD-11 and (b) CSR-7. Sample HYD-11 was deformed to $1.6 \%$ axial strain, and like other hydrostatic experiments shows little evidence of barreling. Microstructural measurements suggest that the carbon reservoir was not full, and we can see carbon beads within the epoxy mould. Sample CSR-7 was deformed to approximately $\sim 21 \%$ strain and barreling of the sample is evident. There is some minor displacement of the sample into the carbon bead reservoir. There are no carbon beads present within the epoxy mould for CSR-7. Based on image analysis the carbon reservoir is presumed to be close to full.

Figure 3. Micrographs of quenched partially molten olivine aggregates. The images on the left show the microstructures of samples after hot-isostatic pressing at $1200^{\circ} \mathrm{C}$ and $300 \mathrm{MPa}$. The images on the right show the microstructures of the same samples after deformation and melt extraction at $1200^{\circ} \mathrm{C}$ and various effective pressures. The $50 \mu \mathrm{m}$ scale bar in panel (a) is appropriate for all panels. Sample HYD-11 (a) before and (b) after hydrostatic compaction. Final melt content $\phi_{\mathrm{f}}=6.6 \%$. Sample HYD-14 (c) before and (d) after hydrostatic compaction. Final melt content $\phi_{\mathrm{f}}=7.5 \%$. Sample CSR-7 (e) before and (f) after constant strain-rate drained deformation test. Final melt content $\phi_{\mathrm{f}}$ $=4.9 \%$. Sample MXD-16 $(\mathrm{g})$ before and $(\mathrm{h})$ after mixed hydrostatic and creep tests. Final melt content $\phi_{\mathrm{f}}=8.3 \%$. Sample MXD-16 was HIPed at slightly too cold a temperature and contained small crystals. The crystals melted during the drained deformation experiment.

Figure 4. Histograms of olivine grain size in samples before and after melt extraction experiments. Probability density functions for the olivine grain sizes are consistent with a log normal distribution. Shown in each panel is the mean grain size and standard deviation along with the $95 \%$ confidence intervals computed from a log normal distribution. Panels on the left show grain size distributions before compaction, and panels on the right show grain size distributions after compaction. (a) and (b) show grain size distributions for powders made from settling. (c), (d), (e), and (f) show grain size distributions for powders created from the fluid ion mill. Both powders show similar grain sizes. Experimental sample numbers are indicated in each panel.

Figure 5. Melt fraction measured as distance from the reservoir using optical micrographs. Mean starting melt fractions denoted by dashed line, and mean final melt 
fractions denoted by solid gray line. Individual measurements shown along with $95 \%$ confidence intervals for each measurement. The standard deviation of the measured melt fractions is indicated by the gray zone. Hydrostatic experiments (a) HYD-11 and (b) HYD-14 show no melt fraction gradients as a function of distance from the reservoir in contrast to the triaxially deformed samples (c) CSR-7 and (d) MXD-16, which show decreased melt content towards the sample ends.

Figure 6. Summary of hydrostatic melt extraction experiments: (a) differential stress and (b) volumetric strain versus axial strain. A small axial load is maintained on the sample ends to measure axial strain. Volumetric strain is calculated from volumometer actuator data. Volumetric strain is corrected to match starting and final melt fractions in experiments HYD-11 and HYD-14. Uncorrected volumetric strain data is shown for HYD-18. Volumetric strain initially increased three times faster than axial strain (dashed line) for all three hydrostatic experiments. The precipitous decrease in volumetric strain at $1.5 \%$ axial strain in HYD-18 is due to sudden leak in the pore fluid pressure system.

Figure 7. Volumetric strain rate versus melt fraction. Volumetric strain rates calculated using the volumometer (circles/grayscale) and axial (square/color) actuators. Axial actuator data has a resolution of $\sim 1 \times 10^{-6} \mathrm{~s}^{-1}$. HYD-14 and HYD-18 appear to have a rapid decrease in volumetric strain rates at around $11 \%$ melt content.

Figure 8. Summary of melt-free olivine experiments: (a) differential stress and (b) volumetric strain versus axial strain. Volumetric strain is calculated from volumometer actuator data with no corrections applied. We used argon gas as the pore fluid pressure for CSR-5 and CSR-10. Samples CSR-12 and CSR-13 were not connected to the pore fluid pressure system and had nominal effective pressures of $0.1 \mathrm{MPa}$. Volumetric strain data reveals CSR-5 dilated after $\sim 10 \%$ axial strain. A rapid leak into pore fluid pressure from confining pressure developing in CSR-10 after $\sim 5 \%$ strain.

Figure 9. Summary of constant strain-rate experiments: (a) differential stress and (b) volumetric strain calculated from the volumometer actuator corrected using the initial and final melt contents. Samples with the smallest about of melt have the greatest steady state flow stresses. As deformation proceeds, samples initially containing 5 and $10 \%$ melt work harden owing to the loss of melt. Compaction is indicated by positive volumetric strain. Volumetric strain increases as the samples deform. Effective confining pressure is instantaneously increased $20 \mathrm{MPa}$ for samples CSR-7, CSR-8 and CSR-9 at $~ 5 \%$ axial strain. This can be seen in both (a) and (b). Samples CSR-2 and CSR-4 dilate after initial periods of compaction. Sample CSR-4 had small crystals present in the melt phase. There is no volumetric strain data for CSR-9. We show the mechanical data from the experiment on sample CSR-10, a nominally melt free olivine aggregate, for comparison.

Figure 10. Volumetric strain rates versus melt fraction. Circles denote effective pressure equal to $30 \mathrm{MPa}$, and squares represent effective confining pressures equal to 50 $\mathrm{MPa}$. We calculate volumetric strain rates using volumetric strain measured with the volumometer data and corrected using the procedure in appendix A. Volumetric strain rates decrease as melt fraction decreases and increase at higher effective confining 
pressures. Samples CSR-2 and CSR-4 transition from compaction to dilation at low melt fractions, and volumetric strain rates go negative. CSR-4 had small crystals present in the melt phase, which may have influenced volumetric strain rates.

Figure 11. Volumetric strain rate for CSR-8. Volumetric strain rates calculated using volumetric strain measured with the volumometer data and corrected using the procedure in appendix A. CSR-8 shows several characteristics similar to HYD14 and HYD-18 in Figure 7. Initially rapid compaction rates suddenly decrease to a lower value. Like the hydrostatic experiment, we assume that the carbon bead reservoir fills up and limits the compaction rate of the sample. At $\sim 23.5 \%$ melt, we increase the effective confining pressure $20 \mathrm{MPa}$, and we observe an increase in volumetric strain rates.

Figure 12. Strain histories of mixed hydrostatic and creep experiments. Pore fluid pressure is maintained at $250 \mathrm{MPa}$ throughout these experiments. Effective mean stress approximately $50 \mathrm{MPa}$ during creep portions (gray shading). (a) MXD-16: creep experiment followed by single hydrostatic experiment. (b) MXD-17: hydrostatic experiment, followed by a creep experiment, and then another hydrostatic experiment. Volumetric strain rates are estimated by fitting lines to the hydrostatic portions of the experiments.

Figure 13. Creep portion of MXD-16 and MXD-17: (a) Axial strain versus time and (b) axial strain rate versus time. Time and axial strain normalized to the start of the creep portion of the experiments. MXD-17 was deformed at a higher differential stress than MXD-16 and consequently had higher axial strain-rates.

Figure 14. The influence of effective mean stress on compaction rate. We plot the ratio of volumetric strain rate before and after a change in the imposed effective mean stress. (a) Our drained deformation experiments compared to previously published hydrostatic experiments on olivine and MORB [Renner et al., 2003]. (b) Ratios of volumetric strain rates shown in (a) categorized by the magnitude of $\sigma_{m_{2}}^{\text {eff }}$. Samples deformed at $\sigma_{m_{2}}^{\text {eff }}$ less than $30 \mathrm{MPa}$ are well fit by the relationship in equation (2.4) with $n$ $=1$. Experiments drained at $\sigma_{m_{2}}^{\text {eff }}$ greater than $60 \mathrm{MPa}$ are more consistent with equation (2.4) when $n=3.5$.

Figure 15. Normalized compaction rates for drained melt extraction experiments. (a) Uncorrected data, (b) data normalized to $\sigma_{m}^{\text {eff }}=50 \mathrm{MPa}$ using (2.4) and $n=1$, and (c) data normalized to $\sigma_{m}^{\text {eff }}=50 \mathrm{MPa}$ using (2.4) and $n=1$ when $\sigma_{m}^{\text {eff }} \leq 40 \mathrm{MPa}$ and $n=3.5$ when $\sigma_{m}^{\text {eff }}>40 \mathrm{MPa}$. CSR experiments show corrected volumetric data, HYD experiments show volumetric strain rates calculated from using the axial displacement, and MXD uses the average value for the triaxial and hydrostatic portions of the experiment. Sample CSR-4 had small crystals in the melt phase that may have influenced the compaction rates. Hydrostatic melt extraction experiments [Renner, et al., 2003] shown for comparison. 
Figure 16. Influence of differential stress on deformation. Data normalized to $\sigma_{m}^{\text {eff }}$ $=50 \mathrm{MPa}$ using (2.4) with (a) $n=1$ and (b) $n=3.5$. Three different melt fractions shown. Differential stress may cause enhanced strain rates at melt contents of $8.5 \%$, when the samples are rapidly strain hardening. However, at lower melt fractions, differential stress appears to have little effect on the melt extraction rates within the resolution of our measurements for both $n=1$ and $n=3.5$.

Figure 17. Comparison of experimental data to theoretical model of compaction in a power law viscous material. We plot normalized compaction rates versus triaxiality. Uncertainties for CSR-6, CSR-7 show the range in normalized volumetric strain rates when we compare uncorrected and corrected volumetric strain data. Data points indicate corrected normalized volumetric strain rates. Uncertainties for CSR-2 and CSR-9 are estimated from the uncertainties in the initial and final melt fractions. At low triaxiality, the theoretical model over estimates volumetric strain rates constrained from corrected volumetric strain measurements but is within the absolute error of the measurements.

Figure 18. Normalized volumetric strain rates for samples with $\phi_{o} \approx 10 \%$. Data normalized to $\sigma_{m}^{\text {eff }}=50 \mathrm{MPa}$ using equation (2.4) with $n=3.5$. Also shown volumetric strain rates calculated from equation (2.3) using two different permeability models. WW: $k=\left(\phi^{3} \mathrm{~d}^{2}\right) / 300$ [Wark and Watson, 1998]. vBW: $k=\left(\phi^{2} \mathrm{~d}^{2}\right) / 1250$ [von Bargen and Waff, 1986]. Hydrostatic compaction data from Renner et al., [2003] shown for comparison.

Figure 19. Experimental values for the ratio of bulk to shear viscosity. Viscosity ratios constrained from average volumetric compaction rates $\left(\dot{\varepsilon}_{v_{T}}^{\text {img }}\right)$ for samples that dilated (CSR-2, CSR-4, and CSR-9), from corrected volumometer data for CSR-6 and CSR-7, and from the average compaction rate inferred for the creep portion MXD-16. The ratio of bulk to shear viscosity increases as melt fraction decreases.

Figure 20. Sample compaction lengths calculated using the McKenzie [1984] model of compaction and the permeability model of Wark and Watson [1997]. Compaction lengths calculated using average volumetric compaction rates $\left(\dot{\varepsilon}_{v_{T}}^{\text {img }}\right)$ for samples that dilated (CSR-2, CSR-4, and CSR-9), corrected volumometer data for CSR-6 and CSR-7, and the average compaction rate inferred for the creep portion MXD-16. We also show the range of sample lengths. Compaction length generally increases as a function of melt content. We observed dilatation during experiments CSR-2 and CSR-4, two samples with small compaction lengths. There was no volumometer data during CSR-9.

Figure 21. Uncorrected and corrected volumetric strain measurements for a) CSR6 and b) CSR-7. The uncorrected volumetric strain data overestimate compaction by over $2 \%$ for CSR-6 and 3.5\% for CSR-7 based on image analysis. Data for CSR-6 is corrected using (2.25), and data for CSR-7 is corrected using (2.26) and (2.27). 
Figure 22. Relative sample weakening as a function of melt fraction. Data are scaled to $50 \mathrm{MPa}$ differential stress and $15 \mu \mathrm{m}$ grain size using a stress exponent $n$ and grain size exponent $m$ indicated in each panel. Shear viscosities are normalized to a nominally melt free viscosity. Data for melt fraction less than $4.5 \%$ use the average melt fractions measured from image analysis before and after deformation (CSR-2, CSR-4, CSR-9 and CSR-10). For data above 4.5\%, melt content is estimated using the volumometer data (CSR-6 and CSR-7). (A) the entire dataset and (b) CSR-6 and CSR-7 data normalized using a diffusion creep rheology. The CK (2.38) and HK-diffusion (2.39) models are shown for comparison. In addition, we show the best exponential $\alpha$ fit to the data. Dislocation creep accommodated grain boundary sliding normalized viscosities for (a) the entire dataset and (b) CSR-6 and CSR-7. The HK-dislocation model (2.40) is compared to the exponential $\alpha$ fit. Dislocation creep normalized for (a) the entire data set and (b) CSR-6 and CSR-7. HK-dislocation model and exponential $\alpha$ fit shown for comparison.

Figure 23. Comparison between shear viscosity from drained deformation experiments and flow-laws. We normalize data to a differential stress of $50 \mathrm{MPa}$ using a stress exponent $n=3.5$ for dislocation creep (DISL, red squares) and dislocation accommodated grain boundary sliding (GBS, blue diamonds) and $n=1$ for diffusion creep (DIFF, green circles). We correct grain size to $15 \mu \mathrm{m}$ using a grain-size exponent $m$ $=0$ for DISL, $m=2$ for GBS, and $m=3$ for DIFF. Flow-laws are plotted using (2.30) and the parameters in Table 6. We show the flow-laws calculated a melt enhancement factor $\alpha$ from undrained (dashed lines) and drained (solid lines) experiments.

Figure 24. Unconfined, drained compaction experiment CSR-1. (a) Sample strain weakens after attaining a peak strength of approximately $32 \mathrm{MPa}$. Optical micrographs (a) before deformation and (b) after deformation. Sample microstructure shows evidence for extreme dilatency during triaxial deformation. Highly reflective features are the epoxy used to impregnate the sample.

Figure 25. Sample images of a high-temperature shear zone. (a) Macroscopic image of sample. The trace of a thin, light shear zone can be followed from the top-right to lower-left corners of the sample. The olivine and melt aggregate can be clearly see to have extruded more into the carbon bead reservoir on the right-hand size of the image indicating a left-lateral sense of shear. Ruler is marked in centimeters increments. (b) Sample micrograph. Initial melt fraction of the sample was $\sim 15 \%$. A fine grained, cohesive $\sim 100 \mu \mathrm{m}$ width shear zone runs through the center of the image. The sense of shear is indicated. Around the central shear zone the aggregate appears to have developed extensive dilatational features.

Figure 26. Mechanical data for CRP-15. Sample is deformed at relatively low stress for approximately $100 \mathrm{~s}$ before the start of the attempted creep test. (a) Differential stress increases rapidly as the load is applied. After approximately $8 \mathrm{~s}$, the material suddenly weakens suggested the formation of a high-temperature shear zone. Approximate duration of "creep test" indicated by shaded gray region. (b) Strain 
continues to rise as sample looses strength. Approximate strain rate before failure $4.8 \times$ $10^{-3} \mathrm{~s}^{-1}$. 


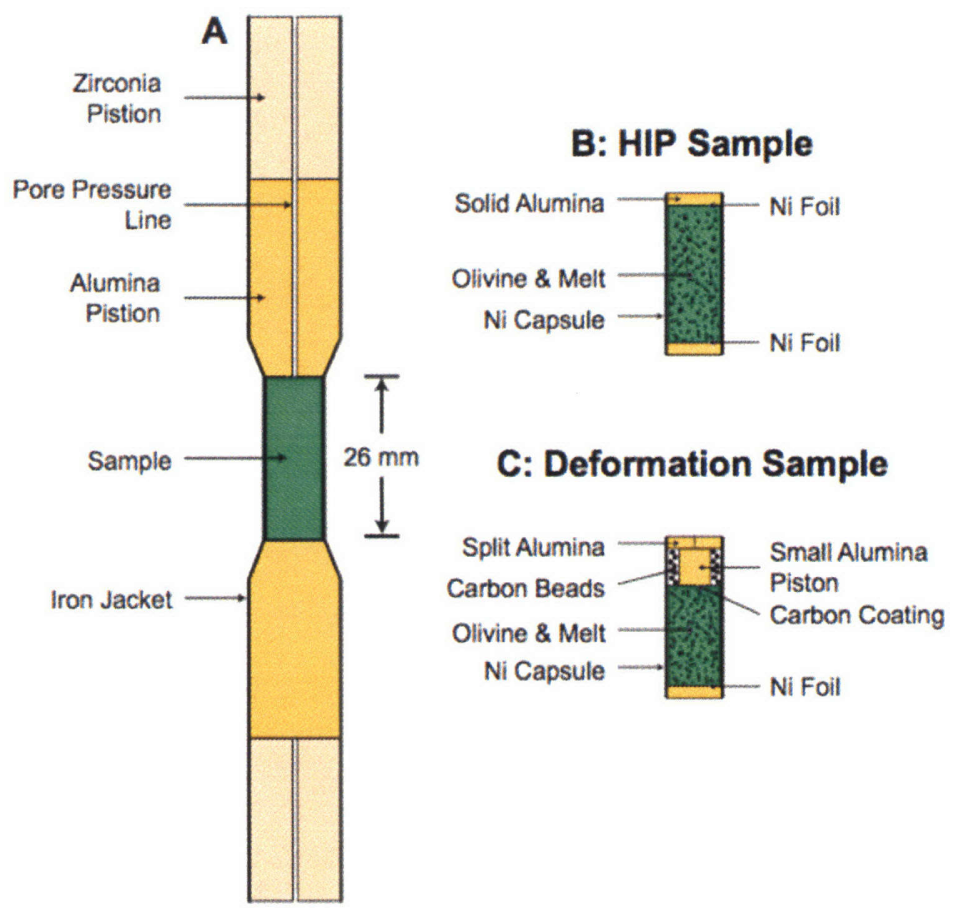

Figure 1. 


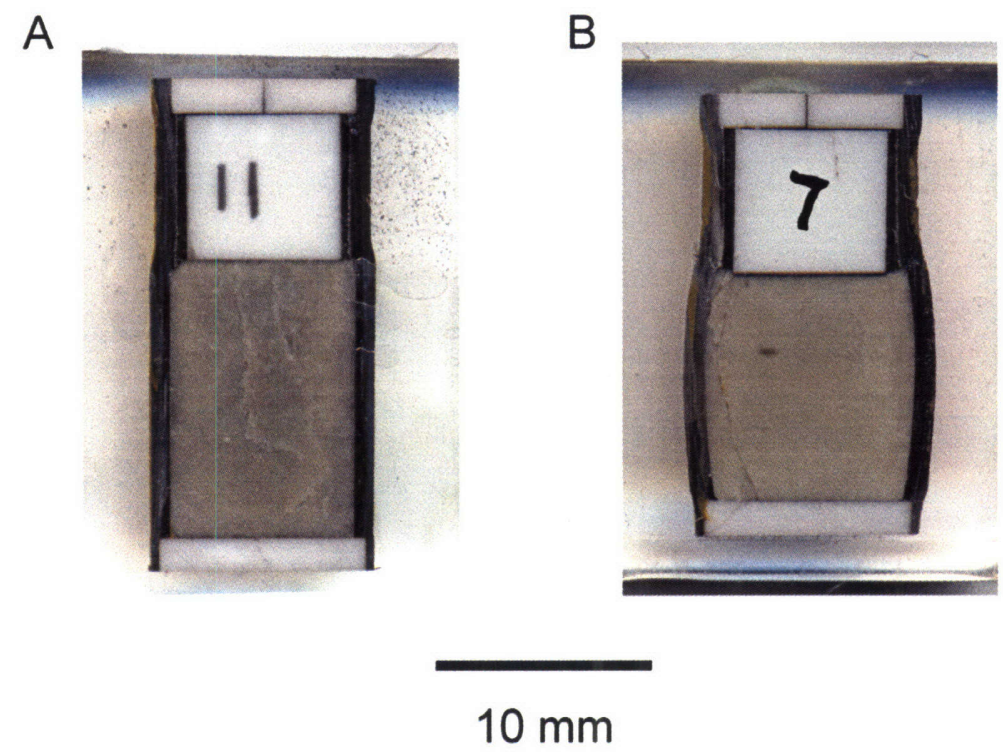

Figure 2. 


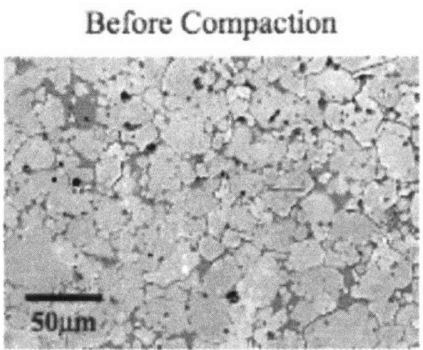

A) HYD $-11, \phi_{0}=9.5 \%$
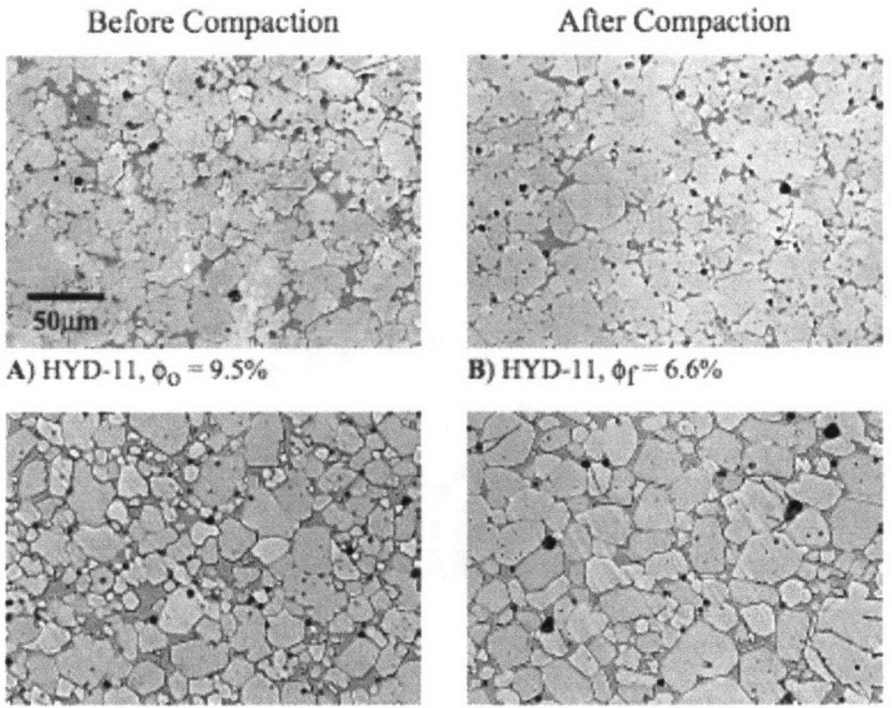

C) HYD $-14, \circ_{0}=13.1 \%$

B) $\mathrm{HYD}-11, \phi_{\mathrm{f}}=6.6 \%$

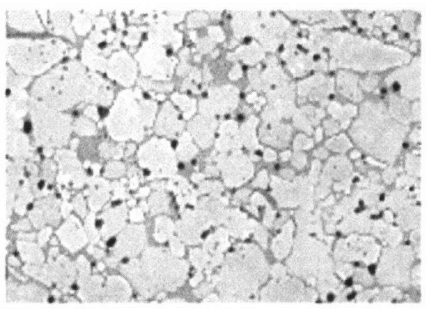

E) CSR-7, $\varphi_{0}=10.0 \%$

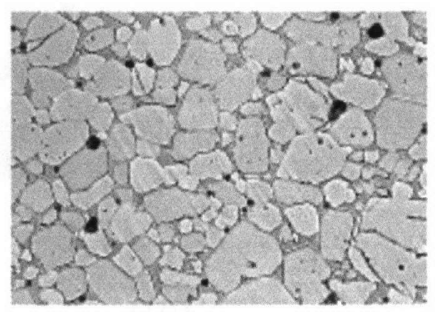

D) HYD-14, $\mathrm{o}_{\mathrm{P}}=7.5 \%$

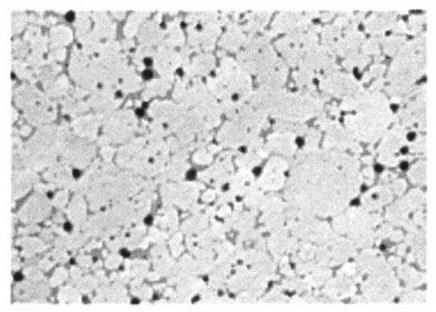

F) CSR $-7, \phi_{\mathrm{f}}=4.9 \%$

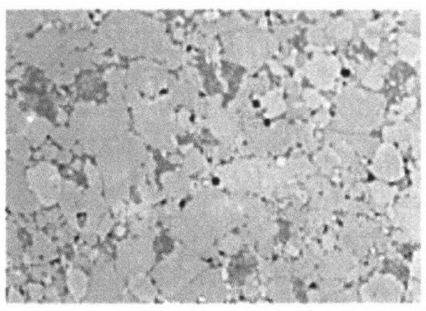

G) CRP-16, $\phi_{0}=14.6 \%$

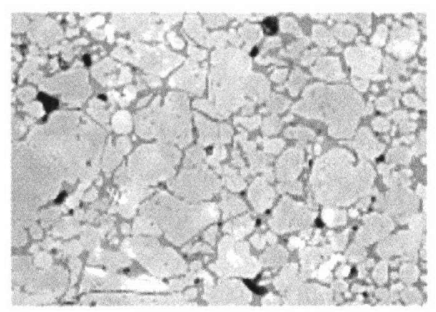

H) CRP- $16, \phi_{f}=8.3 \%$

Figure 3. 

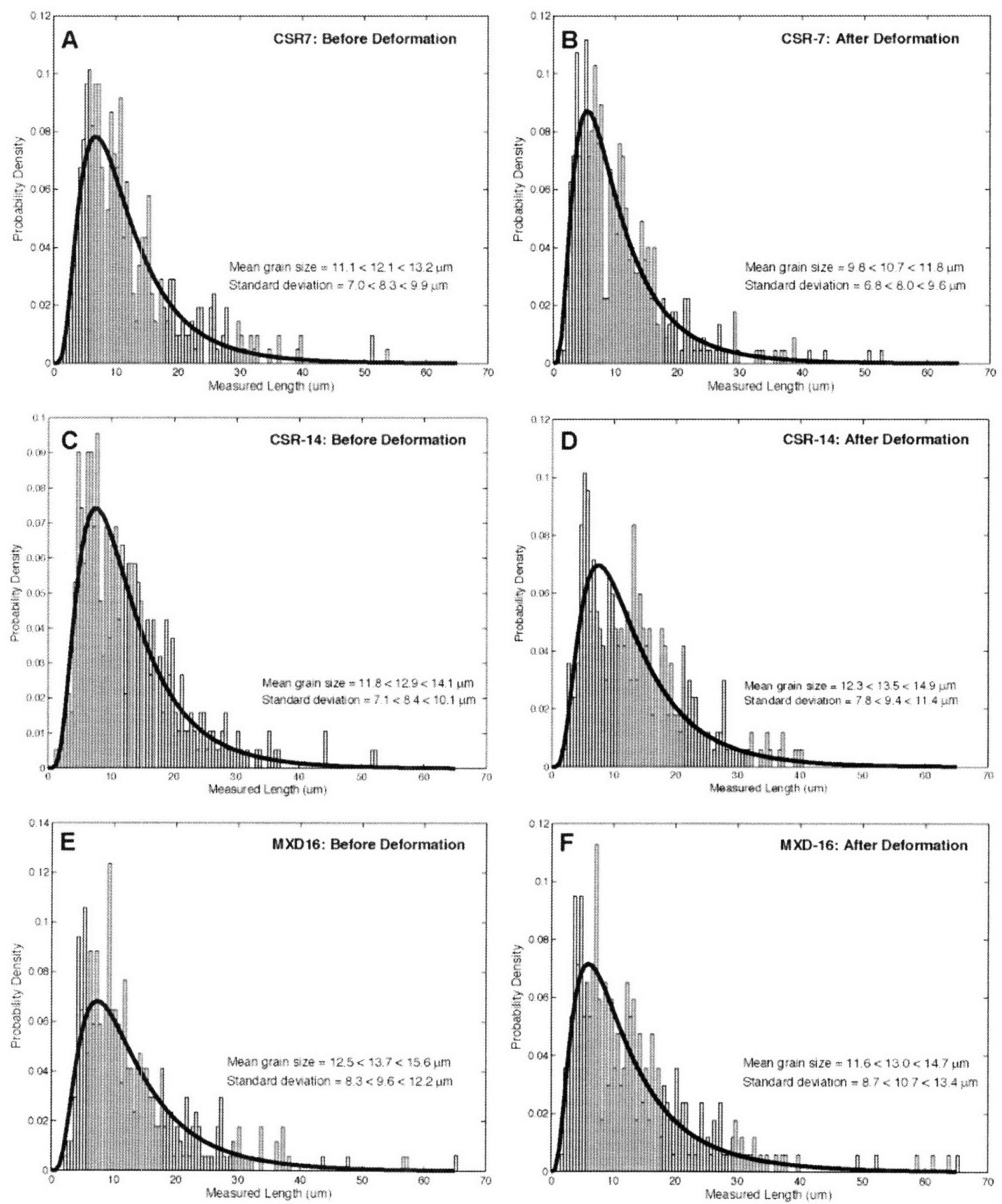

Figure 4. 

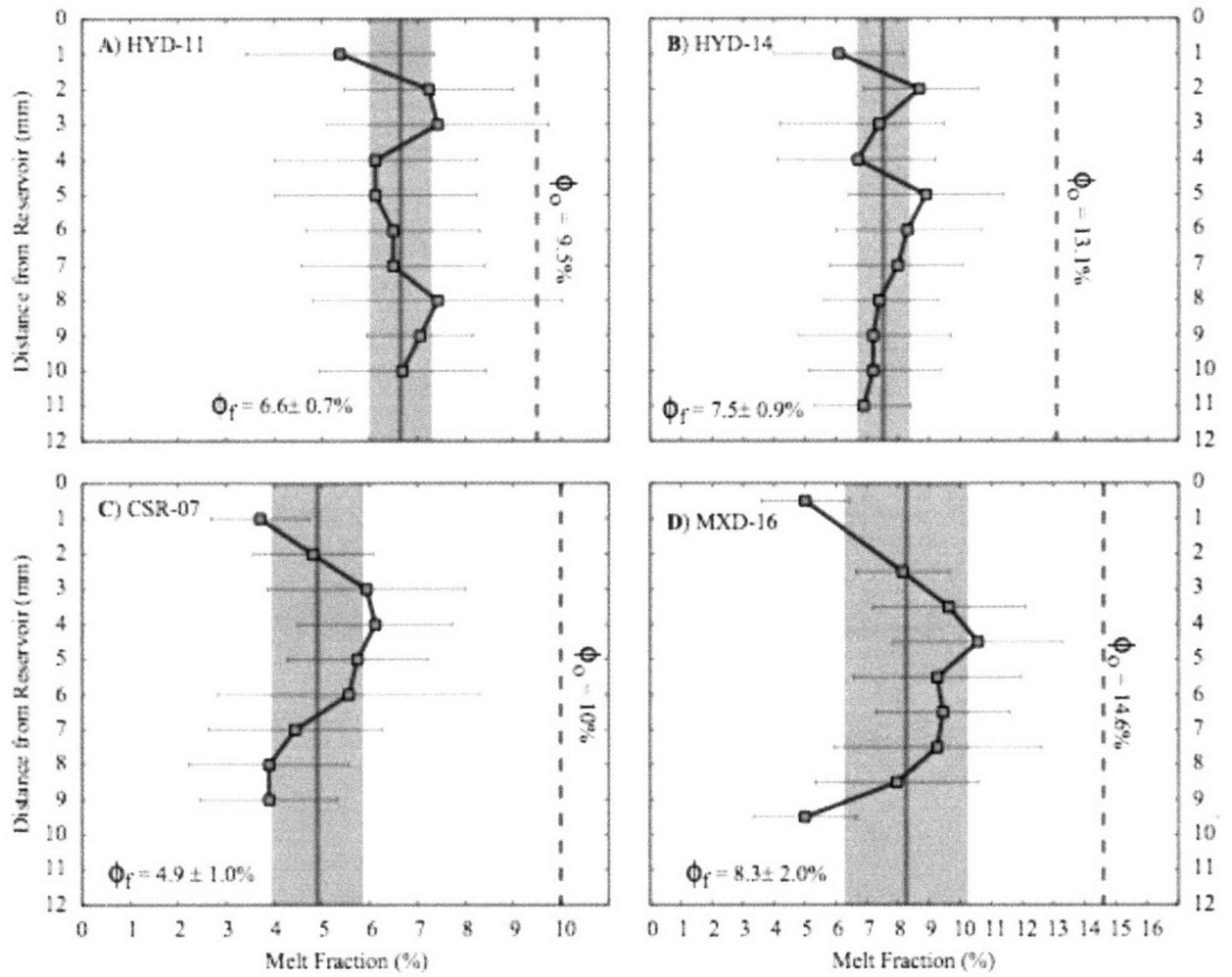

Figure 5. 


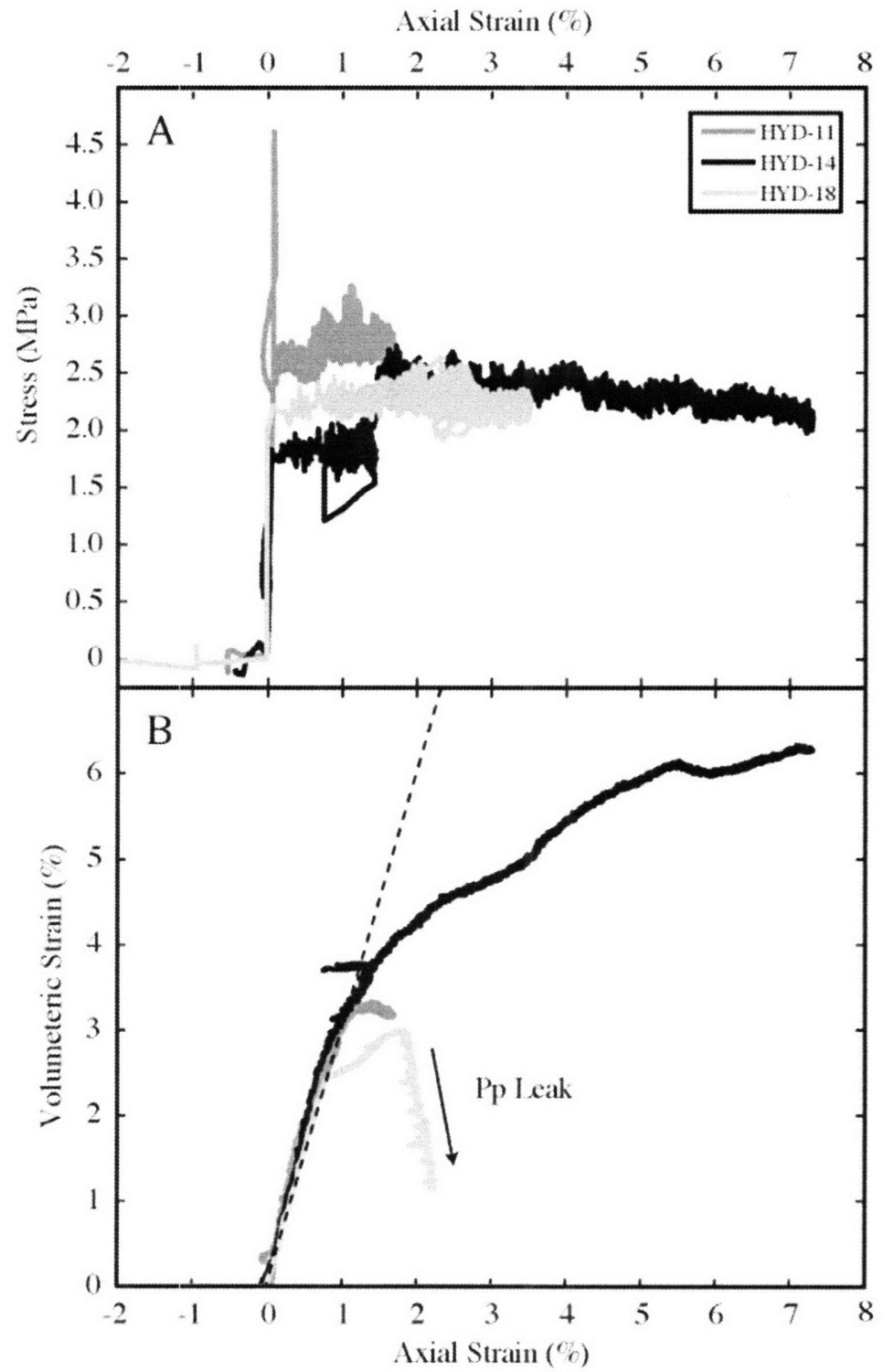

Figure 6. 


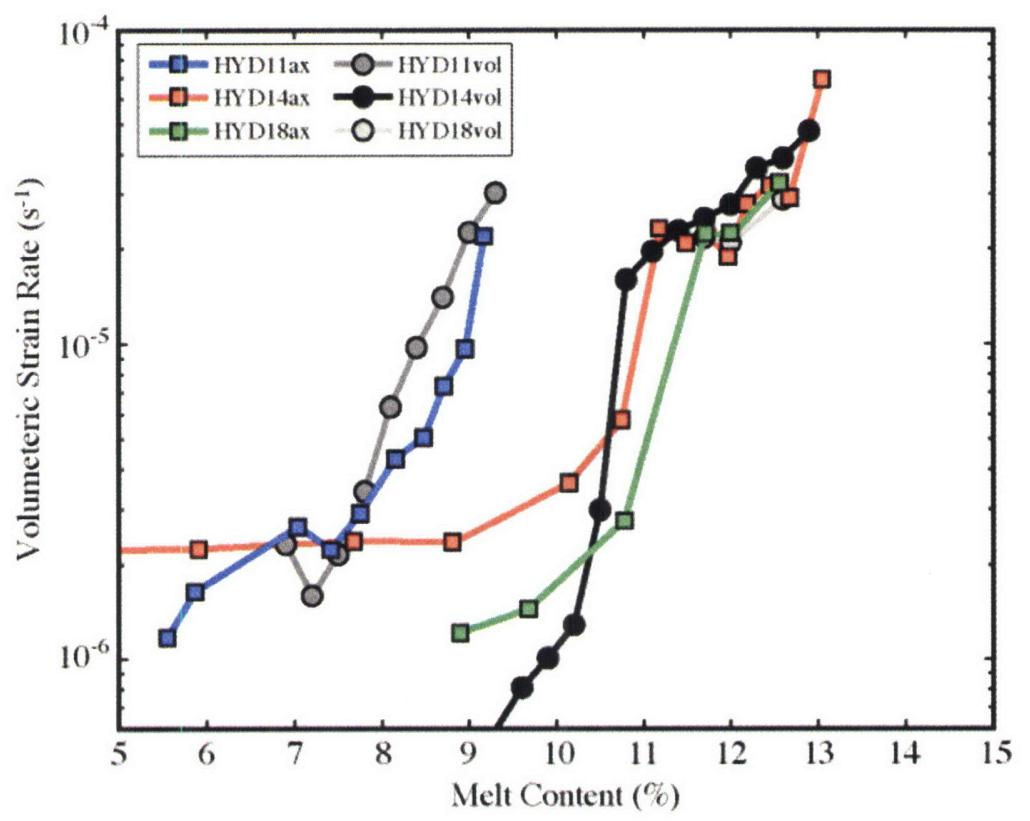

Figure 7. 


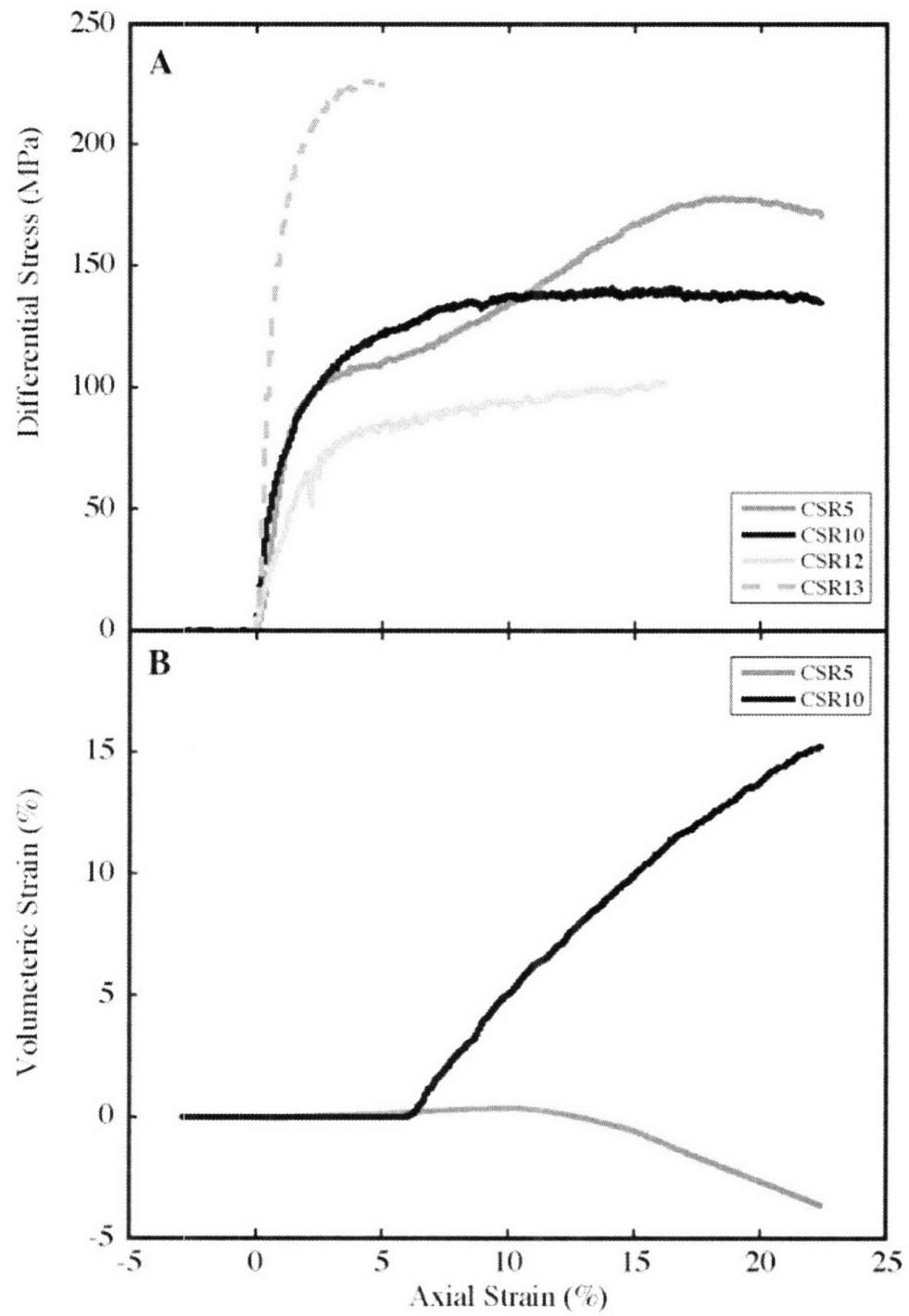

Figure 8. 


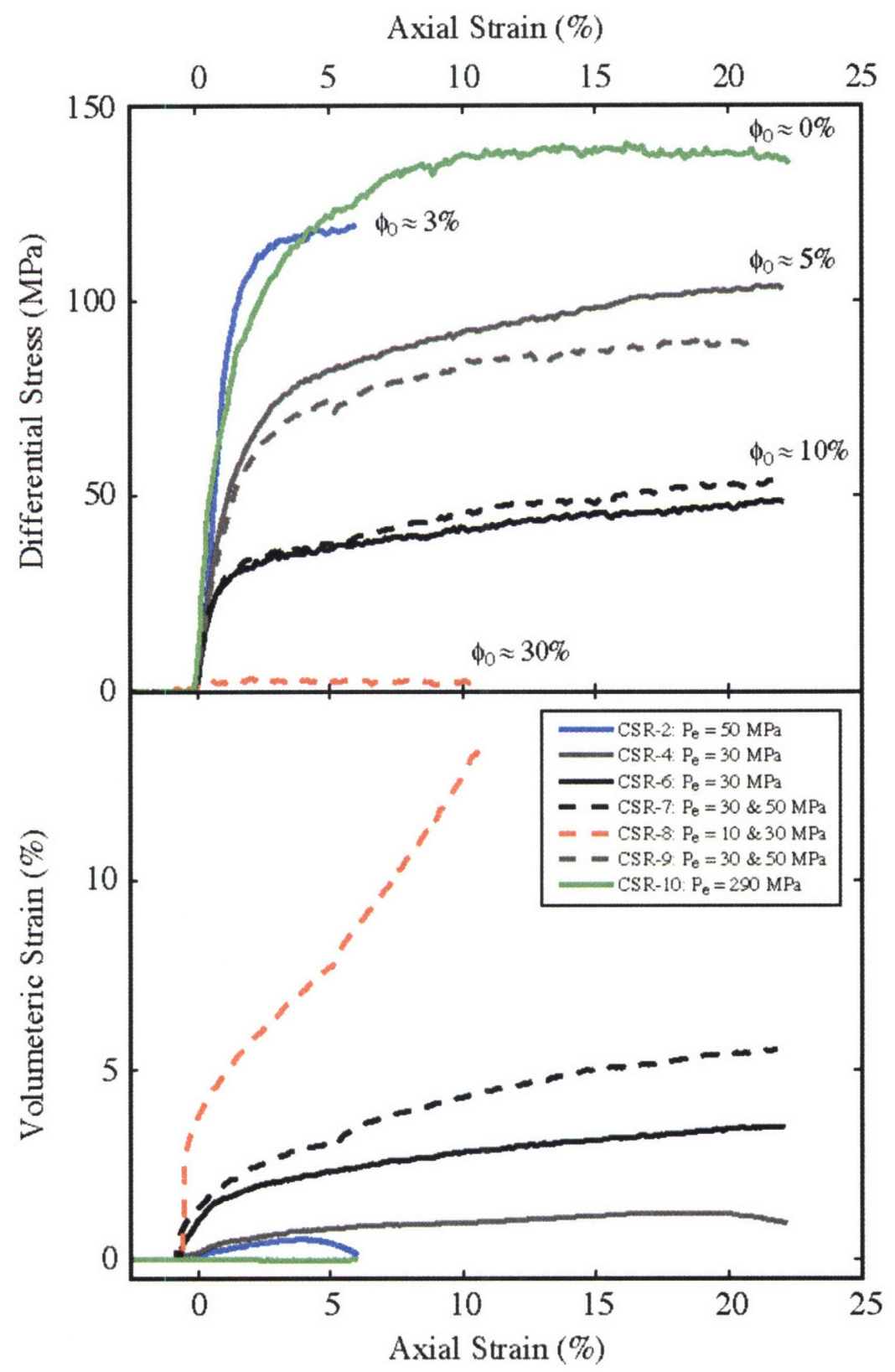

Figure 9. 


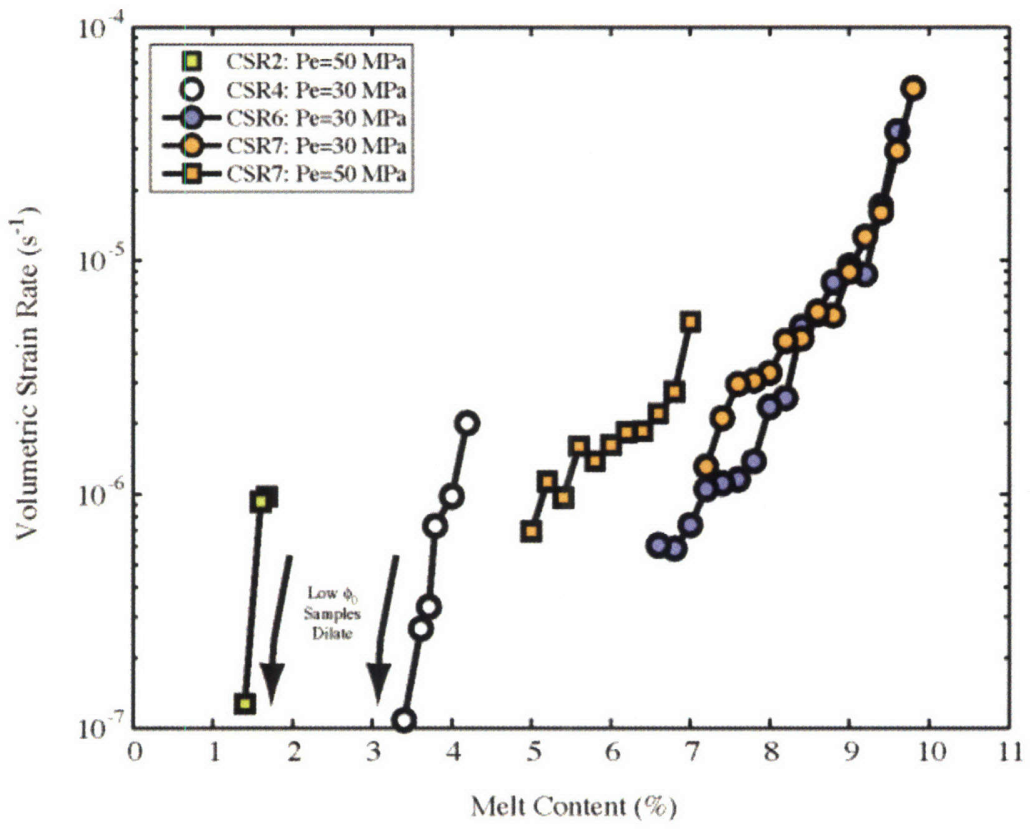

Figure 10. 


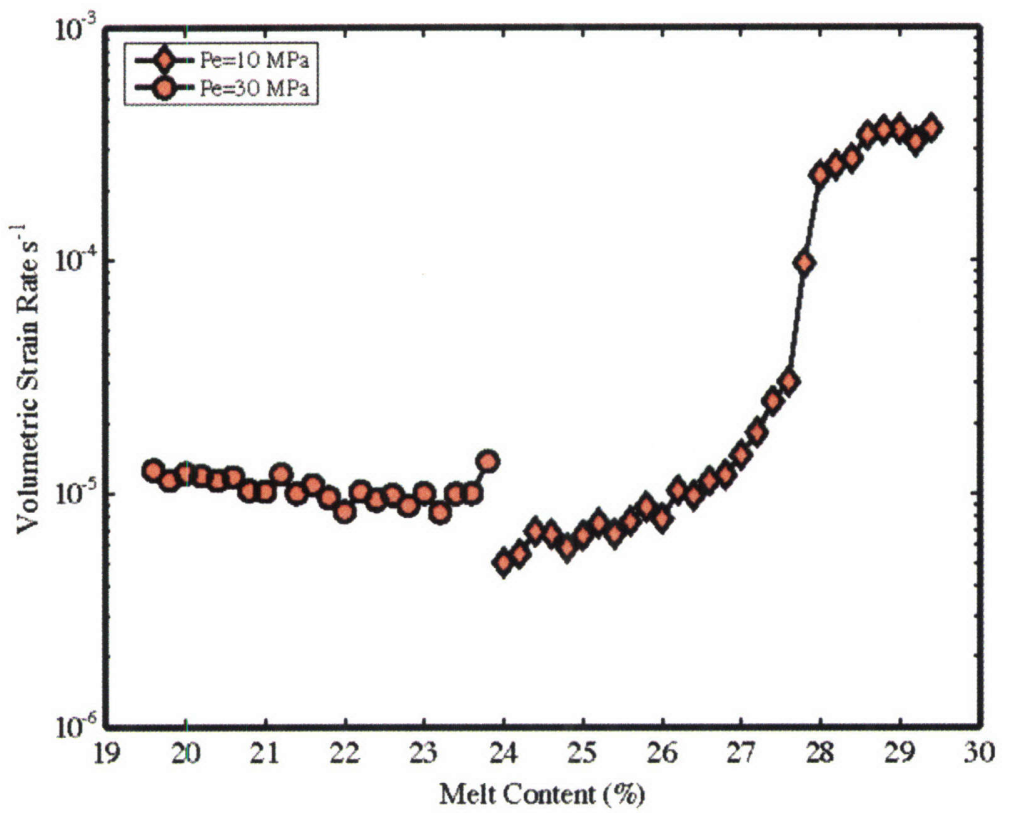

Figure 11.

96 
A) $M X D-16$

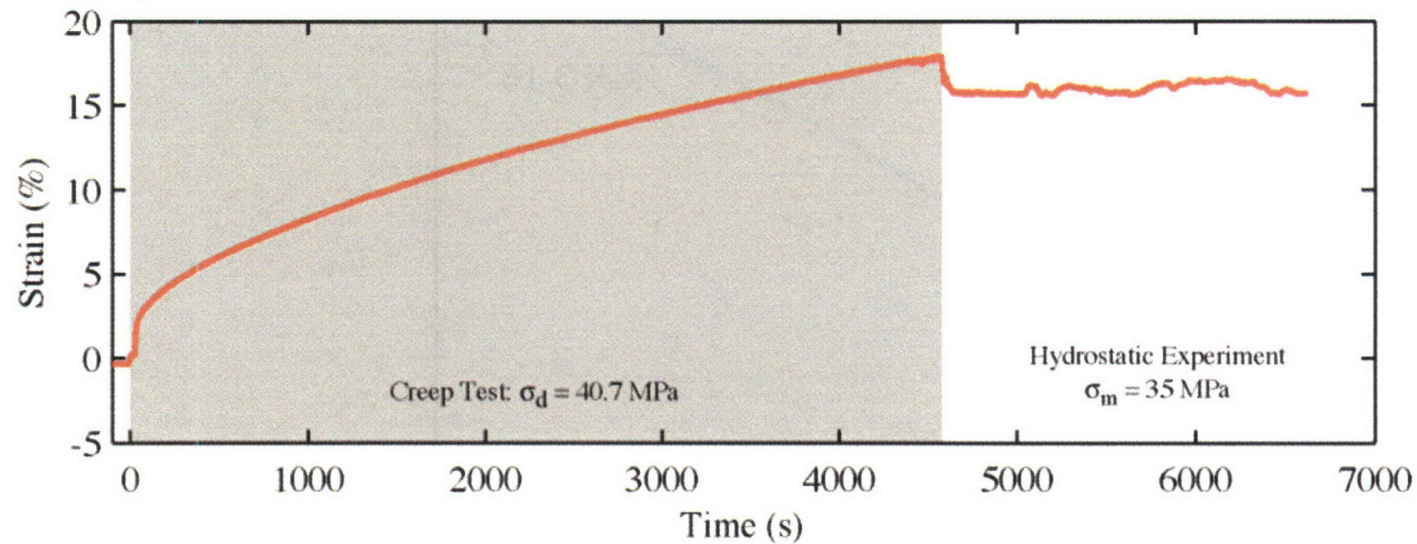

B) MXD- 17

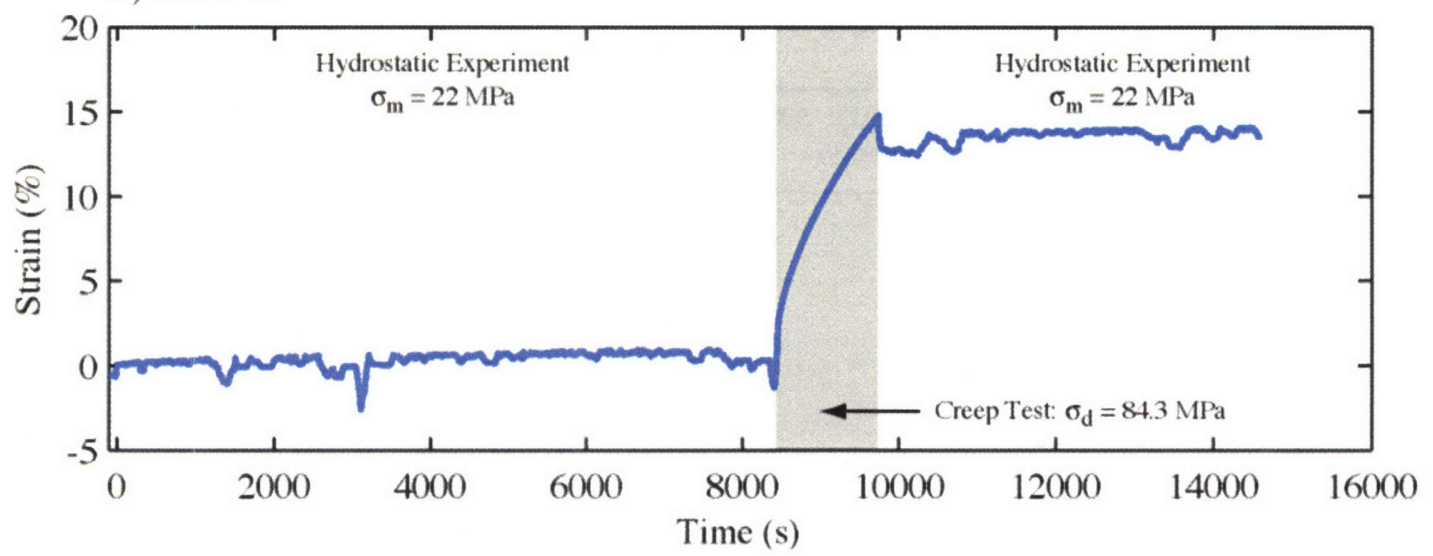

Figure 12. 

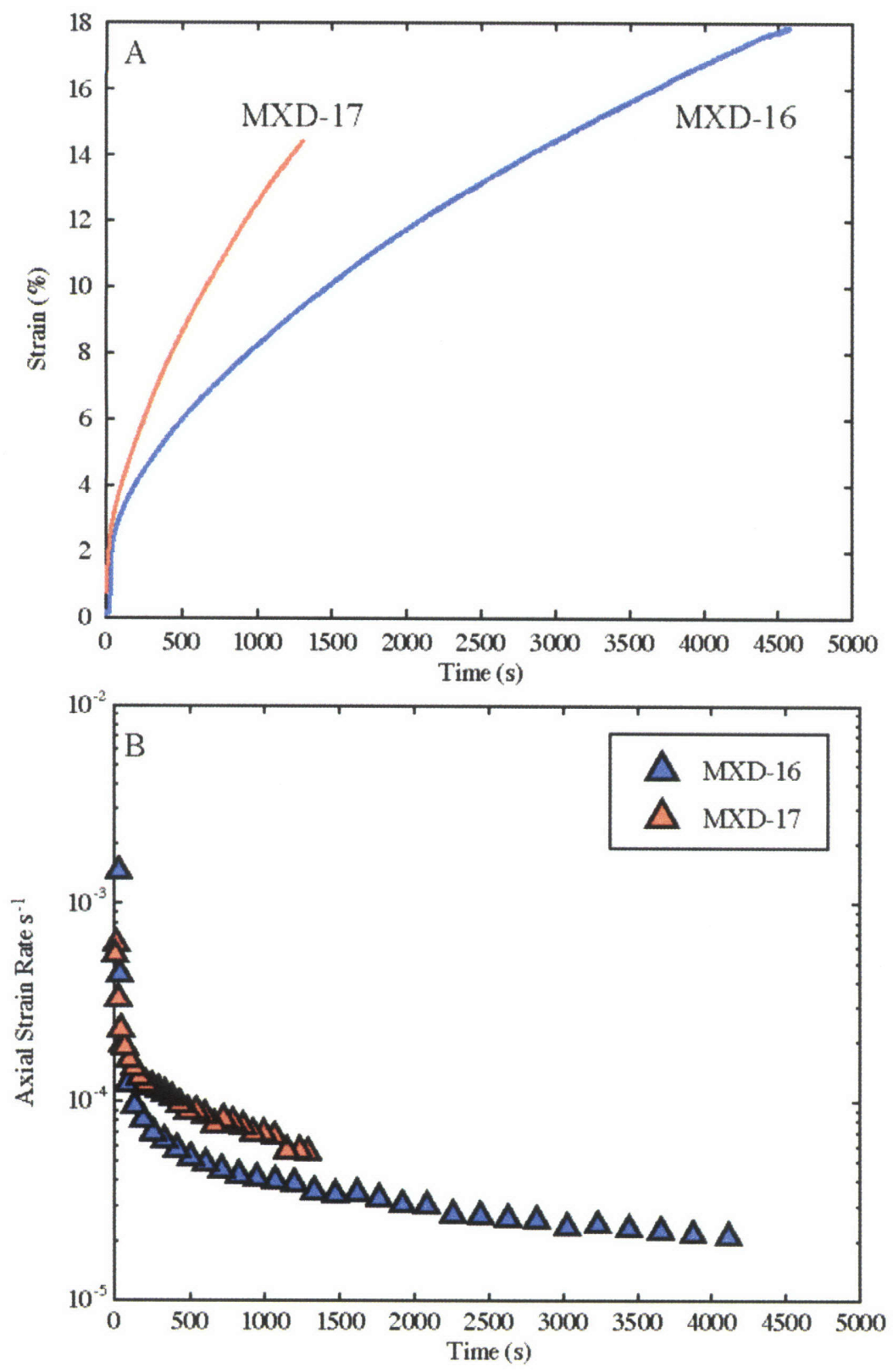

Figure 13. 

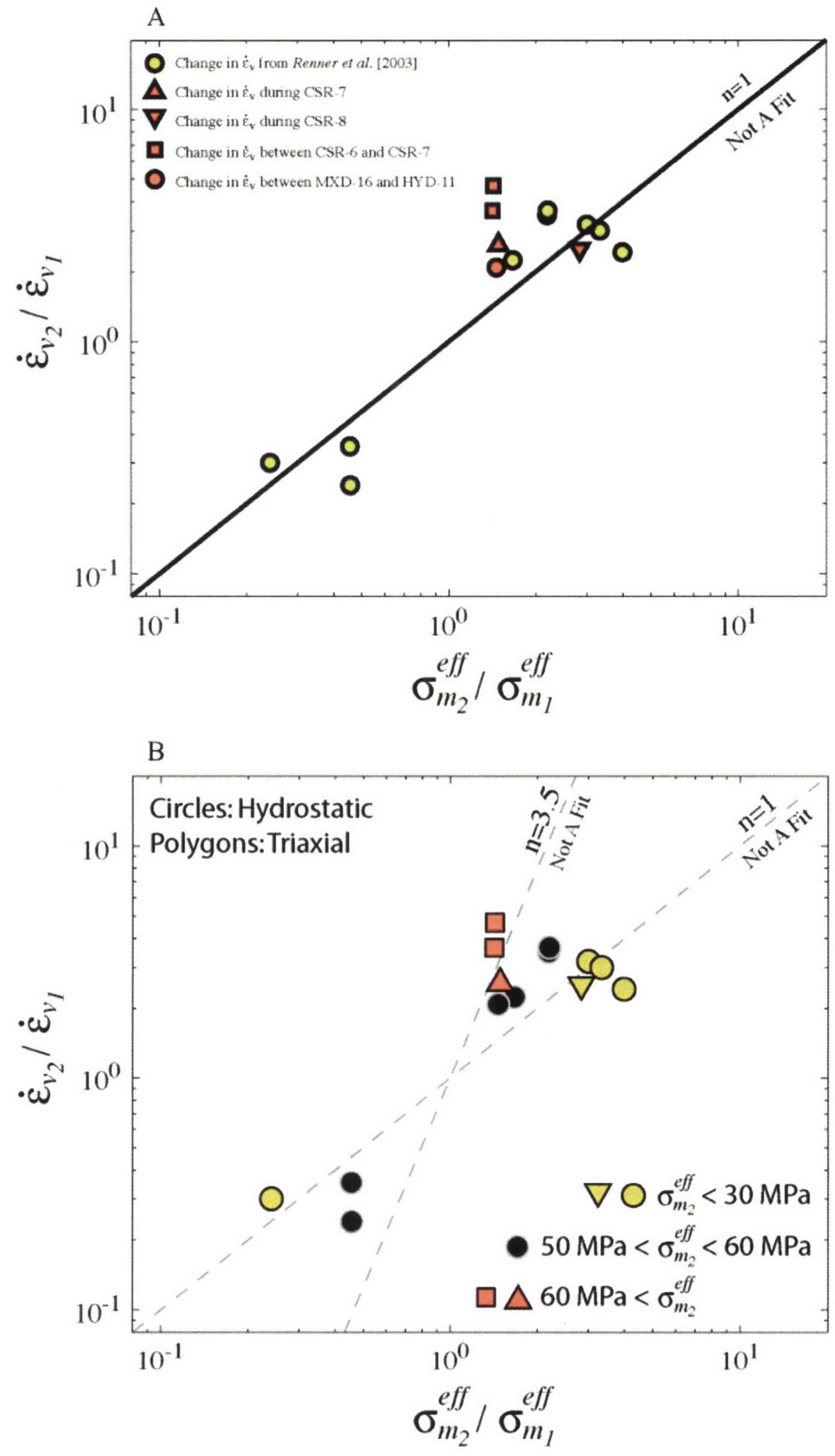

Figure 14. 

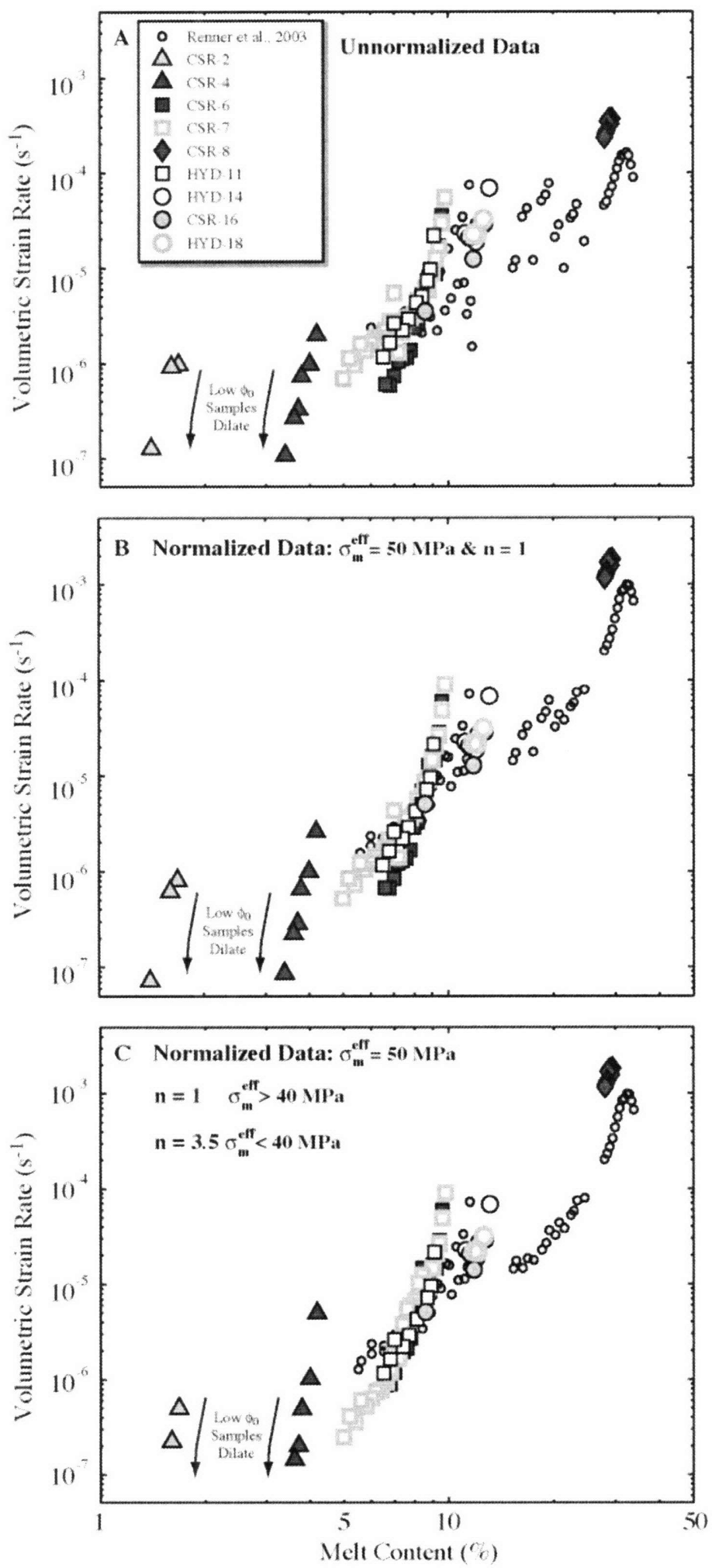

Figure 15. 


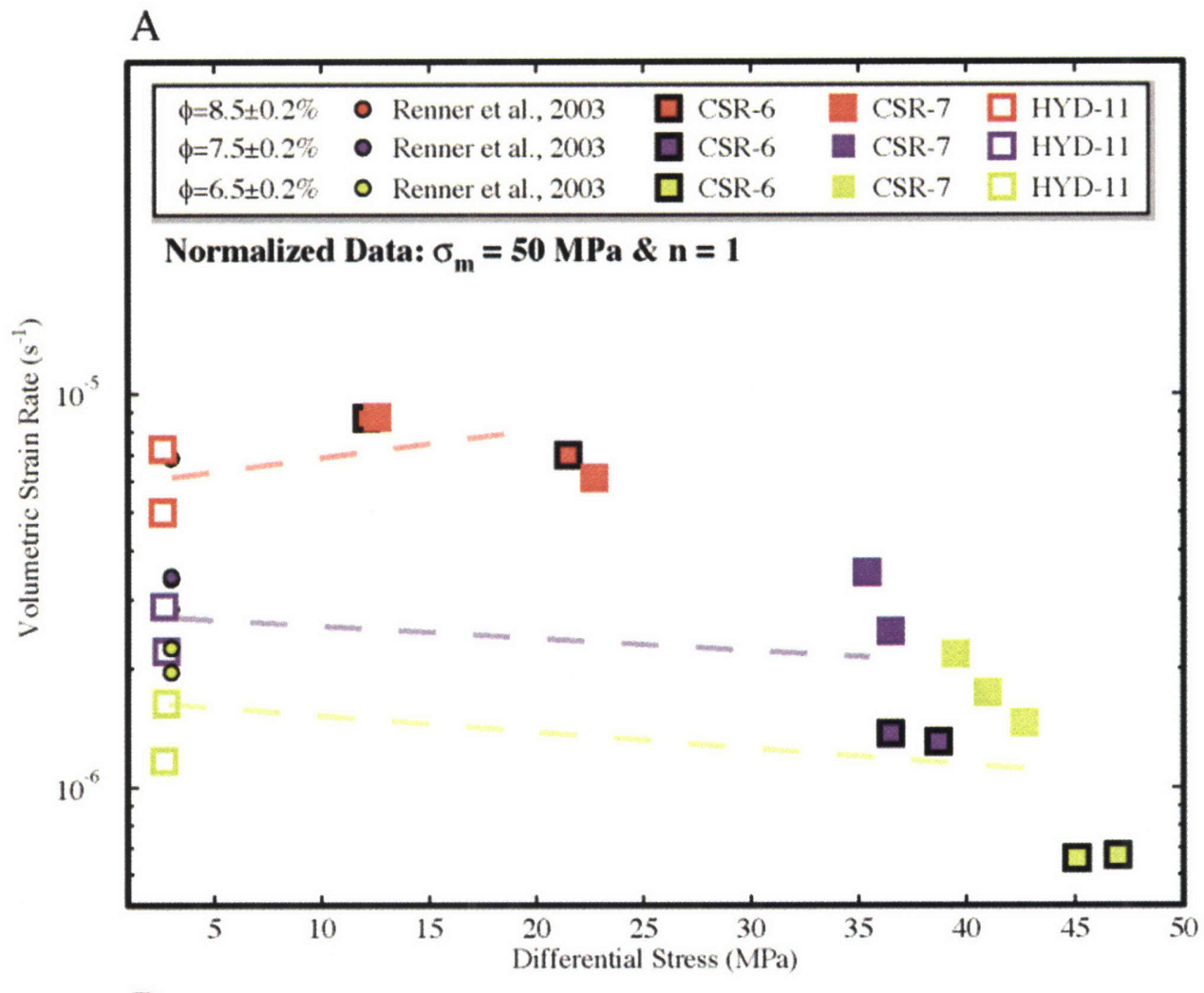

B

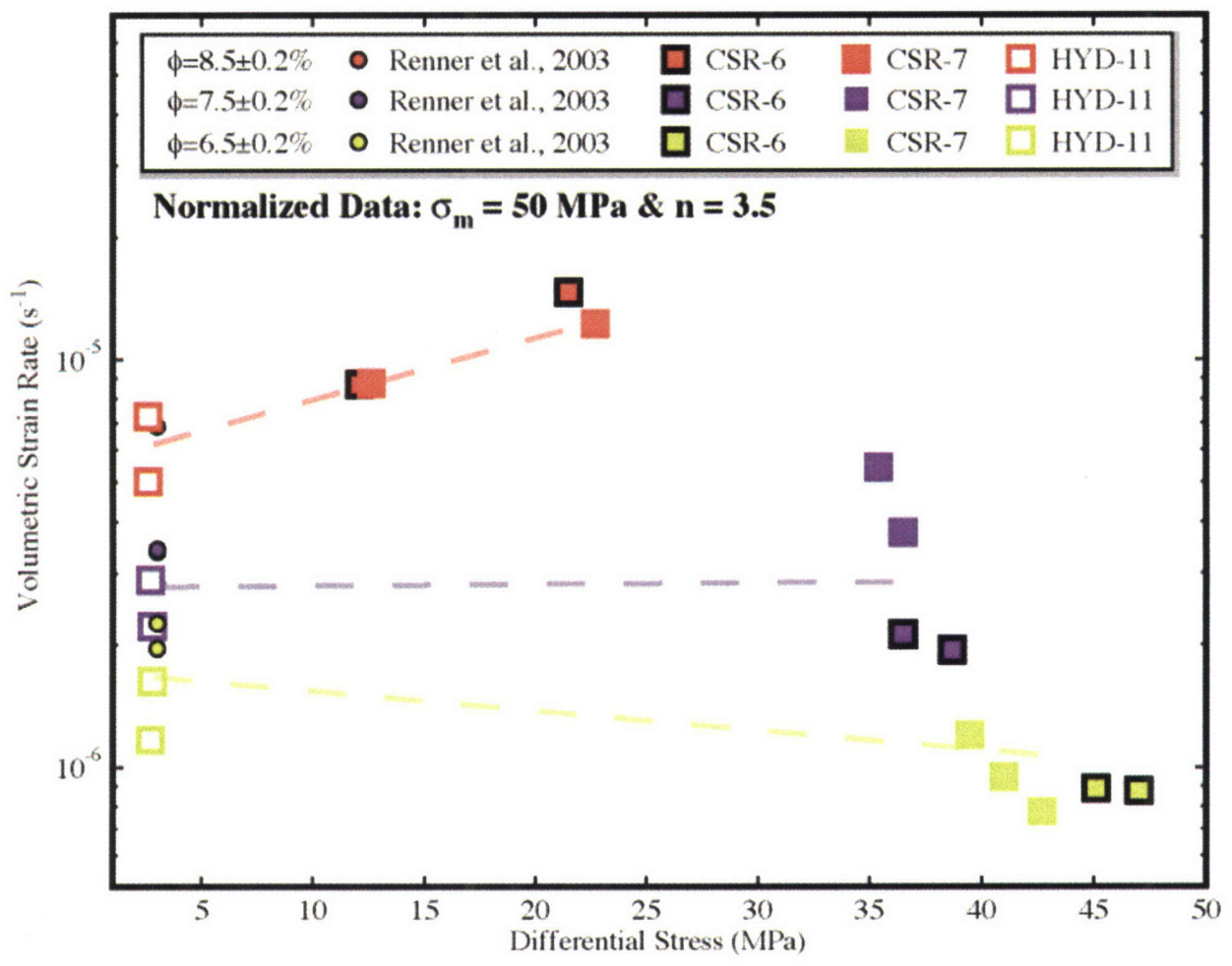

Figure 16. 


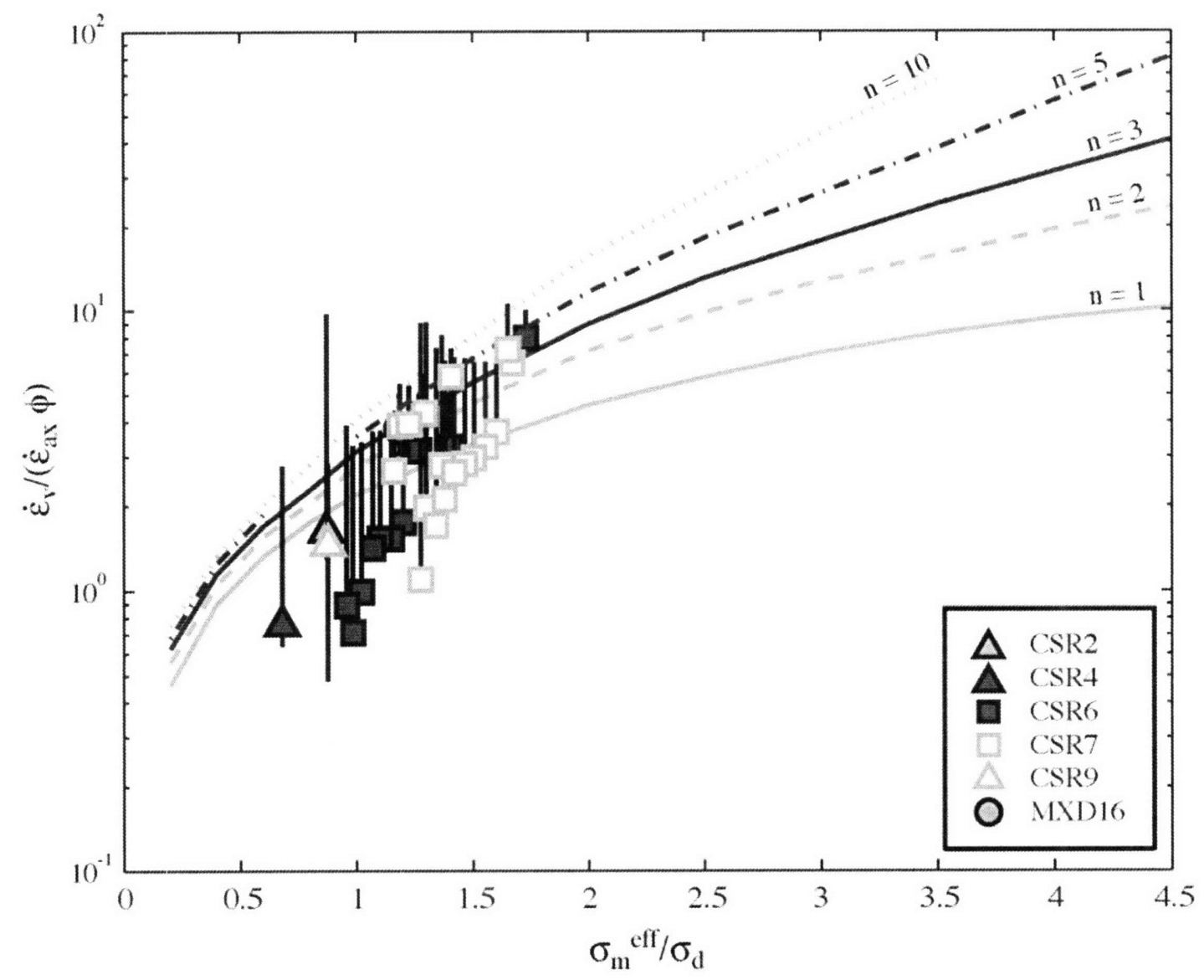

Figure 17. 


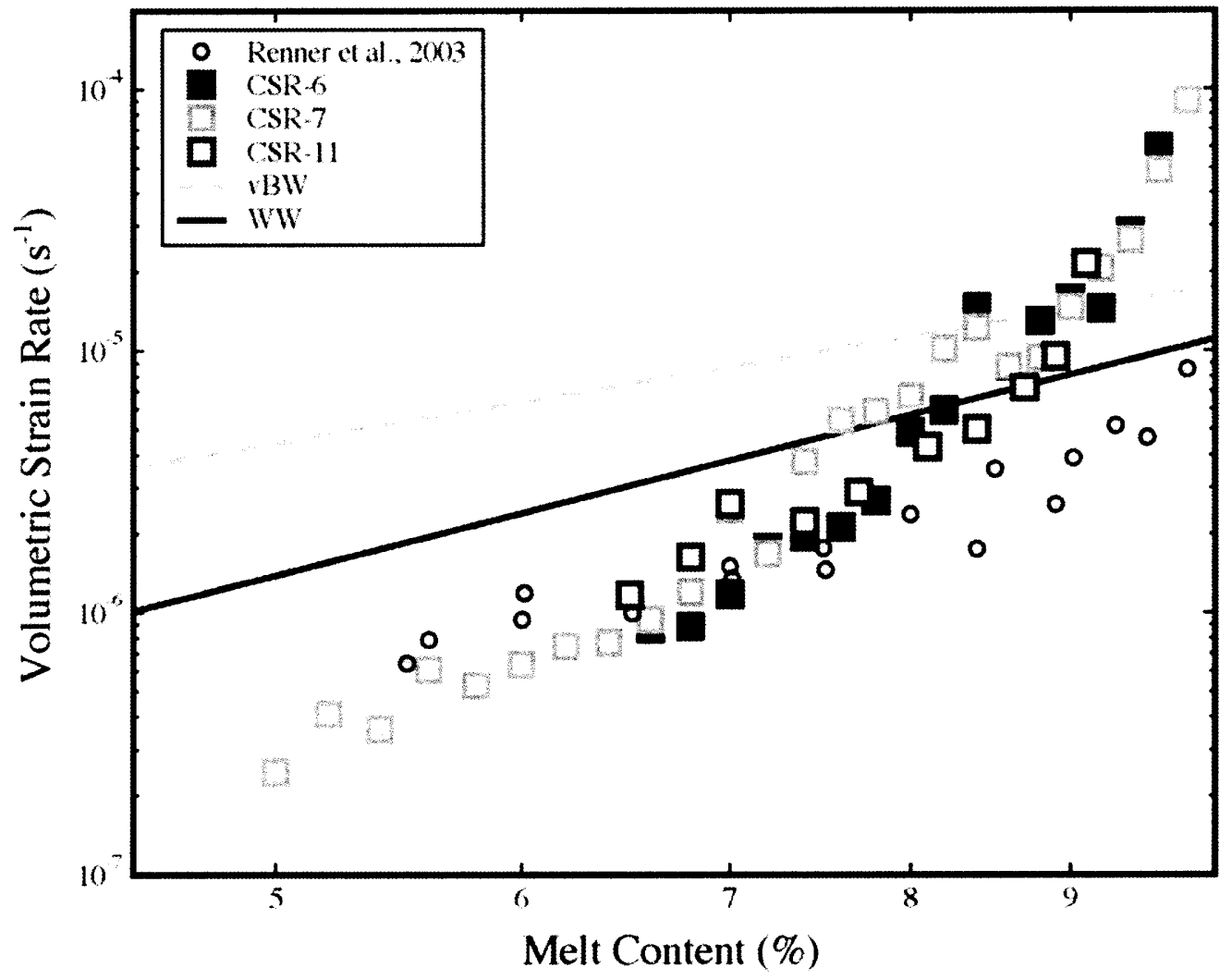

Figure 18. 


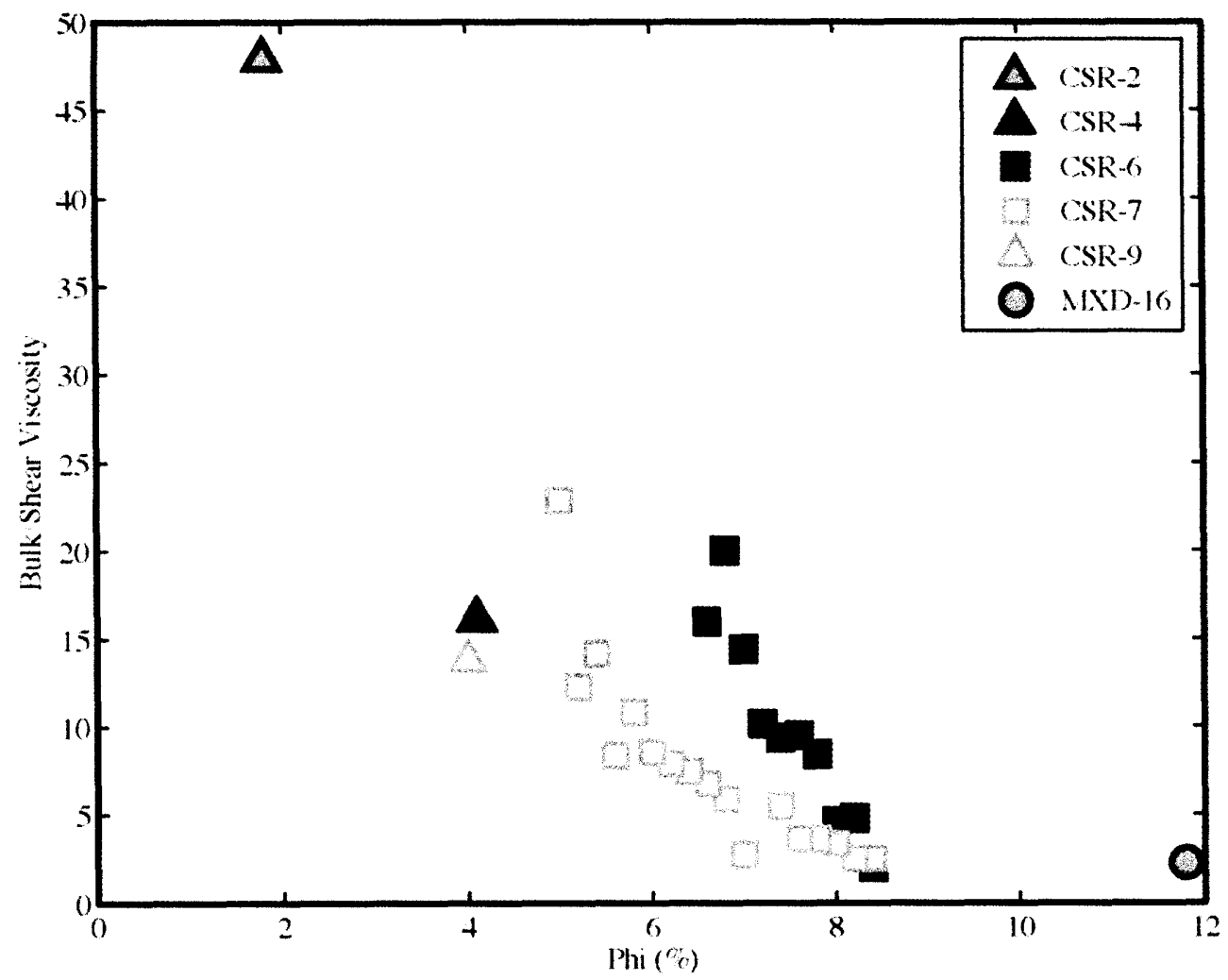

Figure 19. 


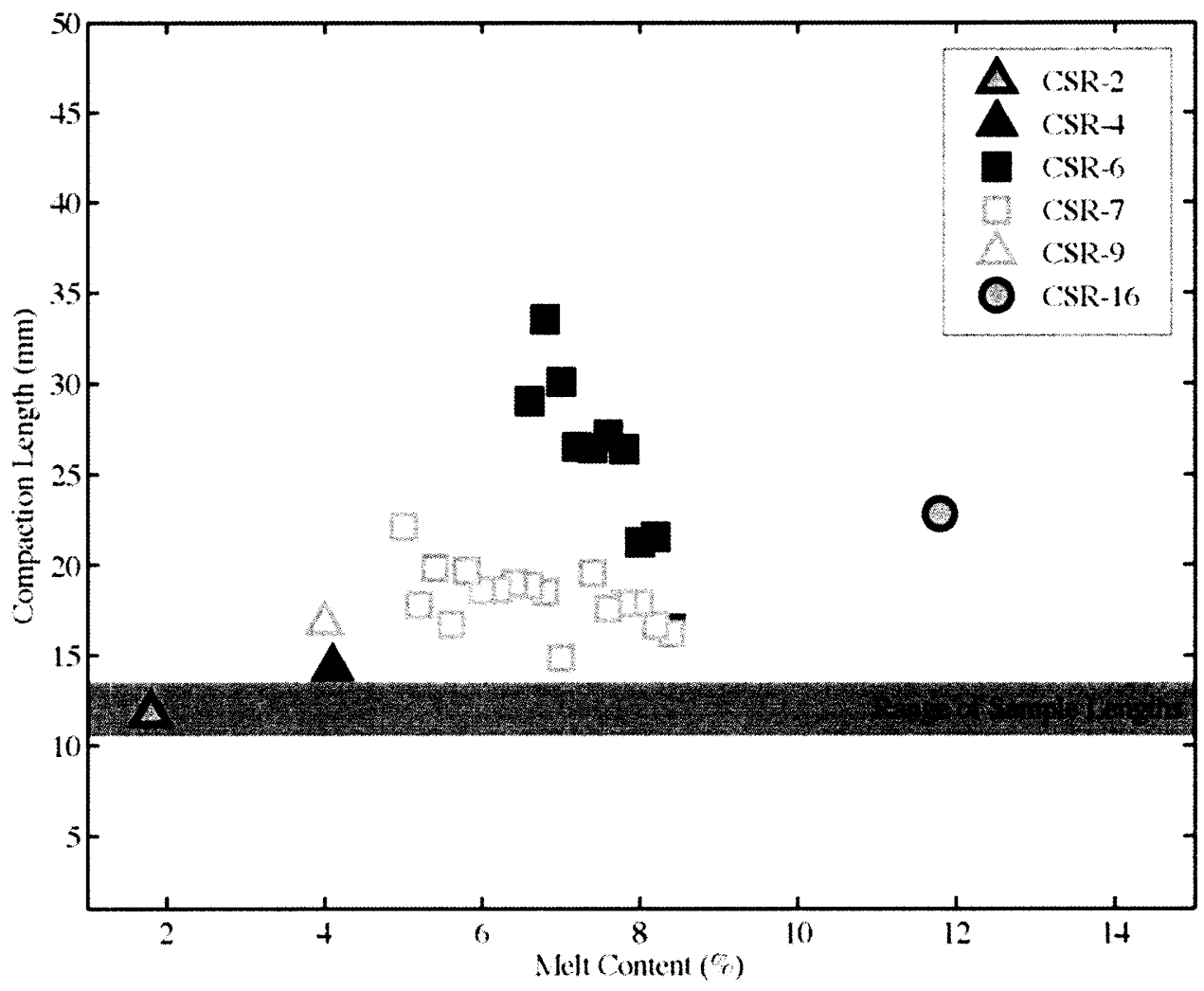

Figure 20. 

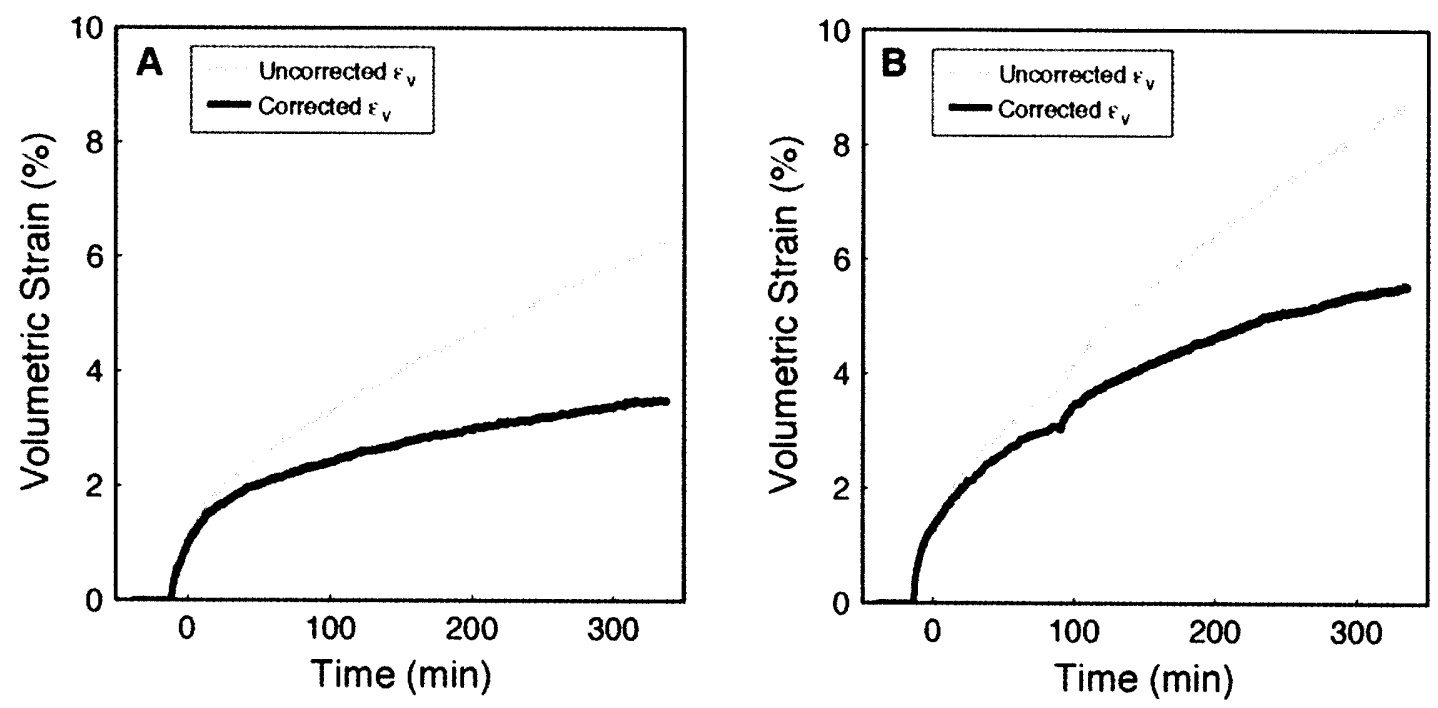

Figure 21 . 

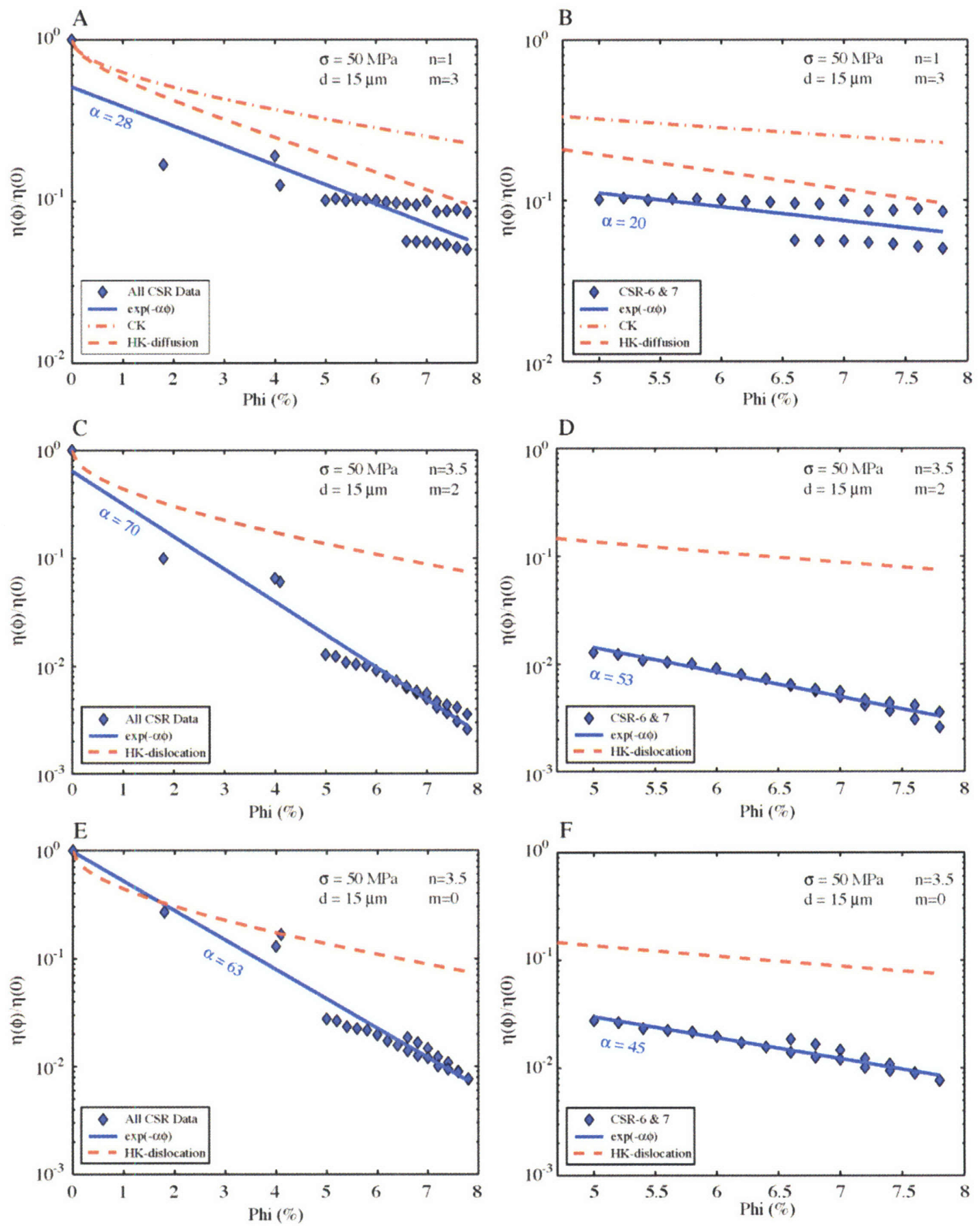

Figure 22. 


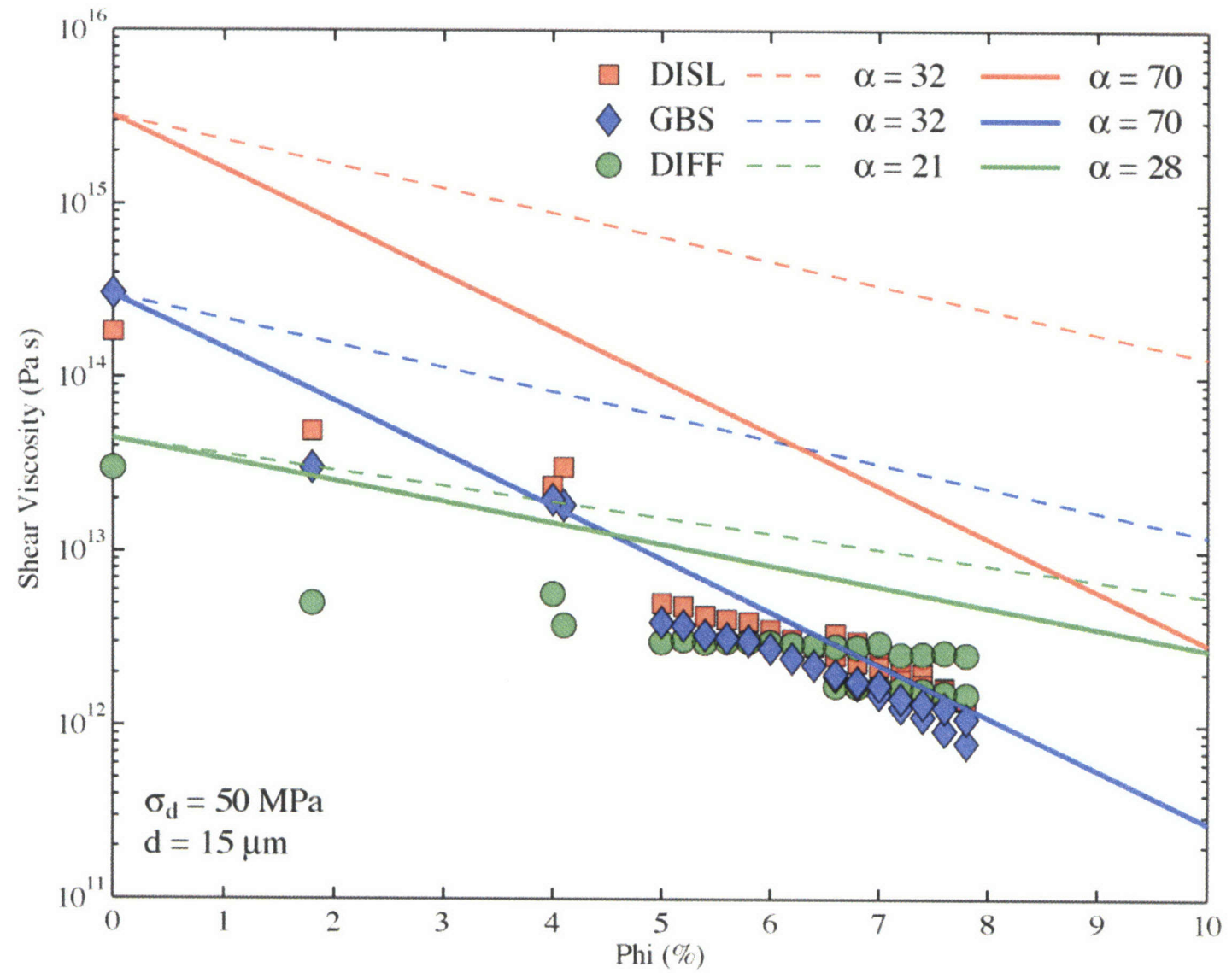

Figure 23. 

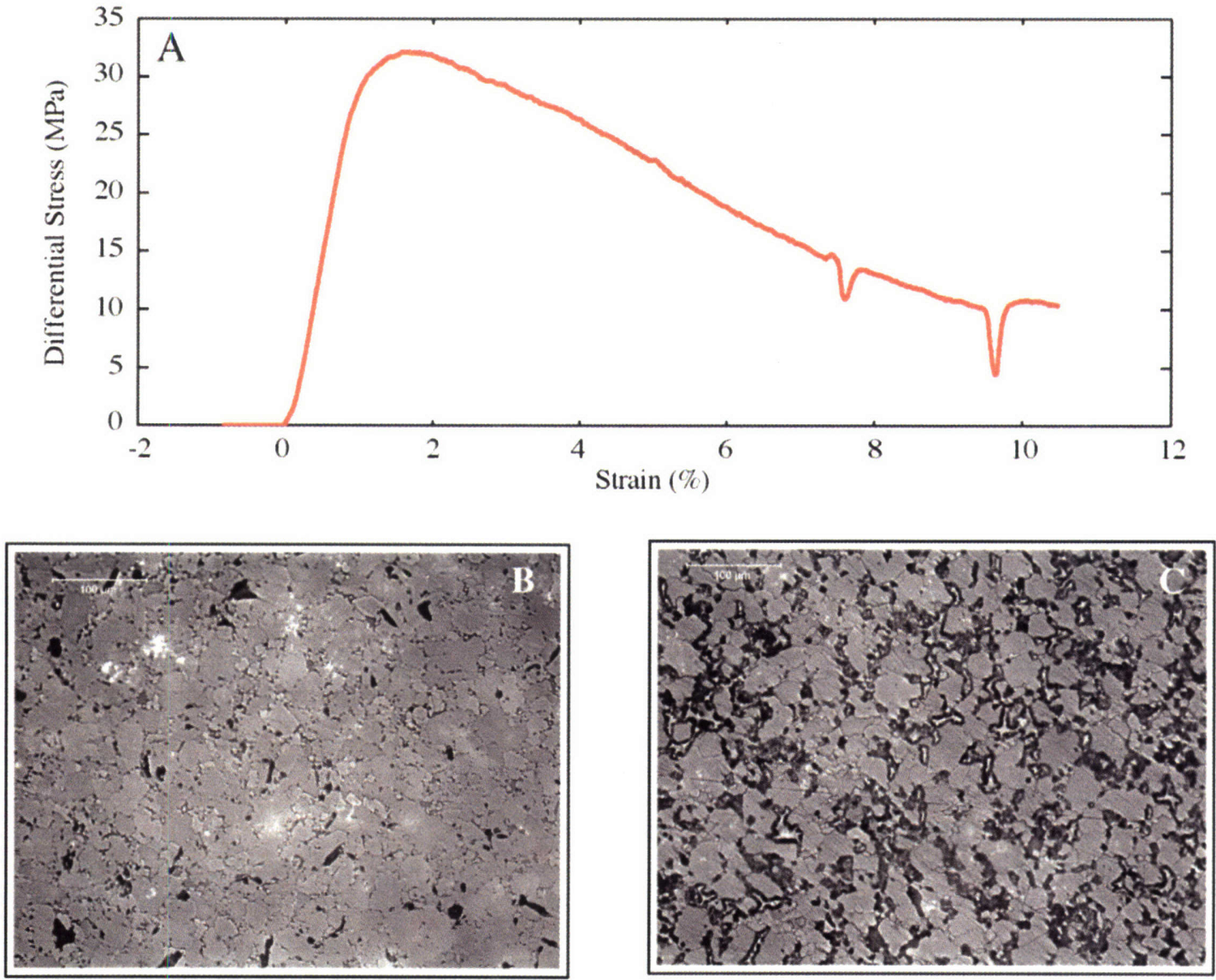

Figure 24. 


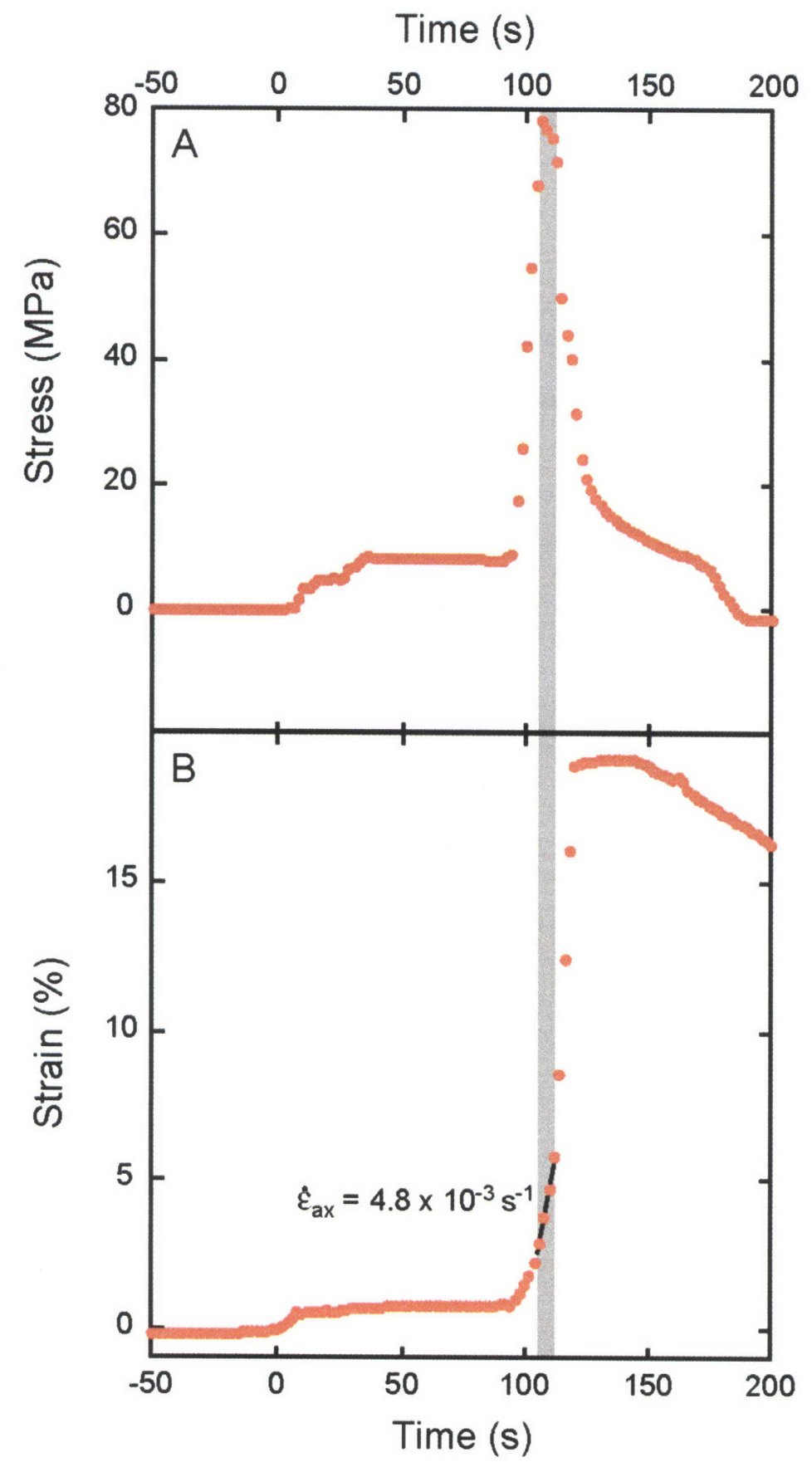

Figure 25. 


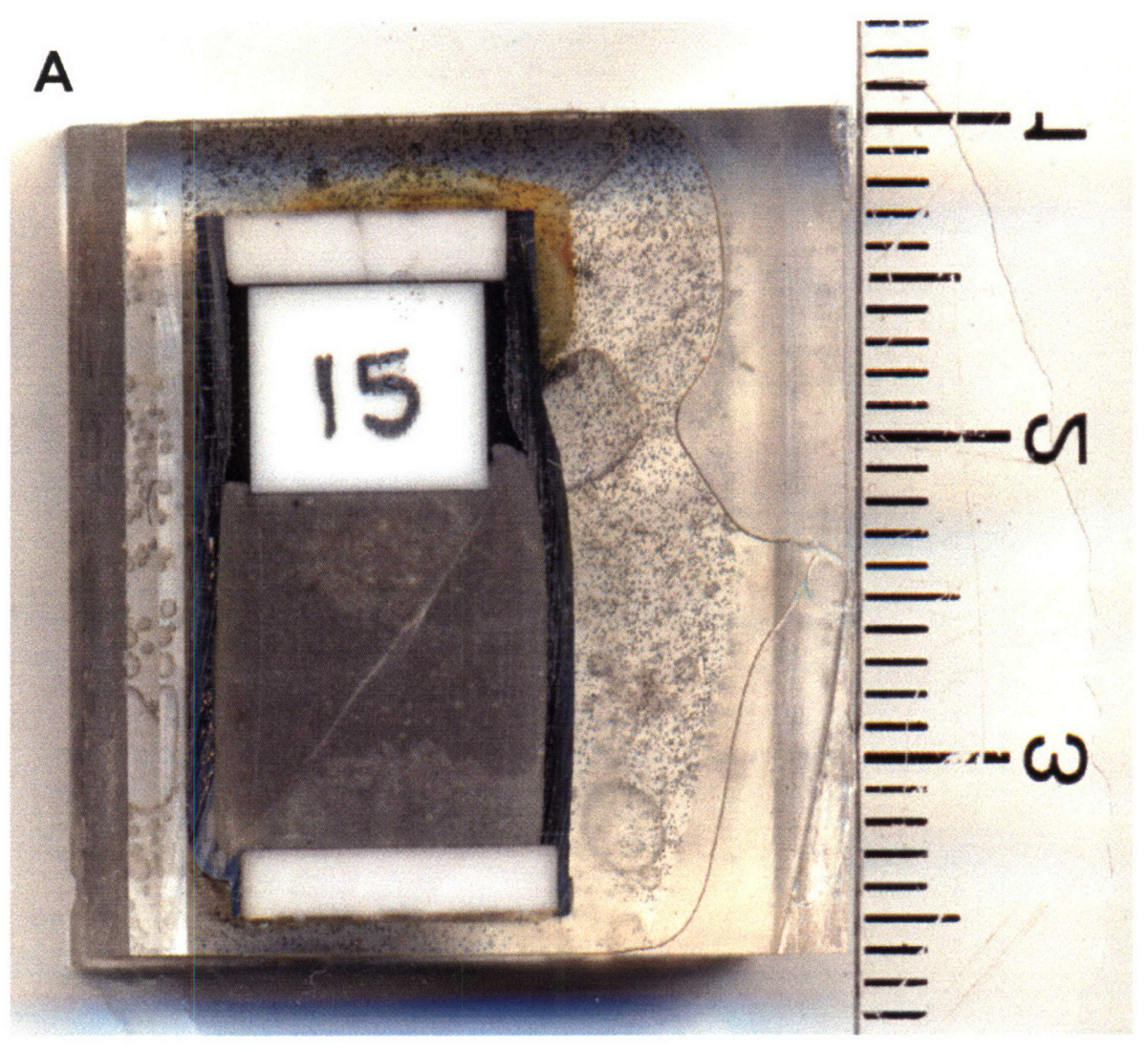

B

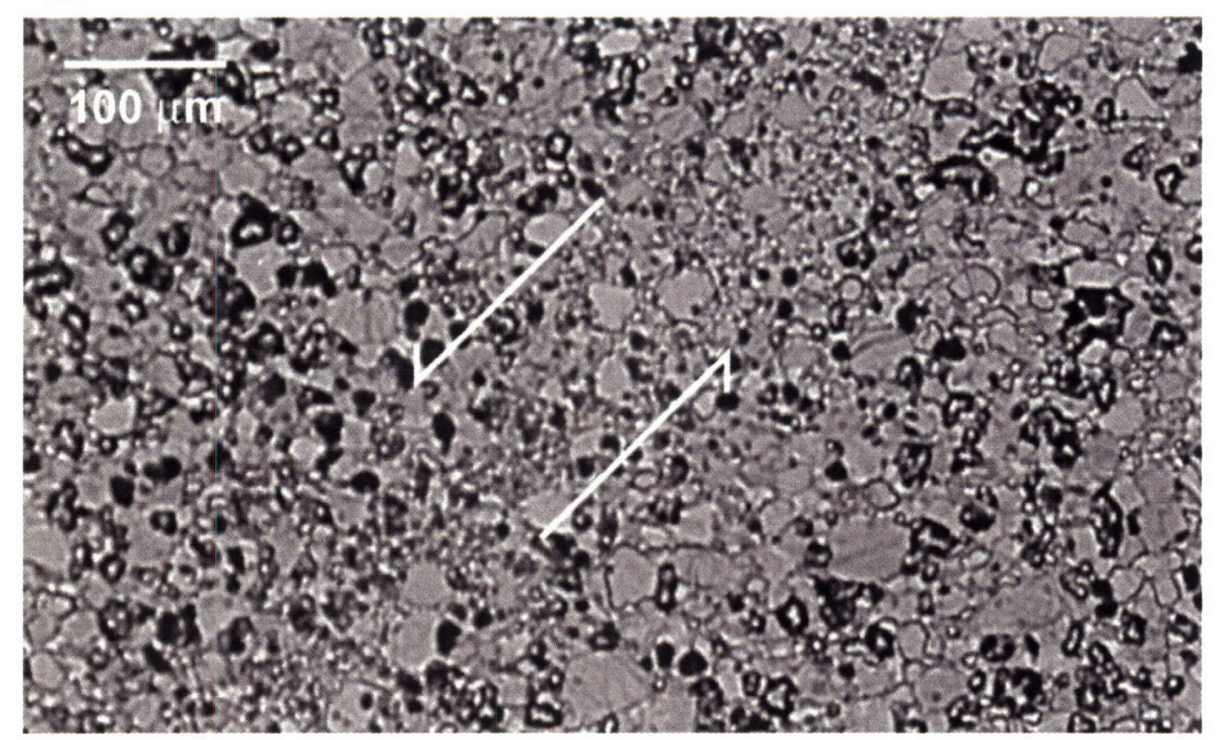

Figure 26. 


\title{
Chapter 3: Kinematics and geometry of active detachment faulting beneath the TAG hydrothermal field on the Mid-Atlantic Ridge ${ }^{1}$
}

\author{
Brian J. deMartin ${ }^{1}$, Robert A. Sohn ${ }^{2}$, Juan Pablo Canales ${ }^{2}$, Susan E. Humphris ${ }^{2}$ \\ ${ }^{1}$ MIT/WHOI Joint Program in Oceanography, Cambridge, MA 02139, USA \\ ${ }^{2}$ Woods Hole Oceanographic Institution, Woods Hole, MA 02543, USA
}

\begin{abstract}
Newly acquired seismic refraction and microearthquake data from the TransAtlantic Geotraverse (TAG) segment of the Mid-Atlantic Ridge at $26^{\circ} \mathrm{N}$ reveal the geometry and seismic character of an active oceanic detachment fault for the first time. Hypocenters from 19,232 microearthquakes observed during an 8-month ocean bottom seismometer deployment form an $\sim 15 \mathrm{~km}$ long, dome-shaped, fault surface that penetrates to depths greater than $7 \mathrm{~km}$ below the seafloor on a steeply dipping $\left(\sim^{70^{\circ}}\right)$ interface. A tomographic model of compressional-wave velocities demonstrates that lower-crustal rocks are being exhumed in the detachment footwall, which appears to roll over to a shallow dip of $\sim 20^{\circ}$ and become aseismic at a depth of $\sim 3 \mathrm{~km}$. Outboard of the detachment the exhumed lithosphere is deformed by ridge-parallel, antithetical, normal faulting. Our results suggest that hydrothermal fluids at the TAG field exploit the detachment fault to extract heat from a region near the crust/mantle interface over long periods of time.
\end{abstract}

\subsection{INTRODUCTION}

The TAG segment of the Mid-Atlantic Ridge (MAR) is notable for hosting one of the largest and best-studied hydrothermal fields on the deep seafloor (Rona et al., 1993; Rona et al., 1986; Scott et al., 1974). Hydrothermal venting has been active at TAG for the past $\sim 140,000$ years (Lalou et al., 1995), and has generated several large mineral deposits within a $\sim 5 \times 5 \mathrm{~km}$ area on the eastern side of the MAR axial valley at $26^{\circ} 08^{\prime} \mathrm{N}$, (Figure 1). High-temperature activity is currently focused at the active TAG mound

\footnotetext{
${ }^{1}$ Submitted to Geology, 12/06
} 
(Humphris and Tivey, 2000; Kleinrock and Humphris, 1996), a massive sulfide deposit $\sim 200 \mathrm{~m}$ diameter $\times \sim 50 \mathrm{~m}$ tall containing $\sim 3.9$ million tons of sulfides (Humphris et al., 1995) and discharging fluids in excess of $360^{\circ} \mathrm{C}$ (Campbell et al., 1988; Chiba et al., 2001; Parker and von Damm, 2005).

The geological conditions and processes that allow for long-lived, focused, hydrothermal discharge and the formation of large mineral deposits in the TAG region have been the topic of considerable speculation. Early research focused primarily on heat extraction from a mid-crustal melt reservoir at the axis (Kong et al., 1992), possibly via circulation through listric faults (Temple et al., 1979; Thompson et al., 1985). Later scenarios favored shallow convection from a local heat source directly beneath the hydrothermal field (Rona et al., 1993; Zonenshain et al., 1989) or removal of heat through a broad cracking front penetrating downwards into the lower crust (Wilcock and Delaney, 1996). The bathymetric salient east of the hydrothermal field has been interpreted as an inside corner high (Tucholke and Lin, 1994), and gabbro and diabase outcrops have been observed on the eastern rift valley wall (Reves-Sohn et al., 2004; Zonenshain et al., 1989). Near-bottom magnetics data have revealed a zone of reduced magnetization on the eastern valley wall (Tivey et al., 2003), which has been interpreted to result from crustal thinning by long-lived extension on a normal fault. These data led to the hypothesis that the hydrothermal field is situated on the hanging wall of an active detachment fault, emphasizing the role of tectonic, rather than volcanic, processes for maintaining long-lived hydrothermal circulation at TAG (Tivey et al., 2003).

\subsection{SEISMIC OBSERVATIONS}

We conducted an ocean bottom seismometer (OBS) experiment to better constrain the geological processes that give rise to long-lived hydrothermal circulation at the TAG field. We recorded continuous microearthquake data for 8 months using a $7 \times 7 \mathrm{~km}$ network of 13 short-period, 4-component, OBSs (Figure 1), and complemented these observations with a seismic refraction survey using the $R / V$ Maurice Ewing's airgun array (8760 $\mathrm{in}^{3}, 350 \mathrm{~m}$ shot spacing). Our main objectives were to use the microearthquake data to constrain the mechanics of faulting, and to use the refraction data to constrain the 
crustal architecture of the TAG segment.

We detected and located 19,232 microearthquakes ( $\sim 80$ events/day, average rate) along a $\sim 30 \mathrm{~km}$ stretch of the ridge axis with local magnitudes $1 \leq \mathrm{M}_{\mathrm{L}} \leq 4$ during our OBS deployment. Hypocenter estimates were made via stochastic descent on a 3D grid using residuals from compressional and shear $(P$ and $S$ ) phase arrivals picked from the seismometer records (see Appendix A). Predicted arrival times were estimated using a bathymetry conforming, depth-averaged velocity model derived from the refraction survey (Figure 2b, inset). Seismic velocities below the depth limit of the refraction survey were constrained using typical MAR values (Hooft et al., 2000) with a fixed depth below the seafloor $(6 \mathrm{~km})$ for the crust-mantle interface. Mean hypocenter accuracies $(95 \%$ confidence level) are $\pm 1.0,0.9$, and $1.1 \mathrm{~km}$ in the N-S, E-W, and vertical directions, respectively (Appendix B: a hypocentral catalogue with uncertainties and residuals for each earthquake is available).

Two distinct zones of seismic activity are evident in the hypocentral records; one set of events forms an arc that wraps around the bulge on the east side of the axial valley, a second set strikes parallel to the ridge beneath the eastern valley wall (Figure 1a). The events along the arc occur on a steep $\left(\sim 70^{\circ}\right)$, west-dipping fault that extends at least $7 \mathrm{~km}$ below the seafloor (Figure 2a). Composite focal mechanisms from first arrival polarities are consistent with normal faulting along the hypocentral trend (dip $80^{\circ}$ ). Seismic activity on this fault decreased dramatically at depths less than $\sim 3 \mathrm{~km}$ (detection threshold of $\mathrm{M}_{\mathrm{L}}$ $\geq 1$ ). The ridge-parallel microearthquakes beneath the eastern valley wall form two spatially distinct clusters at depths of $\sim 2-5 \mathrm{~km}$ below the seafloor. The spatial association of these events with discrete fault planes is somewhat ambiguous, but composite focal mechanisms for both clusters are consistent with antithetic normal faulting on planes dipping eastward (away from the spreading axis) at $65^{\circ}$. (Figure 1a).

We inverted $P$-wave first arrival travel-times using the method of Korenga et al. (2000) to generate a tomographic model of seismic velocities across the ridge axis (Figure 2 and Appendix C). We find that crustal structure is highly asymmetric across the axial valley. The western side of the axial valley has a seismic structure similar to other volcanically constructed MAR segments (e.g., Hooft et al., 2000; White et al., 1992) but the eastern flank is underlain by a large, high-velocity anomaly. Seismic velocities at 
depths below $1 \mathrm{~km}$ on the eastern flank exceed $6.5 \mathrm{~km} / \mathrm{s}$ (compared to $4.5 \mathrm{~km} / \mathrm{s}$ beneath the neovolcanic zone), indicating the presence of lower-crustal and/or serpentinized upper-mantle rocks at anomalously shallow depths. The velocity anomaly dips towards the spreading axis at an angle of $\sim 20^{\circ}$, passes under the active TAG mound at a depth of $\sim 1 \mathrm{~km}$ (Figure 2A), and intersects the hypocenter trend of the west-dipping fault plane at a depth of about $3 \mathrm{~km}$.

\subsection{DISCUSSION}

Our results provide important new constraints for the geometry of faulting and crustal architecture in the TAG region. We find that lithospheric extension on the east side of the axial valley is being accommodated on a curved normal fault with a steep $\left(\sim 70^{\circ}\right)$ dip over the depth interval of $\sim 3-7 \mathrm{~km}$ below the seafloor. We did not detect significant levels of seismic activity on the fault at depths less than $\sim 3 \mathrm{~km}$, but the shallow fault geometry is constrained by our tomographic velocity model. Seismic $(P$ wave) velocities on the east side of the axial valley, which exceed $6.5 \mathrm{~km} / \mathrm{s}$ at depths as shallow as $\sim 1 \mathrm{~km}$ beneath the seafloor, indicate that the fault exhumes lower crustal rocks on a low-angle interface dipping at $\sim 20^{\circ}$ towards the spreading axis. The inferred footwall/hanging wall interface intercepts the west-dipping normal fault just above the depth where it becomes aseismic (Figure 2b), suggesting that the change in seismic behavior is associated with rollover to a low-angle geometry. The transition to aseismic slip on a low-angle plane is consistent with rolling-hinge models (e.g. Buck, 1988) and constraints from faulting mechanics. The relative lack of seismicity along shallow dipping normal faults is also a well-documented characteristic of continental detachments (Collettini and Sibson, 2001; Jackson and White, 1989) and global seismicity compilations (e.g., Wernicke, 1995).

The deeply-penetrating normal fault curves around the eastern axial valley wall, isolating a $\sim 15 \mathrm{~km}$ long, dome-shaped, lens of material from the rest of the spreading axis. Near-bottom magnetics data show that the crust has been thinned by $\sim 3.9 \mathrm{~km}$ of horizontal extension (Tivey et al., 2003), and place the fault termination $\sim 2.5 \mathrm{~km}$ east of the active TAG mound, in roughly the same place where gabbro and diabase outcrops 
have been observed and/or sampled on the seafloor (Reves-Sohn et al., 2004; Zonenshain et al., 1989) (Figure 1b). The low-angle fault geometry inferred from our seismic velocity model is also required to reconcile our microearthquake patterns with the constraints from the magnetics data since any surface connecting the fault termination with the arc of seismicity will necessarily have a dip $\leq 30^{\circ}$ (Figure $2 \mathrm{~b}$ ). A low-angle fault geometry is also needed to reconcile the $\sim 3.9 \mathrm{~km}$ of horizontal extension required by the magnetics data with the local bathymetry profile. This extension would generate $\sim 1.5 \mathrm{~km}$ of vertical relief, consistent with the bathymetry, if accommodated on a fault dipping $20^{\circ}$, as opposed to $\sim 11 \mathrm{~km}$ of relief if extension was accommodated on the $70^{\circ}$ fault surface of the deep hypocenters.

From the constraints imposed by our seismic data and the magnetics data (Tivey et al., 2003) we estimate a total fault rollover $\sim 50^{\circ}$ (i.e., $70^{\circ}$ to $20^{\circ}$ ). This degree of rollover is consistent with paleomagnetic rotations measured at the Fifteen-Twenty and Atlantis massif oceanic core complexes (Blackman et al., 2006; Garcés and Gee, in press), as well as rotations deduced for some continental core complexes (e.g. Manatschal et al., 2001). Highly-rotated crustal blocks, however, have not been observed in the footwall east of TAG (e.g. Karson and Rona, 1990; Zonenshain et al., 1989). This apparent discrepancy is reconciled by considering the age constraints imposed by the magnetics data (Tivey et al., 2003), which indicate that the detachment fault has only been active long enough ( $\sim 350 \mathrm{ky})$ to exhume $\sim 1.5 \mathrm{~km}$ of un-rotated upper crust on a low-angle $\left(20^{\circ}\right)$ fault. The footwall exhibits a dome-shaped morphology but lacks the surface corrugations associated with more advanced stages of core complex evolution, which also supports a young age for the detachment (e.g., Smith et al., 2006).

We conclude that the TAG hydrothermal field is located on the hanging wall of an active, young oceanic detachment, and we use the kinematic and geometric constraints provided by our seismic study to develop a schematic model of lithospheric extension, crustal accretion, and hydrothermal circulation (Figure $2 b$ ). We find no evidence for any crustal melt reservoirs, and our results suggest that hydrothermal fluids must penetrate to greater than $7 \mathrm{~km}$ depth below the seafloor to extract heat from a source large enough (e.g. Humphris and Cann, 2000) to drive long-term, high-temperature, hydrothermal convection. Long-term hydrothermal circulation and the generation of large mineral 
deposits at the TAG field thus appear to be sustained by tectonic, rather than volcanic, processes. These results demonstrate that early-stage detachment faults may host hightemperature hydrothermal systems that are driven by heat from reservoirs in the mantle, and call into question the hypothesis that hydrothermal activity is suppressed at slowly diverging oceanic spreading centers.

Acknowledgements: We thank Joe Cann, Hans Schouten, Mark Behn, and Jeff Gee for helpful discussions, Jeff Karson and Donna Blackman for helpful reviews, the WHOI and LDEO OBSIP groups for technical support with the ocean-bottom seismometers, and the ship's crews of the $R / V s$ Atlantis, Ewing, and Knorr for their efforts at-sea. This work was supported by NSF grant OCE-0137329. 

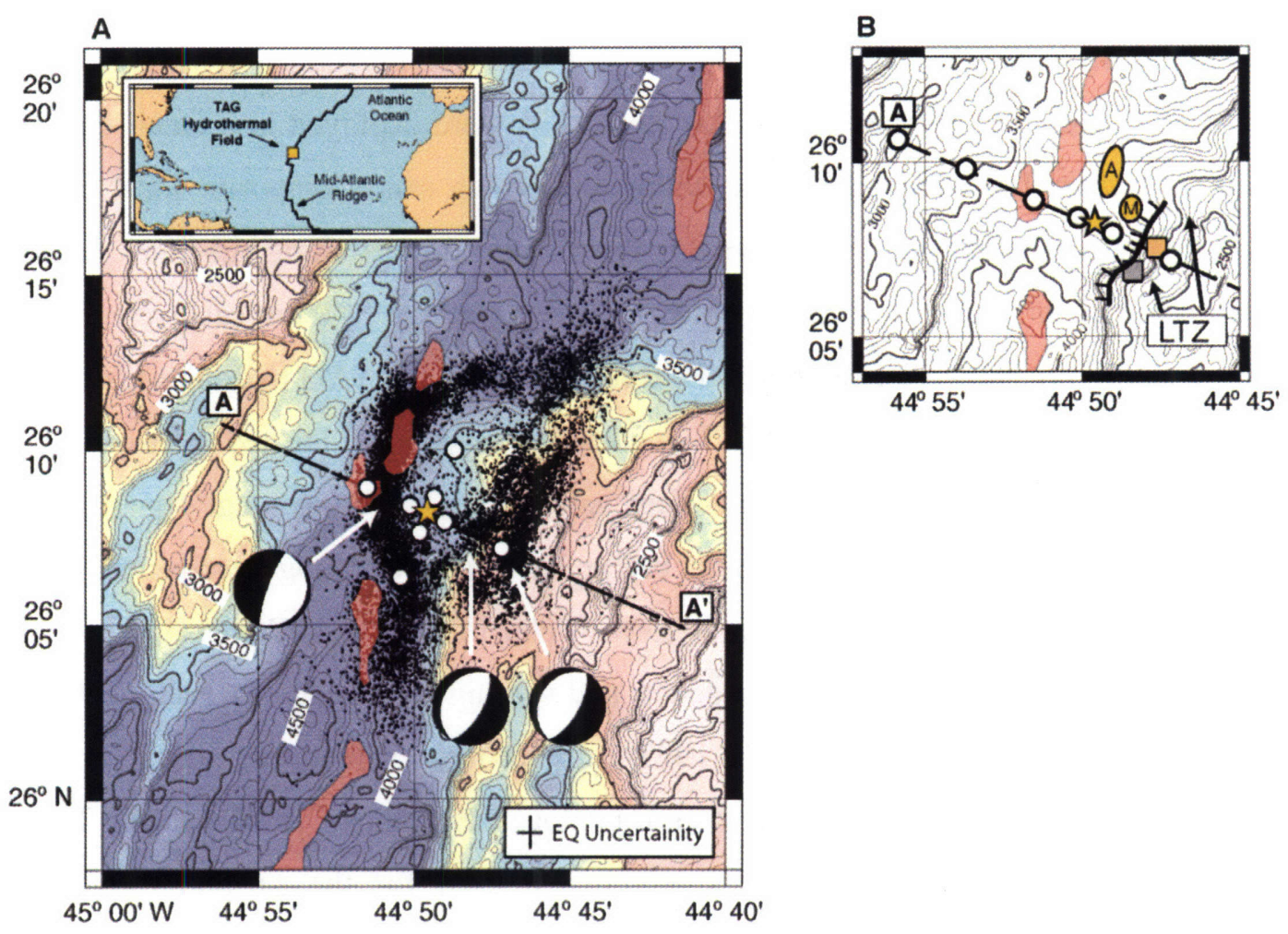

Figure 1. 
Figure 1: Area map of the MAR $26^{\circ} \mathrm{N}$ and the TAG hydrothermal field. A) Bathymetry (100 m contour interval) of the TAG segment with microearthquake epicenters (black dots), the OBS network (white circles), the active TAG mound (brown star), and neovolcanic zones (red patches). Note that five OBSs were deployed in a small cluster around the active TAG mound and lie within the brown star. Composite focal plane solutions (lower-hemisphere) are shown for three event groups along the A-A' crosssection. Average $95 \%$ confidence level epicenter uncertainties $( \pm 1.0 \mathrm{~km}$ east/west, \pm 0.9 $\mathrm{km}$ north/south) are shown for reference. B) Relationship of the TAG hydrothermal field to surface geology. The active TAG mound (brown star) is located between the neovolcanic zone (red patches) and the eastern valley wall. Gabbro (orange square) and diabase (gray square) exposures have been observed and sampled along a prominent fault scarp $\sim 2.5 \mathrm{~km}$ east of the active mound (Reves-Sohn et al., 2004; Zonenshain et al., 1989), and low temperature alteration products and venting have been observed between the arrows labeled 'LTZ' (Rona et al., 1993). Relict high-temperature zones (brown patches, $\mathrm{M}$-Mir zone and $\mathrm{A}-$ Alvin Zone) are located northeast of the active TAG mound. Ocean-bottom seismometers (white circles) used for the seismic refraction velocity inversion are shown along the cross-section. 

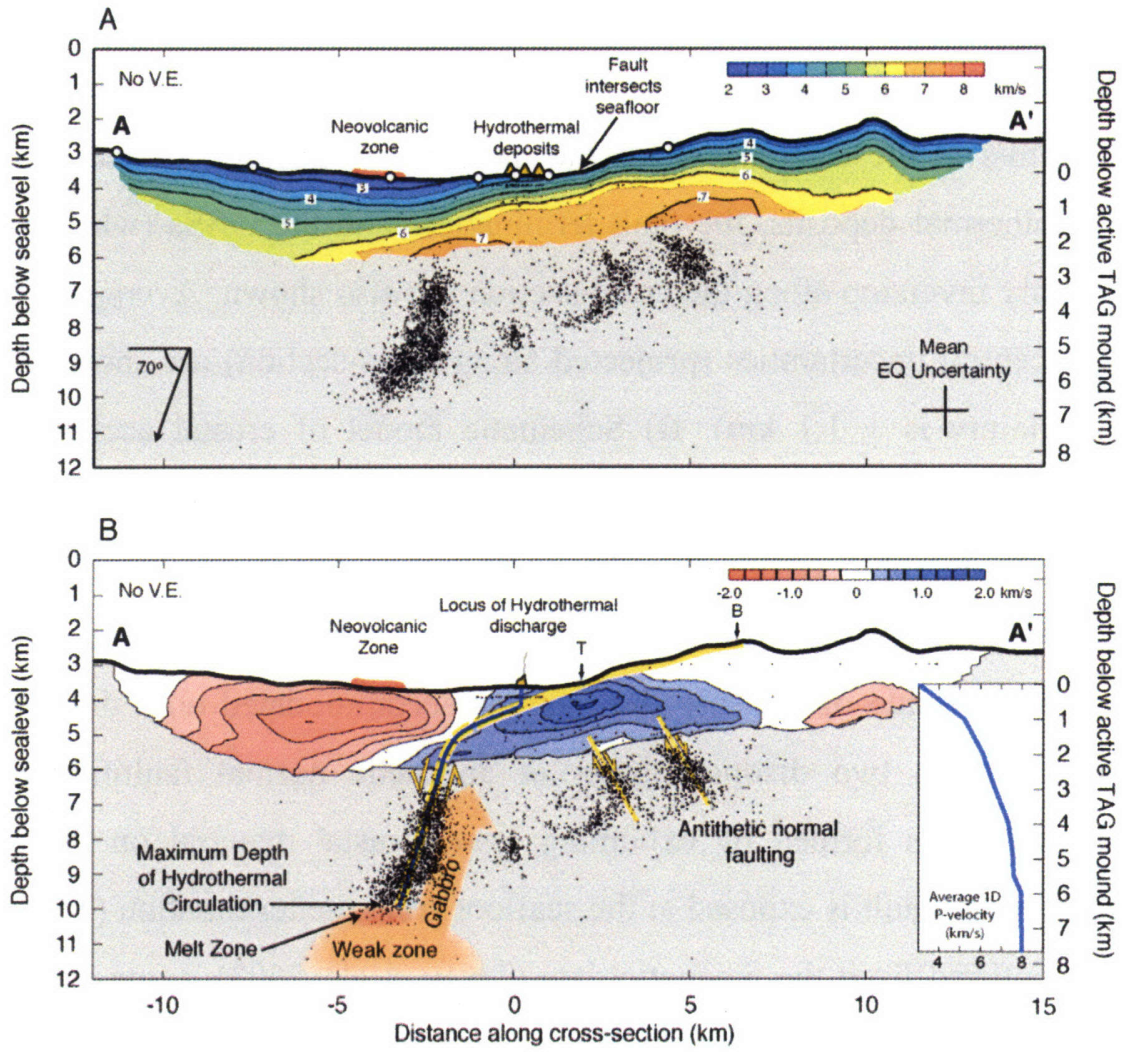

Figure 2. 
Figure 2: Depth sections (no vertical exaggeration) across the axial valley on A-A' from Figure 1. A) $P$-wave velocity model and hypocenters from events within $1 \mathrm{~km}$ of crosssection. Tomographic model uncertainties are typically $<0.1 \mathrm{~km} / \mathrm{s}$, but can be as large as $0.2 \mathrm{~km} / \mathrm{s}$ at the eastern end of the model. The position of the neovolcanic zone, the hydrothermal deposits, the fault termination, and the OBSs (white circles) used for the velocity inversion along the cross-section are also shown. Average $95 \%$ confidence level hypocentral uncertainties (projected along cross-section) are shown for reference (depth uncertainty is $\pm 1.1 \mathrm{~km}$ ). B) Schematic model of crustal accretion, deformation and hydrothermal circulation at TAG with hypocenters and $P$-wave velocity model as for $2 \mathrm{~A}$. The tomographic results are shown as perturbations against the 1-D average model (shown in lower right corner, for reference), as opposed to absolute velocities. Extension on the east side of the spreading axis is accommodated on a dome-shaped detachment fault and on two distinct planes of antithetic normal faulting (yellow lines). New lithosphere is formed by exhuming lower-crustal material on the fault footwall. The detachment fault is exposed at the seafloor from the termination (T) to the breakaway (B) as identified from the magnetic data (Tivey et al., 2003). Long-lived, high-temperature, hydrothermal circulation at the TAG hydrothermal field requires a magmatic heat source (e.g., Cann and Strens, 1982; Humphris and Cann, 2000), but our seismic velocity model and earthquake hypocenters effectively preclude the presence of a crustal magma chamber. This suggests there must be a deep melt reservoir beneath the neovolcanic zone, which may also root the high-angle normal fault. Gabbros crystallizing from this reservoir would then be accreted onto the footwall (orange arrow) during extension. Hydrothermal fluids may flow through the hanging wall at shallow depths, but they must be focused on the detachment deeper in the crust, and they must penetrate to depths of $7+$ $\mathrm{km}$ to extract high-temperature heat from the base of the fault. 
Appendix A: Earthquake waveforms, $P$ - and $S$ - phase arrivals, and composite focal plane solutions.
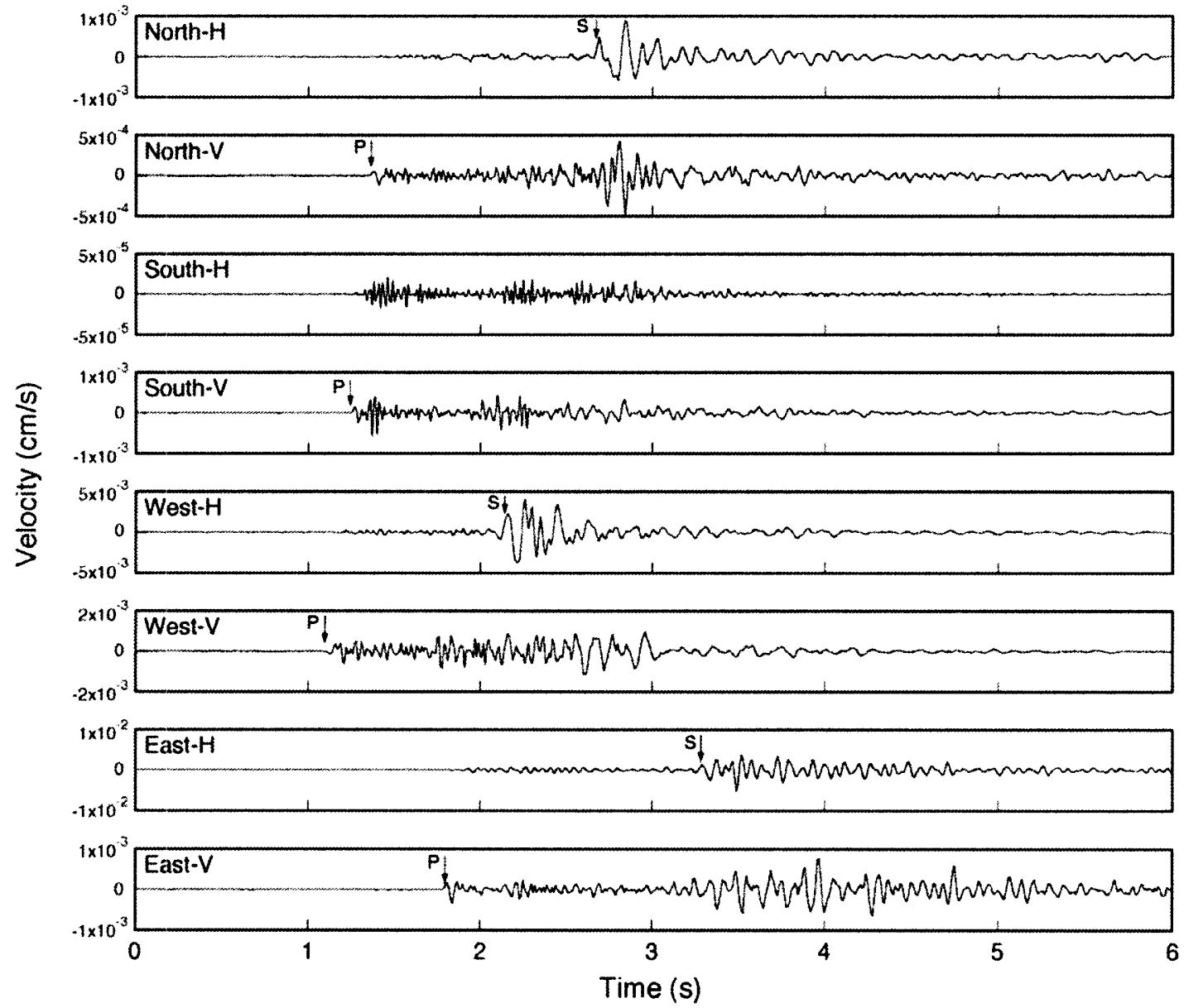

Figure DR1: Earthquake waveforms and compressional $(P)$ and shear $(S)$ phase picks from an event $\left(\mathrm{M}_{\mathrm{L}}=2.57\right)$ located at $26^{\circ} 8.5^{\prime} \mathrm{N},-44^{\circ} 51.34^{\prime} \mathrm{W}$, and $6.5 \mathrm{~km}$ depth on the detachment fault. Vertical (V) and horizontal (H) displacement velocities are shown for the outermost ring of instruments in the network (i.e., northernmost, southernmost, westernmost, and easternmost instruments). Data are band-pass filtered from 5-40 Hz.

Nominal arrival time uncertainties are $75 \mathrm{~ms}$ for $P$-waves, and $150 \mathrm{~ms}$ for $S$ waves. Note that no S-pick was made for the southernmost instrument in Figure DR1. Composite focal plane solutions shown in Figure la were generated using $P$-wave polarity estimates from 3 sets of events. The first set located on the west-dipping arc of seismicity includes 304 events over a depth interval from 4.5 to $9 \mathrm{~km}$ below sea level. The second set located on the linear seismicity trend closest to the axial valley includes 543 events over a depth interval of from 3.5 to $5.9 \mathrm{~km}$ below sea level. The third set 
located on the linear seismicity trend furthest outboard of the axial valley includes 365 events over a depth interval from 3 to $6.7 \mathrm{~km}$ below sea level.

\section{Appendix B: Hypocenter Estimates}

$P$ - and $S$ - phase picks were made for 51,667 events that were detected by all 13 OBSs. Hypocenters were estimated via stochastic descent on a rms residual grid generated by comparing $P$ - and $S$-phase arrival times to travel times predicted using William Menke's Raytrace3d program (Menke, 2005). Satisfactory hypocentral estimates (defined by rms residual $<0.12 \mathrm{~s}$ ) were obtained for 19,232 events. Hypocenter uncertainties were estimated at the $95 \%$ confidence interval using the method of Wilcock and Toomey (1991) as modified by Sohn et al. (1998).

\section{References:}

Menke, W., 2005, Case studies of seismic tomography and earthquake location in a regional context.

Sohn, R.A., Hildebrand, J.A., and Webb, S.C., 1998, Postrifting seismicity and a model for the 1993 diking event on the CoAxial segment, Juan de Fuca Ridge: J. Geophys. Res., v. 103, p. 9867-9877.

Wilcock, W.S.D., and Toomey, D.R., 1991, Estimating hypocentral uncertainties for marine microearthquake surveys: A comparison of the generalized inverse and grid search methods: Marine Geophysical Researches, v. 13, p. 161-171. 


\section{Appendix C: Active source seismic record}
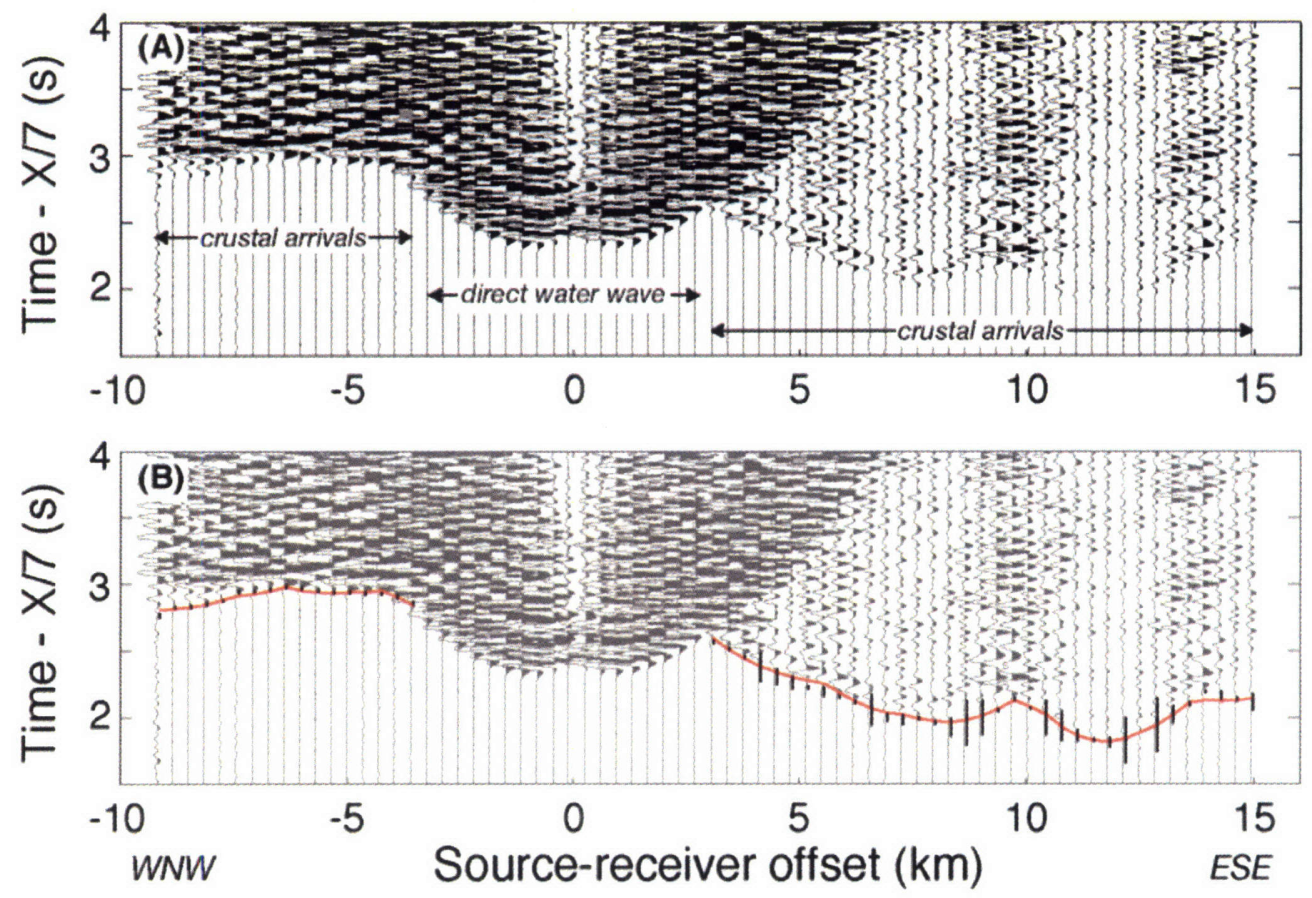

Figure DR2: (A) Example of active-source seismic record section for the OBS located 1 $\mathrm{km}$ to the west of the TAG mound. Vertical axis is travel time reduced to $7 \mathrm{~km} / \mathrm{s}$. Data have been band-pass filtered between 5 and $20 \mathrm{~Hz}$, and amplitudes scaled according to range for display purposes. Labels indicate the nature of first arrivals at different offsets. Travel times were hand-picked, and uncertainty estimates included dependency on the signal-to-noise ratio, uncertainty in both source and receiver locations, and uncertainity in seafloor ray entry points due to out-of-plane topography. (B) Same as (A), with observed travel time picks (vertical bars with length equal to twice the assigned uncertainty) and predicted travel times (red line) by the preferred 2-D model shown in Figure 2a. 


\section{References:}

Blackman, D.K., Ildefonse, B., John, B.E., Ohara, Y., Miller, D.J., MacLeod, C.J., and the Expedition 304/305 Scientists, 2006, Proc. IODP, 304/305: College Station, TX.

Buck, R.W., 1988, Flexural rotation of normal faults: Tectonics, v. 7, p. 959-973.

Campbell, A.C., Palmer, M.R., Klinkhammer, G.P., Bowers, T.S., Edmond, J.M., Lawrence, J.R., Casey, J.F., Thompson, G., Humphris, S., Rona, P.A., and Karson, J.A., 1988, Chemistry of hot springs on the Mid-Atlantic Ridge: Nature, V. 335 , p. $514-519$.

Cann, J.R., and Strens, M.R., 1982, Balck smokers fuelled by freezing magma: Nature, v. 298, p. 147-149.

Chiba, H., Masuda, H., Lee, S.Y., and Fujioka, K., 2001, Chemistry of hydrothermal fluids at the TAG active mound, MAR 26 degrees N, in 1998: Geophysical Research Letters, v. 28, p. 2919-2922.

Collettini, C., and Sibson, R.H., 2001, Normal faults, normal friction?: Geology, v. 29, p. 927-930.

Garcés, M.A., and Gee, J.S., in press, Paleomagnetic evidence of large footwall rotations associated with low-angle faults at the Mid-Atlantic Ridge: Geology.

Hooft, E.E.E., Detrick, R.S., Toomey, D.R., Collins, J.A., and Lin, J., 2000, Crustal thickness and structure along three contrasting spreading segments of the MidAtlantic Ridge, $33.5^{\circ} \mathrm{N}-35^{\circ} \mathrm{N}$ : J. Geophys. Res., v. 105, p. 8205-8226.

Humphris, S.E., and Cann, J.R., 2000, Constraints on the energy and chemical balances of the modern TAG and ancient Cyprus seafloor sulfide deposits: J. Geophys. Res., v. 105, p. 28,477-28,488.

Humphris, S.E., Herzig, P.M., Miller, D.J., Alt, J.C., Becker, K., Brown, D., Bruegmann, G., Chiba, H., Fouquet, Y., Gemmell, J.B., Guerin, G., Hannington, M.D., Holm, N.G., Honnorez, J.J., Iturrino, G.J., Knott, R., Ludwig, R., Nakamura, K., Petersen, S., Reysenbach, A.L., Rona, P.A., Smith, S., Sturz, A.A., Tivey, M.K., and Zhao, X., 1995, The internal structure of an active sea-floor massive sulphide deposit: Nature, v. 377, p. 713-716.

Humphris, S.E., and Tivey, M.K., 2000, A synthesis of geological and geochemical investigations of the TAG hydrothermal field; insights into fluid-flow and mixing processes in a hydrothermal system, in Dilek, Y., Moores, E.M., Elthon, D., and Nicolas, A., eds., Special Paper - Geological Society of America, vol. 349, p. 213235.

Jackson, J.A., and White, N.J., 1989, Normal faulting in the upper continental crust: Observations from regions of active extension: Journal of Structural Geology, v. 11, p. 14-36.

Karson, J.A., and Rona, P.A., 1990, Block-tilting, transfer faults, and structural control of magmatic and hydrothermal processes in the TAG area, Mid-Atlantic Ridge $26^{\circ} \mathrm{N}$; with Suppl. Data 90-21: Geological Society of America Bulletin, v. 102, p. 16351645.

Kleinrock, M.C., and Humphris, S.E., 1996, Structural control on sea-floor hydrothermal activity at the TAG active mound: Nature, v. 382, p. 149-153. 
Kong, L.S.L., Solomon, S.C., and Purdy, G.M., 1992, Microearthquake characteristics of a mid-ocean ridge along-axis high: J. Geophys. Res., v. 97, p. 1659-1685.

Korenaga, J., Holbrook, W.S., Kent, G.M., Kelemen, P.B., Detrick, R.S., Larsen, H.-C., Hopper, J.R., and Dahl-Jensen, T., 2000, Crustal structure of the southeast Greenland margin from joint refraction and reflection seismic tomography: J. Geophys. Res., v. 109, p. 21591-21614.

Lalou, C., Reyss, J.-L., Brichet, E., Rona, P.A., and Thompson, G., 1995, Hydrothermal activity on a $10^{5}$-year scale at a slow-spreading ridge, TAG hydrothermal field, Mid-Atlantic Ridge $26^{\circ} \mathrm{N}$ : J. Geophys. Res., v. 100, p. 17,855-17,862.

Manatschal, G., Froitzheim, N., Rubenach, M.J., and Turrin, B., 2001, The role of detachment faulting in the formation of an ocean-continent transition: insights from the Iberia Abyssal Plain, in Wilson, R.C.L., R.B., W., Taylor, B., and Froitzheim, N., eds., Non-volcanic rifting of continental margins: evidence from land and sea, Volume 187: London, Geol. Soc. London, Spec. Publ.

Parker, C.M., and von Damm, K.L., 2005, Time Series Fluid Compositions from the TAG Hydrothermal Mound, MAR: 1986-2004: American Geophysical Union, Fall Meeting 2005, p. Abstract \#OS22A-07.

Reves-Sohn, R., Humphris, S., and Canales, J.P., 2004, Cruise Report: Seismicity and Fluid Flow of the TAG Hydrothermal Mound-4, WHOI, ftp://obs.whoi.edu/pub/ras/STAG/STAG_Leg4_Cruise_Report.pdf

Rona, P.A., Hannington, M.D., Raman, C.V., Thompson, G., Tivey, M.K., Humphris, S.E., Lalou, C., and Petersen, S., 1993, Active and relict sea-floor hydrothermal mineralization at the TAG hydrothermal field, Mid-Atlantic Ridge: Econ. Geol., v. 88, p. 1987-2013.

Rona, P.A., Pockalny, R.A., Thompson, G., and Anonymous, 1986, Geologic setting and heat transfer of black smokers at TAG hydrothermal field, Mid-Atlantic Ridge 26 degrees N, Eos, Transactions, American Geophysical Union, Volume 67, p. 1021.

Scott, R.B., Rona, P.A., McGregor, B.A., and Scott, M.R., 1974, The TAG hydrothermal field: Nature, v. 251, p. 301-302.

Smith, D.K., Cann, J.R., and Escartín, J., 2006, Widespread active detachment faulting and core complex formation near $13^{\circ} \mathrm{N}$ on the Mid-Atlantic Ridge: Nature, v. 442, p. 440-443.

Temple, D.G., Scott, R.B., and Rona, P.A., 1979, Geology of a submarine hydrothermal field, Mid-Atlantic Ridge, $26^{\circ} \mathrm{N}$ latitude: J. Geophys. Res., v. 84, p. 7453-7466.

Thompson, G., Mottl, M.J., and Rona, P.A., 1985, Morphology, mineralogy, and chemistry of hydrothermal deposits from the TAG area, $26^{\circ} \mathrm{N}$ Mid-Atlantic Ridge: Chern. Geol., v. 49.

Tivey, M.A., Schouten, H., and Kleinrock, M.C., 2003, A near-bottom magnetic survey of the Mid-Atlantic Ridge axis at $26^{\circ} \mathrm{N}$ : Implications for the tectonic evolution of the TAG segment: J. Geophys. Res., v. 108, p. doi:10.1029/2002JB001967.

Wernicke, B., 1995, Low-angle normal faults and seismicity: A review: J. Geophys. Res., v. 100 , p. $20,159-20,174$.

White, R.S., McKenzie, D., and O'Nions, R.K., 1992, Oceanic crustal thickness from seismic measurements and rare earth element inversions: J. Geophys. Res., v. 97, p. 19,683-19,715. 
Wilcock, W.S.D., and Delaney, J.R., 1996, Mid-ocean ridge sulfide deposits: Evidence for heat extraction from magma chambers or cracking fronts?: Earth Planet. Sci. Lett., v. 145, p. 49-64.

Zonenshain, L.P., Kuz'min, M.I., Lisitsin, A.P., Bogdanov, Y.A., and Baranov, B.V., 1989, Tectonics of the Mid-Atlantic rift valley between the TAG and MARK areas $\left(26-24^{\circ} \mathrm{N}\right)$; evidence for vertical tectonism: Tectonophys., v. 159, p. 1-23. 


\title{
Chapter 4: Spatial and Temporal Characteristics of Seismicity at an Active Oceanic Detachment Fault: TAG Segment, Mid-Atlantic Ridge
}

\begin{abstract}
We located 19,232 microearthquakes beneath the axial valley and eastern valley wall of the TAG segment of the Mid-Atlantic Ridge during an eight-month deployment of ocean bottom seismometers. The microearthquakes can be grouped into spatially distinct areas, with most of the seismicity occurring along the detachment fault beneath the axial valley and antithetical normal faults beneath the eastern valley wall. Steady, high-rates of seismicity characterized both areas. We located approximately 10,000 detachment fault events and 5,000 antithetical normal fault events. On average, we observed 43 events/day along the detachment fault and 22 events/day along the faults beneath the eastern valley wall. Microearthquakes hypocenters occurred from $3 \mathrm{~km}$ to greater than $7 \mathrm{~km}$ below the seafloor beneath of the axial valley. Under the eastern valley wall, events occurred at shallower depths ranging between 2 and $4 \mathrm{~km}$. Clustering analysis performed using waveform cross-correlation techniques to identify seismograms with similar characteristics suggests that deformation along the TAG segment is accommodated by steady slip on small patches. Earthquakes along the TAG segment of the Mid-Atlantic Ridge lack the typical mainshock/aftershock sequence representative of most tectonic environments.
\end{abstract}

\subsection{Introduction}

The Trans-Atlantic Geotraverse (TAG) segment of the Mid-Atlantic Ridge $\left(26^{\circ} \mathrm{N}\right)$ is approximately $40 \mathrm{~km}$ long and is bounded to the north and south by non-transform discontinuities at $26^{\circ} 17^{\prime} \mathrm{N}$, and $25^{\circ} 55^{\prime} \mathrm{N}$, respectively (Purdy and Detrick, 1986; Sempere et al., 1990). The median valley is characterized by an hourglass morphology and is 8-10 $\mathrm{km}$ wide and $3600 \mathrm{~m}$ deep at its narrowest point (Figure 1a). The axial valley morphology is asymmetric. The western side is characterized by block faulted basaltic terrain consisting of several fault line scarps 50 to $200 \mathrm{~m}$ in height separated by sedimentcovered terraces (Eberhart et al., 1988; Zonenshain et al., 1990). By contrast, a prominent dome-shaped bulge dominates seafloor morphology on the eastern side of the axial valley. Geological and geophysical evidence indicate that the eastern valley wall is the surface exposure of a young, active detachment fault (deMartin et al., submitted; Tivey et al., 2003). 
The hanging wall of the detachment hosts one of the largest known seafloor hydrothermal fields. The TAG hydrothermal field contains active and relict areas of both high- and low-temperature hydrothermal discharge (Figure 1a), with high-temperature discharge presently being focused at the active TAG mound (Humphris and Tivey, 2000; Kleinrock and Humphris, 1996). The sub-surface patters of hydrothermal convection at the TAG field are not well understood but have been the topic of considerable speculation. Proposed scenarios for hydrothermal circulation include shallow convection from a local heat source directly beneath the hydrothermal field (Rona et al., 1993), heat extraction from a magma chamber or low-velocity zone at mid-crustal depths (Kong, 1990) possibly via circulation through listric faults (Temple et al., 1979; Thompson et al., 1985), and the removal of heat through a broad cracking front penetrating downwards into the lower crust (Wilcock and Delaney, 1996).

\subsection{The Experiment}

The Seismicity and fluid flow of TAG (STAG) experiment was conducted to study the inter-related processes of deformation, crustal accretion, and hydrothermal circulation at the TAG segment. A $7 \times 7 \mathrm{~km}$ network of 13 short-period $(4.5 \mathrm{~Hz})$, 4component ocean bottom seismometers (OBS) recorded continuous microearthquake data (100 samples per second) in the TAG region from June 2003 to February 2004. We positioned OBS's in a series of three rings centered on the active mound with radii of 100 $\mathrm{m}, 1 \mathrm{~km}$, and $3.5 \mathrm{~km}$, hereafter referred to as the inner, middle, and outer ring, respectively. The inner ring comprises five OBS's, while the middle and outer rings comprise 4 OBS's each (Figure 1).

We used the hypocenter estimates and seismic refraction data from the STAG experiment to constrain the geometry of seismic activity on an active oceanic detachment fault for the first time (deMartin et al., submitted). This long-lived normal fault penetrates to at least $7 \mathrm{~km}$ beneath the axial valley with a dip that increases from $\sim 20^{\circ}$ in the shallow crust to as steep as $\sim 70^{\circ}$ near its base. Results from deMartin et al., (submitted) suggest that heat to drive high-temperature hydrothermal convection at TAG is derived from a melt reservoir at a depth of $7+\mathrm{km}$ beneath the axial valley. The localization of deformation along the detachment fault provides a long-lived, high-permeability pathway 
for hydrothermal fluids to extract heat from the melt body near the base of the crust. The episodic nature of high-temperature discharge inferred from the geochronology of the TAG deposits (Lalou et al., 1995) and energy balance calculations (Humphris and Cann, 2000) could result from episodic replenishment of the melt reservoir, episodic perturbations to the permeability structure within the convection system, or some combination of both. Newly acquired seafloor bathymetry maps reveal detachment faults and metamorphic core complexes may be more common than previously thought (Smith et al., 2006). If venting and mineral deposition are common processes on hanging walls of active oceanic detachments, then there could be significantly more high-temperature hydrothermal systems along the flanks of slow- and ultra-slow spreading ridges awaiting discovery. In this chapter, we use the microearthquake catalog from deMartin et al., (submitted) to investigate the spatial and temporal characteristics of seismicity along an active detachment fault for the first time in order to better understand the interplay between earthquakes, fluid-flow and detachment faulting.

\subsection{Seismograms and Seismicity Rates}

Ocean bottom seismometers recorded two primary types of seismic events within the TAG region: (1) small, harmonic events associated with fluid flow and hydraulic processes at the active TAG mound, and (2) larger microearthquakes related to tectonic extension. The OBS network detected tens of thousands of both event types during the eight-month observation period.

The small, harmonic events were primarily detected by the inner-ring of seismometers (Figure 2), which were positioned using wire-line deployment techniques on the perimeter of the active TAG mound. These short, impulsive, single phase, waveforms are similar to hydraulic events observed in subarial geothermal settings (e.g. Bame and Fehler, 1986; Ferrazzini et al., 1990; Kedar et al., 1996). Similar waveforms have also been observed in seismograms from instruments deployed near deep-sea hydrothermal vents (McClain et al., 1993; Sohn et al., 1995). The inner-ring instruments detected approximately 50,000 of these events but hypocenter analysis of these events has not yet been conducted. 
Tectonic events are characterized by waveforms with compressional $(P)$, shear $(S)$ and sea-surface reflected $(W)$ body waves. Typical waveforms for microearthquake activity along the TAG segment have an emergent $P$ arrival, followed by $S$ and $W$ arrivals approximately $0.75 \mathrm{~s}$ and $5 \mathrm{~s}$ later, respectively (Figure $3 \mathrm{a}$ ). We used short-term/longterm average techniques to automatically make $P$ and $S$ phase arrival time picks on vertical and horizontal geophone channels. $S$-wave arrival times are refined by calculating the spectrogram of a $4 \mathrm{~s}$ window around the initial pick and finding the time when spectral levels in a specific frequency band exceeds a threshold value. The algorithms identified events that were detected on all four outer ring instruments. Figure $3 \mathrm{~b}$ shows a histogram of all the events that were detected and located.

\subsection{Hypocenter Analysis}

We detected and located 19,232 tectonic microearthquakes with local magnitudes $1 \leq \mathrm{M}_{\mathrm{L}} \leq 4.4$ during our 8-month OBS deployment (deMartin et al., submitted). The microearthquakes can be divided into four geographically distinct groups: 1. detachment faulting events that form an arc on the east side of the axial valley; 2 . antithetical normal faulting events that form linear trends beneath the eastern valley wall; 3 . and 4. events to the north and south of the detachment fault, respectively (Figure 4). Here we consider the spatial, temporal, and seismological characteristics of events from the first and second groups, which correspond to $54 \%$ and $28 \%$ of the total earthquakes analyzed during this study, respectively.

\subsubsection{Seismicity Rates}

We observed an average of 43 events/day along the detachment fault and 22 events/day along the antithetic normal faults with a moderate decrease in seismicity rates along for both kinds of events over the course of the observational period (Figure 5). Along the detachment fault, the average number of events we detected and located fell from 61 events/day in the first month of the experiment to 23 events/day in the final month of the deployment (Figure 5a). Similarly, the daily number of earthquakes associated with faults within the eastern valley wall decreased from 26 events/day in the first month to 11 events/day in the final month (Figure $5 \mathrm{~b}$ ). 
Overall, seismicity rates were remarkably steady during the experiment, with almost no swarms and no mainshock/aftershock pattern. Seismicity rates on the detachment fault only exceeded the $2 \sigma$ level on days 195 (132 events), 200 (91 events), 212 (87 events), 284 (92 events), and 290 (105 events), while seismicity rates on the antithetic normal faults exceeded the $2 \sigma$ level on days 210 (58 events), 216 (106 events), 217 (53 events), 219 (84 events), 220 (66 events), and 250 (101events). The high seismicity rate on day 250 is associated with a large earthquake that occurred at 23:36:52 on September 6, 2003, and this is the only aftershock sequence observed during the deployment.

Microearthquake activity was relatively continuous in the TAG region throughout the observational period. Events were distributed with time along the strike of the detachment fault (Figure 6a) and the antithetic normal faults (Figure 6b). Over twice as many earthquakes are detected and located on the detachment fault compared to the faults along the eastern side of the axial valley (Figure 7a). For both regions of the TAG segment the cumulative number of earthquakes versus time increases relatively smoothly throughout the seismometer deployment (Figure 7a). These analyses indicate that faults slipped a little everywhere each day.

\subsubsection{Cumulative earthquake moment release}

We used the long-period spectral level of the displacement spectrum from the vertical channels of the OBS's to calculate earthquake seismic moments and magnitudes (Brune, 1970; Hanks and Thatcher, 1972; Sohn et al., 1998). The seismic moment $\left(M_{0}\right)$ is defined as

$$
M_{0}=\frac{4 \pi \rho R v^{3}}{B_{\theta \phi} K} \Omega_{0},
$$

where $\Omega_{0}$ is the long period limit of the displacement spectrum, $B_{\phi \theta}$ is function describing the body wave radiation pattern, $\rho$ is the density of the rock, $R$ is the range of the earthquake from the OBS, $K$ is the reflection coefficient at the recording boundary, and $v$ is the shear wave velocity. We assumed a rock density of $3,000 \mathrm{~kg} / \mathrm{m}^{3}$, a body wave (shear) velocity of $3.0 \mathrm{~km} / \mathrm{s}$, and a reflection coefficient at the seafloor of 1.66 . We used 
$B_{\theta \phi}=0.62$, the average value of $B_{\theta \phi}$ for shear waves over all azimuths (Sohn et al., 1998). Seismic moments calculated for each event instrument pair were averaged to estimate the seismic moment for each event.

We calculated local magnitudes from the moment estimates using the following relationship (Sohn et al., 1998),

$$
\log _{10} M_{0}=16+1.5 M_{L} .
$$

Cumulative moment shown for the detachment fault and antithetic normal faults in Figure $7 \mathrm{~b}$. The moment released by seismic slip in our study area increases relatively uniformly throughout the experiment, with three notable exceptions. Large steps in the moment release curve are on day 249 beneath the eastern valley wall and on day 360 and 370 along the detachment fault. Overall, there are fewer events beneath the eastern valley wall, but they radiate more seismic energy than events along detachment fault owing to the large, $M_{L}=4.4$ event on day 249 . The seismic moment estimate for this event maybe too high, as described below. The median earthquake moment is $1.43 \times 10^{18} \mathrm{dyne}$-cm $\left(M_{L}\right.$ $=1.44)$ for events along the detachment fault and $1.92 \times 10^{18}$ dyne-cm $\left(M_{L}=2.9\right)$ for events within the eastern side of the axial valley. The cumulative moment release remains nearly constant even through seismicity rates decrease towards the end of the experiment. The earthquake size-frequency distribution for both the detachment fault and eastern events is consistent with tectonic processes: the $b$-value is close to one for both sets of events (Figure 8).

We checked our seismic moment estimates by making a second set of estimates using hydrophone pressure levels. Seismic moments from hydrophone data are up to $20 \%$ lower for the larges events, suggesting a systematic upward bias in the geophone moment estimates. An upward bias is also consistent with the fact that the $M_{L}=4.4$ event on September 6, 2003 was not detected by the global seismic network on stations in Puerto Rico or the Canary Islands, which have a detection threshold of $M_{L} \approx 3.8$. Overall it appears as though our geophone derived moment estimates are fairly accurate within the $M_{L}$ range $1.5-2.5$, but may be as much as $20 \%$ too high for larger events. This discrepancy will be resolved by further studies include inspection of ambient noise spectra. 


\subsubsection{Recurrence interval}

The recurrence interval for earthquakes along the detachment fault is roughly half (33.329 minutes) that observed for events beneath the eastern valley wall (63.664 minutes) (Figure 9). These recurrence intervals are nearly identical to the time interval that is calculated by dividing the total number of earthquakes by the total time of the experiment, which yields values of 33.331 minutes for events along the detachment fault and 63.652 minutes for events beneath the eastern valley wall.

We fit gamma probability distribution functions to the measured recurrence intervals along the detachment fault and eastern boundary faults and calculated shape parameters of 0.73 and 0.31 and scaling parameters of 2,732 and 12,220 s $\mathrm{s}^{-1}$, respectively. These shape parameters are similar to a microearthquake study near the San Andreas fault, which calculated shape parameters ranging from 0.3 to 0.8 (Udias and Rice, 1975).

\subsubsection{Depth analysis}

Earthquakes are deeper along the detachment fault than within the eastern valley wall. Earthquakes occur down to greater than $7 \mathrm{~km}$ depth along the detachment fault and to approximately $6 \mathrm{~km}$ beneath the axial valley wall. The average earthquake depth is 4.8 kilometers below the seafloor along the detachment fault compared to $3.8 \mathrm{~km}$ depth from events along eastern boundary faults (Figure 10a-b). Along the detachment fault the total moment release is greatest where the largest number of earthquakes occur (Figure 10c-d). On average, however, earthquakes become larger as a depth increases (Figure 10e-f). Earthquakes along the eastern side of the axial valley show similar characteristics. A large event on day 249 , however, clearly dominates the seismic moment plots at $6.5 \mathrm{~km}$ depth below the sea floor (Figure 10f).

\subsection{Clustering Analysis}

We used waveform cross-correlation techniques to group similar events into discrete clusters. Cross-correlation estimates were made using the vertical OBS channel ( $P$ and $S$ arrivals) for all 19,232 earthquakes, and clusters were formed by identifying earthquake pairs with cross-correlations coefficients $\geq 0.6$ (Shearer, 1997). We identified 1,730 clusters, encompassing 12,459 of the 19,232 events observed during the 
observational period. The vast majority of these clusters contain only a few events (Figure 11). The spatial distribution of the 40 largest clusters is shown in Figure 12a and b. These clusters are distributed on both sides of the active hydrothermal mound, and have spatial dimensions of several kilometers. The highest concentration of clusters is northwest of the active TAG mound.

Clusters can be grouped into three general categories: (1) clusters with relatively constant seismic activity throughout the observation period (Figure 13a); (2) swarm-like clusters with relatively intense seismic activity over a short interval of time (Figure 13b); and (3) clusters that exhibit characteristics of both (1) and (2), e.g. relatively steady seismic activity punctuated by at least one period of intense seismic activity (Figure 13c). The majority of clusters ( 37 out of 40 ) exhibits constant seismic activity throughout the deployment and are grouped in categories one and three. The average recurrence interval for events within these clusters is approximately 230 hours. This remarkably consistent level of microearthquake activity is a key feature of faulting and deformation along the TAG segment. The observation of many small clusters with relatively steady levels of seismicity through the observation period suggests that deformation along the TAG segment is accommodated by steady slip on small patches.

Several clusters clearly delineate fault dips (Figure 15). The orientation of these earthquake hypocenters are consistent with the focal mechanisms and hypocenter locations constrained using stochastic grid-search methods (deMartin et al., submitted). Events along the detachment fault are oriented along a fault dipping at approximately $70^{\circ}-80^{\circ}$. Detachment fault events occur $6-10 \mathrm{~km}$ beneath the sea surface, compared to eastern events that occur 4-6 km beneath the sea surface. Events associated with deformation in the footwall of the detachment fault indicate an antithetical orientation with a dip of $60^{\circ}$ to the west. The geometry suggested from the clustering analysis is consistent with geophysical models, which predict steep normal faulting along the active detachment fault and antithetical normal faulting at $\sim 60^{\circ}$ in the rotated footwall (Buck, 1988).

If extension in the region is equally partitioned between detachment fault and eastern faults, the steeper orientation of the detachment fault suggests a greater number of events must occur along the detachment fault to accommodate a similar amount of 
extension. If we use the orientations observed in Figure 15, and estimate a dip of $75^{\circ}$ for the detachment fault and $60^{\circ}$ for the eastern boundary fault, then from geometric arguments we must have approximately 1.9 more events along the detachment fault than the eastern boundary faults. This is remarkably close to our earlier observations that indicate the detachment fault is approximately twice as active as the eastern boundary fault.

\subsection{Discussion}

The TAG segment of the Mid-Atlantic Ridge has been the focus of two previous seismic studies. Kong et al., (1992) reported results from a three week microearthquake survey of the TAG segment of the Mid-Atlantic Ridge conducted during the summer of 1985. Their ocean bottom seismic network consisted of seven ocean bottom hydrophones and three ocean bottom seismometers. All the instruments except one OBS recorded high quality data throughout the deployment. Their network encompassed an area $20 \times 10 \mathrm{~km}$ and straddled the axial valley floor and the eastern wall from $26^{\circ} 09^{\prime} \mathrm{N}$ southward into the $4500 \mathrm{~m}$ bathymetric deep.

Kong et al., (1992) detected 1600 events over the 23-day deployment, with over 400 events recorded by more than 5 instruments. Hypocenter estimates were obtained for 189 earthquakes, yielding average of 8.5 events per day. The daily number of locatable events ranged from 1 to 12 . Earthquake moments ranged from $4 \times 10^{17}$ to $6 \times 10^{22}$ dyne$\mathrm{cm}$, with $75 \%$ of the earthquakes having moments between $2 \times 10^{18}$ to $6 \times 10^{19}$ dyne-cm. Size-frequency analysis of the earthquake moments yields a $b$ value for all the instruments of $1.02 \pm 0.08$. The cumulative number of earthquakes increased at a relatively continuous rate throughout the deployment, with a notable increase in seismicity rates after a swarm of 5 teleseismic events occurred about $30 \mathrm{~km}$ south of the network during the deployment. Ocean bottom hydrophones deployed within the axial valley recorded considerable more activity than ocean bottom hydrophones deployed on the eastern valley wall. Focal depths of well-recorded earthquakes cluster between 3 and $7 \mathrm{~km}$ below the seafloor. Kong et al., (1992) concluded that events within the axial valley occurred at shallower depths than eastern valley events owing to the presence of a lowvelocity zone beneath the axial valley. 
Our microearthquake survey shares many similarities with the Kong et al., (1992) study. Like Kong et al., (1992), we found low rates of seismic activity near the zone of active hydrothermal venting, we observe a smooth, continuous increases in the cumulative number of events versus time, a $b$-value close to 1 , steep faulting within the axial valley, and significantly more events within the axial valley compared to the eastern valley wall. In addition, the seismic moments calculated in Kong et al., (1992) fall within a similar range as our moment estimates.

One of the most striking differences between the Kong et al., (1992) study and our microearthquake survey is the large difference in seismicity rates. We detected approximately 80 events per day, an order of magnitude greater than Kong et al., (1992). This difference can be attributed to the denser seismic network and more sophisticated instruments used during our more recent deployment. We used a denser array of 4compnent ocean bottom seismometers, and consequently we were able to detect significantly more events. We estimate a completeness value for our catalog of approximately $10^{18}$ dyne-cm compared to a completeness value of $10^{19}$ dyne-cm for the Kong et al., (1992) study. This order of magnitude difference in completeness is reflected in an order of magnitude differences in seismicity rates. This result suggests that seismicity rates in 1985 are not significantly different from what we observed in 2003-4.

Another significant difference between the Kong et al., (1992) study and our results is that we predict deeper earthquakes within the axial valley. Kong et al., (1992) used delay time tomography to constrain the velocity structure at the TAG segment. This technique can provide misleading results if earthquakes are not homogeneously scattered throughout a region. The absence of microearthquakes beneath the active TAG mound, and the configuration of their seismic network, led Kong et al. (1992) to propose a low velocity zone beneath the active TAG mound. This results also lead them to underestimate the depth of earthquakes in the axial valley. We obtain deeper hypocenter estimates for events within the axial valley owing to a significantly improved velocity model (Canales, et al., in prep.) that prohibits the presence of a low-velocity zone beneath the axial valley. The tomographic model constrained from the seismic refraction study has a high-velocity foot wall and low-velocity hanging wall, which could have lead 
Kong et al., (1992) to under predict the depth of seismicity beneath the axial valley and over predict the depth of earthquakes beneath the eastern valley wall.

Smith et al., (2003) described spatial and temporal patterns of seismic activity along the northern Mid-Atlantic Ridge (between $15^{\circ}$ and $35^{\circ} \mathrm{N}$ ) using hydroacoustically detected events. The magnitude of completeness of the hydrophone data set is $\sim 3.0$, with numerous smaller events being recorded. This completeness magnitude is appreciably less than the teleseismic detection limit and provides clearer picture of seismicity along the Mid-Atlantic Ridge. Smith et al., (2003) recorded 3485 events on four or more hydrophones positioned within the SOFAR channel during an approximately 2 years period. Their analysis indicates that while the TAG segment has a relatively low number of teleseismic events over the time period of 1973-2001 compared to other segments of the Mid-Atlantic Ridge, it is one of the more hydroacoustically active segments. This evidence suggests that numerous small earthquakes, as opposed to a few large earthquakes, accommodate slip at the TAG Segment. This observation is consistent with the results from our microearthquake study that suggest slip is taken up by large numbers of small events. In addition to recording significant numbers of smaller events along the TAG segment, Smith et al., [2003] failed to observe an aftershock sequence following a teleseismic event that occurred along eastern valley wall of the TAG segment during their hydrophone deployment. This result agrees very well with our conclusion that faulting at TAG lacks a clear mainshock-aftershock sequence.

\subsection{Comparison To Other Fault Systems}

Earthquakes are rarely isolated events and typically occur as part of mainshockaftershock sequences (Scholz, 2002). Aftershock sequences are generally observed for shallow tectonic earthquakes, and the number of earthquakes following a mainshock has been shown to be linearly proportional to the area of the mainshock area (Yamanaka and Shimazaki, 1990). This scaling relationship suggests that stress generated by a mainshock is scale-invariant and earthquakes of all sizes should trigger aftershock sequences. Based on these scaling relationships several earthquakes throughout our deployment should have triggered detectable aftershock sequences. In most cases, however, we failed to observe significant mainshock-aftershock activity. 
The creeping section of the San Andreas Fault (SAF) (Steinbrugge et al., 1960; Tocher, 1960) is unique among crustal faults in that like the TAG segment it does not exhibit the typical mainshock-aftershock sequence (Figure 16). We compared the cumulative rate of earthquakes along the creeping section of the SAF to the TAG segment of the Mid-Atlantic Ridge over the same time range (Figure 16b). The area where microearthquakes are observed is roughly the same for the two regions, and both regions trigger approximately the same magnitude earthquakes. Seismicity rates are approximately constant for both the creeping section of the SAF and the detachment fault of the TAG segment; however, the overall number of earthquakes along each systems is dramatically different. There are over two orders of magnitude fewer earthquakes along the creeping section of the SAF than along the TAG segment. Moment summation of the microearthquakes along the creeping section of the SAF shows that seismicity accounts for only about $2 \%$ of the total moment release (Amelung and King, 1997). Given the extremely high rates of seismicity along the TAG segment, we suspect a significantly greater portion of extension is accommodated seismically in this area than along the creeping section of the SAF. The observation of steady-state slip along both the creeping section of the SAF and at the TAG segment of the Mid-Atlantic Ridge suggests that similar processes may be important in both regions. Ultimately, the lithology, pore fluid pressure, and loading conditions of the fault zone will determine if sliding is stable or unstable and seismic or aseismic. Understanding similarities and difference between these two regions will provide fundamental constraints on the mechanics of earthquakes and faulting in these two regions.

\subsection{Geological Implications of Faulting at TAG}

Detachment faulting at TAG has been active for the past 175 to $340 \mathrm{ky}$ (Tivey et al., 2003). In this time period, the detachment fault has accommodated $3.9 \mathrm{~km}$ of horizontal extension (Tivey et al., 2003). Seafloor exposures of gabbros and dikes (Zonenshain et al., 1989) indicate deeper crustal sequences have been uplifted by detachment faulting. Along with exhuming lower crustal rocks, mantle peridotite is also likely being uplifted by extension along the detachment fault footwall. The lithologies present along the base of the detachment fault are likely highly variable along strike. 
Conservation of energy calculations dictate that a cooling magma body (Humphris and Cann, 2000) must provide the necessary energy source to drive high-temperature, hydrothermal circulation system at the active TAG mound. As discussed in deMartin et al., (submitted), fluids penetrate down along the flanks of the detachment fault, extract heat from the cooling magma chamber near the crust/mantle interface, and return to the surface along the detachment fault. Downward percolating fluids likely tap heat from discrete magma chambers spatially isolated along the base of the detachment fault. Cooling magma chambers will crystallize to form gabbro. In regions between crystallized magma reservoirs, mantle peridotite will be present. The detachment fault surface is thus likely comprised of patches of gabbro, peridotite and their alteration products. These lithologically distinct patches will generate unique rupture patterns owing to differences in frictional coefficients and might represent what we are imaging with our clustering analysis. The spatially variable, episodic nature of high-temperature discharge inferred from the geochronology of the TAG deposits (Lalou et al., 1995) and energy balance calculations (Humphris and Cann, 2000) could result from episodic replenishment of the melt reservoir, episodic perturbations to the permeability structure within the convection system, or some combination of both.

\section{References:}

Amelung, F., and King, G.C.P., 1997, Earthquake scaling laws for creeping and noncreeping faults: Geophys. Res. Let., v. 24, p. 507-510.

Bame, D., and Fehler, M., 1986, Observations of long period earthquakes accompanying hydraulic fracturing: Geophys. Res. Let., v. 13, p. 149-152.

Brune, J.N., 1970, Tectonic stress and the spectra of seismic shear waves from earthquakes: J. Geophys. Res., v. 75, p. 4997-5009.

Buck, R.W., 1988, Flexural rotation of normal faults: Tectonics, v. 7, p. 959-973.

deMartin, B., Reves-Sohn, R., Canales, J.P., and Humphris, S., submitted, Kinematics and geometry of active detachment faulting beneath the TAG hydrothermal field on the Mid-Atlantic Ridge: Geology.

Eberhart, G.L., Rona, P.A., and Honnorez, J., 1988, Geological controls of hydrothermal activity in the Mid-Atlantic Ridge: Marine Geophysical Research, v. 10, p. 233259.

Ferrazzini, V., Chouet, B., Fehler, M., and Aki, K., 1990, Quantitative analysis of longperiod events recorded during hydrofracture experiments at Fenton Hill, New Mexico: J. Geophys. Res., v. 95, p. 21,871-21,884.

Hanks, T.C., and Thatcher, W., 1972, A graphical representation of seismic source parameters: J. Geophys. Res., v. 77, p. 4393-4405. 
Humphris, S.E., and Cann, J.R., 2000, Constraints on the energy and chemical balances of the modern TAG and ancient Cyprus seafloor sulfide deposits: J. Geophys. Res., v. 105 , p. $28,477-28,488$.

Humphris, S.E., and Tivey, M.K., 2000, A synthesis of geological and geochemical investigations of the TAG hydrothermal field; insights into fluid-flow and mixing processes in a hydrothermal system, in Dilek, Y., Moores, E.M., Elthon, D., and Nicolas, A., eds., Special Paper - Geological Society of America, vol. 349, p. 213-235.

Kedar, S., Sturtevant, B., and Kanamori, H., 1996, The origin of harmonic tremor at Old Faithful Geyser: Nature, v. 379, p. 708-711.

Kleinrock, M.C., and Humphris, S.E., 1996, Structural control on sea-floor hydrothermal activity at the TAG active mound: Nature, v. 382, p. 149-153.

Kong, L.S.L., 1990, Variations in Structure and Tectonics along the Mid-Atlantic Ridge, $23^{\circ} \mathrm{N}$ and $26^{\circ} \mathrm{N}$ : Cambridge, MA.

Kong, L.S.L., Solomon, S.C., and Purdy, G.M., 1992, Microearthquake characteristics of a mid-ocean ridge along-axis high: J. Geophys. Res., v. 97, p. 1659-1685.

Lalou, C., Reyss, J.-L., Brichet, E., Rona, P.A., and Thompson, G., 1995, Hydrothermal activity on a $10^{5}$-year scale at a slow-spreading ridge, TAG hydrothermal field, Mid-Atlantic Ridge $26^{\circ}$ N: J. Geophys. Res., v. 100, p. 17,855-17,862.

McClain, J.S., Begnaud, M.L., Wright, M.A., Fondrk, J., and Von Damm, G.K., 1993, Seismicity and tremor in a submarine hydrothermal field: the northern Juan de Fuca Ridge: Geophys. Res. Lett., v. 20, p. 1883-1886.

Purdy, G.M., and Detrick, R.S., 1986, Crustal structure of the Mid-Atlantic Ridge at $23^{\circ} \mathrm{N}$ from seismic refraction studies: Journal of Geophysical Research, v. 91, p. 37393762.

Rona, P.A., Hannington, M.D., Raman, C.V., Thompson, G., Tivey, M.K., Humphris, S.E., Lalou, C., and Petersen, S., 1993, Active and relict sea-floor hydrothermal mineralization at the TAG hydrothermal field, Mid-Atlantic Ridge: Econ. Geol., v. 88, p. 1987-2013.

Scholz, C.H., 2002, The Mechanics of Earthquakes and Faulting: Cambridge, Cambridge University Press, $471 \mathrm{p}$.

Sempere, J.-C., Purdy, G.M., and Schouten, H., 1990, Segmentation of the Mid-Atlantic Ridge between 24 degrees $\mathrm{N}$ and 30 degrees $40^{\prime} \mathrm{N}$ : Nature, v. 344, p. 427-431.

Shearer, P.M., 1997, Improving local earthquake locations using the L1 norm and waveform cross-correlation: Application to the Whittier Narrows, California aftershock squence: J. Geophys. Res., v. 102.

Smith, D.K., Cann, J.R., and Escartín, J., 2006, Widespread active detachment faulting and core complex formation near $13^{\circ} \mathrm{N}$ on the Mid-Atlantic Ridge: Nature, v. 442, p. 440-443.

Smith, D.K., Escartin, J., Cannat, M., Tolstoy, M., Fox, C.G., Bohnenstiehl, D.R., and Bazin, S., 2003, Spatial and temporal distribution of seismicity along the northern Mid-Atlantic Ridge $\left(15^{\circ} \mathrm{N}-35^{\circ} \mathrm{N}\right)$ : J. Geophys. Res., v. 108, p. doi:10.1029/2002JB001964.

Sohn, R.A., Hildebrand, J.A., and Webb, S.C., 1998, Postrifting seismicity and a model for the 1993 diking event on the CoAxial segment, Juan de Fuca Ridge: J. Geophys. Res., v. 103, p. 9867-9877. 
Sohn, R.A., Hildebrand, J.A., Webb, S.C., and Fox, C.G., 1995, Hydrothermal microseismicity at the megaplume site on the Southern Juan de Fuca Ridge: Bulletin of the Seismological Society of America, v. 85, p. 775-786.

Steinbrugge, K.V., Zacher, E.G., Tocher, D., Whitten, C.A., and Claire, C.N., 1960, Creep on the San Andreas fault: Bull. Seismol. Soc. Am., v. 50, p. 389-415.

Temple, D.G., Scott, R.B., and Rona, P.A., 1979, Geology of a submarine hydrothermal field, Mid-Atlantic Ridge, $2^{\circ} \mathrm{N}$ latitude: J. Geophys. Res., v. 84, p. 7453-7466.

Thompson, G., Mottl, M.J., and Rona, P.A., 1985, Morphology, mineralogy and chemistry of hydrothermal deposits from the TAG area, 26 degrees N, MidAtlantic Ridge, in Kitano, Y., ed., Chemical Geology, Volume 49, p. 243-257.

Tivey, M.A., Schouten, H., and Kleinrock, M.C., 2003, A near-bottom magnetic survey of the Mid-Atlantic Ridge axis at $26^{\circ} \mathrm{N}$ : Implications for the tectonic evolution of the TAG segment: J. Geophys. Res., v. 108, p. doi:10.1029/2002JB001967.

Tocher, D., 1960, Creep rate and related measurements at Vineyard, California: Bull. Seismol. Soc. Am., v. 50, p. 396-404.

Udias, A., and Rice, J., 1975, Stastical analysis of microearthquake activity near San Andreas Geophyical Observatory, Hollister, California: BSSA, v. 65, p. 809-827.

Wilcock, W.S.D., and Delaney, J.R., 1996, Mid-ocean ridge sulfide deposits: Evidence for heat extraction from magma chambers or cracking fronts?: Earth Planet. Sci. Lett., v. 145, p. 49-64.

Yamanaka, Y., and Shimazaki, K., 1990, Scaling relationship between the number of aftershocks and the size of the main shock: J. Phys. Earth, v. 38, p. 305-324.

Zonenshain, L.P., Kuz'min, M.I., Lisitsin, A.P., Bogdanov, Y.A., and Baranov, B.V., 1989, Tectonics of the Mid-Atlantic rift valley between the TAG and MARK areas $\left(26-24^{\circ} \mathrm{N}\right)$; evidence for vertical tectonism: Tectonophys., v. 159, p. 1-23.

Zonenshain, L.P., Lisitsin, A.P., Kuzmin, M.I., Bogdanov, Y.A., and Anonymous, 1990, Tectonics and hydrothermal activity in the TAG area (central Atlantic) according to MIR submersible dives, Eos, Transactions, American Geophysical Union, Volume 71, p. 1650. 


\section{Figure Captions}

Figure 1. Overview maps. (a) Bathymetry of the TAG Segment of the Mid-Atlantic Ridge. Inset identifies the geographic location of the study area. Current hightemperature venting is focused at the active TAG mound (brown star). Neovolcanic zones identified by side-scan sonar shown in transparent red. Ocean bottom seismometers (solid white circles) are arranged in a series of three rings. Dashed lines identify the outer ring and middle rings, located approximately 3.5 and $1 \mathrm{~km}$ from the active TAG mound. (b) Micro-bathymetric map of the TAG mound made using the SM2000 on Jason2. The active mound comprises two platforms. Active venting is currently focused at the northwest corner of the top platform. Inner-ring OBS's are identified with white circles. Temperature probes in high-temperature (black squares) and low-temperature (white square) vents also shown.

Figure 2. Active mound seismicity. Seismicity at the active TAG mound is characterized by short, harmonic events. (a) Seismogram for an inferred hydrothermal event at the active TAG mound recorded on the inner-ring OBS's. Data has been bandpass filtered at $5-40 \mathrm{~Hz}$. (b) Histogram of inner-ring seismicity. We detected approximately 100 events/day throughout the first $2 / 3$ of the experiment. Increased whale activity after day 325 obscures subsequent seismic activity at the active mound.

Figure 3. Tectonic seismicity. (a) Sample waveforms from an event located along the detachment fault (vertical and one horizontal channel shown). Data has been bandpass filtered at 5-40 Hz. Automatic compressional $(P)$ and shear $(S)$ arrivals indicated. (b) Histogram of detected and located tectonic events. Approximately 80 events/day were detected and located on all instruments. Seismic activity appears to have decreased throughout the deployment.

Figure 4. Earthquake epicenters (gray dots) shown with ocean bottom seismometers (inverted triangles) and active TAG mound (brown star). Five seismometers were deployed within approximately $50 \mathrm{~m}$ of the active TAG mound, and are not shown at this scale. We constrained hypocenters using the methods described in Chapter 4. We group earthquakes into four geographical areas. Events along the detachment fault are shown in blue (region I), and events within the eastern valley wall are shown in red (region II). Mean earthquake uncertainty at the $95 \%$ confidence interval and a $5 \mathrm{~km}$ scale bar is shown in the lower right.

Figure 5. Histograms of daily earthquake activity from (a) the detachment fault (blue) and (b) eastern valley wall (red). Select days with anomalously high seismic activity noted. The detachment fault averages twice as many earthquakes per day than the faults within the eastern boundary wall.

Figure 6. Along strike variation in earthquake hypocenters plotted a function of time. Earthquakes projected onto the line separating regions I from II in Figure 1, where the active TAG mound represents $0 \mathrm{~km}$ along strike. The strike of this line corresponds to the 
approximate strike of the axial valley in this region. Earthquakes occur along the entire strike of (a) the detachment fault (blue) and (b) the eastern valley wall events (red) throughout the observational period.

Figure 7. Time series analysis. (a) Cumulative number of events and (b) moment release plotted as function of time for the detachment fault (blue) and the eastern boundary faults (red). The cumulative number of events increases relatively steadily through time for events in both regions I and II. Cumulative moment release calculated using vertical channels increases relatively uniformly, with notable exceptions. Constraints from nearby broadband instruments and the seismic moment estimate from geophone data suggests the seismic moment release for the large event along the eastern side of the axial valley on day 249 is $20-25 \%$ too high. Total moment release for this event is more similar to the size of the large events along the detachment fault near the end of the deployment.

Figure 8. Size-frequency analysis for (a) events along the detachment and (b) events within the eastern valley wall. Both regions have $b$-values approximately equal to 1 , consistent with tectonic faulting.

Figure 9. Histograms of recurrence interval between two consecutive events for (a) detachment faults (red) and eastern boundary faults (blue). The median time between earthquakes is 17 min for detachment faults and 31 min for eastern boundary faults.

Figure 10. Earthquake characteristics as a function of depth below the seafloor. Hypocenter locations are deeper for (a) detachment fault events (blue) than (b) eastern boundary fault events (red). The sum of earthquake moments at a given depth (c) along the detachment fault and (d) within the eastern valley wall is greatest where the most number of events occurs. Average earthquake moments (e) along the detachment fault and (f) within the eastern valley wall generally decrease at shallower depths.

Figure 11. Number of earthquakes in clusters delineated by a minimum cross-correlation coefficient of 0.6 . We show (a) linear and (b) log plots. We identified 1730 clusters with at least two events. Increasing or decreasing the minimum cross-correlation coefficients divides earthquakes into fewer clusters with more earthquakes.

Figure 12. Map view of the forty largest clusters identified from the histogram in Figure 11 (a) epicenters and (b) scaled centroids. Cluster centroids are scaled to the number of events in the cluster (scale in the lower right). Earthquake clusters are identified both to the east and west of the active hydrothermal system. The largest clusters in terms of spatial extent and number of events are grouped north-northeast of the active TAG mound.

Figure 13. Histograms of the number of earthquakes per day for a few example clusters. All clusters show strong spatial constrains; however, clusters can show one of three temporal characteristics: (a) steady activity throughout the observational period, (b) periods of intense activity with extremely few other events observed, or (c) a combination of both. 
Figure 14. Spatially clustered events with well-delineated cross-sections: (a) epicenters and (b) hypocenters. Eastern events dip approximately $60^{\circ}$ to the west. Hypocenters are more dispersed for the detachment fault events, but their orientation is consistent with steep normal faulting dipping to the west.

Figure 15. Cumulative number of events versus time for the (a) creeping section and locked portion of the San Andreas fault (SAF). The events along creeping section are within the region between $36.368 \%-120.934^{\circ}$ and $36.096 \%-120.657^{\circ}$ and the depths $2-10$ $\mathrm{km}$. The events from the locked zone are from the area between $35.978 \%-120.537^{\circ}$ and $35.749^{\circ} / 120.306^{\circ}$ and depths between $3-12 \mathrm{~km}$. (b) The cumulative number of events versus time along the creeping section of the SAF compared to the cumulative number of events along the detachment fault of the TAG segment. Scale for the creeping section events shown at right, scale for detachment fault events shown at left. 

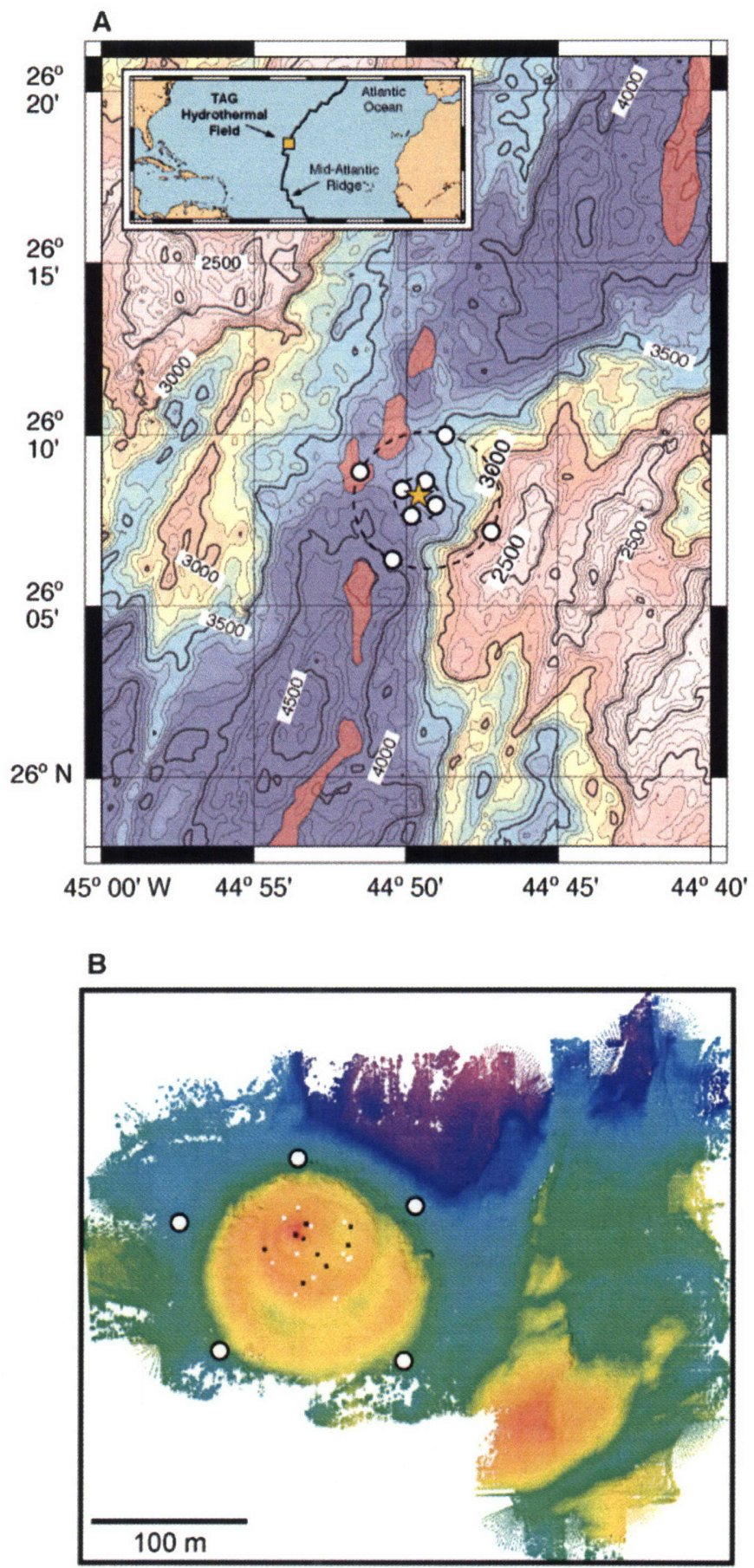

Figure 1. 

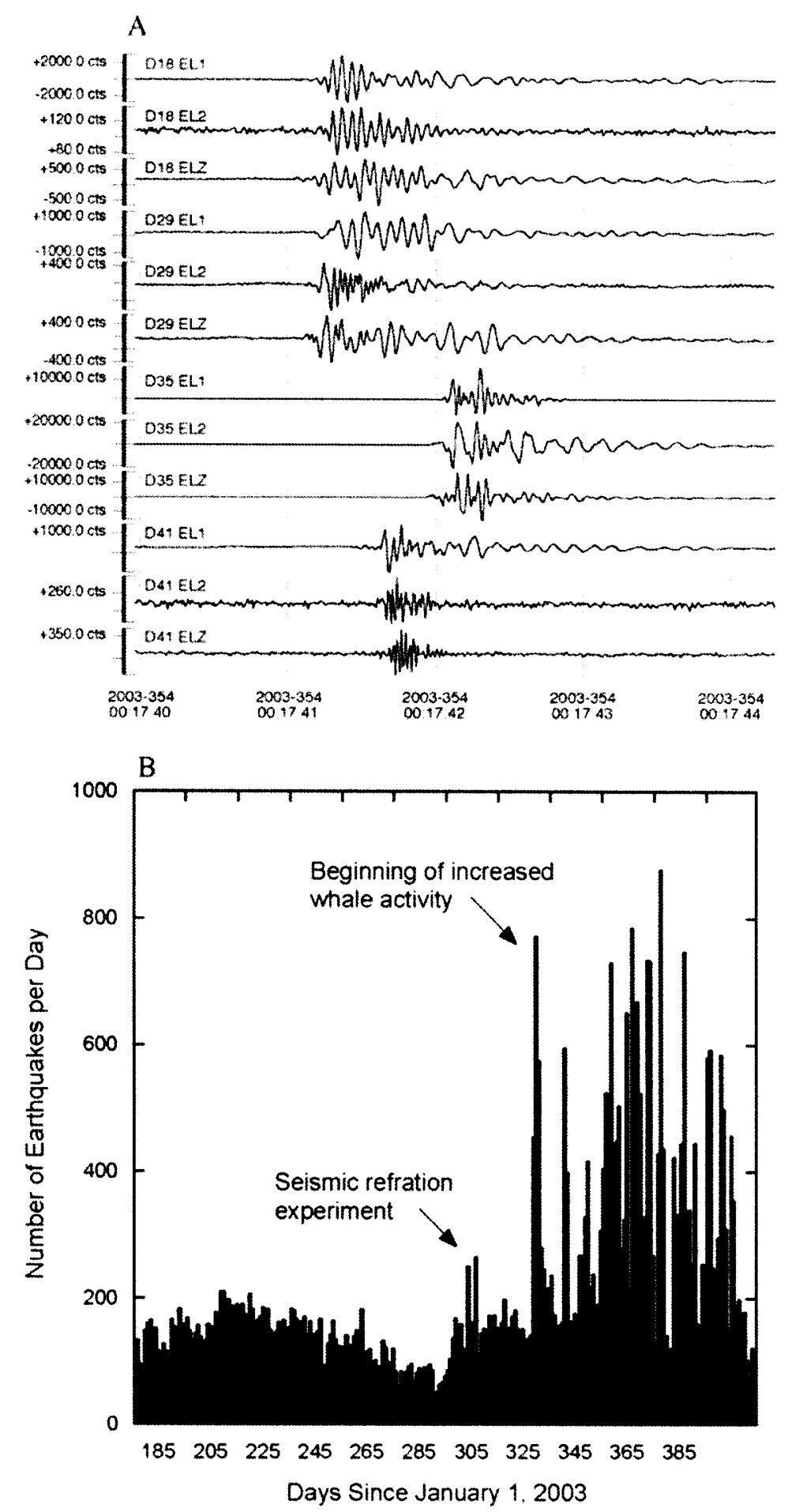

Figure 2. 


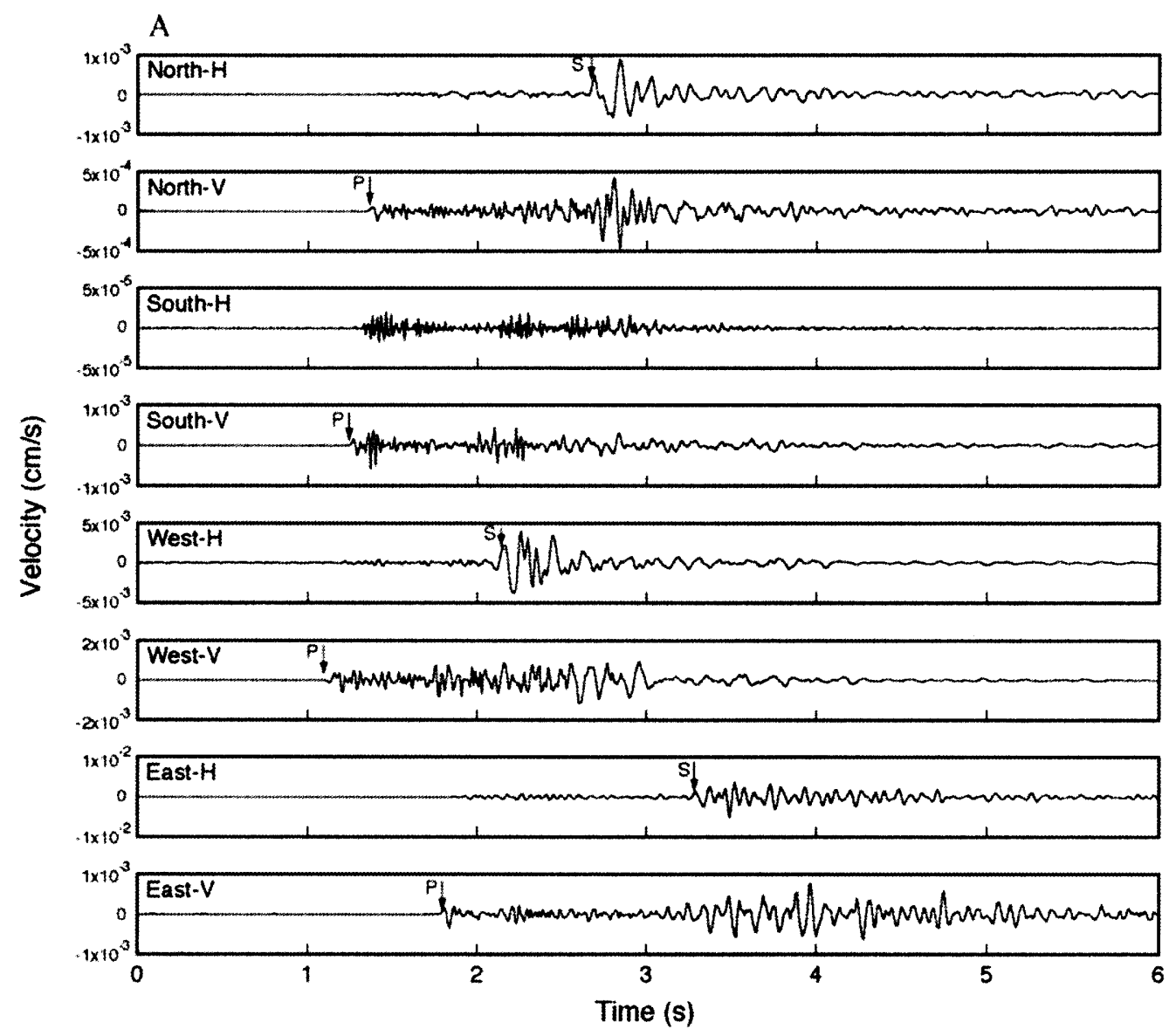

B

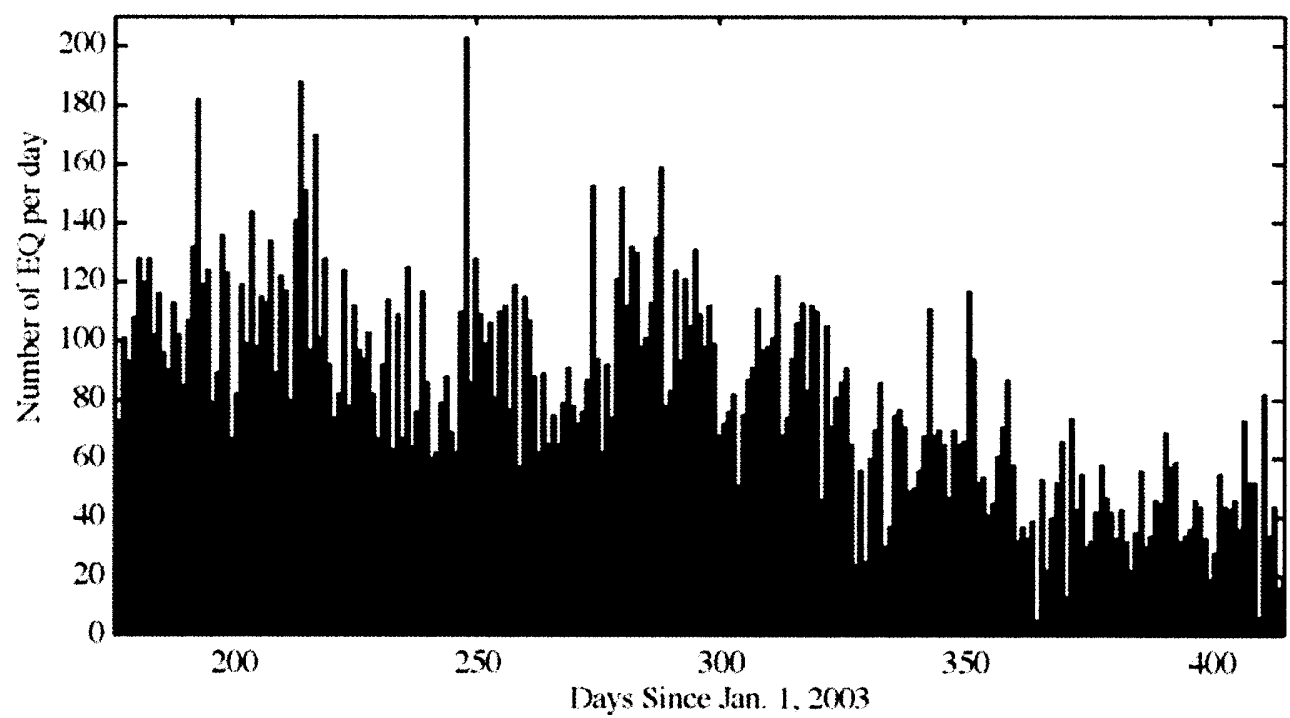

Figure 3. 


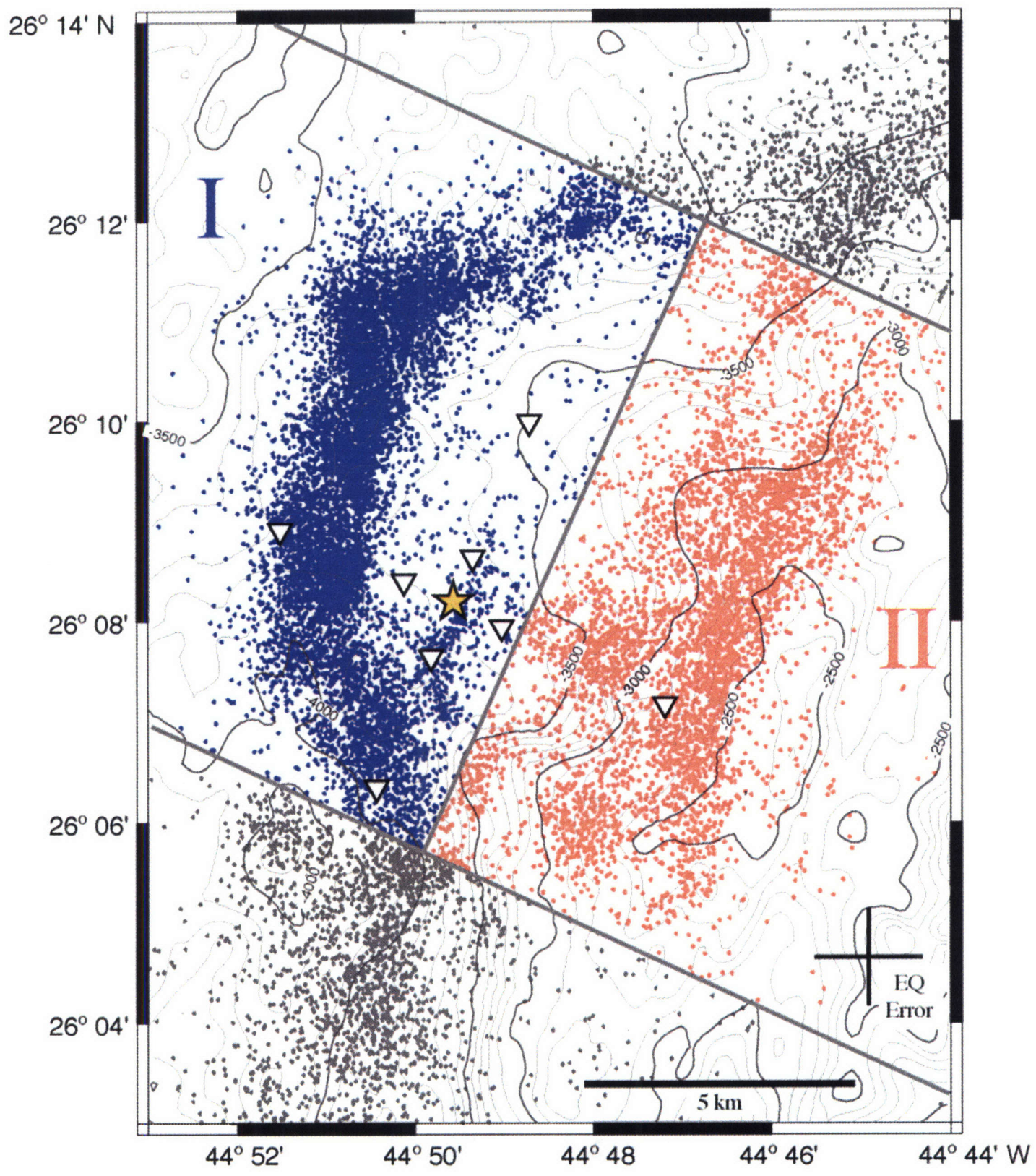

Figure 4 . 

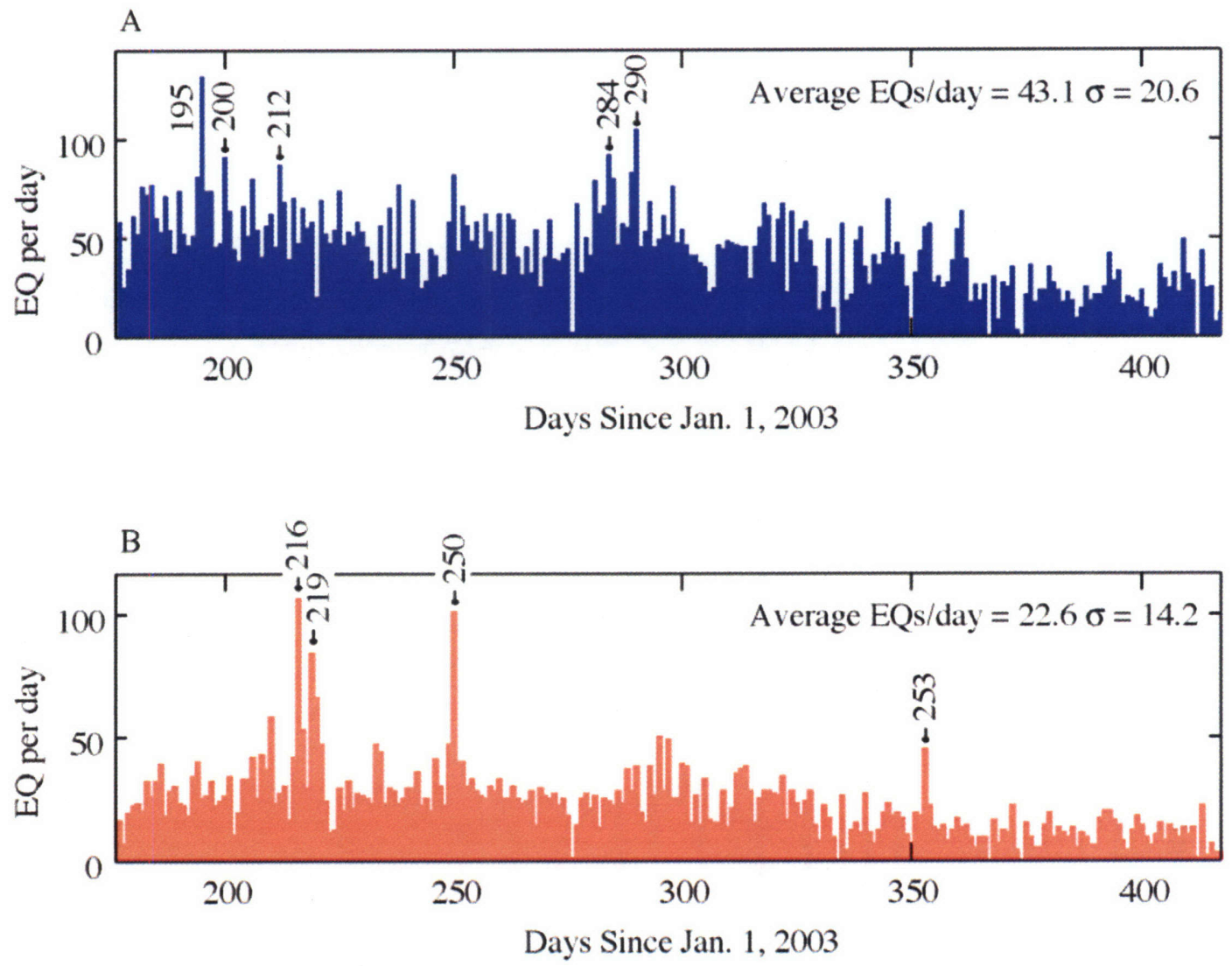

Figure 5. 

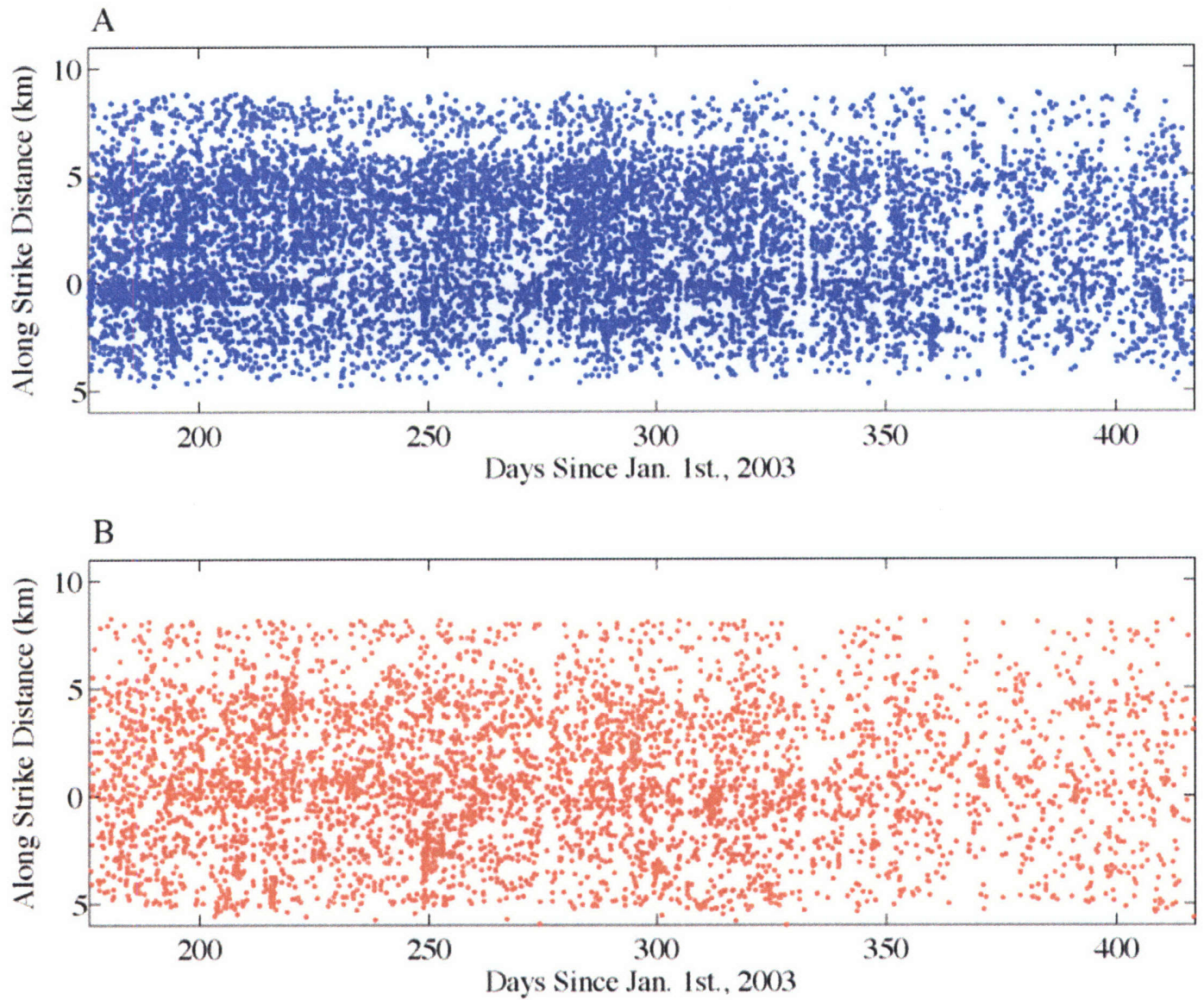

Figure 6. 

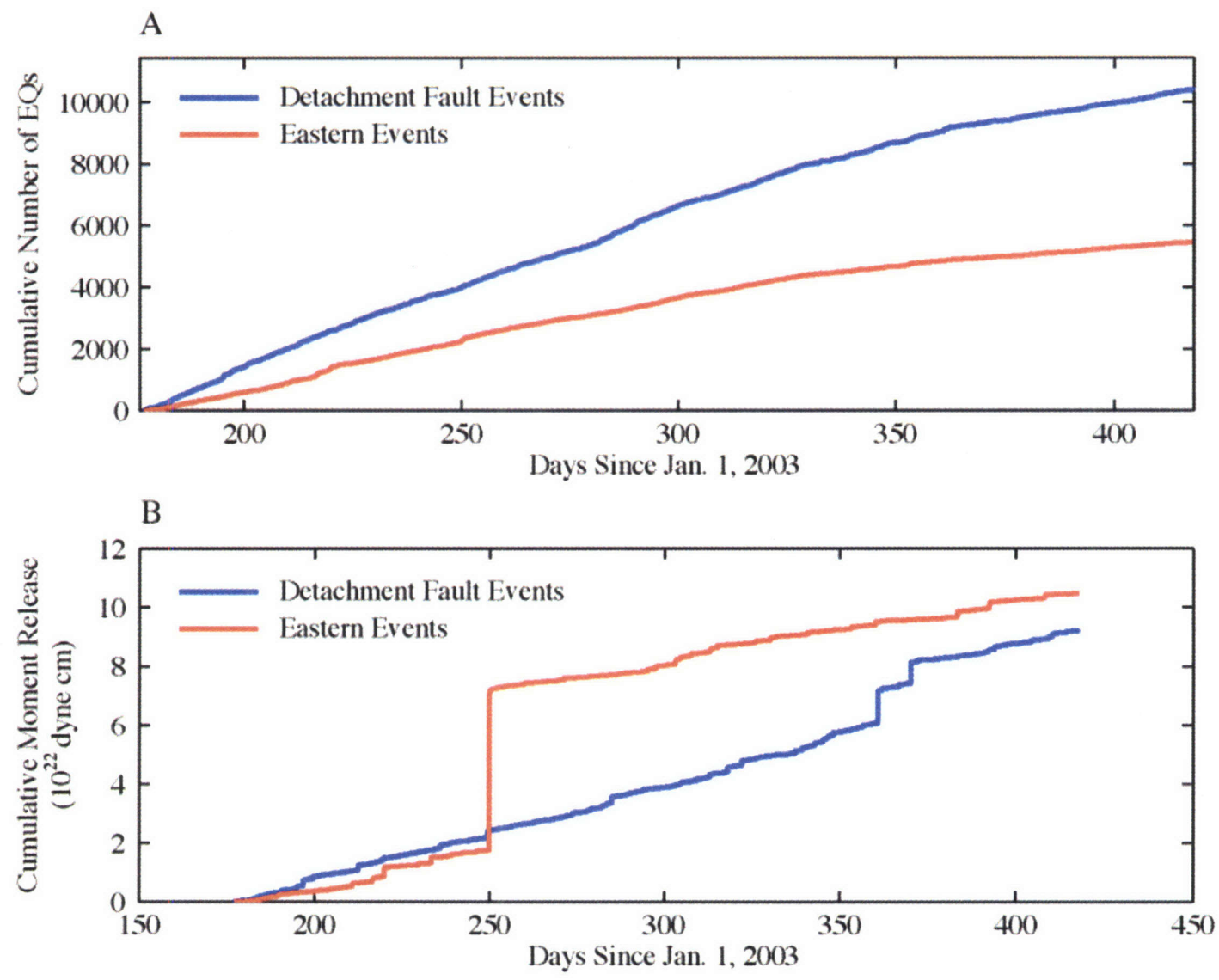

Figure 7. 

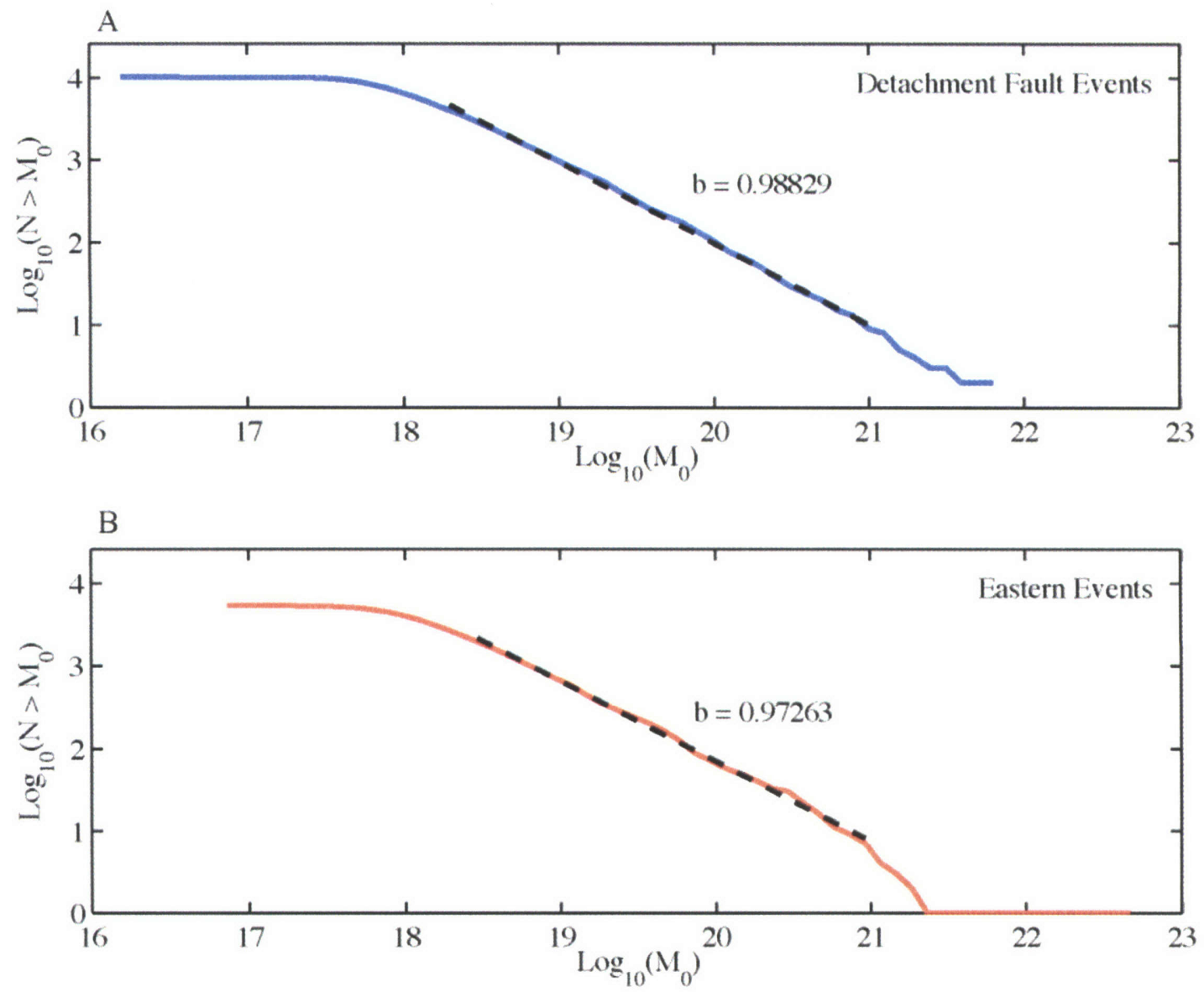

Figure 8 . 

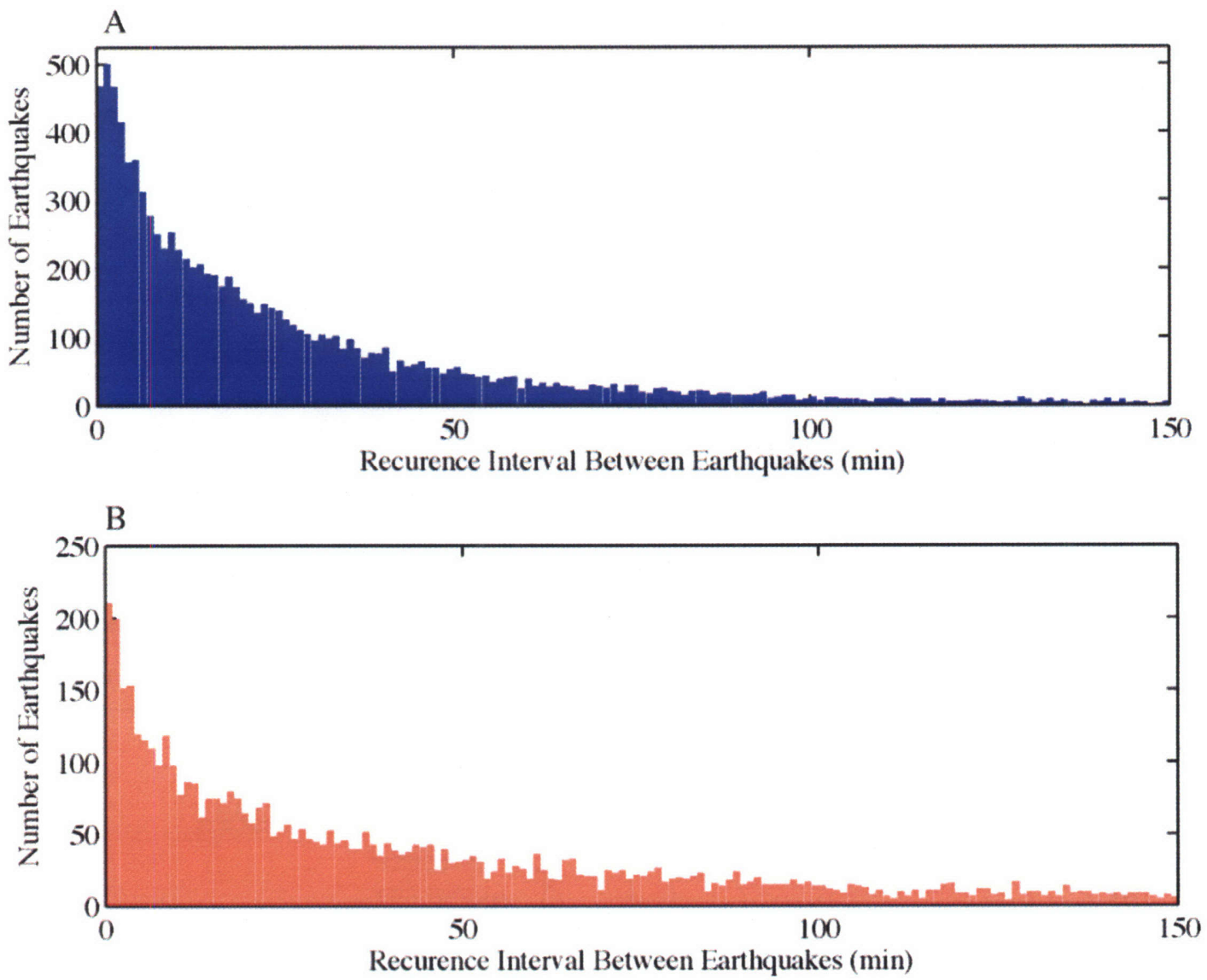

Figure 9. 

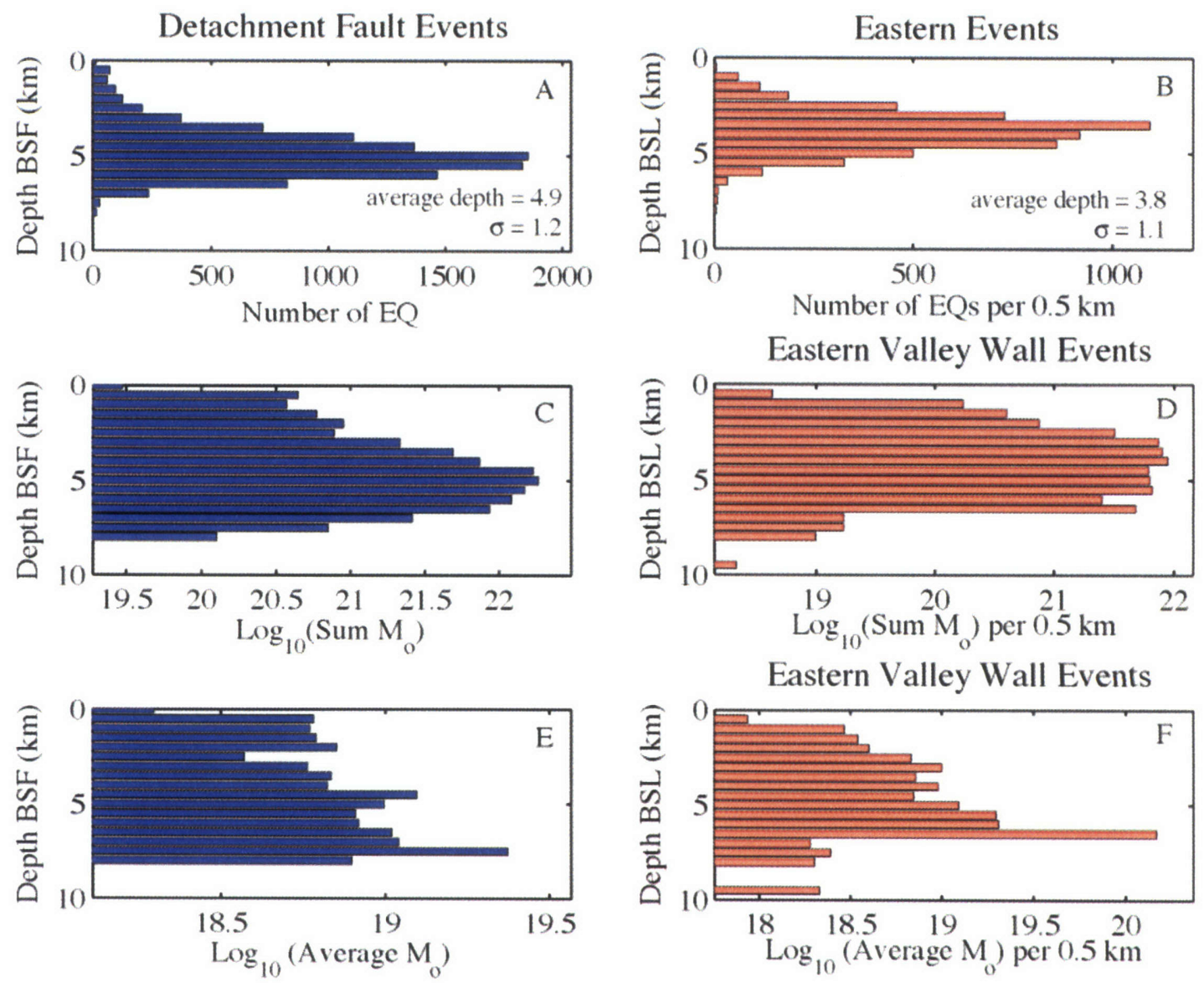

Figure 10. 

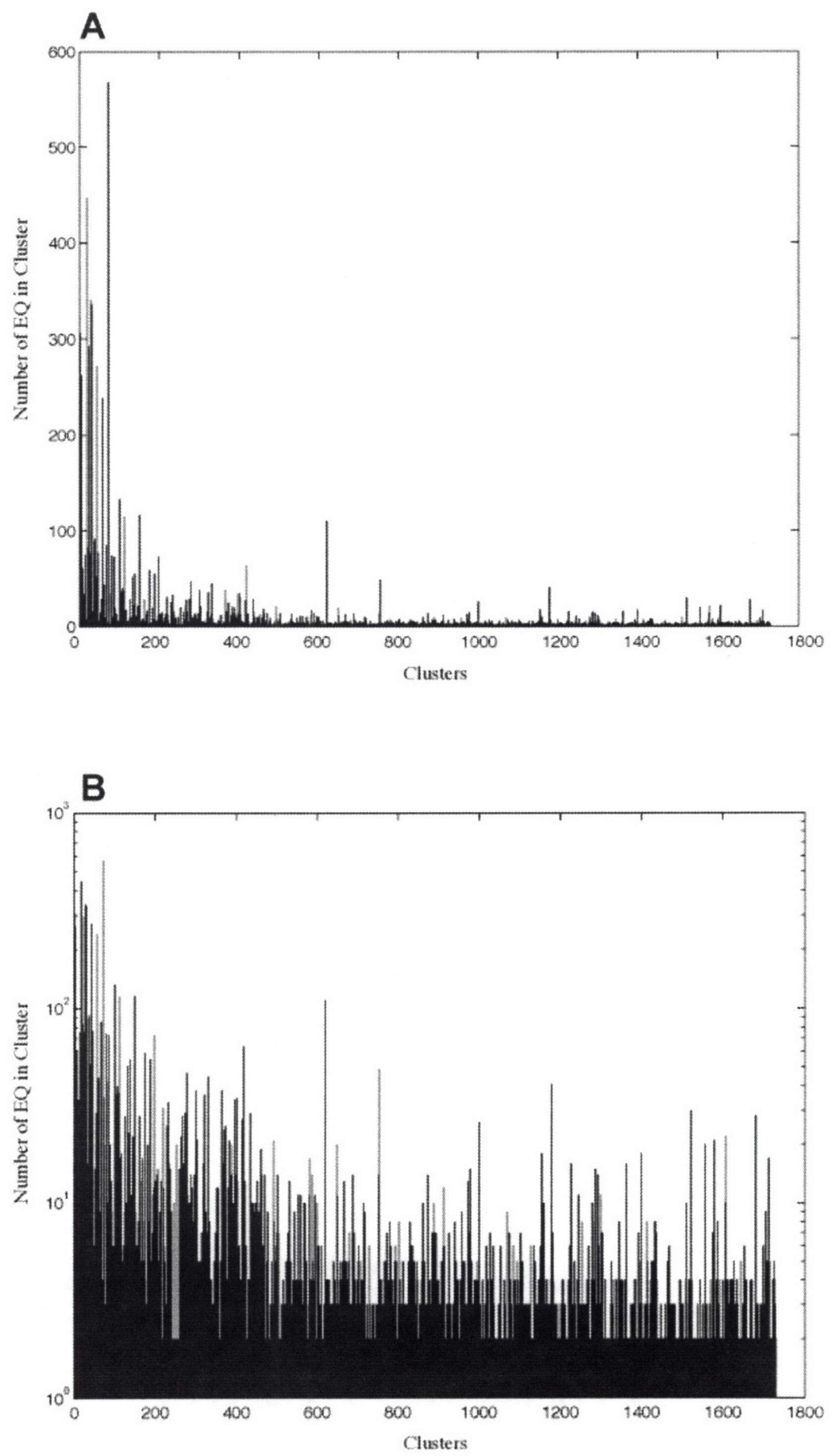

Figure 11. 


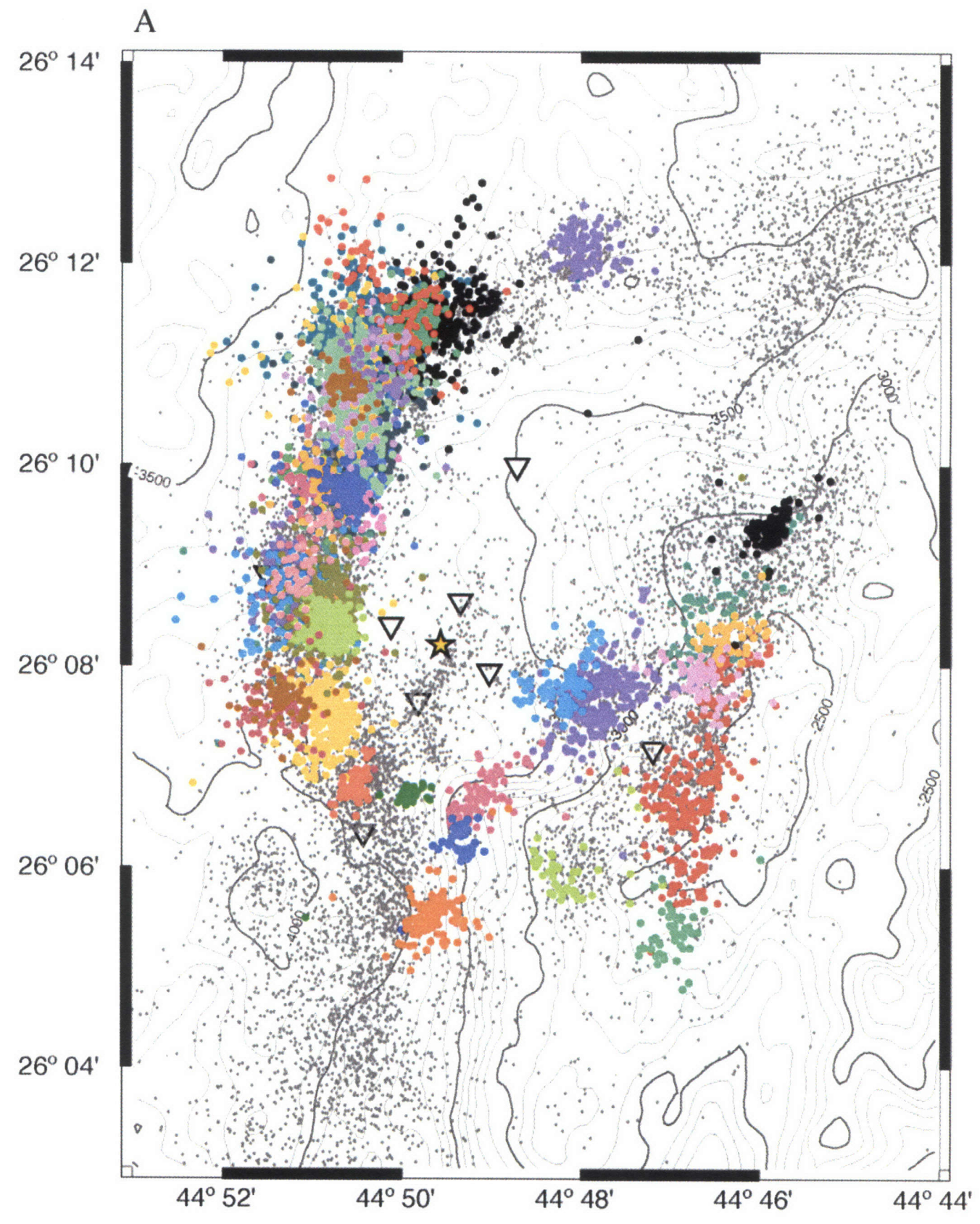

Figure 12. 


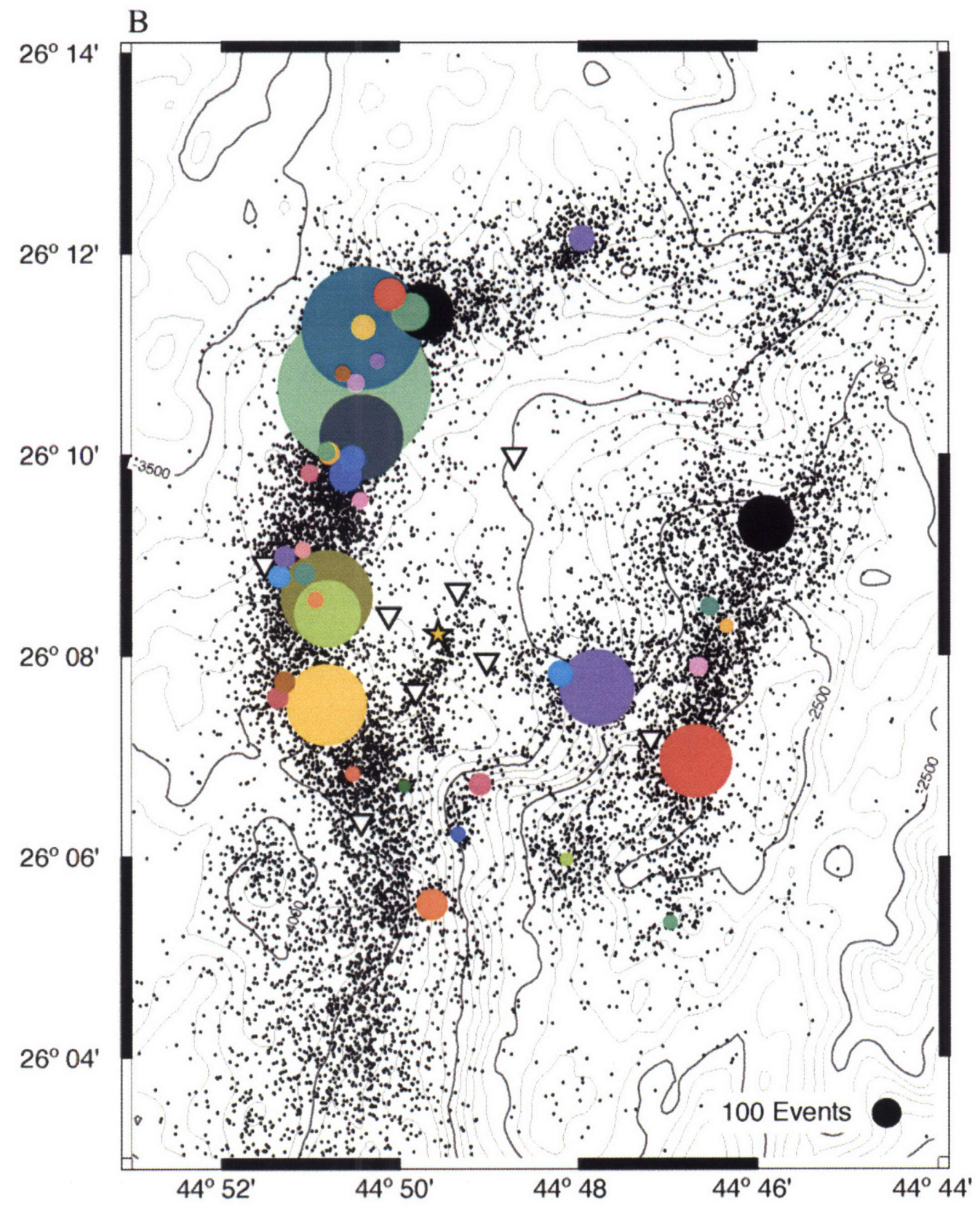

Figure 12. 

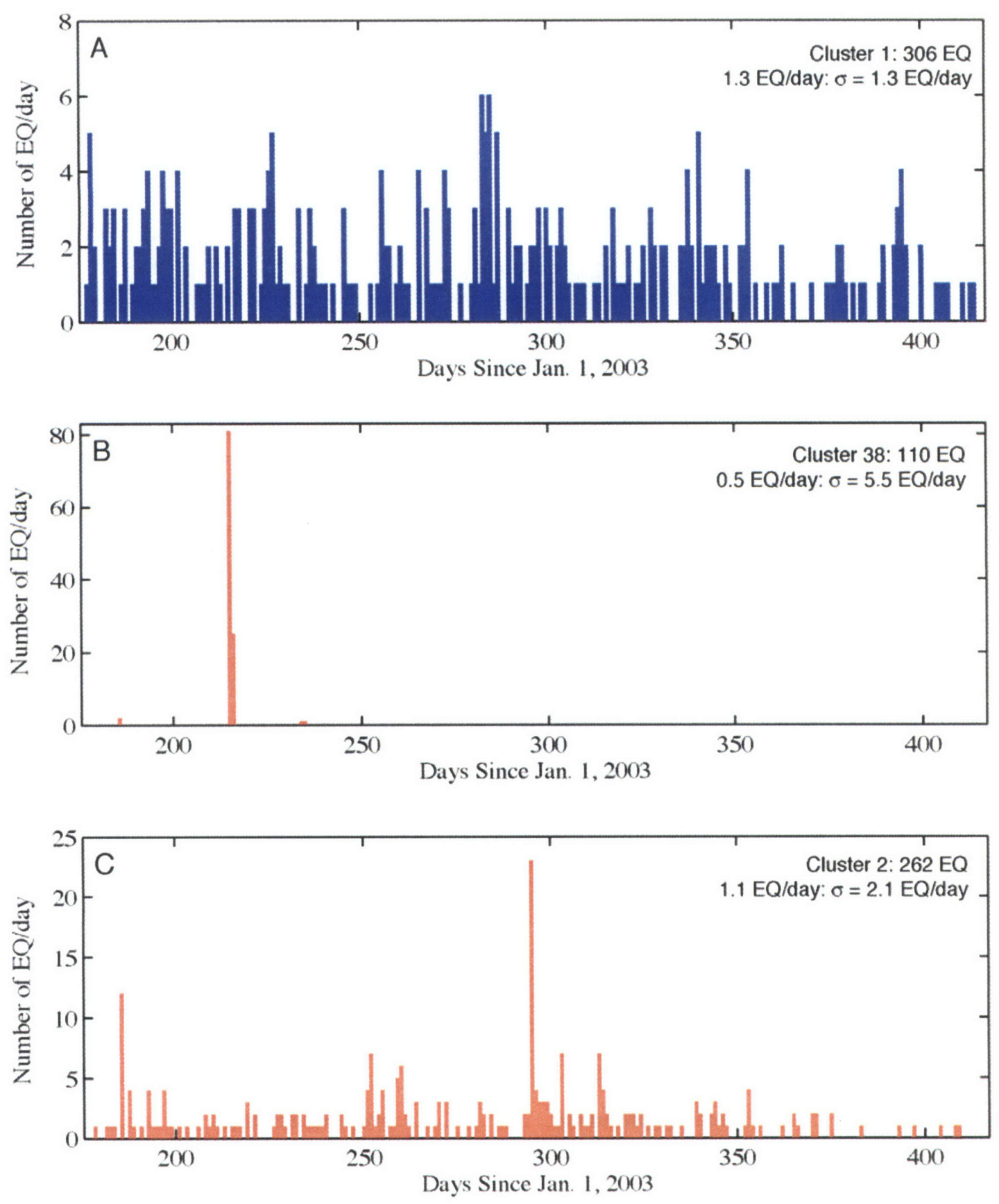

Figure 13. 

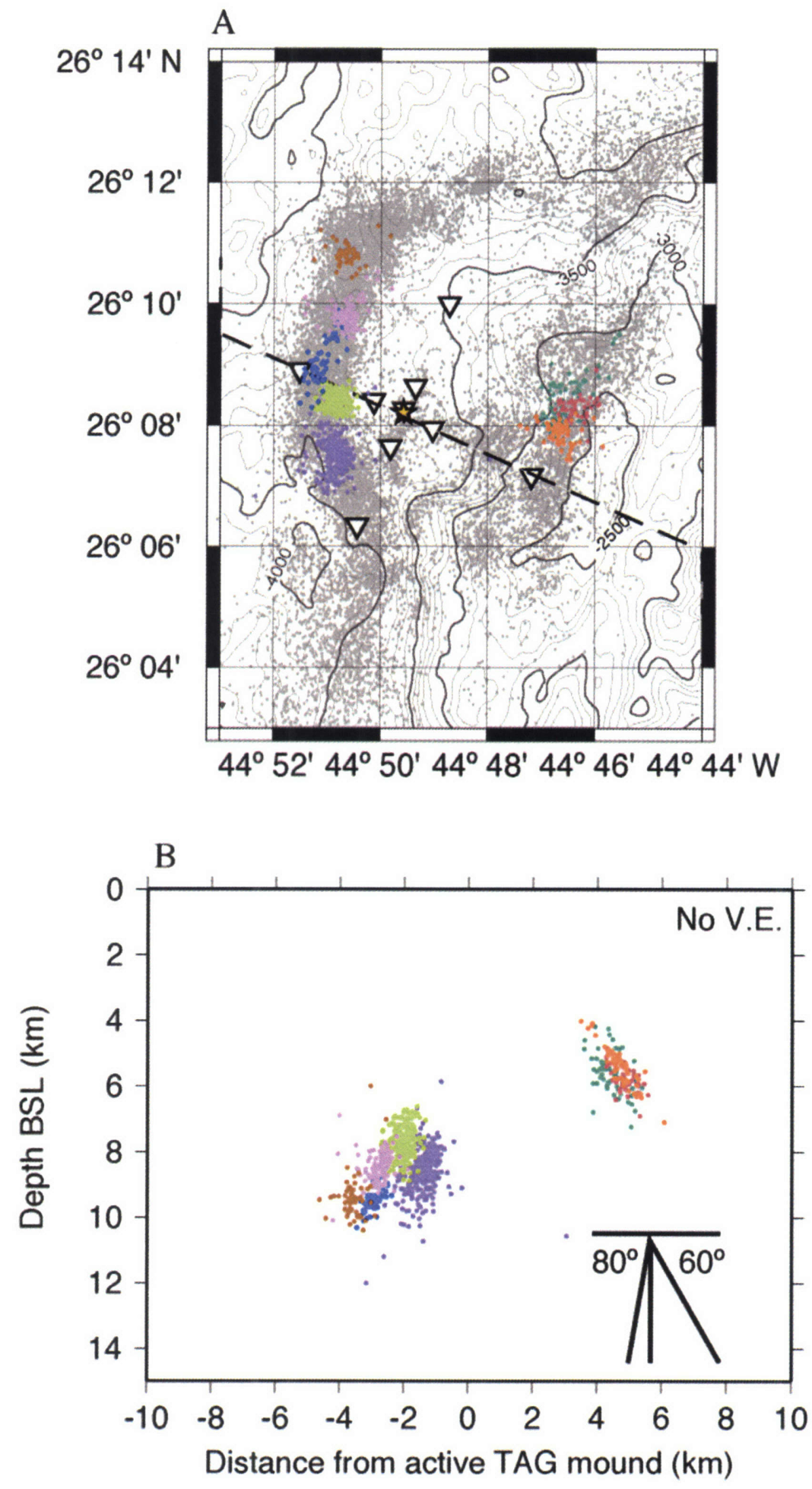

Figure 14. 

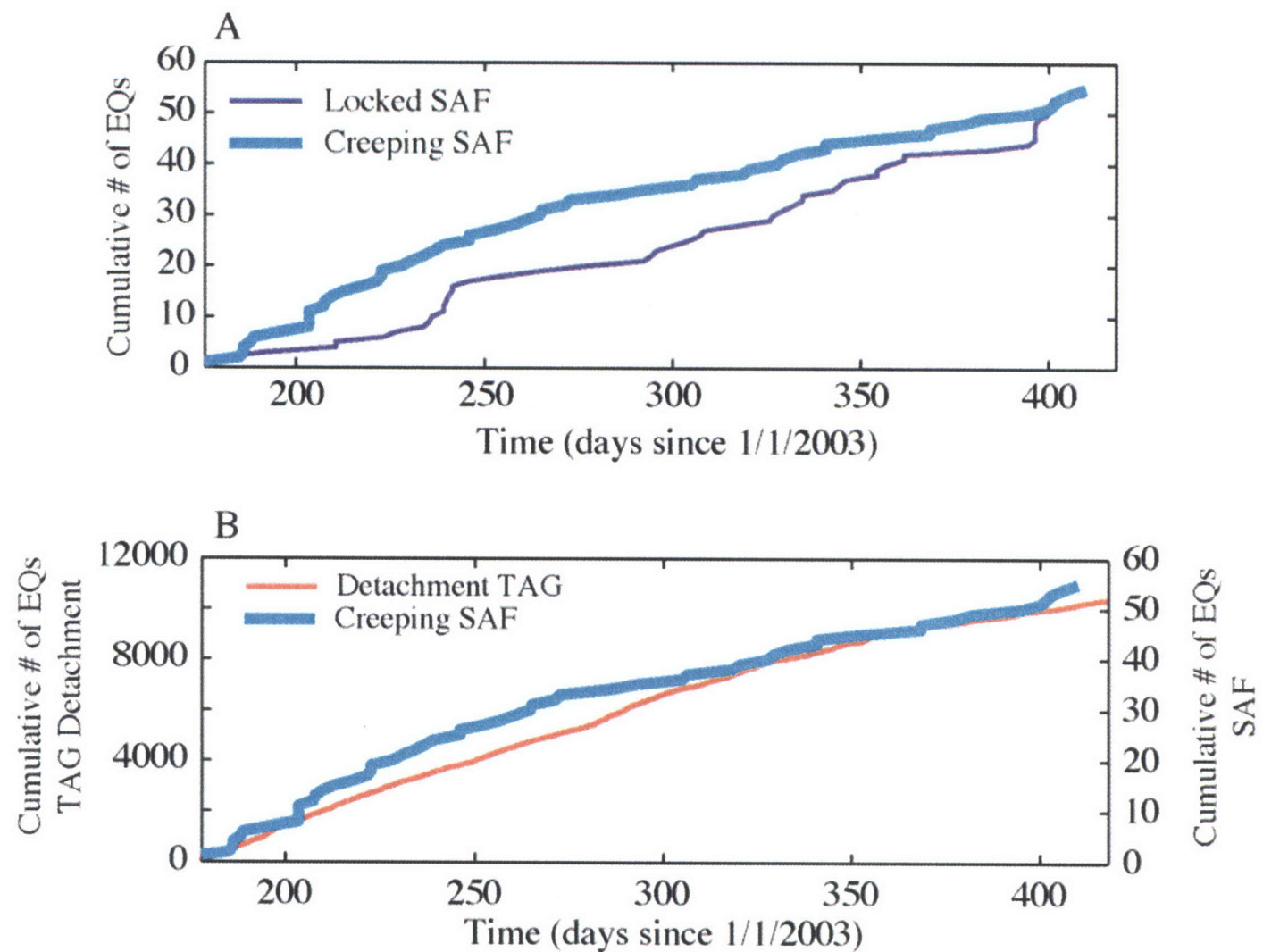

Figure 15. 


\title{
Chapter 5: Experimental Constraints on Thermal Cracking of Peridotite at Oceanic Spreading Centers
}

\author{
Brian deMartin \\ MIT/WHOI Joint Program in Oceanography, Marine Geology and Geophysics, 390 Woods Hole Rd., \\ Woods Hole, MA, 02345 \\ Greg Hirth \\ Woods Hole Oceanographic Institution, Department of Geology and Geophysics, 390 Woods Hole Rd., \\ Woods Hole, MA, 02345.

\section{Brian Evans}

Massachusetts Institute of Technology, Department of Earth, Atmospheric, and Planetary Sciences, 77 Massachusetts Ave., Cambridge, MA 02139.

\begin{abstract}
We couple two-dimensional micromechanical models for thermal cracking with fracture mechanics data for olivine to constrain the conditions where diffuse fluid flow could occur in the oceanic lithosphere. In addition, we ran controlled cooling rate experiments on hot-pressed olivine aggregates to test the micromechanical models of thermal cracking in peridotite and study the evolution of permeability due to thermal cracking. In our experiments, impermeable olivine aggregates, formed at elevated temperatures and pressures, are subsequently cooled at constant rates. In situ permeability measurements, made as the aggregate cooled, allow us to determine when an interconnected microcrack network develops. By varying grain size and confining pressure during the experiments, we were able to either enhance or suppress thermal cracking within the olivine samples. When the results of our experiments are coupled with micromechanical models, we estimate a polycrystalline olivine fracture toughness of approximately $0.6 \mathrm{MPa} \mathrm{m} \mathrm{m}^{1 / 2}$. We scaled the results of our experiments to the Earth using models that account for the influence of grain size, cooling rate, and confining pressure on the onset of thermal cracking in olivine aggregates. The depth extent of thermal cracking is estimated by coupling micromechanical models of stress intensity resulting from anisotropic thermal contraction with thermal models for upwelling mantle at oceanic spreading centers. Our analysis indicates that thermal cracking of peridotite is likely at depths less than 4 to $6 \mathrm{~km}$ beneath the seafloor. These predictions agree well with the depth of a transition from serpentinized to unaltered peridotite in the oceanic lithosphere determined from seismic observations.
\end{abstract}

\subsection{Introduction}

Fluid flow at mid-ocean ridges cools the oceanic lithosphere [Sclater et al., 1980], drives the biological and chemical evolution of hydrothermal systems [Murton et al., 1999], and controls the rheology and tectonics of the lithosphere [Francis, 1981]. Fluids 
present in the mantle alter ultramafic rocks to serpentine, which can strongly influence the strength of the oceanic lithosphere [e. g., Escartin et al., 1997a; Moore et al., 1997]. Faults provide conduits for focused flow at oceanic spreading centers and likely provide the high-permeability channels necessary to sustain high-temperature hydrothermal vents. By contrast, seismic [Canales et al., 2000] and ODP [Cannat et al., 1995] studies on rotated footwall blocks of detachment faults at slow spreading ridges provide evidence for distributed serpentinization and, therefore, fluid flow in the oceanic lithosphere. In this case, diffuse flow can be accommodated through a zone of thermally fractured rock producing distributed serpentinization of the lithosphere at slow spreading ridges.

Thermally induced microcracks form due to the accumulation of residual stresses at the grain-scale. Pioneering work on thermally cycled steel [Boas and Honeycombe, 1947], ceramics [Kuszyk and Bradt, 1973], and crystalline rocks [Simmons and Richter, 1976] demonstrated the influence of thermal expansion anisotropy and mismatch on the development of residual stresses and the formation of microcracks. The magnitude of residual stresses is governed by the thermoelastic properties (e.g., thermal expansivity and elastic compressibility) of the minerals comprising the aggregate and the magnitude of the temperature and pressure changes in the elastic regime. For conditions at oceanic spreading centers, thermal expansion anisotropy and mismatch between mineral grains generate larger residual stresses than those owing to differences in elastic expansion during depressurization. Therefore, thermal effects control the accumulation of internal stresses in these environments. Because olivine is the most abundant phase in the upper mantle, we hypothesize that anisotropic contraction of cooling olivine grains controls the accumulation of residual stresses and, ultimately, the formation of microcracks in the oceanic lithosphere. We illustrate an example of serpentinization occurring predominantly along grain boundary microcracks in a natural peridotite in Figure 1.

To help understand the role of thermal cracking in allowing the onset of diffuse fluid flow in the crust and upper mantle, we ran experiments on dense aggregates of hotpressed olivine. Experiments on continental crustal rocks, e.g. granite, [Bauer and Johnson, 1979] and quartzite [Siddiqi, 1997], demonstrate that thermally induced cracking can create an interconnected permeability network. Micromechanical models developed by studying the effects of thermal cracking on natural rocks provide important 
constraints on the mechanisms controlling microfracture [e.g., Evans and Clarke, 1980; Fredrich and Wong, 1986]. The stress intensity required for microcrack propagation can be estimated by coupling experimental observations with micromechanical models for thermal cracking [Fredrich and Wong, 1986]. In the following sections, we (1) review micromechanical models developed to constrain the growth of thermally induced fractures in polycrystalline, single-phase rocks, (2) describe experiments designed to constrain the thermal cracking process in olivine aggregates, and (3) couple the micromechanical models with results from thermal models of oceanic spreading centers to constrain conditions where thermal cracking occurs in the oceanic lithosphere.

\subsection{Micromechanical Models}

Theoretical studies of grain boundary cracking due to thermal expansion anisotropy have often focused on two-dimensional, elastically isotropic grain configurations [Carlson et al., 1990; Clarke, 1980; Evans, 1978; Fredrich and Wong, 1986]. In these models, stress singularities are predicted where three or more grains meet with identical, isotropic elastic moduli and unequal thermal expansion coefficients. Because of these stress singularities, grain boundary flaws present at grain boundary junctions are likely sites for microcrack nucleation. Using a closed form solution, Evans [1978] calculated the stress intensity factor along a grain boundary to estimate the critical flaw size required for growth of grain boundary microcracks during cooling. The predicted flaw size agreed well with data for magnesium titanate [Kuszyk and Bradt, 1973] if the grain boundary defects were about one tenth to three tenths the grain size. Fredrich and Wong [1986] used a similar model to calculate temperature changes where thermal cracks propagate in continental crustal rocks. Their calculations correlate well with stereological observations of grain boundary and intragranular crack densities in thermally cycled Westerly granite. Carlson et al. [1990] developed two-dimensional, plane stress, numerical simulations for four hexagonal grains embedded in an infinite, isotropic, elastic medium to constrain when grain boundary cracking would occur in a polyphase aggregate. The primary goal of Carlson et al. [1990] was to predict microcracking events as a function of pressure and temperature; their numerical 
simulations compare well with acoustic emission data on thermally cycled Westerly granite [Wang et al., 1989].

The role of three-dimensional grain configurations in microcrack nucleation and development was analyzed by Ghahremani and Hutchinson [1990]. These authors compared the stress distribution near vertices, where four grains meet at a point, to the stress distribution around junctions, where three grains meet along a line. Qualitatively, the results of three-dimensional and two-dimensional models agree. When thermal expansion anisotropy is appreciable, both vertices and junctions are likely sites for microcrack nucleation. Quantitatively, vertices concentrate stress more than junctions, indicating that two-dimensional models underestimate stress intensities along grain boundaries. Nonetheless, the theoretical results of Evans [1978], Fredrich and Wong [1986], and Carlson et al. [1990] reproduce many important aspects of laboratory experiments on thermally cycled materials (e.g., critical flaw size, microcrack density, and microcracking rate as function of pressure and temperature). In this section, we discuss the general implications of the thermal cracking models. Particular emphasis is given to the Fredrich and Wong [1986] model, which presents a closed form solution to thermally induced stresses along a grain boundary, and therefore, provides a method to readily estimate the stress intensity factor in our cooling olivine aggregates.

The micromechanical models illustrate how the onset of thermal cracking depends on cooling rate, grain size, and confining pressure. At high temperatures, viscous creep processes dissipate residual stresses in polycrystalline aggregates. As a material cools, the rate of stress dissipation diminishes. At some temperature, which we refer to as the viscoelastic transition temperature $(T)$, creep processes are not rapid enough to effectively relax the thermally induced stresses. For faster cooling rates, $T^{\prime}$ is higher, and the temperature over which an aggregate accumulates residual stresses increases. Grain size affects $T^{\prime}$ if viscous relaxation occurs via diffusion; larger grain sizes inhibit diffusioncontrolled viscous processes and result in a higher $T^{\prime}$. Grain size also controls the average flaw size in an aggregate [Brace et al., 1972]. Because stress concentrations are greater at the tips of longer, narrower flaws, cracking is enhanced for larger grain sizes. Confining pressure decreases the stress concentration at the flaw tips. Thus, higher confining pressures suppress thermal cracking. 
To predict the conditions where microcracks form in cooling aggregates, it is first necessary to quantify $T^{\prime}$. Anisotropic thermal contraction in single-phase, polycrystalline aggregates generates tensile and compressive stresses along grain boundaries. At elevated temperatures, rapid diffusion facilitates the relaxation of residual stresses [e.g., Evans and Clarke, 1980]. Relaxation occurs via diffusive transport of material between adjacent grain faces, shown schematically in Figure 2a. This process is limited by the rate at which atoms are removed from boundaries under compression and deposited on boundaries in tension. If the relaxation rate is sufficiently rapid, atom removal and deposition occurs evenly along the grain boundary, resulting in a parabolic, steady-state stress distribution (Figure 2b). Positive stresses are tensional. Grain boundary stresses are at their minimum and maximum values where there is no net flux of atoms (i.e., $d \sigma / d t=0$ ). For the model shown in Figure 2a, there is no net flux at the grain junction $(J)$ and the center of the grain face $(O)$. Across the grain junction $(A)$, the net flux of atoms is greatest, and stress is equal to half the mean stress along the boundary. The mean stress $(\langle\sigma\rangle)$ in a cooling aggregate is a function of absolute temperature $(T)$, grain size $(L)$, effective grain boundary width $\left(\delta_{b}\right)$, diffusional displacement rate of the boundary $\left(\dot{\delta}_{d}\right)$, atomic volume of the diffusing species $(\Omega)$, and diffusion coefficient $\left(D_{b}\right)$ [Evans and Clarke, 1980]:

$$
\langle\sigma\rangle=\frac{k T L^{2} \dot{\delta}_{d}}{6 \Omega D_{b} \delta_{b}} .
$$

To quantify $T^{\prime}$, the time derivative of stress along the boundary is related to the displacement rate of the grain boundary, $\dot{\delta}_{e}-\dot{\delta}_{d}$, where $\dot{\delta}_{e}$ is the elastic displacement rate of the grain boundary and $\dot{\delta}_{d}$ is the displacement rate induced by the diffusive transport of atoms along the grain boundary. At temperatures above $T^{\prime}, \dot{\delta}_{d}$ is much greater than $\dot{\delta}_{e}$, allowing viscous relaxation of residual stresses. At temperatures below $T^{\prime}, \dot{\delta}_{d}$ is much smaller than $\dot{\delta}_{e}$, and residual stresses accumulate rapidly. 
Using expressions they derived for $\langle\sigma\rangle, \dot{\delta}_{e}$, and $\dot{\delta}_{d}$, Evans and Clarke [1980] formulated the following differential equation for the evolution of $\langle\sigma\rangle$ along a grain boundary in an aggregate cooling at a constant rate:

$$
\frac{d\langle\sigma\rangle}{d T}=\frac{12 \Omega \delta_{b} D_{o} E}{\sqrt{3} k_{b} L^{3} \dot{T}} \frac{e^{-Q / R T}}{T}\langle\sigma\rangle-\frac{\beta E \Delta \alpha}{(1+v)},
$$

where $\dot{T}$ is cooling rate, $R$ is the universal gas constant, $Q$ is the activation enthalpy for grain-boundary diffusion, $D_{o}$ is pre-exponential coefficient for grain-boundary diffusion of the rate-limiting species, $E$ is Young's modulus, $v$ is Poisson's ratio, $k_{b}$ is Boltzmann's constant, and $\beta$ is a coefficient that depends on the orientations of the adjacent grains. Thermal expansion anisotropy is characterized by $\Delta \alpha$, the deviation of the maximum thermal expansion coefficient from the mean value of the thermal expansion coefficients. Variable names and values are listed in Table 1 . The first term on the right side of equation (2) accounts for diffusional relaxation of grain boundary stresses, while the second term describes the elastic contribution to the grain boundary displacement rate during cooling. A numerical solution to equation (2) is shown in Figure 3. $T^{\prime}$ is defined as the temperature obtained by extrapolating the elastic (linear) portion of the curve to a zero stress condition.

An approximate, analytic series expansion solution for $T^{\prime}$ in equation (2) is [Evans and Clarke, 1980]

$$
T^{\prime} \approx \frac{Q / R}{\ln \left[\frac{12 \Omega \delta_{b} D_{o} E}{\sqrt{3} n k_{b} L^{3} \dot{T}}\right]},
$$

where $n$ is a fitting parameter. For a given cooling rate and grain size, we determined $T^{\prime}$ from (2) and then solved (3) for $n$. Using a least-squares method, we calculated $n$ for an olivine aggregate at a range of cooling rates and grain sizes appropriate for laboratory and natural conditions. With $n=23$, equation (3) agrees with equation (2) within $\pm 5^{\circ} \mathrm{C}$ for cooling rates ranging from $1{ }^{\circ} \mathrm{C} \mathrm{s}^{-1}$ to $1^{\circ} \mathrm{C} \mathrm{kyr}^{-1}$ and grain sizes of $1 \mu \mathrm{m}$ to $0.1 \mathrm{~m}$ (Figure 4). In subsequent analyses, we use equation (3) to calculate $T^{\prime}$. 
Once an aggregate cools below $T^{\prime}$, thermally induced stresses accumulate owing to the anisotropy of thermal expansion of the mineral grains; the magnitude of the stress increase is proportional to the amount of cooling. Using a square inclusion model (Figure 5), Fredrich and Wong [1986] derive an expression for the normal stress acting on a twodimensional grain boundary due to anisotropic thermal expansion,

$$
\sigma_{y y}(x)=\frac{E \Delta \alpha\left(T^{\prime}-T\right)}{2 \pi\left(1-v^{2}\right)}\left|\frac{4 L^{2}}{4 L^{2}+(2 L-x)^{2}}-\frac{4 L^{2}}{4 L^{2}+x^{2}}+\ln \left[\frac{2 L-x}{x}\right]-\frac{1}{2} \ln \left[\frac{4 L^{2}+(2 L-x)^{2}}{4 L^{2}+x^{2}}\right]\right|(4)
$$

where $x$ represents the distance from an arbitrary corner. Notice that the magnitude of $\sigma_{y y}$ is proportional to $\Delta T=\left(T^{\prime}-T\right)$, where $T$ is temperature of the cooling aggregate. The stress along the grain boundary is asymmetric; one half of the boundary is under compression while the other half is under tension [Fredrich and Wong, 1986]. The stress field is singular at the grain corners. In reality, the singularity must be relaxed by inelastic deformation near the corner. To avoid the stress singularity in our models, we calculate the stresses along grain boundaries for $\mathrm{x} \geq 10^{-3} \mathrm{~L}$.

Microcracks in brittle materials nucleate along grain boundaries in response to stress concentrations caused by flaws, such as small cavities or precipitates. Observations in natural le.g., Sprunt and Brace, 1974] and hot-pressed laboratory samples [e.g., Olgaard and Evans, 1988] reveal ubiquitous grain boundary flaws. Furthermore, mechanical observations indicate that the length of critical flaws that control deformation often scale with grain size [Lawn, 1993]. Thermally induced intergranular cracking occurs when the tensile stress intensity factor $\left(K_{I}\right)$ at the tip of a grain boundary flaw exceeds the critical stress intensity $\left(K_{I C}\right)$. The critical stress intensity, also called the fracture toughness, is a material property and is independent of cooling rate, grain size and confining pressure.

The stress intensity at the crack-tip depends on the geometry of the flaw, the external loading on the boundary, and the magnitude of the residual stresses [Lawn, 1993]. The magnitude of stress intensity at the crack tip is a superposition of the stress intensities produced by the residual stress along the boundary and the confining pressure. As residual stress along the boundary increases during cooling, stress intensity at the crack tip rises, promoting fracture. Conversely, as confining pressure increases, stress 
intensity at the crack tip decreases. For a grain with flaw size $a$ under confining pressure $\left(P_{c}\right)$, the tensile stress intensity factor is given by [Fredrich and Wong, 1986],

$$
K_{1}=\sqrt{\frac{2}{\pi a}} \int_{0}^{a} \frac{\sigma_{y y}(x) \sqrt{x}}{\sqrt{a-x}} d x-P_{c} \sqrt{\pi a} .
$$

Intergranular crack propagation is, therefore, most likely for large changes in temperature and low confining pressures.

Figure 6 shows the dependence of the stress intensity factor on flaw size, temperature, and confining pressure for olivine aggregates calculated from equation (5) with a grain size of $1 \mathrm{~mm}$. Crack growth occurs when $K_{I}>K_{I C}$. For $K_{I C}$ in the range of 0.2 to $3.0 \mathrm{MPa} \mathrm{m}{ }^{1 / 2}$, typical values for crustal rocks [Atkinson and Meredith, 1987], thermal cracks can grow over a large range of flaw sizes. For all changes in temperature and pressure, the stress intensity decreases after reaching a peak value at a certain flaw size (Figure 6), indicating that grain boundary cracking induced by thermal expansion anisotropy is stable [Fredrich and Wong, 1986].

The confining pressure necessary to suppress cracking in a cooling rock can be calculated from equation (5) given a value of $K_{I C}$. Such a calculation can be used to evaluate the conditions where thermal fractures, and the concomitant development of a permeable crack network, may promote diffuse fluid flow in the lithosphere. Although olivine is the most abundant mineral in the upper mantle, relatively few fracture mechanics measurements have been conducted on olivine to constrain $K_{I C}$. Atkinson [1984] estimated $K_{I C}$ for olivine from Swain and Atkinson's [1978] fracture surface energy measurements on the [010] and [001] cleavage planes in single-crystal olivine. Using the Vickers indentation technique, Swain and Atkinson [1978] measured fracture surface energies of the preferred cleavage plane [010] and the [001] plane of $0.98 \mathrm{~J} \mathrm{~m}^{-2}$ and $1.26 \mathrm{~J} \mathrm{~m}^{-2}$, corresponding to $K_{I C}$ equal to $0.59 \mathrm{MPa} \mathrm{m} \mathrm{m}^{1 / 2}$ and $0.73 \mathrm{MPa} \mathrm{m} \mathrm{m}^{1 / 2}$, respectively [Atkinson, 1984]. Using the lower value of $K_{I C}=0.59 \mathrm{MPa} \mathrm{m}{ }^{1 / 2}$, we iteratively solved equation (5) to evaluate the influence of pressure, temperature change, and grain size on thermal cracking. The results of our analysis, illustrated in Figure 7, demonstrate the trade-offs among confining pressure, temperature change, and grain size on the initiation of thermal cracking. Based on the calculations illustrated in Figure 4, $\Delta T$ under geologic conditions at an oceanic spreading center may reach $600-900^{\circ} \mathrm{C}$. 
Therefore, the results shown in Figure 7 indicate that as material rises and cools from high pressure and temperature beneath an oceanic ridge it will thermally crack when it reaches shallow depths.

There are at least two caveats for the application of the micromechanical models shown in Figure 7 to the analysis of thermal cracking beneath oceanic ridges. First, we used a two-dimensional model to calculate the stress intensity along grain boundaries. As discussed above, two-dimensional models predict smaller stress accumulations along grain boundaries than three-dimensional models, and therefore, may underestimate the actual stress intensity. Second, we used the fracture surface energy along the preferred cleavage plane of olivine to constrain $K_{I C}$. In an olivine aggregate, microcracks will form at flaws along grain boundaries, in addition to cleavage planes. The critical stress intensity factor for grain boundaries may be smaller than the $K_{I C}$ for cleavage planes. To address these issues, we have run a series of thermal cracking experiments on cooling olivine aggregates. The conditions where microcracks form an interconnected network were determined by measuring permeability as the samples were cooled and depressurized. Coupling the results of the permeability measurements with the micromechanical models, we have a novel method for estimating $K_{I C}$, which can help us assess the uncertainty introduced by the limitations discussed above.

\subsection{Experimental Techniques}

The micromechanical models illustrate how we can trade-off cooling rate and grain size to investigate thermal cracking at laboratory time scales. At natural cooling rates of $1^{\circ}{\mathrm{C} \mathrm{yr}^{-1}}^{-10} 1^{\circ} \mathrm{C} \mathrm{kyr}^{-1}, T^{\prime}$ for peridotite with a grain size of $1 \mathrm{~mm}$ ranges from $1070^{\circ} \mathrm{C}$ to $840^{\circ} \mathrm{C}$, respectively (Figure 4). By contrast, we produced olivine aggregates with average grain sizes of 18 to $35 \mu \mathrm{m}$. At experimental cooling rates of $1{ }^{\circ} \mathrm{C} \mathrm{s}^{-1}$ to $1^{\circ} \mathrm{C}$ $\min ^{-1}, T^{\prime}$ is $1200^{\circ} \mathrm{C}$. Thus, residual stresses in cooling mantle peridotite accumulate over a smaller temperature range than the laboratory aggregates. However, as discussed in the previous section, coarser-grained aggregates have larger flaws that generate greater residual stress concentrations at flaw tips. Therefore, while natural peridotites have lower $T^{\prime}$, the models indicate that by trading-off cooling rate and grain size similar values of $K_{I}$ are produced under laboratory and natural conditions. 
The experiments were designed to determine when thermal cracking creates an interconnected microfracture network in an originally uncracked peridotite. Samples were first hot-pressed to create impermeable, relatively uncracked olivine aggregates. After the hot-press, samples were cooled and depressurized at different rates to evaluate the influence of grain size, cooling rate, confining pressure, and temperature change on the development of a microfracture network. The formation of an interconnected fracture network was detected by measuring the permeability of the sample during cooling and depressurization. The experimental conditions at which the permeability network forms can then be coupled with the micromechanical models to estimate a critical stress intensity factor.

\subsubsection{Sample Preparation and Experimental Procedure}

Samples were prepared by hot, isostatic pressing of powders of San Carlos olivine (Fo91). The powders, with grain sizes of $30-38 \mu \mathrm{m}$ and $38-63 \mu \mathrm{m}$, were first coldpressed into $\mathrm{Ni}$ capsules (26 mm long, $11.8 \mathrm{~mm}$ O.D., $11.0 \mathrm{~mm}$ I.D.) with a uniaxial stress of approximately $100 \mathrm{MPa}$. Porous alumina discs ( $3 \mathrm{~mm}$ thick, $20 \%$ porosity) confined the olivine powder at both ends of the Ni capsule. After the cold-press, samples were dried in an evacuated oven for at least 12 hours at $320 \mathrm{~K}$. Then they were inserted into an iron sleeve (Figure 8) and hot pressed at $1200{ }^{\circ} \mathrm{C}$ and $300 \mathrm{MPa}$ for 4 to 8 hours in an internally heated, argon-gas-medium apparatus [Paterson, 1970]. During the hotpress, thermally activated processes dissipate stresses, and produce a dense, low-porosity olivine aggregate. As with other high-temperature, high-pressure experiments on olivine [e. g., Hirth and Kohlstedt, 1995; Karato, 1989], we utilized a Ni cylinder to buffer oxygen fugacity at $\mathrm{Ni}-\mathrm{NiO}$.

Immediately following the hot-press, while the sample was still at elevated temperature and pressure, we conducted a sinusoidal permeability test [Fischer and Paterson, 1992] to confirm that the sample was sufficiently dense to close all interconnected porosity. Once we had formed an impermeable aggregate, the sample was cooled at a constant rate between $0.1{ }^{\circ} \mathrm{C} \mathrm{s}^{-1}$ to $1{ }^{\circ} \mathrm{C} \mathrm{s}^{-1}$. During cooling, the pore pressure system was open to the atmosphere, and confining pressure was allowed to decrease with decreasing temperature. Samples were cooled to about $500^{\circ} \mathrm{C}$, a temperature well below 
$T^{\prime}$, and a second sinusoidal permeability test was carried out. During this permeability test, the confining pressure was approximately $260 \mathrm{MPa}$ and the pore pressure $\left(P_{f}\right)$ was about $20 \mathrm{MPa}$. After measuring permeability at $500{ }^{\circ} \mathrm{C}$, pore pressure was dropped to atmospheric pressure, and temperature decreased to room temperature with an additional concomitant decrease in confining pressure to about $220 \mathrm{MPa}$. Permeability was then measured as a function of effective pressure $\left(P_{e}=P_{c}-P_{f}\right)$ using the sinusoidal permeability technique.

At the end of experiments, the samples were extracted from the apparatus and their jackets dissolved with aqua regia. The samples were then ground into cylinders 10.5 $\mathrm{mm}$ long and $9 \mathrm{~mm}$ in diameter. Using a low-speed, diamond saw, $3 \mathrm{~mm}$ discs were cut from one end of each sample for microstructural analysis, and the remaining $7.5 \mathrm{~mm} \times 9$ $\mathrm{mm}$ cylindrical samples were jacketed with a $3 \mathrm{~mm}$ thick polyurethane rubber jacket and inserted into a wide-range permeameter [Bernabé, 1987]. The wide-range permeameter provided additional constraints on sample permeability as a function of effective pressure. We utilized long-period (3600 s) sinusoidal oscillations [Fischer and Paterson, 1992], as well as the transient pulse method [Brace et al., 1968] for one sample, to measure permeability. Once the samples were loaded into the wide-range permeameter, confining pressure was raised to $40 \mathrm{MPa}$. After confirming that there was no leak in confining pressure, the water pore fluid pressure was increased to $20 \mathrm{MPa}$. Twenty-four to forty-eight hours elapsed before the start of a permeability test. This hiatus allowed the system to equilibrate after the pressure adjustment. During the permeability measurements, pore pressure was held constant at $20 \mathrm{MPa}$, and confining pressure was increased incrementally from $40 \mathrm{MPa}$ to $180 \mathrm{MPa}$.

\subsubsection{Permeability Measurement Techniques}

3.2.1. Sinusoidal Pore Pressure Method. The sinusoidal pore pressure technique is based on the measurement of the phase delay and attenuation of an oscillation of the pore fluid pressure as it propagates through the sample [Fischer, 1992]. A sinusoidal pressure oscillation is induced on the upstream side of the sample, and the pressure response is observed at the other end, the downstream side. The response of the 
downstream side is another sinusoid that is phase shifted and attenuated relative to the upstream oscillation.

The magnitudes of the phase shift and attenuation depend on the permeability $(k)$ and the storage capacity per unit volume of the sample $\left(\beta_{c}\right)$, as well as several experimental parameters: the height $(h)$ and cross-sectional area $(A)$ of the sample, the period of pore pressure oscillation $(\tau)$, the dynamic viscosity of the pore fluid $(\eta)$, and the storage capacity of the downstream reservoir $\left(B_{d}\right)$. Storage capacity is defined as the change in volume of pore fluid stored per unit change in pore fluid pressure $\left(B=\partial V / \partial P_{p}\right)$. Permeability is calculated by using phase lag and attenuation measurements to numerically solve for two dimensionless parameters $\psi$ and $\gamma$ [Fischer and Paterson, 1992]. Storage capacity and permeability of the sample are then given in terms of $\psi$ and $\gamma$ by,

$$
\begin{gathered}
\beta_{c}=\frac{B_{d}}{h A \gamma}, \\
k=\frac{\pi \eta \beta_{c}}{\tau}\left(\frac{h}{\psi}\right)^{2}=\frac{\pi \eta B_{d} h}{\tau A \psi^{2} \gamma} .
\end{gathered}
$$

Phase delay and attenuation were determined using Fourier analysis. Transient effects at the initiation of the permeability test generally decayed within the first cycle, and only data from the second cycle onwards were used for processing. Eight to ten cycles were analyzed. An example of the upstream and downstream pore pressure recorded during a permeability measurement is shown in Figure 9a. To calculate phase delay and attenuation, we first removed small linear trends in the time-domain pressure data that arise from small leaks in the pore pressure system. Next, we converted data into the frequency domain, where the power and phase spectrum were calculated. After verifying that the maximum power occurred at the imposed frequency, the phase delay was calculated by subtracting the downstream phase value from the upstream phase value. Care was taken to avoid $2 \pi$ offsets. The amplitude attenuation was found by setting the energy in all frequencies to zero, except that at the imposed value. The data were then inverted to the time domain, and the amplitude of the recovered signals was measured. Attenuation was defined as the ratio of the amplitude of the upstream side to 
the amplitude of the downstream side. The resolution of the sinusoidal pore pressure method was approximately $10^{-20} \mathrm{~m}^{2}$ during thermal cracking experiments and $5 \times 10^{-19} \mathrm{~m}^{2}$ the during wide-range permeameter experiments. The sensitivity during the thermal cracking experiments is higher because low-viscosity argon (as opposed to water) is used as the pore fluid.

3.2.2. Transient Pulse Method. In the transient pulse method, an approximately $0.1 \mathrm{MPa}$ change of pore pressure is imposed on one side of a sample that was originally uniformly pressurized. The convention is to call this side the upstream side, regardless of the direction of fluid flow. The pore pressure is then allowed to return to equilibrium (Figure $9 \mathrm{~b}$ ). The time it takes for the differential pore pressure $\delta P_{p}$ to return to equilibrium is a function of permeability. The decay curve of the differential pore pressure is approximately exponential and the decay time $t$ is inversely proportional to the permeability [Brace et al., 1968]

$$
\delta P_{p}(t) \propto \exp (-\xi t)
$$

where

$$
\xi=\frac{A k\left(B_{u}+B_{d}\right)}{\eta h B_{u} B_{d}},
$$

and $B_{u}$ is the storage capacity of the upstream reservoir. We calculated permeability by plotting the log of the differential pore pressure decay versus time. Using experimentally determined values for the apparatus storage capacities, as well as the cross sectional area and length of the sample, permeability is determined from the slope of the line. The resolution of the transient pulse method in the wide-range permeameter is approximately $5 \times 10^{-20} \mathrm{~m}^{2}$.

\subsection{Results of Thermal Cracking Experiments}

We ran eight successful thermal cracking experiments designed to test the importance of cooling rate, hot press duration, initial grain size, and confining pressure on thermal cracking. The sample properties, experimental parameters, and the maximum pressure where permeability was observed for each experiment are summarized in Table 2. For all experiments, regardless of cooling rate, hot-press duration, or initial grain size the samples were impermeable after the hot-press and remained impermeable while at 
elevated temperatures. Permeability was observed for two coarser-grained samples as they depressurized at $20^{\circ} \mathrm{C}$. The results of the permeability measurements on these samples, OTC-9, and OTC-12, are shown in Figure 10a. Several samples, OTC-1, OTC10, OTC-11, and OTC-15, remained impermeable throughout the duration of the thermal cracking experiments and provide important constraints on $K_{I C}$. Sample OTC-3 was permeable at $P_{e}=10 \mathrm{MPa}$ (Figure 10a). A confining pressure leak into the pore pressure system prevented us from making permeability measurements at higher pressures. We could not measure permeability during OTC-5 because there was a significant leak of pore pressure to the atmosphere.

We used a wide-range permeameter to further constrain the permeability of several samples after they were extracted from the high-temperature, gas-medium apparatus. Transient pulse measurements conducted on OTC-3 a month after the thermal cracking experiment are consistent with the in situ permeability measurement (Figure 10a). Long-period (1800-3600 s), sinusoidal permeability measurements were conducted on four samples (OTC-1, OTC-5, OTC-10, and OTC-11) 15-20 months after the thermal cracking experiments. While the finer-grained sample OTC-1 remained impermeable, coarser-grained samples OTC-10 and OTC-11 became permeable in the period since the thermal cracking experiment. In addition, we measured the permeability of sample OTC5. We plot the results of the sinusoidal permeability measurements in the wide-range permeameter in Figure 10b. These results, performed months after fabrication of the samples, suggest that time is also an important variable in controlling the evolution of permeability.

Samples OTC-12 and OTC-15, run at identical conditions to OTC-3 and OTC-1, respectively, were designed to test the reproducibility of our experiments. As shown in Figure 10a, the permeabilities of OTC-12 and OTC-3 agree within a factor of two. Similarly, samples OTC-1 and OTC-15 both remained impermeable at all effective pressures. 


\subsubsection{Influence of Experimental Parameters on Permeability}

The differences in the onset and magnitude of permeability in our samples reflect variations in the extent of microcracking that arise due to differences in cooling rate, hotpress duration, time between measurements, grain size, and confining pressure. Cooling rate had no discernable effect over the conditions we tested. As discussed below, the range in cooling rate was probably not large enough to influence significantly the viscoelastic transition temperature ( $\left.T^{\prime}\right)$ for the grain sizes of our samples.

Longer hot presses inhibited the formation of an interconnected microcrack network during the thermal cracking experiments. The three coarser-grained samples with measurable permeability during the thermal cracking experiments were all hotpressed for four hours prior to cooling and depressurization. By contrast, a coarse-grained sample hot-pressed for 8 hours (OTC-10) was impermeable during the thermal cracking experiment. The effect of hot-press duration is also constrained by OTC-11. This experiment was designed to determine if a mixed initial grain size enhanced grain growth during hot pressing. During this experiment, the pore fluid system exhibited larger than normal noise. Thus, we extended the hot-press for an additional 2 hours to ensure that the sample was impermeable prior to cooling. After the eventual 6 hour hot-press, no permeability was observed over the entire range of effective pressures. Despite the high noise level for OTC-11, the spectral characteristics of the pore-fluid pressure data at low effective pressures indicated that the sample remained impermeable.

Measurements of permeability made after the samples were extracted from the high-temperature, gas-medium apparatus suggest that microcracking continues at ambient conditions. While OTC-10 and OTC-11 remained impermeable during the thermal cracking experiments, relatively high permeabilities for these same samples were measured in the wide-range permeameter 15 months after they were fabricated (Figure 10b). In addition, the permeability of OTC- 5 measured 18 months after it was fabricated was almost an order of magnitude greater than that measured during thermal cracking experiments on samples with a similar grain size and hot press duration (compare Figure $10 \mathrm{a}$ and $10 \mathrm{~b})$. 
Samples with the smallest initial powder size of 30-38 $\mu \mathrm{m}$ (OTC-1 and OTC-15) remained impermeable throughout thermal cracking experiments. In contrast to the coarser-grained samples, the permeability of OTC-1 remained below the resolution of the wide-range permeameter during measurements made 20 months after the thermal cracking experiments.

During decompression of two samples (OTC-9 and OTC-12), permeability was observed at high effective pressure using the sinusoidal technique. These samples, hotpressed under identical conditions, first exhibited measurable permeability at similar effective pressures. In the case of OTC-9, permeability was first measured after the confining pressure was lowered from $220 \mathrm{MPa}$ to $170 \mathrm{MPa}$ at $20^{\circ} \mathrm{C}$. For OTC-12, no permeability was observed at $600{ }^{\circ} \mathrm{C}$ and a confining pressure of $240 \mathrm{MPa}$. When temperature was lowered to $20^{\circ} \mathrm{C}$ with a concomitant decrease in confining pressure to $210 \mathrm{MPa}$ the sample became permeable. The pore fluid pressure was $20 \mathrm{MPa}$ during permeability measurements. Thus, permeability was first observed at effective pressures of $150 \mathrm{MPa}$ and $190 \mathrm{MPa}$, respectively, for these samples. After OTC-12 became permeable, permeability increased an order of magnitude (from $4 \times 10^{-20} \mathrm{~m}^{2}$ to $4 \times 10^{-19}$ $\mathrm{m}^{2}$ ) as the effective pressure decreased from $190 \mathrm{MPa}$ to $20 \mathrm{MPa}$ (Figure 10a). A similar influence of effective pressure on permeability is shown for the other permeable samples in Figure 10.

\subsubsection{Microstructural Analysis}

We used two methods to characterize the microstructure of the olivine aggregates following extraction from the gas-medium apparatus. First, we measured the density of the samples to quantify porosity. Second, we qualitatively analyzed the extent of thermal cracking and measured grain size using optical and scanning electron microscopy.

We measured the density $(\rho)$ of thermally cracked samples in two ways. First, to estimate the total porosity we calculated density by measuring the height, radius, and mass of the cylindrical samples. Total porosity was calculated assuming that the difference in density between the samples and San Carlos olivine $\left(\rho=3330 \mathrm{~kg} \mathrm{~m}^{-3}\right)$ was only attributable to the presence of air filled pores $(\rho \approx 0)$. These rough density 
measurements yield a total porosity estimate of approximately $1 \%$ for the fine-grained samples and 3\% for the coarse-grained samples. Error in measuring the height and radius of the cylindrical samples yields about $1 \%$ uncertainty in porosity. Second, to calculate the amount of isolated porosity we used Archimedes' method to measure the density of the samples $\left(\rho_{s}\right)$,

$$
\rho_{s}=\frac{M_{a} \rho_{w}}{\left(M_{a}-M_{w}\right)},
$$

where $M_{a}$ is the mass of the sample in air, $M_{w}$ is the mass of the sample in water, and $\rho_{w}$ is the density of water. Values for isolated porosity, listed in Table 2, range from $0.0 \%$ to $2.7 \%$ and are apparently independent of hot press duration, and cooling rate. Both methods used to determine density indicate that the samples fabricated using the finer grained powders have a higher density and lower porosity than coarser grained samples.

SEM micrographs reveal microcracks in all samples. However, the fracture density is greatest in the coarser-grained samples with measurable permeability. Orientation contrast images $(1000 \mathrm{x})$ of two samples, cooled at similar rates with different initial grain sizes, are shown in Figure 11. Both grain boundary and intragranular microcracks are more prevalent in the coarser grained sample (OTC-3). As discussed in the micromechanical model section, the observation of more prevalent cracking in the coarser grained sample is consistent with the influence of grain size on fracture toughness.

Pores on the order of the grain size are observed in the coarse grained sample (Figure 11b). The porosity measurements for the coarse grained sample indicate that these large pores are surfacial features produced by plucking out weakly attached grains during polishing and were not present during the thermal cracking experiments. The greater number of pluck-outs in this sample is consistent with the observation of more widespread microcracking in the coarse grained aggregates. The small pores (crosssectional areas $<1 \mu \mathrm{m}^{2}$ ), observed in both the fine grained and coarse grained samples, were likely present and isolated following the hot-press step and could have been sites for crack initiation during cooling.

The average grain size of the samples shown in Figure 11 was determined by using electron backscatter diffraction (EBSD) to create grain orientation maps. We set the 
SEM to analyze electron backscatter patterns in $2 \mu \mathrm{m}$ steps across a $90 \times 10^{3} \mu \mathrm{m}^{2}$ rectangular area of the sample surface. Reliable orientations were obtained for approximately $65 \%$ of the analyzed points. To determine the grain size, we first removed poorly determined grain orientations and then extrapolated areas of constant grain orientation to fill space between the well-analyzed areas. Individual grains were identified as regions of constant grain orientations, misoriented more than $10^{\circ}$ with their neighbors. These analyses yield average grain areas of $110 \mu \mathrm{m}^{2}$ for the fine-grained sample and $380 \mu \mathrm{m}^{2}$ for the coarse-grained sample hot-pressed four hours. The grain size of these samples $(18 \mu \mathrm{m}$ and $33 \mu \mathrm{m})$ was calculated by multiplying the equivalent circle diameters of the average grain areas by 1.5 [Underwood, 1970].

\subsection{Discussion of Experimental Results}

We observe evidence for the formation of thermally induced microcracks in olivine aggregates from permeability measurements and microstructural observations. Our observations indicate that the tendency for microcracks to form an interconnected network during thermal cracking experiments is influenced by grain size, hot-press duration, and effective pressure. However, for the range of grain sizes used during the experiments, cooling rates were too rapid to decrease the visco-elastic transition temperature significantly below $1200^{\circ} \mathrm{C}$ (Figure 4). Thus, the temperature change driving the increase in stress within the aggregates was approximately $1180^{\circ} \mathrm{C}$ for all samples. This conclusion is consistent with our observation that differences in cooling rate did not influence our results.

Permeability measurements reveal that longer hot press durations inhibited the formation of microfractures during thermal cracking experiments, although this conclusion is based on only two data points. This observation is contrary to what one would expect due to the kinetics of grain growth if the porosity of all the samples was the same [e. g., Evans et al., 2001]. Longer hot press duration should yield larger grain sizes, which are more likely to fracture if the flaw size scales with grain size. However, the difference in hot-press duration of our experiments was not large enough to significantly change the grain size. Using data for grain growth of olivine [Karato, 1989], an increase 
in grain size of only $2 \mu \mathrm{m}$ would be expected for a coarser-grained sample (i.e., grain size of $\sim 35 \mu \mathrm{m}$ ) annealed for 8 versus 4 hours. We hypothesize that microcracking was apparently inhibited by longer hot-press durations because flaws (e.g. pores) were more effectively removed. Owing to the decreased number of flaws, crack initiation sites are apparently decreased, inhibiting the formation of an interconnected permeability network.

The permeability of three samples (OTC-5, OTC-10, OTC-11) measured 15-20 months after they were fabricated suggests that subcritical crack growth enhances the formation of an interconnected microcrack network. One caveat to this interpretation is that the samples may be damaged during removal of the jacket, and the grinding and cutting done in preparation for the wide-range permeameter measurements. The interpretation of our microstructural observations may also be compromised by damage imparted during sample preparation. For this reason, in our analysis of the conditions where thermal cracking initiates in the oceanic lithosphere, we concentrate on the results of in situ permeability measurements made during the thermal cracking experiments.

\subsubsection{Estimating $K_{I C}$}

We use our experimental observations, in conjunction with micromechanical models to provide constraints on the critical stress intensity factor $\left(K_{I C}\right)$ in olivine aggregates. As discussed below, our thermal cracking experiments yield three values for $K_{I}$ necessary to induce an interconnected microcrack network. These values reflect differences in our experiments and provide a range of values for fracture toughness that may be applicable in the Earth.

The onset of permeability observed during two thermal cracking experiments at elevated pressure provides an estimate of $K_{I}$ necessary to form an interconnected microcrack network. During these two experiments an interconnected microcrack network was first observed in situ after cooling the samples to room temperature at a confining pressure of $170 \mathrm{MPa}$ (OTC-9) and $210 \mathrm{MPa}$ (OTC-12). Values for $K_{I}$ as a function of flaw size and a range of confining pressures are shown in Figure 12 for an aggregate cooled $1180^{\circ} \mathrm{C}$ with a grain size of $33 \mu \mathrm{m}$. Maximum values of $K_{I}$ for a confining pressure of $170 \mathrm{MPa}$ and $210 \mathrm{MPa}$ are $0.32 \mathrm{MPa} \mathrm{m}^{1 / 2}$ and $0.25 \mathrm{MPa} \mathrm{m}^{1 / 2}$, 
respectively. Averaging these values, we estimate a stress intensity of $0.29 \mathrm{MPa} \mathrm{m} \mathrm{m}^{1 / 2}$ necessary to induce an interconnected microcrack network in a coarse-grained olivine aggregate hot-pressed 4 hours.

Samples that remained impermeable throughout the thermal cracking experiments provide additional values of $K_{I}$ required to induce an interconnected microcrack network. For these samples, thermally induced stresses were insufficient to produce an interconnected microcrack network. However, using the same technique discussed above, we can estimate the maximum stress intensities attained in these samples. Samples OTC1, with an average grain size of $18 \mu \mathrm{m}$, and OTC-15 were run at identical conditions using the same powders. Using equation (5) for a temperature change of $1180^{\circ} \mathrm{C}$ and a confining pressure of $0.1 \mathrm{MPa}$ yields a maximum $K_{I}=0.63 \mathrm{MPa} \mathrm{m}^{1 / 2}$. Similarly, a sample with a calculated grain size of $35 \mu \mathrm{m}$ hot-pressed 8 hours (OTC-10) also remained impermeable over the course of the thermal cracking experiment. The maximum $K_{I}$ calculated for this coarse-grained sample is $0.87 \mathrm{MPa} \mathrm{m}^{1 / 2}$.

Stress intensities calculated from the coarse-grained thermal cracking experiments provide a range of estimates on $K_{I}$ required to form an interconnected microcrack network. The lowest estimate is calculated from coarse-grained samples hot-pressed 4 hours. As described above, these samples may have had more crack initiation sites (e.g., flaws) owing to their larger initial grain sizes and shorter hot-press durations. Upon cooling and depressurization, the increased number of flaws enhanced the development of an interconnected microcrack network, and therefore, $K_{I}$ was large enough to induce widespread cracking. Flaws are more effectively removed with longer hot-press durations, and thus, the coarse grain sample hot-pressed 8 hours yields a higher estimate of $K_{I}$ necessary to form an interconnected microcrack network. However, the observation of permeability in this sample 15 months after the thermal cracking experiment implies that over time an interconnected microcrack network may form at stress intensities of approximately $0.87 \mathrm{MPa} \mathrm{m}^{1 / 2}$.

The magnitude of stress intensity calculated from our thermal cracking experiments agrees well with previous measurements of the fracture toughness of olivine. The results of thermal cracking experiments yield three values of stress intensity that average to $0.6 \mathrm{MPa} \mathrm{m}{ }^{1 / 2}$, a value that corresponds well with the $K_{I C}$ determined for the 
weak cleavage plane of olivine (0.59 $\left.\mathrm{MPa} \mathrm{\textrm {m } ^ { 1 2 }}\right)$ [Atkinson, 1984]. In addition, microstructural observations of some microcracks in the impermeable fine-grained sample (Figure 11a) indicate that locally $K_{I}$ exceeded $K_{I C}$. This observation emphasizes that the permeability measurements do not directly correspond with the nucleation of individual grain boundary cracks. Rather, the permeability measurements provide a method of estimating the stress intensity necessary for the formation of an interconnected crack network. Given that $K_{I C}$ is a material parameter (independent of pressure, temperature, cooling-rate, grain-size, etc.), the correlation of our calculated values of $K_{I}$ with the olivine cleavage fracture toughness is encouraging. Using the bounds on $K_{I}$ provided by the coarse-grained samples as uncertainties in our measurements, we conclude that $K_{I C}$ is $0.6 \pm 0.3 \mathrm{MPa} \mathrm{m}^{1 / 2}$.

\subsubsection{Modeling Thermal Cracking in the Oceanic Lithosphere}

We use the constraints on $K_{I C}$ from the thermal cracking experiments to estimate the range of conditions where thermally induced microcracking occurs in the oceanic lithosphere. We first iteratively solved equation (5) to quantify the role of pressure, temperature change, and grain size on thermal cracking for the estimated range of $K_{I C}$. The results of our calculations, shown in Figure 13, yields a range of pressures where an interconnected microcrack network will develop for a given temperature change and grain size. Larger temperature changes and grain sizes fracture at higher pressures than smaller temperature changes and grain sizes. The uncertainty in pressure, arising from the uncertainty in $K_{I C}$, is greater for larger changes in temperature and smaller grain sizes. For the range of $K_{I C}$ estimated from our experiments, thermal cracking would initiate at low confining pressures for moderate changes in temperature. For example, for $\Delta T>400^{\circ} \mathrm{C}$ and a grain size of $1 \mathrm{~mm}$, microcracks can nucleate over a range of confining pressures in the upper few kilometers of the oceanic lithosphere.

To calculate where thermal cracking may occur in slow spreading oceanic spreading system, we employed the mantle flow and temperature model of Phipps Morgan and Forsyth [1988] as modified by Shaw and Lin [1996] and Behn et al. [2002]. We model an oceanic ridge with a half-spreading rate of $10 \mathrm{~mm} \mathrm{yr}^{-1}$ and a crustal thickness that varies from $8 \mathrm{~km}$ near the center of the segment to $3 \mathrm{~km}$ near the end of the 
segment [Hooft et al., 2000]. Mantle temperature was set to $1320^{\circ} \mathrm{C}$ and the magma injection temperature at the spreading axis was set to $1150^{\circ} \mathrm{C}$. Hydrothermal cooling was permitted where the lithosphere was cooler than the visco-elastic transition temperature. Presumably, in regions cooler than the visco-elastic temperature and hotter than where we predict thermal microfractures form, fluid flow will be limited to large-scale faults. In regions where thermal cracking is occurring, we would expect enhanced cooling to occur due to the greater flux of diffuse flow though the mantle. At present, the model does not incorporate these feedback processes.

The flow and temperature model implements a two step process to first calculate flow in the passively upwelling upper mantle and then determine the steady state temperature of this system. To calculate the visco-elastic transition temperature contour, the cooling rates along mantle streamlines were calculated. Cooling rates for the upwelling mantle were approximately $0.1^{\circ} \mathrm{C} \mathrm{ky}^{-1}$. Using equation (3) with a mantle grain size of $1 \mathrm{~mm}$ places the visco-elastic transition contour near the $800^{\circ} \mathrm{C}$ isotherm. The thermal cracking front can then be determined by calculating stress intensity using equation (5) along the streamline and comparing it with the critical stress intensity factor determined from experimental analysis. Because $K_{I C}$ is a material parameter, it does not need to be scaled to natural conditions. However, the calculation does assume that the initial flaw size in the natural rock scales with grain size in the same way as the laboratory samples. We show the uncertainty in our experiments by plotting the zone of cracking resulting from $K_{I C}$ equal to $0.3 \mathrm{MPa} \mathrm{m}^{1 / 2}$ through $0.9 \mathrm{MPa} \mathrm{m}^{1 / 2}$.

The results of the flow and temperature model are shown in Figure 14. Each figure represents a slice though the ridge segment, perpendicular to the spreading axis. Figure 14a shows the center of the segment, and Figure $14 \mathrm{~b}$ shows the end of the segment, near the transform fault. Thermal fracturing of the upwelling mantle peridotite is limited to the segment end, where mantle material rises to shallow depths. At the center of the segment, where the oceanic crust is thicker, thermal cracking in the mantle peridotite is inhibited by a combination of a small decrease in temperature from the visco-elastic transition temperature and greater lithostatic pressure. Near the segment ends, where mantle peridotite rises to a depth of $3 \mathrm{~km}$, lithostatic pressure is insufficient to inhibit the formation of thermal fractures owing to a larger temperature change. The 
thickness of the thermally cracked zone near the segment ends depends on $K_{I C}$. The smallest estimate of $K_{I C}\left(0.3 \mathrm{MPa} \mathrm{m}{ }^{1 / 2}\right)$ yields the thickest thermally cracked zone $(6 \mathrm{~km})$. Aggregates with higher $K_{I C}$ must rise to shallower depths before cracking initiates.

Modeling results suggest that thermal cracking at the spreading axis should occur where upwelling, cooling mantle peridotite rises to a depth of 6 to $4 \mathrm{~km}$ at the ridge axis. If thermal cracking is pervasive, as inferred from our experimental results, an interconnected permeability network can form, allowing fluid to penetrate and alter the lithosphere. These measurements show that thermal expansion anisotropy of olivine is sufficient to create an interconnected permeability structure, at least near transform boundaries.

Several additional processes may effect the formation of microcracks in the oceanic lithosphere. First, thermal expansion mismatch between different mineral grains and anisotropic elastic properties may enhance microcrack formation. Second, the cooling effects of diffuse fluid flow may enhance the formation of microcracks in the oceanic lithosphere. Third, the slow growth of cracks resulting from subcritical crack growth may enhance cracking at the time scale of oceanic spreading. All three of these processes would enhance crack growth in the oceanic lithosphere and yield deeper zones of thermally fracture rocks. In contrast, differential stresses can generate recrystallized grain sizes smaller than $1 \mathrm{~mm}$ in the upper mantle [e.g., Karato et al., 1980; Van der Wal et al., 1993]. Smaller grain sizes will inhibit the formation of microcracks (e.g., notice the shallower zone of thermal cracking illustrated in Figure 13a) and may lead to zones of unaltered peridotite in the uppermost mantle.

Although the thermal models used here neglect several processes (e.g., multiple mineral phases, hydrothermal cooling, subcritical crack growth), they do illustrate the mutual dependence of pressure and temperature. Temperature decreases within the cooling mantle enhance the formation of microcracks, while pressure acts to suppress microcracking. Thus, thermal cracking is easiest at ridge segment ends where mantle peridotite uplifts to shallow depths. In zones where enhanced cooling occurs owing to hydrothermal circulation, the onset of thermal cracking will be deeper; in zones where the oceanic lithosphere is less effectively cooled, thermal cracking will only occur at shallower depths. 


\subsubsection{Serpentinization of Peridotite and Seismic Evidence for Thermal Cracking}

The region of thermal cracking predicted by our analysis compares well with the conditions at which serpentinization is inferred to occur based on seismic surveys. Extensive exposures of serpentinized peridotites are present along oceanic fracture zones and the inside corner highs of slow spreading ridges [Bonatti, 1976; Dick, 1989; Miyashiro et al., 1969]. The influx of volatiles into mantle peridotite along faults and subsequent diffuse flow of the fluid into the rock along thermal fractures at low temperatures results in serpentinization of mantle peridotite [O'Hanley, 1996]. Both the frictional strength [Moore et al., 1997] and the fracture strength [Escartin et al., 1997a] of serpentinized mantle peridotite are less than that of unaltered peridotite. Thus, the serpentinization process probably has a substantial influence on the tectonic evolution of the oceanic lithosphere [Escartin et al., 1997b]. Because serpentinites have slower compressional and shear-wave velocities than unaltered peridotite [Miller and Christensen, 1997], seismic techniques can be used to locate serpentinized portions of the oceanic lithosphere.

Along the Mid-Atlantic Ridge (MAR), south of the Kane Transform (MARK area), serpentinized peridotites crop out in a belt approximately $2 \mathrm{~km}$ wide and $20 \mathrm{~km}$ long along the western median valley wall [Karson et al., 1987]. These serpentinites likely were exposed during an episode of amagmatic plate separation in which little gabbroic crust was formed and detachment faulting occurred [Karson and Lawrence, 1997]. Serpentinites collected along the seafloor in this region using Alvin and Nautile include harzburgites, peridotites containing primarily olivine and orthopyroxene, that are altered to form massive or schistose serpentinites [Karson et al., 1987]. During ODP Leg 153, serpentinized harzburgites were sampled to depths of $200 \mathrm{~m}$ in this area [Cannat et al., 1995]. These field observations, coupled with models for similar tectonic regions [e.g., Tucholke et al., 1998] imply that serpentinized peridotites occur down to the unaltered mantle.

Seismic velocity structures south of the MARK area, shown in Figure 15, indicate that a transition to unaltered peridotite occurs at a depth of 3-4 $\mathrm{km}$ [Canales et al., 2000]. The grey patterned zone in Figure 15 shows a velocity profiles typical of 0-7 Ma oceanic 
crust. The black profile $(x=-6.3 \mathrm{~km})$ is the profile where serpentinized peridotite crops out, while the profile labeled $x=7.0 \mathrm{~km}$ shows the seismic section for the oceanic lithosphere on the conjugate side of the ridge where no serpentinites are observed. The increase in velocity to roughly $8.0 \mathrm{~km} / \mathrm{s}$ at a depth of $3-4 \mathrm{~km}$ in the velocity profiles for areas where serpentinized peridotite crops out is consistent with the prediction of a thermally cracked zone in the upper 4 to $6 \mathrm{~km}$ of the seafloor. These observations corroborate our conclusion that thermally induced microcracks along grain boundaries contribute to the diffuse alteration of the oceanic lithosphere.

\subsection{Conclusions}

Stresses resulting from anisotropic thermal contraction of olivine during cooling and depressurization are sufficient to create an interconnected permeability network in laboratory samples. Using micromechanical models for grain boundary cracking in single-phase materials, we estimate the critical stress intensity factor necessary for interconnected microfracturing in olivine to be $0.6 \pm 0.3 \mathrm{MPa} \mathrm{m}^{1 / 2}$. If natural peridotites have the same fracture toughness as the laboratory samples, we estimate that thermal cracking may occur in the upper 4 to $6 \mathrm{~km}$ of the seafloor near transform faults. The likely presence of multiple mineral phases, hydrothermal cooling, increased grain size, and subcritical crack growth would increase the likelihood of cracking and deepen the zone of thermal cracking in the oceanic lithosphere. Conversely, mantle grain sizes less than $1 \mathrm{~mm}$ will reduce the likelihood of cracking and yield a thinner zone of thermally cracked rock. Seismic refraction surveys in regions where serpentinites crop out suggest that the transition from altered to unaltered mantle rock occurs at 3-4 $\mathrm{km}$, a value consistent to that estimated here, given the uncertainties in scaling. These results indicate that thermally induced microcracking, and subsequent alteration, plays an essential role in the thermal, chemical, and rheological evolution of the oceanic lithosphere.

\section{Acknowledgements}

Xiaohui Xiao provided extensive assistance with the Paterson Rig at MIT. Uli Mok and Yves Bernebé helped with permeability analysis and in the operation of the 
wide-range permeameter. Mark Behn got us up and running with the thermal and flow model for oceanic spreading centers. Javier Escartín provided images of serpentinized peridotite. We are grateful for insightful reviews by Joanne Fredrich, Teng-Fong Wong, and Joe Cann and discussions with Wenlu Zhu. This research was supported by the NSF grants OCE-0095936 (MIT) and OCE-9907244 (WHOI). 
Table 1: Variable Symbols and Values Used

\begin{tabular}{|c|c|c|c|c|}
\hline Variable & Variable Name & Units & Value & Reference \\
\hline$a$ & Flaw Size & $\mathbf{m}$ & & \\
\hline$A$ & Cross Sectional Area Sample & & & \\
\hline$B_{d}$ & $\begin{array}{l}\text { Storage Capacity Downstream } \\
\text { Reservoir }\end{array}$ & $\mathrm{m}^{3} \mathrm{~Pa}^{-1}$ & & \\
\hline$B_{u}$ & $\begin{array}{l}\text { Storage Capacity Upstream } \\
\text { Reservoir }\end{array}$ & $\mathrm{m}^{3} \mathrm{~Pa}^{-1}$ & & \\
\hline$D_{o}$ & $\begin{array}{l}\text { Grain Boundary Diffusion } \\
\text { Coefficient }\end{array}$ & $\mathrm{m} \mathrm{s}^{-2}$ & $1.510^{-08} \delta_{b}^{-1}$ & [Hirth and Kohlstedt, 1995] \\
\hline$E$ & Young's Modulus & $\mathbf{P a}$ & $19710^{9}$ & [Hirth and Kohlstedt, 1995] \\
\hline$h$ & Sample Height & $\mathrm{m}$ & & \\
\hline$k$ & Permeability & $\mathrm{m}^{2}$ & & \\
\hline$k_{b}$ & Boltzmann's Constant & $\mathrm{JK}^{-1}$ & $1.3810^{-23}$ & \\
\hline$K_{I}$ & Stress Intensity Factor & $\mathrm{Pa} \mathrm{m}^{1 / 2}$ & & \\
\hline$K_{I C}$ & Critical Stress Intensity Factor & $\mathrm{Pa} \mathrm{m}^{1 / 2}$ & $0.6 \pm 0.3$ & [this paper] \\
\hline$L$ & 1/2 Grain Size & $\mathrm{m}$ & & \\
\hline$M_{a}$ & Mass in Air & $\mathrm{kg}$ & & \\
\hline$M_{w}$ & Mass in Water & $\mathrm{kg}$ & & \\
\hline$n$ & Fitting Parameter & & 23 & [this paper] \\
\hline$P_{c}$ & Confining Pressure & $\mathrm{Pa}$ & & \\
\hline$P_{e}$ & Effective Pressure & $\mathrm{Pa}$ & & \\
\hline$P_{p}$ & Pore Pressure & $\mathbf{P a}$ & & \\
\hline$Q$ & $\begin{array}{l}\text { Activation Enthalpy for Grain } \\
\text { Boundary Diffusion }\end{array}$ & $\mathrm{J} \mathrm{mol}^{-1}$ & $3.7510^{5}$ & [Hirth and Kohlstedt, 1995] \\
\hline$R$ & Universal Gas Constant & $\mathrm{J} \mathrm{mol}^{-1} \mathrm{~kg}^{-1}$ & 8.314 & \\
\hline$\tau$ & Period & & & \\
\hline$T$ & Temperature & $\mathrm{K}$ or ${ }^{\circ} \mathrm{C}$ & & \\
\hline$\dot{T}$ & Cooling Rate & $\mathrm{K} \mathrm{s}^{-1}$ & & \\
\hline$T^{\prime}$ & $\begin{array}{l}\text { Visco-elastic Transition } \\
\text { Temperature }\end{array}$ & $\mathrm{K}$ or ${ }^{\circ} \mathrm{C}$ & & \\
\hline$x$ & Distance & $\mathbf{m}$ & & \\
\hline$\beta$ & Boundary Angle & radians & $\pi / 6$ & \\
\hline$\beta_{c}$ & Storage Capacity Per Unit Volume & $\mathrm{Pa}^{-1}$ & & \\
\hline$\Delta \alpha$ & Thermal Expansion Anisotropy & $\mathrm{K}^{-1}$ & $3.110^{-6}$ & [Bouhifd et al., 1996] \\
\hline$\gamma$ & Dimensionless Parameter & & & \\
\hline$\delta_{b}$ & Effective Grain Boundary Width & $\mathbf{m}$ & $1.510^{-08} \mathrm{D}_{0}^{-1}$ & [Hirth and Kohlstedt, 1995] \\
\hline$\dot{\delta_{d}}$ & $\begin{array}{l}\text { Diffusive Displacement Rate of } \\
\text { Grain Boundary }\end{array}$ & $\mathrm{m} \mathrm{s}^{-1}$ & & \\
\hline$\dot{\delta}_{e}$ & $\begin{array}{l}\text { Elastic displacement rate of Grain } \\
\text { Boundary }\end{array}$ & $\mathrm{m} \mathrm{s}^{-1}$ & & \\
\hline$\delta P_{p}$ & Differential Pore Pressure & $\mathrm{Pa}$ & & \\
\hline$\eta$ & Dynamic Viscosity of Pore Fluid & Pas & & \\
\hline$\rho_{w}$ & Density of Water & $\mathrm{kg} \mathrm{m}^{-3}$ & 1000 & \\
\hline$\rho_{s}$ & Density of Sample & $\mathrm{kg} \mathrm{m}^{-3}$ & & \\
\hline$\sigma$ & Stress & $\mathrm{Pa}$ & & \\
\hline$\psi$ & Dimensionless Parameter & & & \\
\hline$v$ & Poisson's Ratio & & 0.246 & [Hirth and Kohlstedt, 1995] \\
\hline$\Omega$ & Atomic Volume & $\mathrm{m}^{3}$ & $1.2310^{-29}$ & [Hirth and Kohlstedt, 1995] \\
\hline
\end{tabular}


Table 2: Summary of Thermal Cracking Runs.

\begin{tabular}{lllllll}
\hline $\begin{array}{l}\text { Sample } \\
\text { Number }\end{array}$ & $\begin{array}{l}\text { Initial } \\
\text { Grain Size } \\
(\mu \mathrm{m})\end{array}$ & $\begin{array}{l}\text { Hot Press } \\
\text { Duration } \\
(\mathrm{hr})\end{array}$ & $\begin{array}{l}\text { Cooling } \\
\text { Rate } \\
\left(\mathrm{K} \mathrm{min}^{-1}\right)\end{array}$ & $\begin{array}{l}\text { Maximum } P_{e}(\mathrm{MPa}) \\
\text { Where Permeability } \\
\text { Measured }\end{array}$ & $\begin{array}{l}\text { Final } \\
\text { Density } \\
\left(\mathrm{g} \mathrm{cm}^{-3}\right)\end{array}$ & $\begin{array}{l}\text { Isolated } \\
\text { Porosity (\%) }\end{array}$ \\
\hline OTC-1 & $30-38$ & 4 & 25 & $\mathrm{n} / \mathrm{a}^{*}$ & 3.33 & 0.0 \\
OTC-3 & $38-63$ & 4 & 20 & $140^{\dagger}$ & 3.27 & 1.8 \\
OTC-5 & $38-63$ & 4 & 6 & $140^{\dagger}$ & 3.27 & 1.8 \\
OTC-9 & $38-63$ & 4 & 10 & 150 & 3.25 & 2.4 \\
OTC-10 & $38-63$ & 8 & 60 & $160^{\dagger}$ & 3.24 & 2.7 \\
OTC-11 & mixed $^{\ddagger}$ & 6 & 60 & $160^{\dagger}$ & 3.30 & 0.9 \\
OTC-12 & $38-63$ & 4 & 20 & 190 & 3.28 & 1.5 \\
OTC-15 & $30-38$ & 4 & 25 & $\mathrm{n} / \mathrm{a}^{*}$ & 3.32 & 0.3 \\
\hline
\end{tabular}

Permeability never observed in OTC-1 and OTC-15.

${ }^{\dagger}$ Permeability measurements in wide-range permeameter.

${ }^{\ddagger}$ OTC- 11 had a mixed initial grain size one part $30-30 \mu \mathrm{m}$ and 14 parts $38-63 \mu \mathrm{m}$.

Figure Captions

Figure 1: Reflected light micrograph of Balsam Gap dunite. Veins of lizardite and chrysotile serpentine (s) are distributed along grain boundaries between olivine (Ol) grains and along intergranular cracks, forming an interconnected network. Image provided by J. Escartín.

Figure 2: Schematic illustration and calculation of grain boundary stresses. (a) For an anisotropic grain cooling at high temperature, grain boundaries undergo an elastic displacement $\delta_{e}$, owing to thermal contraction, and a diffusional displacement $\delta_{d}$, owing to the diffusional transport of atoms. Shaded areas indicate the zones of mass transport. Arrows in the center of the grain illustrate the anisotropy in thermal expansion. (b) Plot of stress versus distance showing the superposition of elastic and diffusional stresses along grain boundaries. Compressional stresses along the grain boundary $J A$, lead to a net flux of atoms to the grain boundary $A A^{\prime}$. Modified from Evans and Clarke [1980]. 
Figure 3: Stress accumulation in a cooling olivine aggregate for two different cooling rates calculated using equation (2). The visco-elastic transition temperature $(T)$ is defined by extrapolating the elastic (linear) portion of the curve to zero stress. The grain size used in the calculation was $1 \mathrm{~mm}$.

Figure 4: Visco-elastic transition temperature $T^{\prime}$ as a function of grain size. Results from the numerical solution of equation (2), denoted by symbols, are compared to the series solution of equation (3), denoted by the solid lines. Regions indicating typical laboratory and Earth conditions are shaded. For cooling rates and grain sizes used in the laboratory and inferred in the Earth, the results of the numerical and series expansion solutions agree to within $\pm 5^{\circ} \mathrm{C}$.

Figure 5: Coordinate system used for the analysis of grain boundary cracking due to thermal expansion anisotropy. Arrows inside the square grain indicate the orientation of the principal thermal expansion coefficients. Cracking occurs along the grain boundary due to the presence of a flaw with length $a$. Modified from Fredrich and Wong [1986].

Figure 6: Stress intensity at the flaw tip as a function of flaw size for a grain size of $1 \mathrm{~mm}$. (a) Effect of temperature change $\left(\Delta T=T^{\prime}-T\right)$. (b) Effect of confining pressure. Larger temperature changes or lower confining pressures increase the stress intensity values at flaw tips.

Figure 7: Pressure dependence of thermal cracking as a function of grain size and temperature change for $K_{I C}=0.59 \mathrm{MPa} \mathrm{m} \mathrm{m}^{1 / 2}$. High confining pressures and small temperature changes suppress thermally induced grain boundary cracks. Larger grain sizes are more likely to crack than smaller grain sizes.

Figure 8: Experimental sample assembly. Olivine powder is first cold-pressed into the $\mathrm{Ni}$ capsule and porous alumina spacers are placed on both ends. The $\mathrm{Ni}$ capsule, containing the olivine sample, is then placed in an Fe jacket with ceramic pistons on both sides. 
Figure 9: Unprocessed permeability data for OTC-3. (a) Sinusoidal permeability test. Upstream signal is denoted by solid, gray circles, while the downstream signal is represented by open, dark circles. The steady decrease in pore pressure on the downstream side is due to a small leak in the pore pressure system. Permeability is calculated by measuring the amplitude attenuation and phase lag between the two signals. (b) Transient pulse permeability test. The pressure difference between the upstream and downstream reservoirs (differential pressure) is plotted versus time. Permeability is calculated using the decay time of the differential pressure after a pressure pulse is generated in one reservoir. Small changes in the temperature of the laboratory generate perturbations in the differential pressure measurement.

Figure 10: Summary of permeability measurements. (a) In situ and transient pulse permeability measurements. In situ permeability measurements on OTC-3, OTC-9, and OTC-12 were conducted using the sinusoidal oscillation method in the gas-medium apparatus with argon gas as the pore fluid. Transient pulse measurements on OTC-3 conducted a month after synthesis using water as the pore fluid agree with in situ permeability measurements at low-effective pressure. (b) Sinusoidal oscillation permeability measurements in the wide-range permeameter using water as the pore fluid 15-20 months after samples fabricated. The decrease in permeability with increasing effective pressure likely results from closure of low-aspect ratio cracks.

Figure 11: Orientation contrast images. The electron micrographs show two samples, cooled at similar rates, with different grain sizes. Images $(1000 \mathrm{x})$ reveal cracks in both samples, although cracking is less prevalent in the sample with the smaller grain size, OTC-1 (a), than the sample with the larger grain size, OTC-3 (b). Large pores, likely due to pluck-outs, are present in OTC-3.

Figure 12: Stress intensity at the flaw tip as a function of flaw size calculated using equation (5) with a grain size of $33 \mu \mathrm{m}$ and $\Delta T=1180{ }^{\circ} \mathrm{C}$. Permeability was first observed at $170 \mathrm{MPa}$ for OTC-9 and $220 \mathrm{MPa}$ for OTC-12. As described in the text, 
these observations yield a stress intensity necessary to induce an interconnected microcrack network of approximately $0.3 \mathrm{MPa} \mathrm{m}^{1 / 2}$.

Figure 13: Plot of confining pressure versus $\Delta T$ showing conditions where thermal fractures initiate for our experimentally estimated range of $K_{I C}=0.6 \pm 0.3 \mathrm{MPa} \mathrm{m}^{1 / 2}$ and grain sizes of $100 \mu \mathrm{m}$ and $1 \mathrm{~mm}$. Larger temperature changes and smaller grain sizes yield a larger pressure range for the thermal cracking front.

Figure 14: Thermal models for a slow spreading ridge (half-rate $=1 \mathrm{~mm}$ ) showing where thermal cracking may occur at segment centers (a) and near transform faults (b). Cross-sections are perpendicular to the spreading axis. Thin black lines denote isotherms. The dashed white line denotes the visco-elastic transition temperature ( $T$ ). In (b), the black dashed line represents the thermal cracking front for $K_{I C}=0.3 \mathrm{MPa} \mathrm{m}^{1 / 2}$, and the thick black line represents the thermal cracking front for $K_{I C}=0.9 \mathrm{MPa} \mathrm{m}{ }^{1 / 2}$. Pervasive cracking of the oceanic mantle is predicted to occur above these two lines. At the center of the ridge segment (a), thermal cracking is inhibited due to the presence of a thick $(\sim 8$ $\mathrm{km}$ ) crustal layer. Near the segment ends (b) where the crust is thinner (3 km), thermal cracking is calculated to occur in mantle peridotite at depths less than 4-6 km.

Figure 15: Velocity versus depth profiles for the MARK area of the Mid-Atlantic Ridge. The width of each profile represents two standard deviations after averaging 2D structures to form a 1D profile. Typical velocity profiles for 0-7 Ma oceanic crust are denoted by the patterned grey zone, while the black profile $(x=-6.3 \mathrm{~km})$ represents the velocity where serpentinized peridotite outcrops on the seafloor. The profile labeled $\mathrm{x}=$ $7.0 \mathrm{~km}$ represents the seismic structure for an area a similar distance from the axis on the opposite side of the ridge. The increase in velocity to approximately $8.0 \mathrm{~km} / \mathrm{s}$ at a depth of 3-4 km in the black profile is consistent with a transition from partially serpentinized to unaltered peridotite. Figure modified from [Canales et al., 2000]. 


\section{References}

Atkinson, B.K., Subcritical crack growth in geological materials, J. Geophys. Res., 89 (B6), 4077-4114, 1984.

Atkinson, B.K., and P.G. Meredith, Experimental fracture mechanics data for rocks and minerals, in Fracture Mechanics of Rock, edited by B.K. Atkinson, pp. 477-525, Academic Press, London, 1987.

Bauer, S.J., and B. Johnson, Effects of slow uniform heating on the physical properties of Westerly and Charcoal granites, in Proc. 20th U.S. Symp. Rock Mech, pp. 7-18, 1979.

Behn, M.D., J. Lin, and M.T. Zuber, Mechanics of normal fault development at midocean ridges, J. Geophys. Res., 107 (B4), doi: 10.1029/2001JB000503, 2002.

Bernabé, Y., A wide range permeameter for use in rock physics, Int. J. Rock Mech. Min. Sci. \& Geomech. Abstr., 24, 309-315, 1987.

Boas, W., and R.W.K. Honeycombe, The anisotropy of thermal expansion as a cause of deformation in metals and alloys, Proc. R. Soc. Lond. A, 188, 427-439, 1947.

Bonatti, E., Serpentinite protrusions in the oceanic crust, Earth Planet. Sci. Lett., 32, 107113, 1976.

Bouhifd, M.A., D. Andrault, G. Fiquet, and P. Richet, Thermal expansion of forsterite up to the melting point, Geophys. Res. Let., 23 (10), 1143-1146, 1996.

Brace, W.F., E. Silver, K. Hadley, and C. Goetze, Cracks and pores: A closer look, Science, 178, 162-164, 1972.

Brace, W.F., J.B. Walsh, and W.T. Frangos, Permeability of granite under high pressure, J. Geophys. Res., 73, 2225-2236, 1968.

Canales, J.P., J.A. Collins, J. Escartín, and R.S. Detrick, Seismic structure across the rift valley of the Mid-Atlantic Ridge at $23^{\circ} 20^{\prime}$ (MARK area): Implications for crustal accretion processes at slow spreading ridges, J. Geophys. Res., 105 (B12), 28,41128,425, 2000.

Cannat, M., et al., Proceedings of the Ocean Drilling Program, Initial Reports, Ocean Drilling Program, College Station, TX, 1995.

Carlson, S.R., M. Wu, and H.F. Wang, Micromechanical Modeling of Thermal Cracking in Granite, in The Brittle-Ductile Transition in Rocks, The Heard Volume, edited by A.G. Duba, W.B. Durham, J.W. Handin, and H.F. Wang, pp. 37-48, American Geophysical Union, Washington, D.C., 1990.

Clarke, D.R., Microfracture in brittle solids resulting from anisotropic shape changes, Acta Metall., 28, 913-924, 1980.

Dick, H.J.B., Abyssal peridotites, very slow spreading ridges and ocean ridge magmatism, in Magmatism in the Ocean Basins, edited by A.D. Saunders, and M.J. Norry, pp. 71-105, Geol. Soc. Spec. Publ., London, 1989.

Escartín, J., G. Hirth, and B. Evans, Effects of serpentinizaion on the lithospheric strength and the style of normal faulting at slow-spreading ridges, Earth Planet. Sci. Lett., $151,181-189,1997 \mathrm{a}$. 
Escartín, J., G. Hirth, and B. Evans, Nondilatant brittle deformation of serpentinites: Implications for Mohr-Coulomb theory and the strength of faluts, J. Geophys. Res., 102, 2897-2913, $1997 \mathrm{~b}$.

Evans, A.G., Microfracture from thermal expansion anisotropy-I. Single phase systems, Acta Metall., 26 (1845-1853), 1978.

Evans, A.G., and D.R. Clarke, Residual stresses and microcracking induced by thermal contraction inhomogeneity, in Thermal Stresses in Severe Environments, edited by D.P.H. Hasselman, and R.A. Heller, pp. 629-648, 1980.

Evans, B., J. Renner, and G. Hirth, A few remarks on the kinetics of static grain growth in rocks, Int. J. Earth Sciences, 90, 88-103, 2001.

Fischer, G.J., The determination of permeability and storage capacity: Pore pressure oscillation method, in Fault mechanics and transport properties of rocks, edited by B. Evans, and T.-f. Wong, pp. 187-211, Academic Press, London, 1992.

Fischer, G.J., and M.S. Paterson, Measurement of permeability and storage capacity in rocks during deformation at high temperature and pressure, in Fault mechanics and transport properties of rocks, edited by B. Evans, and T.-f. Wong, pp. 213252, Academic Press, London, 1992.

Francis, T.J.G., Serpentinization faults and their role in the tectonics of slow spreading ridges, J. Geophys. Res., 86, 11,616-11,622, 1981.

Fredrich, J.T., and T.-f. Wong, Micromechanics of thermally induced cracking in three crustal rocks, J. Geophys. Res., 91 (B12), 12,743-12,764, 1986.

Ghahremani, F., and J.W. Hutchinson, Three-dimensional effects in microcrack nucleation in brittle polycrystals, J. Am. Ceram. Soc., 73, 1548-1554, 1990.

Hirth, G., and D.L. Kohlstedt, Experimental constrains on the dynamics of the partially molten upper mantle: Deformation in the diffusion creep regime, J. Geophys. Res., 100, 1981-2000, 1995.

Hooft, E.E.E., R.S. Detrick, D.R. Toomey, J.A. Collins, and J. Lin, Crustal thickness and structure along three contrasting spreading segments of the Mid-Atlantic Ridge, $33.5^{\circ} \mathrm{N}-35^{\circ} \mathrm{N}$, J. Geophys. Res., 105, 8205-8226, 2000.

Karato, S.-i., Grain growth kinetics in olivine aggregates, Tectonophysics, 168, 255-273, 1989.

Karato, S.-i., M. Toriumi, and T. Fujii, Dynamic recrystallization of olivine single crystals during high-temperature creep, Geophys. Res. Let., 7, 649-652, 1980.

Karson, J.A., and R.M. Lawrence, Seismic velocities of lower crustal and upper mantle rocks from the slow spreading Mid-Atlantic Ridge, south of the Kane transform zone (MARK), Proc. Ocean Drill. Program, Sci. Results, 153, 5-21, 1997.

Karson, J.A., G. Thompson, S.E. Humphris, S.E. Edmond, J.M. Edmond, W.B. Bryan, J.R. Brown, A.T. Winters, R.A. Pockalny, J.F. Casey, A.C. Campbell, G. Klinkhammer, M.R. Palmer, R.J. Kinzler, and M.M. Sulanowska, Along-axis variations in seafloor spreading in the MARK area, Nature, 328, 681-685, 1987.

Kuszyk, J.A., and R.C. Bradt, Influence of grain size on the effects of thermal expansion anisotropy in $\mathrm{MgTi}_{2} \mathrm{O}_{5}$, J. Am. Ceram. Soc., 56, 420-423, 1973.

Lawn, B., Fracture of Brittle Solids, 378 pp., Cambridge University Press, Cambridge, 1993. 
Miller, D.J., and N.I. Christensen, Seismic velocities of lower crustal and upper mantle rocks from the slow spreading Mid-Atlantic Ridge, south of the Kane transform zone (MARK), Proc. Ocean Drill. Program, Sci. Results, 153, 437-454, 1997.

Miyashiro, A., F. Shido, and M. Ewing, Composition and origin of serpentinites from the Mid-Atlantic Ridge, $24^{\circ} \mathrm{N}$ and $30^{\circ} \mathrm{N}$ latitude, Contrib. Mineral. Petrol., 23, $117-$ $127,1969$.

Moore, D.E., D.A. Lockner, Ma Shengli, R. Summers, and J.D. Byerlee, Strengths of serpentinite gouges at elevated temperatures, J. Geophys. Res., 102, 14,78614,801, 1997.

Murton, B.J., L.J. Redbourn, C.R. German, and E.T. Baker, Sources and fluxes of hydrothermal heat, chemicals and biology within a segment of the Mid-Atlantic Ridge, Earth Planet. Sci. Lett., 171, 201-317, 1999.

O'Hanley, D.S., Serpentinites, Records of Tectonic and Petrological History, 277 pp., Oxford University Press, Oxford, 1996.

Olgaard, D.L., and B. Evans, Grain growth in synthetic marbles with added mica and water, Contrib. Mineral. Petrol., 100, 246-260, 1988.

Paterson, M.S., A high temperature high pressure apparatus for rock deformation, Int. J. Rock Mech. Min. Sci., 7, 517-526, 1970.

Phipps Morgan, J., and D. Forsyth, Three-dimensional flow and temperature perturbations due to a transform offset: Effects on oceanic curst and upper mantle structure, J. Geophys. Res., 93, 2955-2966, 1988.

Sclater, J.G., C. Jaupart, and D. Galson, The heat flow through oceanic and continental crust and the heat loss of the Earth, Rev. Geophys. Space Phys., 18, 269-311, 1980.

Shaw, W.J., and J. Lin, Models of ocean ridge lithospheric deformation: Dependence on crustal thickness, spreading rate, and segmentation, J. Geophys. Res., 101 (B8), 17,977-17,933, 1996.

Siddiqi, G., Transport Properties and Mechanical Behavior of Synthetic Calcite-Quartz Aggregates, Ph.D. thesis, Massachusetts Institute of Technology, Cambridge, MA, 1997.

Simmons, G., and D. Richter, Microcracks in rocks, in The Physics and Chemistry of Minerals and Rocks, edited by R.J.G. Sterns, pp. 105-137, Wiley-Interscience, New York, 1976.

Sprunt, E.S., and W.F. Brace, Direct observation of microcavaties in crystalline rocks, Int. J. Rock Mech. Min. Sci. \& Geomech. Abstr., 11, 139-150, 1974.

Swain, M.V., and B.K. Atkinson, Fracture surface energy of olivine, Pure Appl. Geophys., 116, 866-872, 1978.

Tucholke, B.E., J. Lin, and M.C. Kleinrock, Megamullions and mullion structure defining oceanic metamorphic core complexes on the Mid-Atlantic Ridge, J. Geophys. Res., 103 (B5), 9857-9866, 1998.

Underwood, E.E., Quantitative Stereology, 274 pp., Addison Wesley, Reading, MA, 1970.

Van der Wal, D., P.N. Chopra, M. Drury, and J.D. FitzGerald, Relationships between dynamically recrystallized grain size and deformation conditions in experimentally deformed olivine rocks, Geophys. Res. Let., 20, 1497-1482, 1993. 
Wang, H.F., B.P. Bonner, S.R. Carlson, B.J. Kowallis, and H.C. Heard, Thermal stress cracking in granite, J. Geophys. Res., 94, 1745-1758, 1989. 


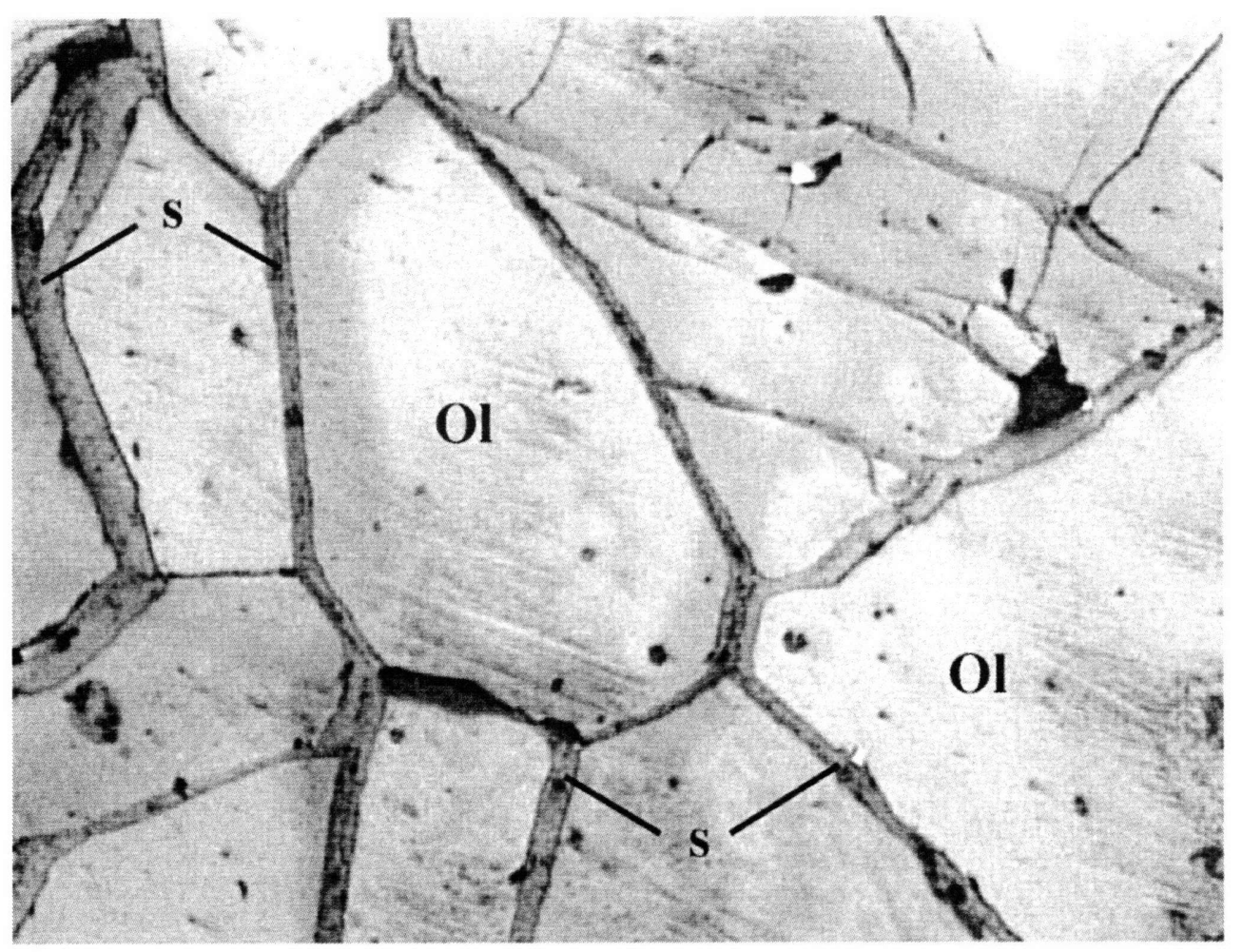

Figure 1 

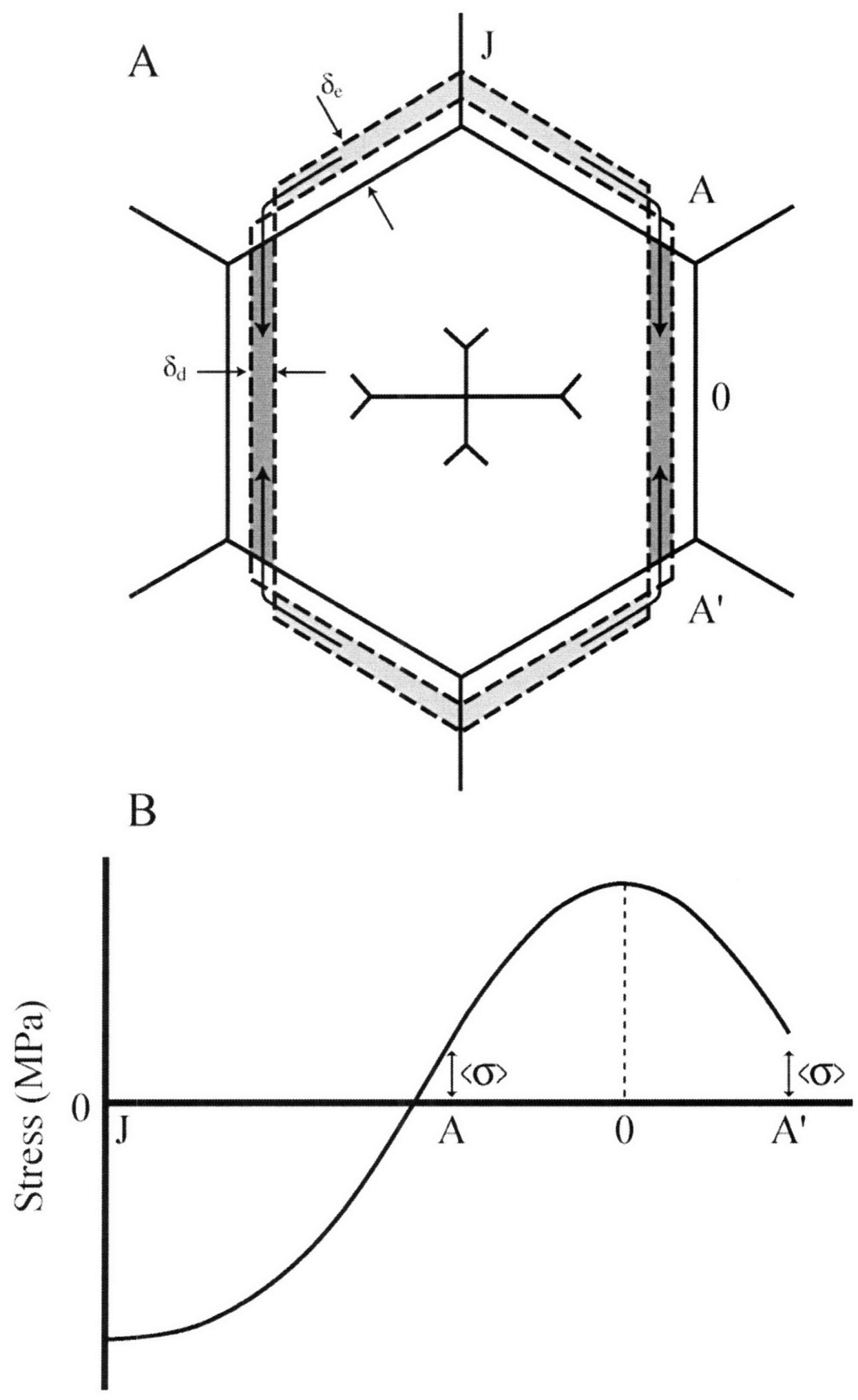

Figure 2 


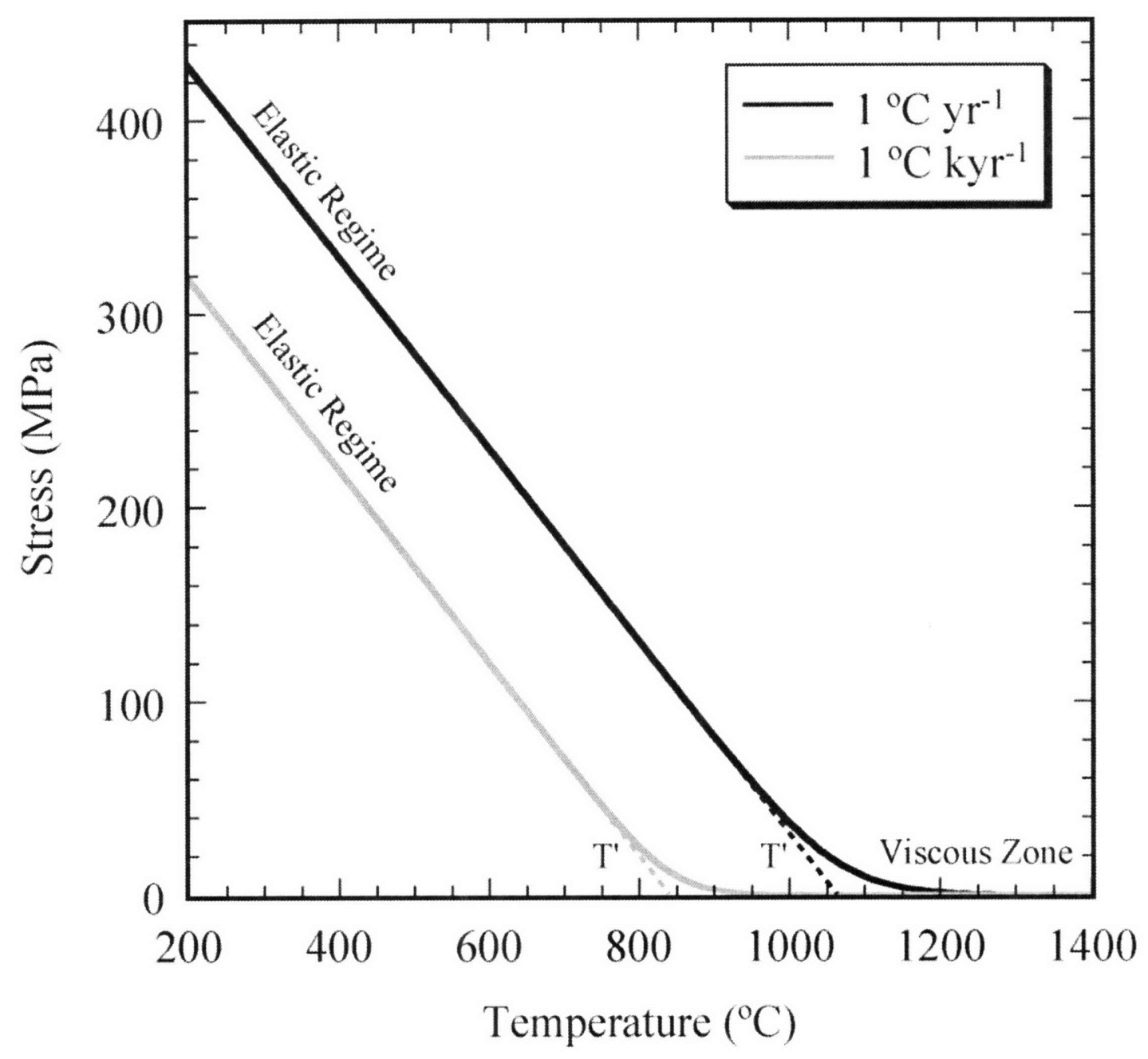

Figure 3 


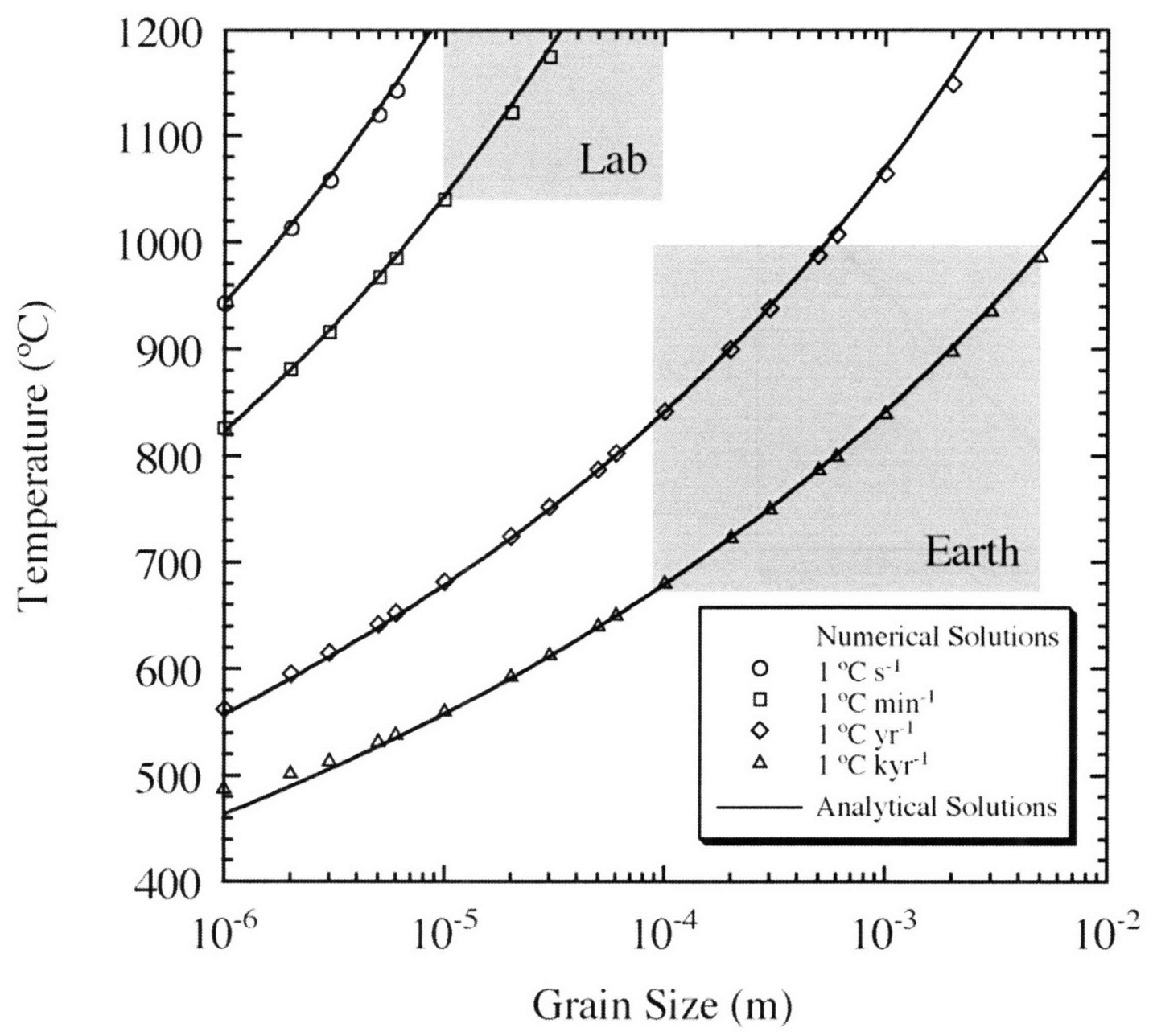

Figure 4 


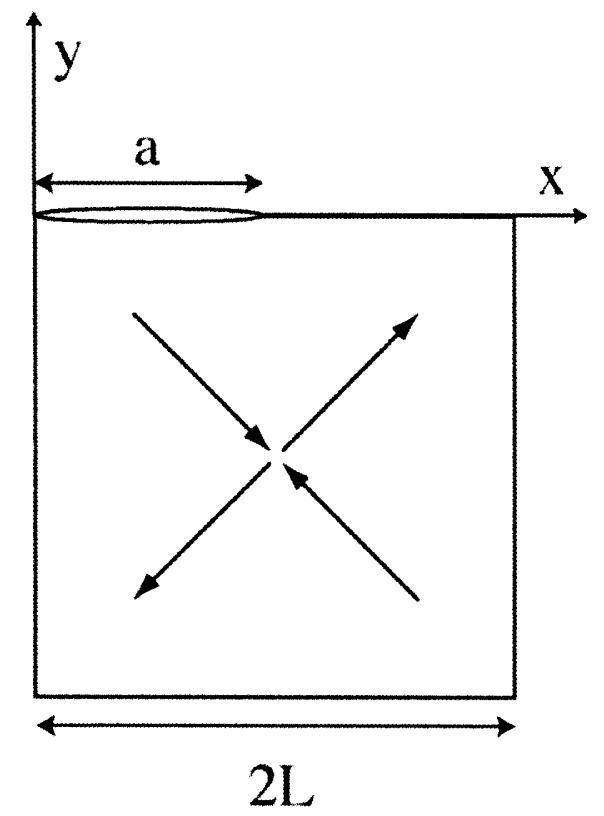

Figure 5 

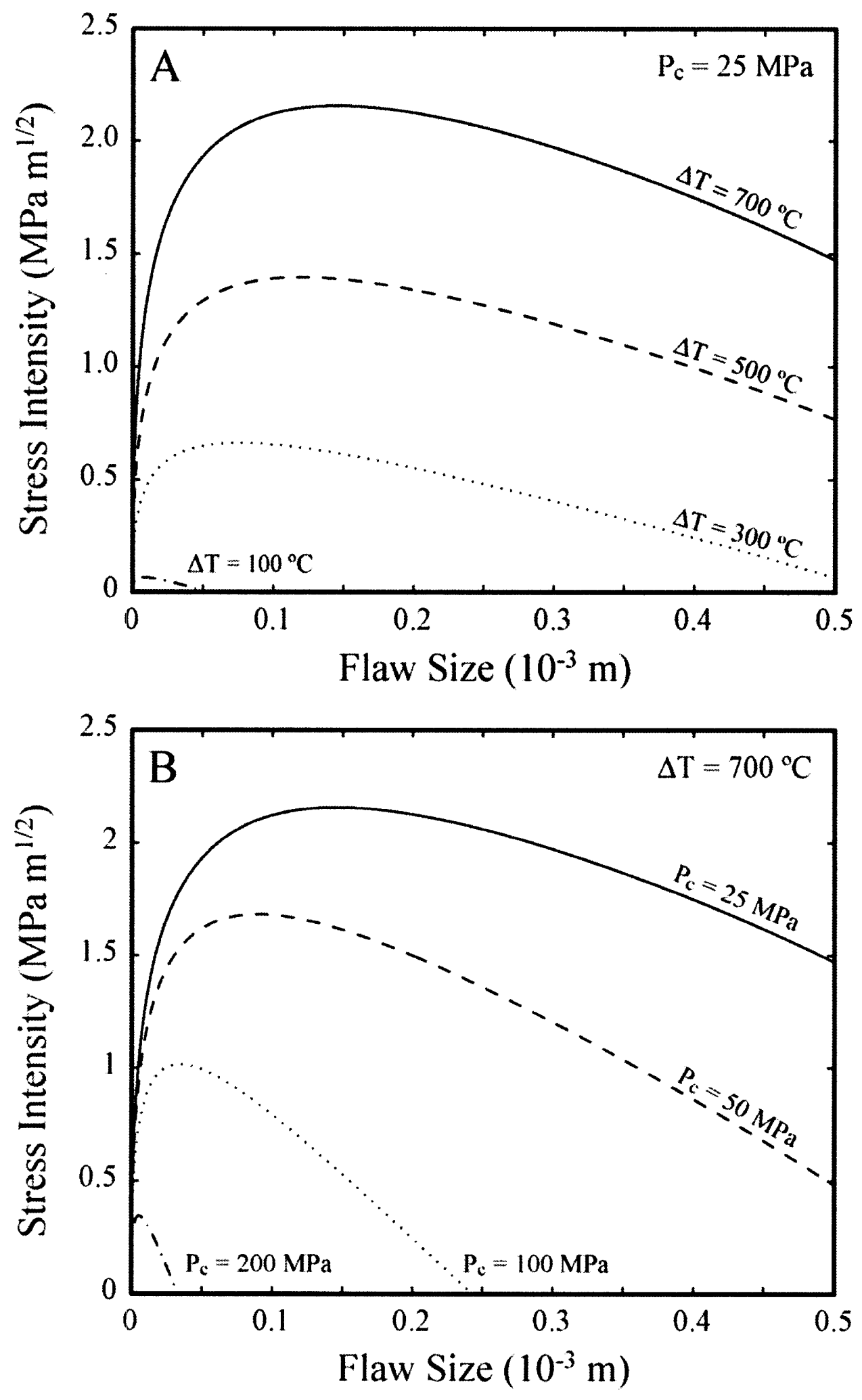

Figure 6 


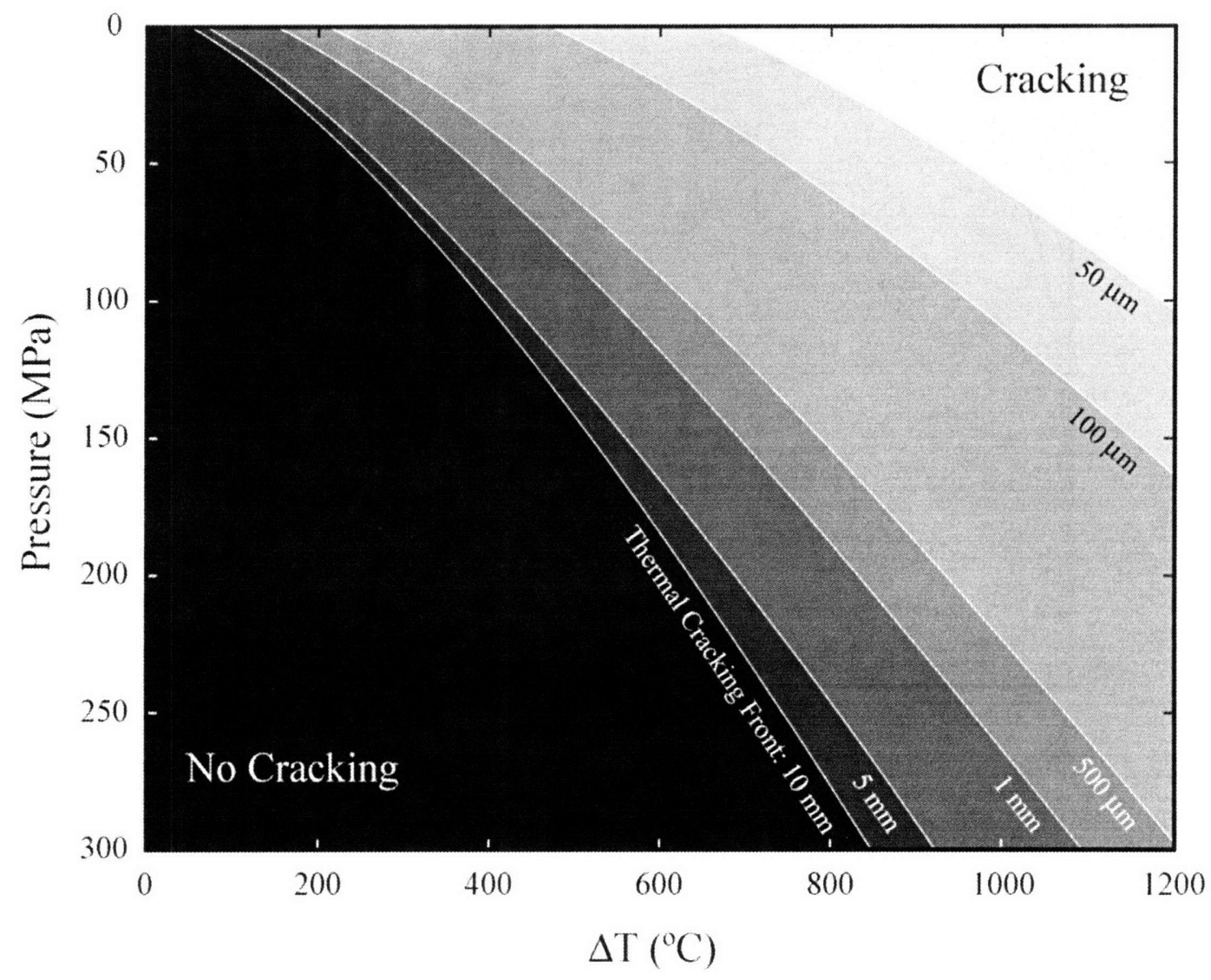

Figure 7 


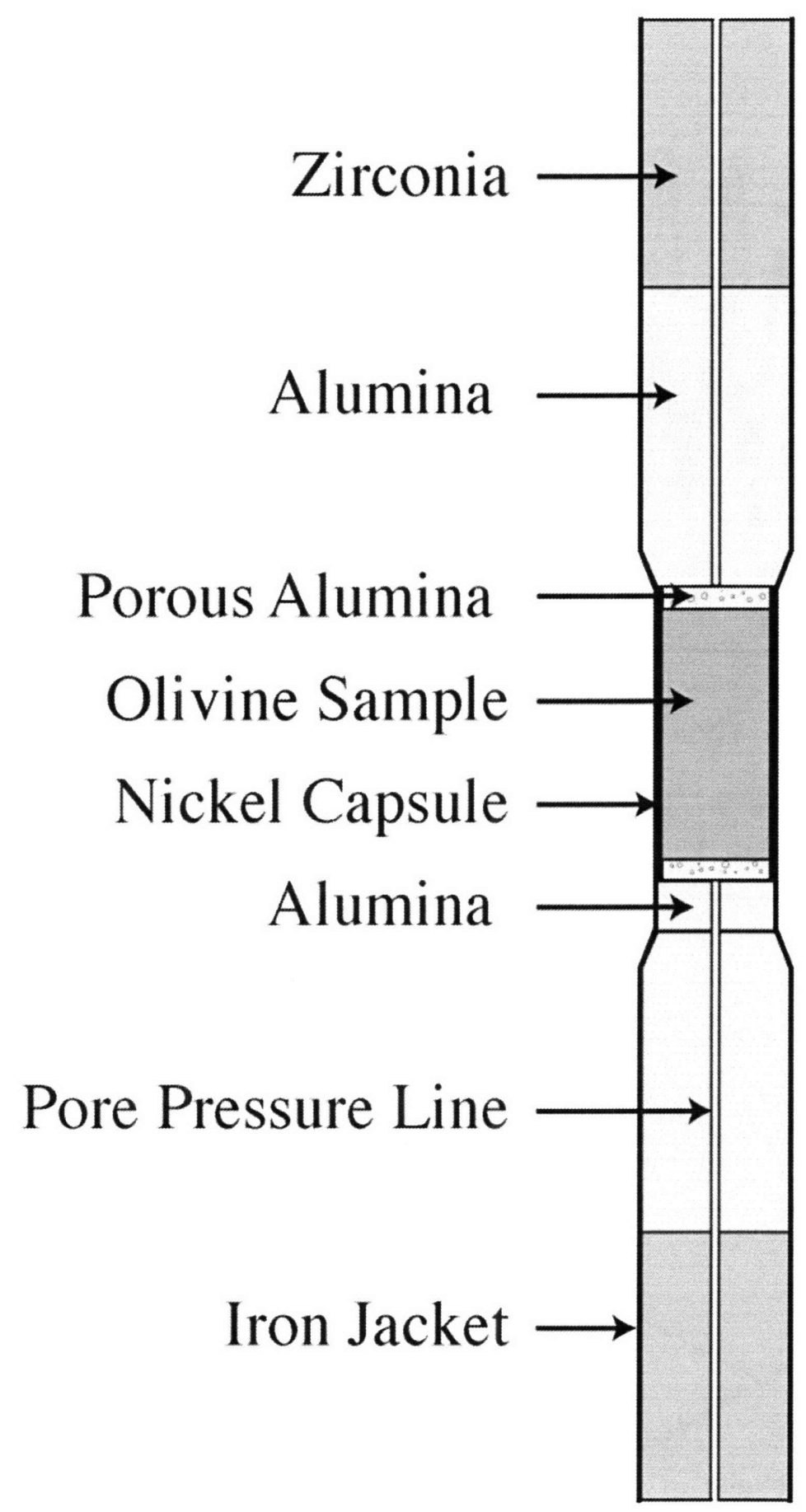

Figure 8 

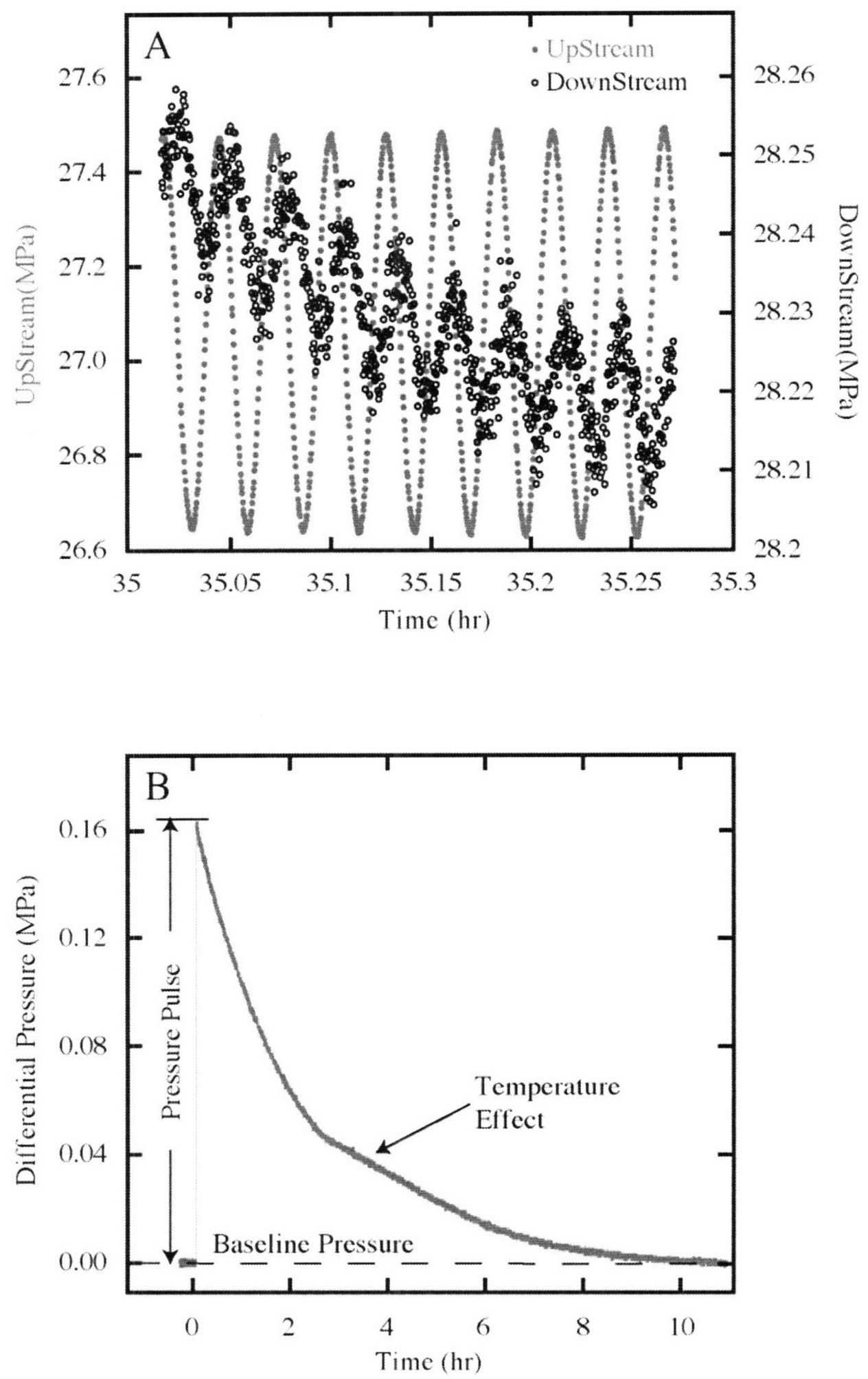

Figure 9 

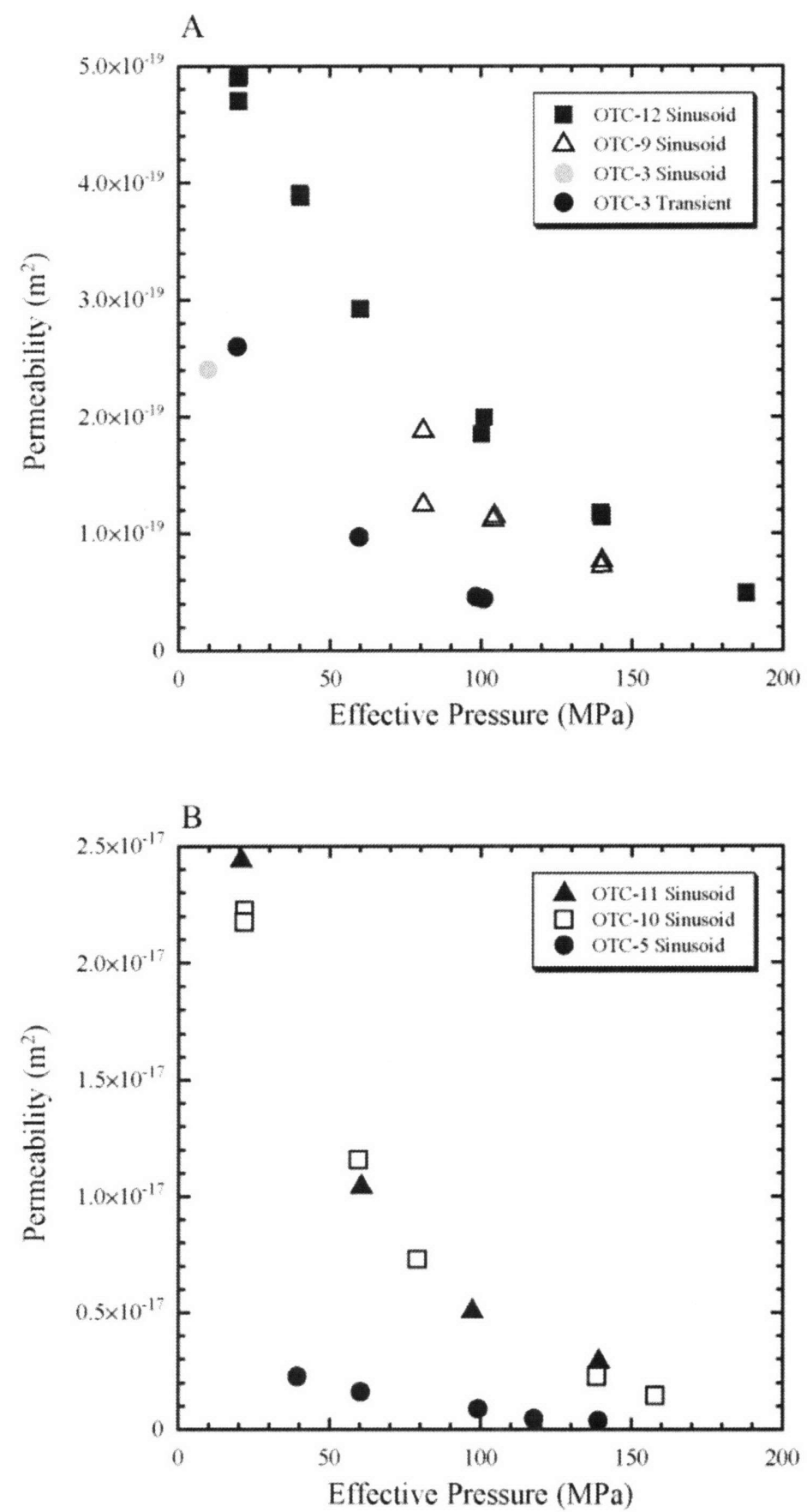

Figure 10 

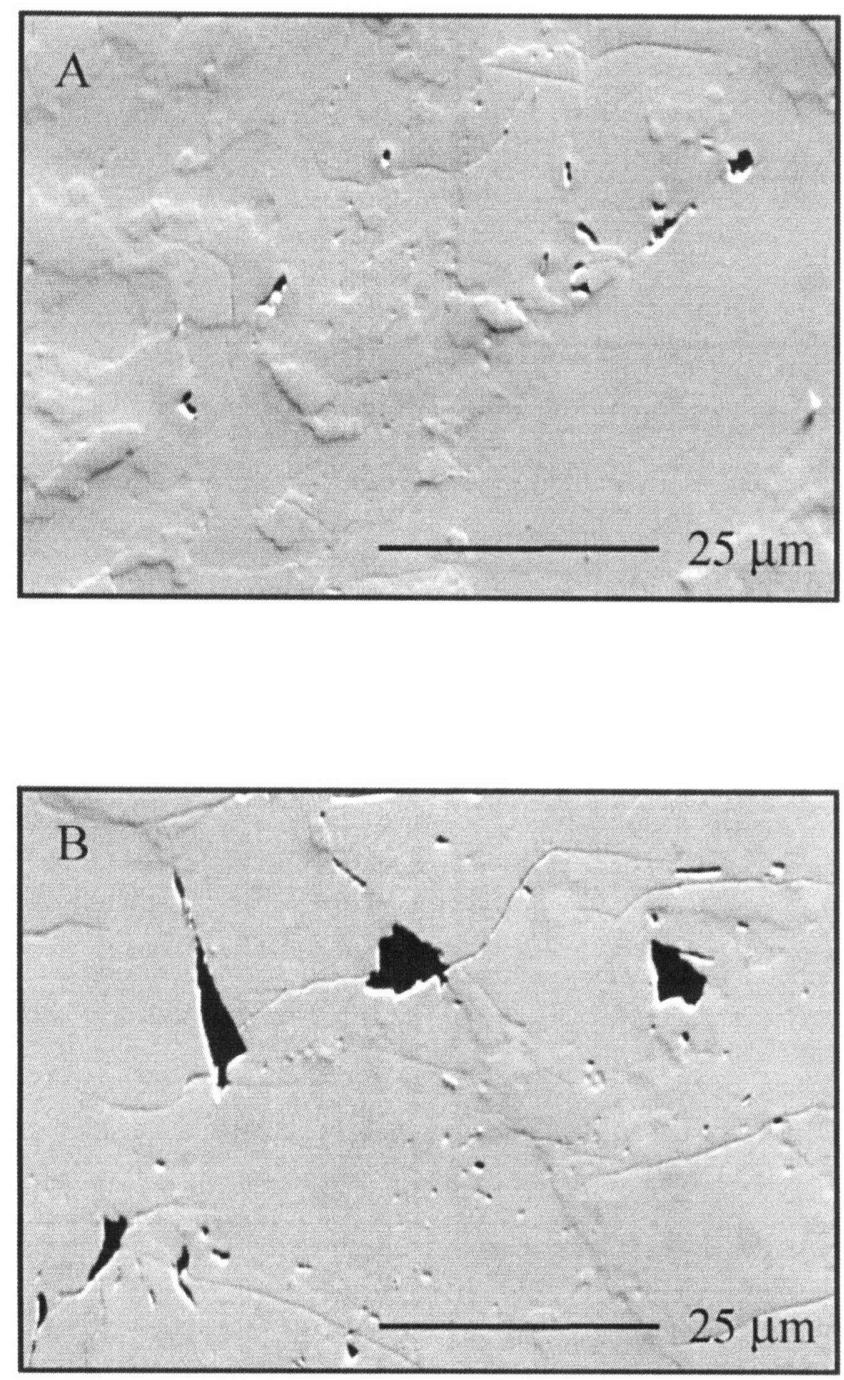

Figure 11 


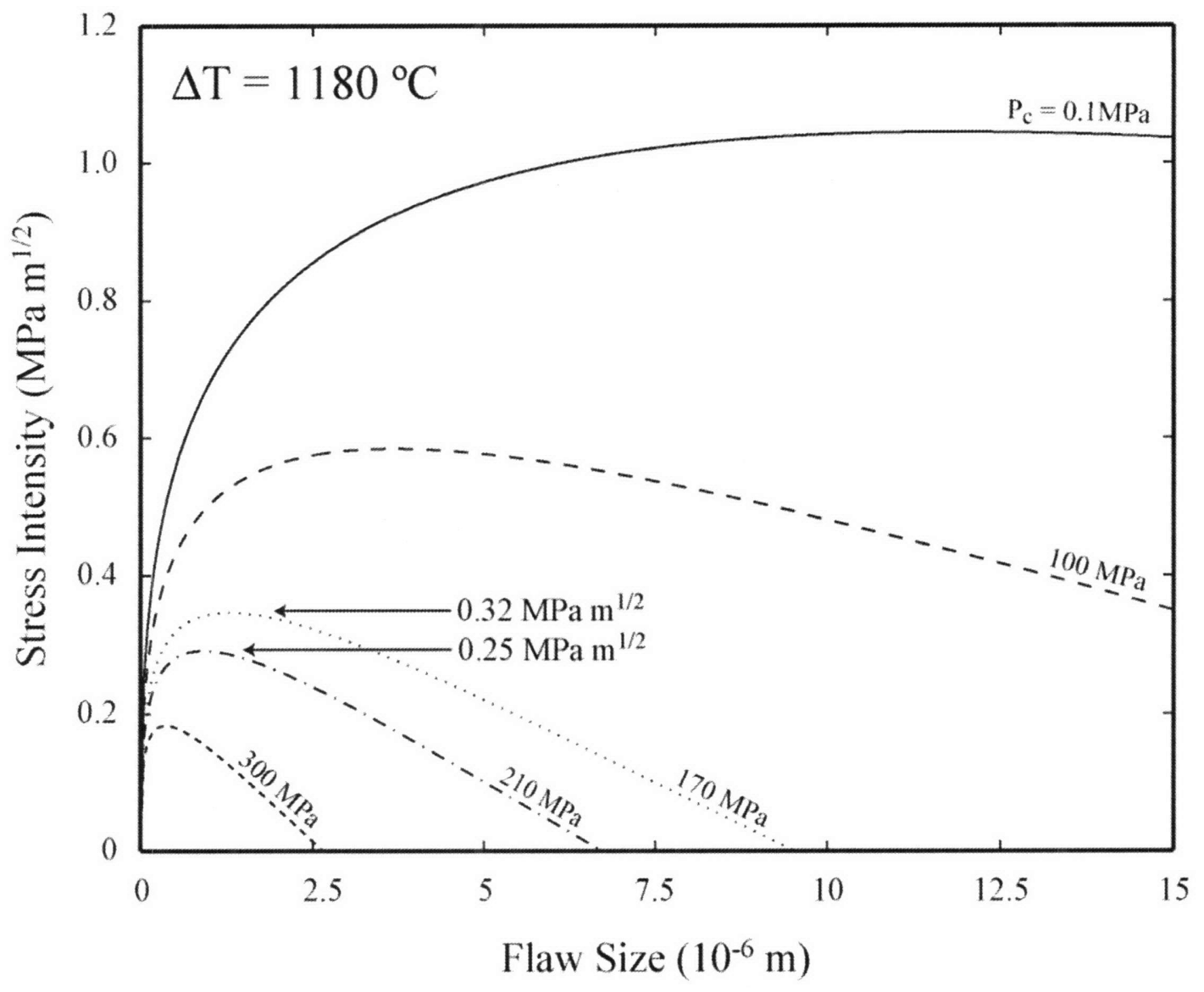

Figure 12 

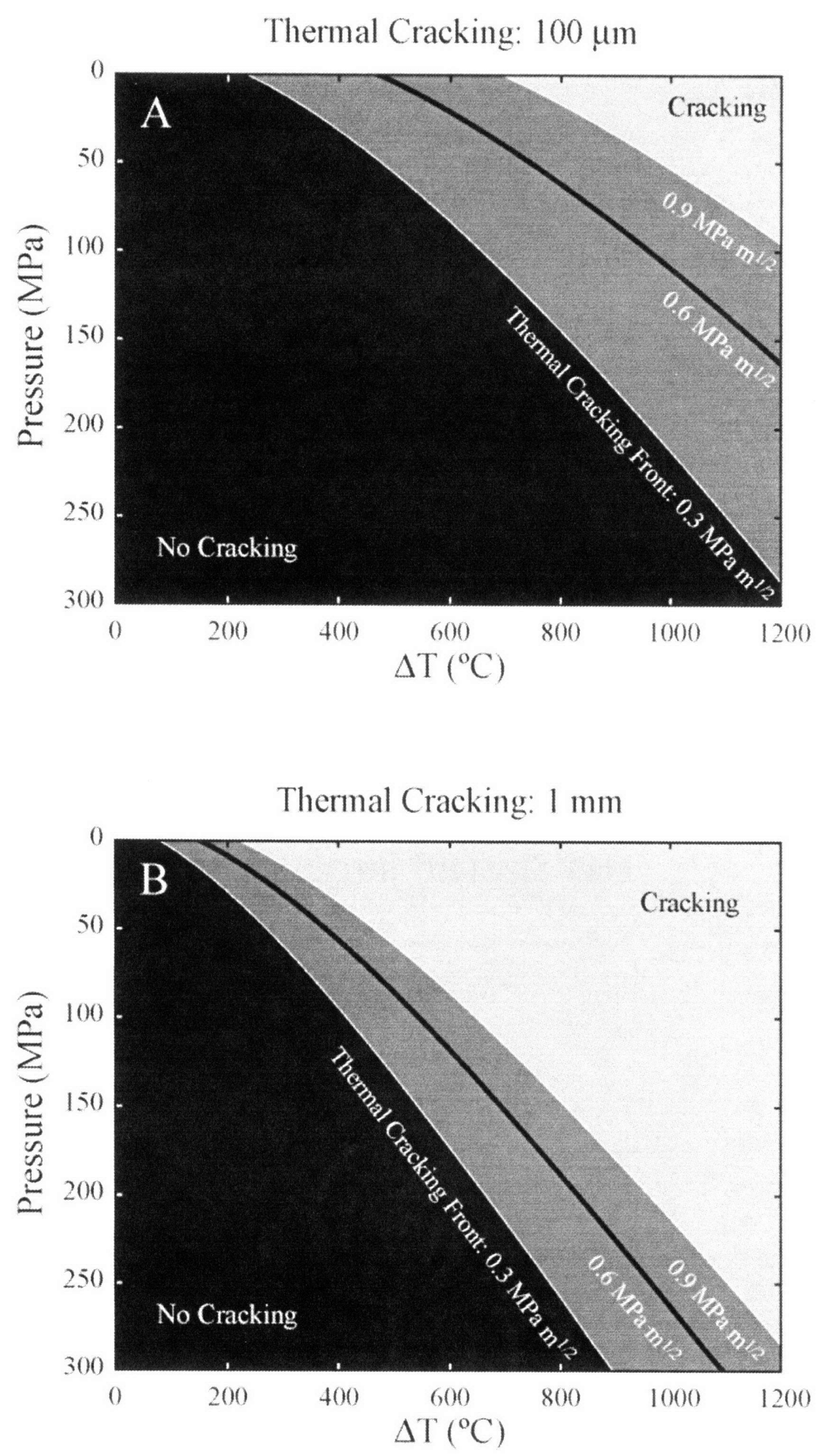

Figure 13 

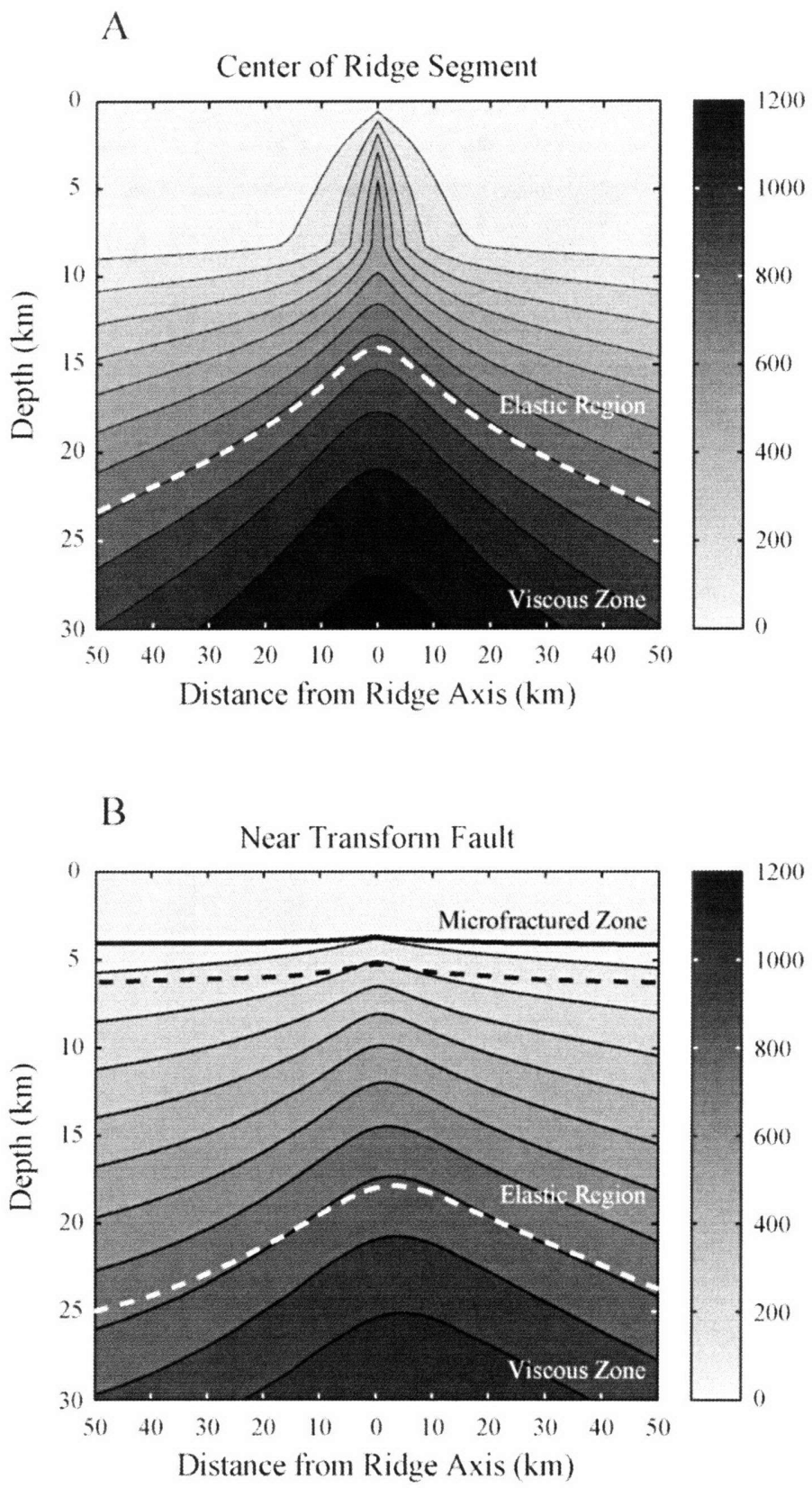

Figure 14 


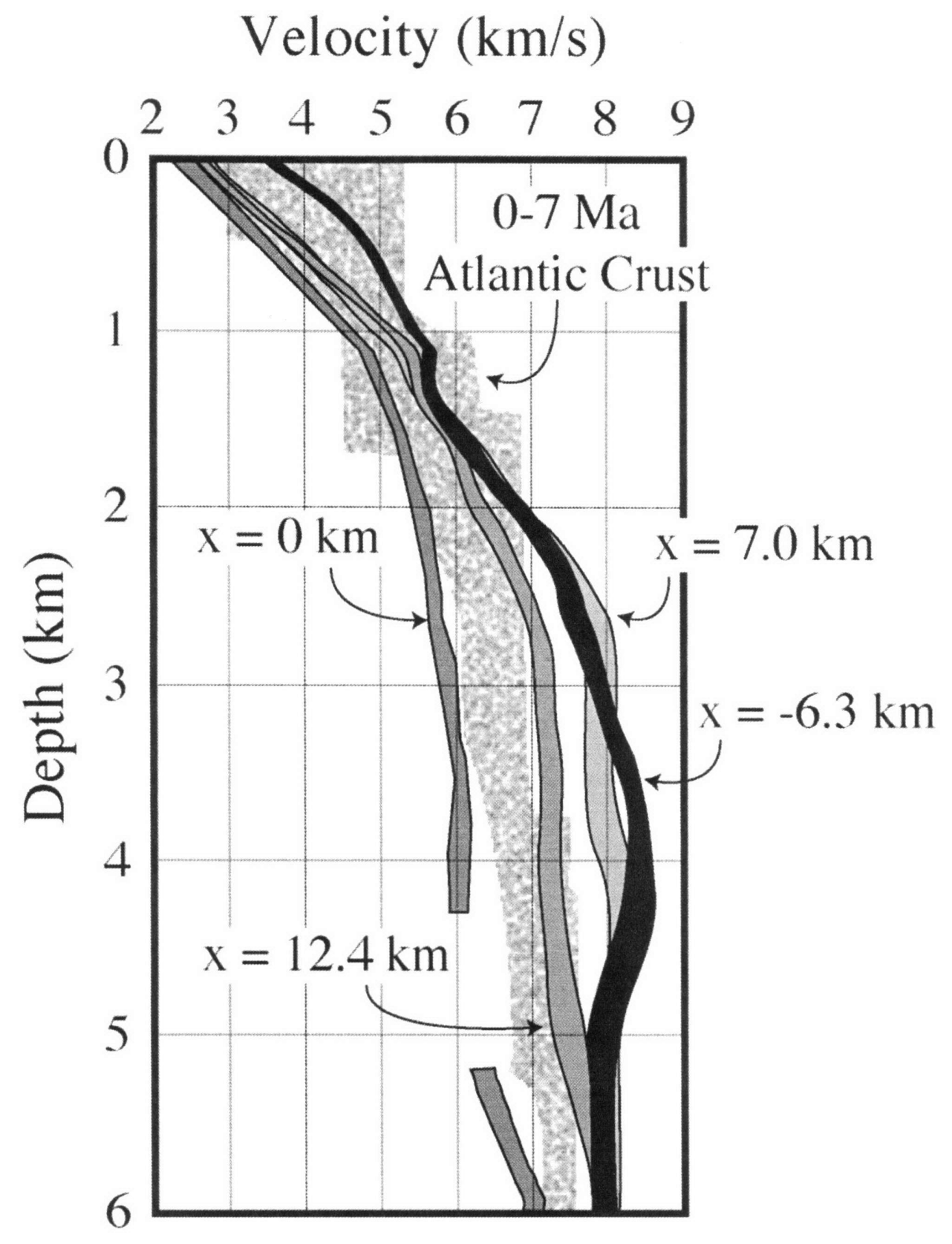

Figure 15 